

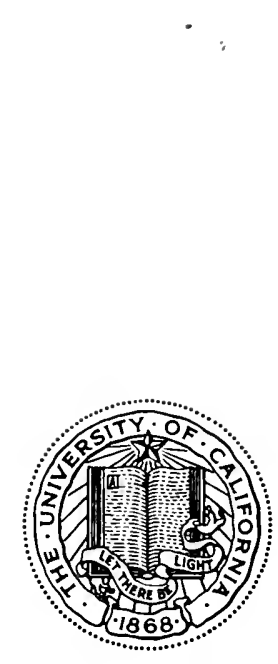

THE LIBRARY

OF

THE UNIVERSITY

OF CALIFORNIA

LOS ANGELES 
This book is DUE on the last date stamped below 1

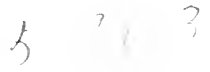



ARISTOCRACY AND EVOLUTION 
BY SAME AUTHOR.

LABOUR AND THE POPULAR WELFARE. Tenth Thousand.

Crown 8vo. Cloth. Price go cts.

CLASSES AND MASSES.

Second Thousand.

Crown 8vo. Cloth. Price $\$ 1.25$.

NEW YORK: THE MACMILLAN COMPANY, 66 Fifth Arenue. 


\title{
ARISTOCRACY AND EVOLUTION
}

\author{
A STUDY OF THE RIGHTS, THE ORIGIN, \\ AND THE SOCIAL FUNCTIONS OF \\ THE WEALTHIER CLASSES
}

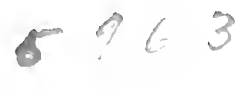

BY

\author{
W. H. MALLOCK \\ AUthor OF 'IS LIFE WORTh LIVING?' 'A hUMAN DOCUMENT,' \\ 'Labovr and the popular welfake,' etc.
}

Toute civilisation est l'œuvre des aristocrates.

RENAN.

'Tis thus the spirit of a single mind

Mates that of multitudes take one direction,

As roll the waters to the breathing wind,

Or roams the herd beneath the bull's protection, Or as a little dog will lead the blind,

Or a bell-wether form the flock's connection

By tinkling sounds, when they go forth to victual,

Such is the sway of your great men o'er little.

There was not now a luggage-boy but sought

Danger and spoil with ardour nuch increased:

And why? Because a little - odd - old man,

Stript to his shirt, was come to lead the van.

$$
\text { BYRON. }
$$

Xam Work

\section{THE MACMILLAN COMPANY}

LONDON: MACMILLAN \& CO., LTD.

I 898

All rights reserved 
Copyright, r898,

By THE MACMILlaN COMPANY.

Norbood Biss

J. S. Cushing \& Co. - Berwick \& Smith Norwuod Mass. U.S.A. 


\section{PREFACE}

THE word aristocracy as used in the title of this volume has no exclusive, and indeed no special, reference to a class distinguished by hereditary political privileges, by titles, or by heraldic pedigree. It here means the exceptionally gifted and efficient minority, no matter what the position in which its members may have been born, or what the sphere of social progress in which their exceptional efficiency shows itself. I have chosen the word aristocracy in preference to the word oligarchy because it means not only the rule of the few, but of the best or the most efficient of the few.

Of the various questions involved in the general argument of the work, many would, if they were to be examined exhaustively, demand entire treatises to themselves rather than chapters. This is specially true of such questions as the nature of men's congenital inequalities, the effects of different classes of motive in producing different classes of action, and the effects of equal education on unequal talents and temperaments. But the practical bearings of an argument are more readily grasped 
when its various parts are set forth with comparative brevity, than they are when the attention claimed for each is minute enough to do it justice as a separate subject of inquiry; and it has appeared to me that in the present condition of opinion, prevalent social fallacies may be more easily combated by putting the case against them in a form which will render it intelligible to everybody, and by leaving many poirits to be elaborated, if necessary, elsewhere.

I may also add that the conclusions here arrived at, with whatever completeness they might have explained, elaborated, and defended, would not, in my opinion, do more than partially answer the questions to which they refer. This volume aims only at establishing what are the social rights and social functions, in progressive communities, of the few. The entire question of their duties and proper liabilities, whether imposed on them by themselves or by the State, has been left untouched. This side of the question I hope to deal with hereafter. It is enough to observe here that it is impossible to define the duties of the few, of the rich, of the powerful, of the highly gifted, and to secure that these duties shall be performed by them, unless we first understand the extent of the functions which they inevitably perform, and admit frankly the indefeasible character of their rights. 


\section{CONTENTS}

\section{BOOK I}

\section{CHAPTER I}

\section{The Fundamental Error in Modern Sociological Study}

Science during the middle of this century excited popular interest mainly on account of its bearing on the doctrines of Christianity

Its popularity is now beginning to depend on its bearing not on religious

problems, but on social . . . . . . . . . . 3

Science itself is undergoing a corresponding change . . . . 4

Its characteristic aim during the middle of the century was to deal with

physical and physiological evolution . . . . . . 4

Its characteristic aim now is to deal with the evolution of society . 5

Social science itself is not wholly new . . . . . . . 5

What is new is the application to it of the evolutionary theory . . 6

This excites men by suggesting great social changes in the future, . 7

which will give a speculative meaning to the history of humanity, . $\quad 8$

or secure for men now existing, or for their children, practical social ad-

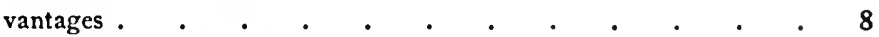

Men have thus a double reason for being interested in social science, and sociologists a double reason for studying it; . . . . . 9

and it has attracted a number of men of genius, who have applied to it methods learned in the school of physical science . . . . 9

Yet despite their genius and their diligence, all parties complain that the results of their study are inconclusive . . . . . . 10

Professor Marshall and Mr. Kidd, for instance, complain of the fact, but can suggest no explanation of it . . . . . . . 10 What can the explanation be? . . . . . . . . II 
The answer will be found in the fact just referred to - that social science PAGE attempts to answer two distinct sets of questions; . . . . 12

and one set-namely, the speculative - it has answered with great success; . . . . . . . . . . . . . 12

it has failed only in attempting to answer practical questions . . . 13

Now the phenomena with which it has dealt successfully are phenomena of social aggregates, considered as wholes; . . . . .

but the practical problems of to-day, with which it has dealt unsuccessfully, arise out of the conflict between different parts of aggregates . Social science has failed as a practical guide because it has not recognised this distinction; . . . . . . . . .

and hence arise most of the errors of the political philosophy of this century

\section{CHAPTER II}

\section{The Attempt to merge the Great Man in the} AGgregate

Whatever may be done by some men, or classes of men, sociologists are at present accustomed to attribute to man . . . . . .

Mr. Kidd's Social Evolution, for instance, is based entirely on this procedure . . . . . . . . . . . . . . 17

He quotes with approval two other writers who have been guilty of it; . 18 who both attribute to man what is done by only a few men; . . $\quad$ r 9 and the consequences of their reasoning are ludicrous . . . . 20

Mr. Kidd's reasoning itself is not less ludicrous. The first half of his argument is that religion prompts the few to surrender advantages to the many, which, if they chose to do so, they could keep . .

The second half is that the many could have taken these advantages from the few, and that religion alone prevented them from doing so .

This contradiction is entirely due to the fact that, having first divided the social aggregate into two classes, he then obliterates his division, and thinks of themboth as "man" . . . . . .

Mr. Kidd's confusion ts the result of no accidental error. It is the inevitable result of a radically fallacious method; . . . . . 24 and of this method the chief exponent is Mr. Herbert Spencer, . $\quad 24$ as a short summary of his arguments will show . . . . $\quad 25$ 
Mr. Spencer starts with saying that the chief impediment to social science is the great-man theory; . . . . . . .

for, if the appearance of the great man is incalculable, progress, if it depends on him, must be incalculable also; . . . . . 26

but if the great man is not a miraculous apparition, he owes his greatness to causes outside himself; . . . . . . .

and it is these causes which really produce the effects of which he is the proximate initiator . . . . . . . . .

These effects, therefore, are to be explained by reference not to the great man, but to the causes that are behind the great man . . .

The true causes, says Mr. Spencer, of all social phenomena are physical environment and men's natural character . . . . . 29

The first physical cause of progress was an exceptionally fertile soil $\quad 29$ and an exceptionally bracing climate . . . . . . . 29

All the conquering races came from fertile and bracing regions . . 30

There were other regions more fertile, but these were enervating; and hence the inhabitants of the former enslaved the weaker inhabitants of the latter . . . . . . . . . . . Again, division of labour, on which industrial progress depends, was caused by difference in the products of different localities, . $\quad 3 \mathbf{I}$

which led to the localisation of industries . . . . . 32

The localisation of industries in its turn led to road-making; . . $\quad 33$

and roads made possible the centralisation of authority and interchange of ideas . . . . . . . . . . • .

Next, as to men's natural character, which is the other cause of progress, • • • • • • • • • • •

their primitive character did not fit them to progress, . . . 34

till it was gradually improved by the evolution of marriage and the family - especially of monogamy . . . . . . . 34

Monogamy represents the survival of the fittest kind of sexual union $\quad 35$

It developed the affections and the practice of efficient co-operation $\quad 35$

The family being established, the nation gradually rose from it . . $3^{6}$

One family increased, and gave rise to many families, which were obliged, in order to get food, to separate into different groups; . . . 36

and the recompounding of these groups, for purposes of defence or aggression, formed the nation; . . . . . . . 37

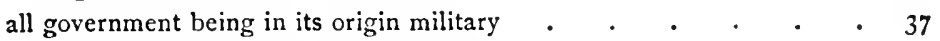

But as the arts of life progress, industry emancipates itself from governmental control, and becomes its own master, and also forms the basis of political democracy . . . . . . . 
Now, if we consider all these conclusions of Mr. Spencer's, . . .

we shall find them to be all conclusions about aggregates as wholes, not

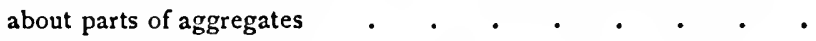

The only differences recognised by him between men are differences between one homogeneous aggregate and another, . . . . 40

and differences between similar men who happen to be occupied differently . . . . . . . . . . . .

But, as has already been said, the social problems of to-day arise out of a conflict between different parts of the same aggregate; therefore the phenomena of the aggregate as a whole do not help us . .

The conflict between the parts of the aggregate arises from inequalities of position . . . . . . . . . . . 43

of which Mr. Spencer's sociology takes no account . . . 44

Social problems arise out of the desire of those whose positions are inferior to have their positions changed; . . . . . 45

and the practical question is, is the change they desire possible? . . 45

To answer this question we must examine into the causes why such and such individuals are in inferior, and others in superior positions .

Are inequalities in position due to alterable and accidental circumstances? . . . . . . . . . . . . .

Or are they due to congenital inequalities which no one can ever do away with? . . . . . . . . . . . 47

Social inequalities are partly due to circumstances; . . . $\quad .48$

but most people will admit that congenital inequalities in talent have much to do with them . . . . . . . 48

Why then insist on this fact? . . . . . . . . . 49

Because this fact is precisely what our contemporary sociologists ignore, 49

as Mr. Spencer shows us by his distinct admissions and assertions, as well as by the character of his conclusions . . . . . 50

His condemnation of the great-man theory is a removal of all congenital inequalities from his field of study; . . . . . . . 5 I

and he actually defines an aggregate as being composed of approximately equal units . . . . . . . . . . 52

His failure and that of others, as practical sociologists, arises from their building on this false hypothesis . . . . . . . 


\section{CHAPTER III}

\section{Great Men, as the true Cause of Progress}

The ignoring of natural inequalities is a deliberate procedure. Let us see how it is defended . . . . . . . . . 55

Let us examine Mr. Spencer's defence of it . . . . . . 55

He defends it in two ways; . . . . . . . . . 55

(I) by saying that the great man does not really do what he seems to do; . . . . . . . . . . . . 55

(2) by saying that what he seems to do is not really much . . 56

He admits that the great man does do something exceptional in war; . 57

but denies that he does anything exceptional in the sphere of peaceful progress . . . . . . . . . . . . 57

But how does the great man fulfil his function in war? By ordering others . . . . . . . . . . . $5^{8}$

The great man, in peace, does precisely the same thing . . . 59

Mr. Spencer, for example, orders the compositors who put his books into type. . . . . . . . . . . 59

The inventor orders the men by whom his inventions are manufactured. . . . . . . . . . 60

The great man of business orders his employees . . . . . 6r

The hotel-keeper orders his staff . . . . . . . . . 62

All these men resemble the great military commander; and if the latter is a social cause, so are the former . . . . . 63

Next, as to the contention that the great man is the proximate cause only, and not the true cause - . . . . . . . . 63

This, as Mr. Spencer and those popular writers of to-day show us, $\quad 64$ resolves itself into four arguments : . . . . . . . 65

(I) That every first discovery involves all that have gone before it; . 66

(2) that the discoverer's ability itself is the product of past circumstances; . . . . . . . . . . 66

(3) that often the same discovery is made by several men at once; 66

(4) that the difference between the great and the ordinary man is slight . . . . . . . . . . 66

Simultaneous discovery only shows that several great men, instead of one, are greater than others . . . . . . . . . . . $\quad$. 67

The extent of the great man's superiority depends on how it is measured 
It may be slight to the speculative philosopher, but to the practical man it is all-important . . . . . . . . . .

s for the two other arguments, which admit the great man's greatness, but deny that it is his own, . . . . . . . .

they are both true speculatively, but are practically untrue, or irrele. vant; . . . . . . . . . • • .

just as statements of averages and classification of goods may be true and relevant for one purpose, and false and irrelevant for another

Thus the argument that the great man owes his faculties to his ancestors, and through his ancestors to the society which helped to develop his ancestors, though a speculative truism, . . .

leads to nothing but absurdities if we apply it to practical life . . For if the great workers owe their greatness to the whole of past society, the men who shirk work owe their idleness to it; and if the former deserve no reward, the latter deserve no punishment .

The same argument applies to morals; and if accepted, we should have to admit that nobody really did, or was really responsible for, anything

Finally, let us take the argument that most of what the great man does depends on past discoveries and past achievements, to which he does but add a little . . . . . . . . .

If this argument means anything, it must mean that greatness is commoner than it is vulgarly thought . . . . . . 78

But is this the case? Does Shakespeare's debt to his antecedents make Shakespeares more numerous? . . . . . . .

Shakespeare's contemporaries had the same national antecedents that he had; but they could not do what he did . . . . . 80

Men inherit the past only in so far as they can assimilate it . . . 80

Socialists say that inventions once made become common property $\quad 81$

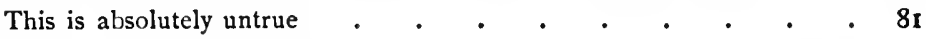

The discoveries and inventions of the past are the property of those only who can absorb and use them . . . . . $\quad 82$

Thus the introduction of the past into the question leaves the differences between the great man and others undiminished . . . $\quad 82$

If the ordinary man does anything, the great man does a great deal more 83 and in practical reasoning he is a true cause for the sociologist . . 83 And, curiously enough, Mr. Spencer unconsciously admits this . $\quad$. 84 He declares that the Napoleonic wars were entirely due to the maleficent greatness of Napoleon . . . . . . . . 84 
He defends patents because they represent the very substance of the inventor's own mind; . . . . . . . . .

and he attributes the modern improvement in steel manufacture to Sir

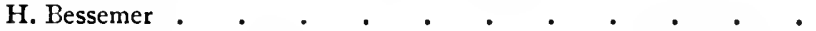
So much, then, being established, we must consider two difficulties sug. gested by it

\section{CHAPTER IV}

\section{The Great Man as distinguished from the Physiologi- CALLy FitTest SURvivor}

It may be objected that modern sociology does not, as here asserted, neglect the great man, for it adopts the doctrine of the survival of the fittest

It may be asked, on the other hand, what place the great man has in an exclusively evolutionary theory of progress . . . . 90 The fittest survivor is not the same as the great man . . . 90 He plays a part in progress, but not the saine part. . . . . 90 The fittest men, by surviving, raise the general level of the race, and promote progress only in this way . • . . . . 9 - 1

The great man promotes progress by being superior to his contemporaries . . . . . . . . . . . . . 92

The movement of progress is double; . . . . . . . 93 one movement being very slow, the other rapid . . . . 93 The survival of the fittest causes the slow movement . . . 93 The rapid movement is caused by the great man . . . . . 95 Next, as to evolution - what does the word mean? . . . . 95 Its great practical characteristic, as put forward by Darwin, is that it is opposed to the doctrine of design, or divine intention; . . . 96

and yet, according to Darwin, species resulted from the intention of each animal to live and propagate . . . . . . 96

Species, therefore, according to the evolutionist, is the result of intention, but not the result intended . . . . . . 97

Evolution, in fact, is the reasonable sequence of the unintended . $\quad 97$ This is as true of social evolution as it is of biological . . . 97 Many of the social conditions of any age result from the past, but were intended by nobody in the past; . . . . . . 98 for instance, many of the social effects of railways and cheap printing $\quad 98$ 
Therefore, whenever any great man produces some change intentionally

he has to work with unintended materials . . . . . 99

We can see this in the progress of dramatic art; . . . . $\quad .99$

also in the progress of philosophy . . . . . . . 100

And yet in each case the intended elements are equal or are greater

than the unintended . . . . . . . . . 100

We see the same thing in the bistory of the Times printing press . . IOI

It was the result of many kinds of unintended progress, constantly re-

combined by intention . . . . . . . . . 102

Evolution, in fact, is the unintended result of the intentions of great

men . . . . . . . . . . . . 104

The unintended or evolved element in progress is what concerns the speculative philosopher . . . • . . . . • 105

The intended element, which originates directly in the great man, is what is of interest for practical purposes . . . . . . 106

\section{BOOK II}

\section{CHAPTER I}

\section{The Nature and the Degrees of the Superiorities of Great MeN}

The causality of the great man being established, we must consider more precisely what greatness is . . . . . . . III

Mr. Spencer will help us to a general definition of it . . . 112

He divides the human race into the clever, the ordinary, and the stupid . . . . . . . . . . . . $\quad$. II3

Now if all the race were stupid, it is plain there would be no progress; . II4 nor would there be any if all the race were ordinary; . . . . II4

therefore progress must be due to the clever, who are, as Mr. Spencer

says, a "scattered few" . . . . . . . . . . 115

This is the great-man theory reasonably stated . . . . . II5

For great men are not necessarily heroes, as Carlyle thought, . . II6

nor divided absolutely from all other men . . . . . 116

Greatness is various in kind and degree, . . . . . $\quad$ II7

but, at all events, there is a certain minority of men who resemble

each other in being more efficient than the majority . . . II7

We see this in poetry, . . . . . . . . . . II8

in singers, . . . . . . . . . . . I18 
in the scholarship of boys at the same school, . . . . . 119

and similarly in practical life . . . . . . . . . Irg

Enough men, as it is, have equal opportunities, to show how unequal

men are in their powers of using them . . . . . . 120

No doubt a man may be ordinary in one respect and great in another; 120

but the majority are not great in any . . . . . . . 121

The measure of a man's greatness as an agent of social progress is the overt results actually produced by him . . . . . . I 2 I

A selfish doctor, if successful, is greater than a devoted doctor, if

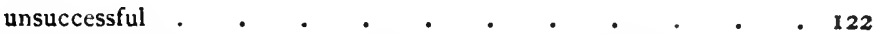

The fact that many men who produce no social results seem better and more brilliant than many men who do produce them, makes some argue that these results require no greatness for their production .

But the most efficient forms of greatness have often nothing brilliant about them . . . . . . . . . . . 123

A lofty imagination is often the enemy to practical efficiency; . 124

and great efficiency is often independent of exceptional intellect . 125

Intellect is required for progress, e.g. in invention; . . . . 125

but the inventor by himself is often helpless, . . . . . . 125

and has to ally himself with men whose exceptional gifts are unimpres-

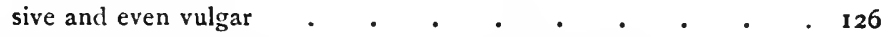

Greatness is not one quality, but various combinations of many . $\quad 127$

Greatness, then, is merely those qualities which, in any domain of progress, make the few more efficient than the many . . . . 127

The great-man theory, then, merely asserts that if some men were not more efficient than most men, no progress would take place at all 128

But great men, in spite of these differences, all promote progress in the same way

\section{CHAPTER II}

\section{Progress the Result of a Struggle not for Survival BUT FOR DOMINATION}

In order to see how the great man promotes progress, we must consider

that whilst the fittest survivor only promotes it . . . . I 30

by living, whilst others die, . . . . . . . . . I30

the great man promotes progress by helping others to live . . 13x $^{\text {x }}$

He promotes progress not by what he does himself, but by what he helps others to do . . . . . . . . . . 132 
We can see this by considering the progress of knowledge which, as

J. S. Mill says, is the foundation of all progress . . . . 132

But all progress in knowledge is the work of "decidedly exceptional individuals," . . . . . . . . . . . 134

as Mill admits, though in curiously confused language . • . . I35

Now how do the exceptional individuals, when they acquire knowledge,

promote progress by doing so? . . . . . . . 136

They promote progress by conveying their knowledge to, and imposing their conclusions on, others • • • • • • • • I37

A similar thing is true of invention, which is knowledge applied . $\quad 138$

Invention promotes progress only because the inventor influences the actions of the workmen who make and use his machines . . I39

The man of business ability promotes progress also only by so ordering others that the precise wants of the public are supplied . . . 140

And the same principle is obviously true in the domain of war, politics, and religion . . . . . . . . . • . 14I

Greatness, however, is not in all cases equally beneficial . . 142

The influence of some great men is more advantageous than that of others . . . . . . . . . . . 143

Progress, then, involves a struggle through which the fittest great men shall secure influence over others, and destroy the influence of the less fit . . . . . . . . . • .

We now come to another point of difference between the fittest great man and the fittest survivor . . . . . . • .

The social counterpart to the Darwinian struggle for survival is to be found in the struggle of labourers to find employment . . . 144

But this is not the struggle to which historical progress is due . . 145

For the most rapid progress has taken place without any increased fitness in the labourers . • . . . . • • . 145

The progressive struggle in industry is confined entirely to the employers; . . . . . . . . . . . . 146

and in every domain of progress it is confined to the leaders, to the exclusion of those who are led . . . . . . 146

In the progressive struggle between great men, the mass of the community play no part whatever . . . . . . . . 147

Let us take, for instance, two rival hotel-keepers . . . . . 148

One becomes bankrupt, and the other takes over his hotel and his staff . . . . . . . . . . . . $\mathrm{I}_{4} 8$

The sole struggle is between the employers, not the employed . 148 
The staff of the unsuccessful hotel-keeper gain, not lose, by being employed by the successful

Historical progress, then, results from a struggle not for subsistence, but for domination.

\section{CHAPTER III}

\section{The Means by which the Great Man applies his}

\section{Greatness to Wealth-Production}

All gain by the domination of the fittest, except the few who fail to secure power for themselves

We must consider, however, that the great men who struggle for domination would not do so without some strong motive; . . 152

and also that they cannot dominate others except by some particular means . . . . . • • • • • • . 153

Now the question of motive we will treat of hereafter. At present we will confine ourselves to the question of means . . . . 153

These vary in each domain of social activity . . . . . . I53 In some they are too obvious to need discussion . . . . $\quad$ I54

We need consider what they are only in the domains of politics and wealth-production . . . . . . . • . 155

The question is most important in its bearings on wealth-production . 156 The great man in wealth-production can influence the actions of others by two means only - by the slave-system and the wage-system . 157

The slave-system secures obedience by coercion, the wage-system by inducement . . . . . . . . . . . . 157

Wage-capital, not fixed capital, gives the primary power to capitalism as a productive agent . . . . . . . 158 Wage-capital is an accumulation of the necessaries of life, . . $\quad$ r 59 owned or controlled by a few persons, . . . . . . 159 and apportioned by them amongst many, on certain conditions . . 160 Karl Marx entirely misunderstood what these conditions are . . . 160 The essence of these conditions is that the many shall be technically directed by the few . . . . . . . . . . 16I

The question of how much the few appropriate of the product is a separate question altogether . . . . . . . . I62

The corvée system or slavery would make wage-capital superfluous; and this shows what the essential function of wage-capital is . . I62 
So-called "co-operation" is merely the wage-system disguised . . $\begin{gathered}\text { PAGR } \\ \text { I63 }\end{gathered}$

There are, then, only two alternatives - the wage-system and the slavesystem; • • . • . . . . . . . . 164

as we shall find by considering how the socialists can only escape the wage-system by substituting slavery. . . . . . . 165

For they would secure industrial obedience by coercion, . . . 166

not through the worker's desire to earn his living. And this is the essence of slavery . . . . . . . . . . 166

Next let us consider the means by which the great directors of industry compete against one another . . . . . . . . $\quad$. 167

Under capitalism they do so, owing to the fact that the man who cannot direct industry so as to please the public loses his capital, and with it the means of direction . . . . . . . 167

The wage-system is the only efficient means of competition of this kind . . . . . . . . . . . . 168

The socialists, though they affect to be opposed to competition altogether, . . . . . . . . . . . . 168

re-introduce it into their own system, . . . . . . . I70

the only change being that it is associated with the slave-system, which is very cumbrous and inefficient . . . . . . . I 170

Competition between employers, then, is a part of every system that permits of progress; . . . . . . . . 172

and since the re-introduction of slavery is practically impossible, we must regard the wage-system as a permanent feature of progressive societies..$\quad \cdot \quad \cdot \quad \cdot \quad \cdot \quad \cdot \quad \cdot \quad \cdot \quad \cdot \quad \cdot \quad 172$

We might reduce society to ashes, but this system and capitalistic competition would arise out of them; . . . . . . . $\quad$ I73

for capitalistic competition means the domination of the fittest great men $\quad 174$

The industrial obedience of the many to the few is the fundamental

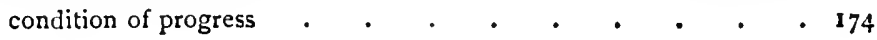

\section{CHAPTER IV}

\section{The Means by which the Great Man acquires Power in Politics}

In discussing the means by which the great man wields power in politics, the debatable question differs from the question raised by his power in industry; . . . . . . . 176 
for the points that are debated in the case of the great wealth-producer are admitted by all in the case of the governor . . . . 176

The greatest democrat admits that the governor must be an exceptional man, . • • • • . • • • • • • 177

and also that he must be chosen by elective competition . . . 177

There is a competitive element even in autocracies, . . . 178

and democracies are essentially competitive . . . . . $\quad$. 178

All parties also agree that laws must be enforced by pains and penalties . . . . . . . . . . . . 179

Denocrats are peculiar only in their theory that the sole greatness required in their governors is a perceptive and executive greatness, which will enable them to carry out the spontaneous wishes of the many . . . . . . . . . . . .

This is the only point in which the democratic theory differs from the aristocratic . . . . . . . . . . .

The democratic ruler is, theoretically, a balance for weighing the wills of the many, . . . . . . . . . . . 181

or a machine for executing their "mandates"; . . . . . 182

and there are signs which might suggest that the few in politics are really becoming the mere instruments of the many . . . . 182

But these signs are deceptive; for what seems the will of the many, really depends on the action of another minority . . . .

Opinions, to derive power from the numbers who hold them, must be identical; . . . . . . . . . . . 184

but they seldom are identical till a few men bave manipulated them . 184

Thus what seems to be the opinion of the many is generally dependent on the influence of a few $. \quad . \quad . \quad . \quad . \quad . \quad . \quad$.

The many, for instance, would never have had any opinions on Free Trade or Bimetallism if the few had not worked on them . . . . . . . . . . . .

Popular opinion requires exceptional men, as nuclei, round which to form itself . . . . . . . . . . . 187

Thus even in what seems extremest democracy the few are essential . 188

Democrats, however, may argue that under democracy the few do, in the long-run, carry out the wishes of the many . . . .

Even were this true, the current formulas of democracy would be false, for unequal men would be essential to executing the wishes of equals

Now in reality the few are never mere passive agents; . . . . 
but nevertheless the many do impress their will on them to a great extent . . . . . . . . . . . . 190

The question is to what extent? . . . . . . . . 19I

This introduces us to a new side of the problem - the extent of the power of the many . . . . . . . . . . I9I

This is greater in politics than in industry; . . . . . 192 and yet when we think it over we shall see that it is great in most domains of activity . . . . . . . . . . 192

We had to take it for granted at starting. We must now examine it . 193

\section{BOOK III}

\section{CHAPTER I}

How to Discriminate between the Parts CONTRibuted to a Joint Product by the Few and by the Many

Mill declares that when two agencies are essential to producing an effect, their respective contributions to it cannot be discriminated . 197 Mill argues thus with special reference to land and labour; . . . 198 but he overlooks what in actual life is the main feature of the case . 198 The labour remaining the same, the product varies with the quality of the land . . . . . . . . . . . . 198

The extra product resulting from labour on superior land is due to

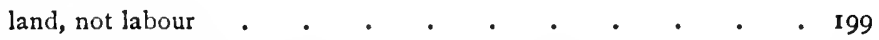

This is easily proved by a number of analogous illustrations . . 199 Mill errs by ignoring the changing character of the effect . . . 201

The case of labour directed by different great men is the same as the case of labour applied to different qualities of land. The great men produce the increment . . . . . . . . 202

Labour, however, must be held to produce that minimum necessary to support the labourer, . . . . . . . . . 203 both in agriculture $. \quad . \quad . \quad . \quad . \quad . \quad .203$ and in all kinds of production . . . . . . . . 204

The great man produces the increment that would not be produced if his influence ceased . $. \quad . \quad . \quad . \quad . \quad . \quad 204$

Labour, it is true, is essential to the production of the increment also; 205 
but we cannot draw any conclusions from the hypothesis of labour ceasing;

for the labourer would have to labour whether the great men were there or no

cessation of the great man's influence is a practical alternative; the cessation of labour is not, . . . . . . . . 206 as we see by frequent examples . . . . . . . . 206

Thus the great man, in the most practical sense, produces what labour would not produce in his absence . . . . . . . 208

An analysis of practical reasoning as to causes generally will show us the truth of this . . . . . . . . . . 208

For practical purposes the cause of an effect is that cause only which may or may not be present; . . . . . . . . 209

as we see when men discuss the cause of a fire, . . . . . 210 or of the accuracy of a chronometer, . . . . . . . 210 or the causes of danger to a man hanging on to a rope . . . . 211

But there is another means of discriminating between the products of exceptional men and ordinary men . . . . . . . 212

This is by an analysis of the faculties necessary to produce the product . 213 Are these faculties possessed by all, or by a few only? . . . . 213

\section{CHAPTER II}

\section{The Nature and Scope of purely Democratic Action, or the Action of Average Men in Co-operation}

Carlyle was wrong in his claim for the great man because he failed to note that his powers were conditioned by the capacities of the ordinary men influenced by him . . . • . . .

The socialists are wrong because, seeing that the many do something, they argue that they do everything . . . . . . .

What the many do is limited. We must see precisely what the limits

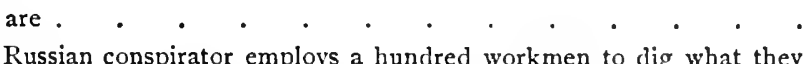

If a Russian conspirator employs a hundred workmen to dig what they think is a cellar, but is a mine for blowing up the Czar, . . .

the conspirator contributes the entire criminal character of the enterprise . . . . . . . . . . .

When a choir sings Handel's music, Handel contributes the specific character of the sounds sung by them . . . . . . $2 \mathrm{I}$ 
Let us turn to the facts of progress, . . . . . . . 217

and begin with economic progress and progress in knowledge . . 218

In the case of economic progress we must apply the method of inquiring what is produced by labour with and without the assistance of the great man . . . . . . . . . • •

To the question of progress in knowledge we must apply the method of inquiring what faculties are involved in it . . . . . 219

These are faculties entirely confined to the few . . . . . 219

And now let us turn to political government . . . . . . 220

What can the faculties of average men do when left to themselves? 220

They can accomplish only the simplest actions, . . . . . 220

and formulate only the simplest demands . . . . . 221

The moment matters become at all complex the faculties of the exceptional man are required . $. \quad . \quad . \quad . \quad . \quad$.

Now in any civilised country few governmental measures are really

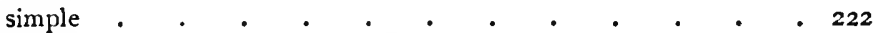

Exceptional men must simplify them for the many . $\quad$. . 222

Thus the voice of the many, in all complex cases, echoes the voice of the few . . . . . . . . . . . 223

This, bowever, is not the end of the matter; . . . . . $\quad 224$

for the details of governmental measures are not the whole of government • . • • • • • • • • • • 224

The true power of democracy is to be seen in religious and family life $\quad 224$

Though the influence of the great man in religion is enormous, . 225 yet religions have only grown and endured because they touch the heart of the average man . • . . . . . . . . 225

Christianity exemplifies this fact, . . . . . . . . 225 and especially Catholicism . . . . . . . . . 226

The doctrines formulated by the aristocracy of Popes and Councils originated among the mass of common believers . • • • 227

Theologians and councils merely reasoned on the materials thus given them.$\quad \cdot \quad \cdot \quad \cdot \quad \cdot \quad \cdot \quad \cdot \quad \cdot \quad \cdot \quad \cdot$.

Catholicism shows the great part played by the many so clearly, because the part played by the few is defined by it so sharply . . .

Catholicism, however, is only alluded to here because it illustrates the essential nature of truly democratic action . • . . . 229

Thus enlightened by it, let us turn back to family life . . . . 230

Catholicism shows that democracy is a natural coincidence of conclusions . . . . . . . . . . . . 231 
The home life of a nation depends on the same coincidence, or on spon-

taneously similar propensities . . . . . . . .

This truly democratic coincidence forces all governments to accommo.

date themselves to it . . . . . . . . . 233

The same democratic power determines the structure of our houses, $\quad 233$

and the furniture and other commodities in them, . . . . 234

and indeed all economic products . . . . . . . . . 234

For though in the process of production the many are dependent on the

few . . . . . . . . . . . .

(a fact which the powers of trade unionism do but make more appar-

ent), . . . . . . . . . . • .

et it is the wants and tastes of the many which determine what shall be

produced; . . . . . . . . . . . 238

and though great men elicit these wants by first supplying them, . 239

the wants themselves must be latent in the nature of the many, and when

once aroused are essentially democratic phenomena . . .

Thus though economic supply is aristocratic, economic demand is purely

democratic . . . . . . . . . . 240

The most gifted brewer cannot make the public drink beer they do not

like . . . . . . . . . . • • • 24 r

Now in politics also there is a similar demand and supply; . . . 242

but the truly democratic demand in politics is not for laws . . 242

The demand for laws is not the counterpart of a demand for commodi.

ties, for commodities are demanded for their own sake, laws for the

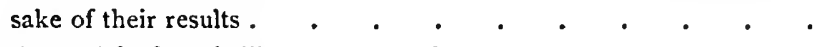

The demand for laws is like a demand that commodities shall be made

by some special kind of machinery . . . . . . . 243

No one makes this latter demand. Economic demand is single; politi-

cal demand is double $. \quad . \quad . \quad . \quad . \quad . \quad . \quad$.

Political democracy is vulgarly identified with the demand not for social

goods, but for machinery . . . . . . . .

But in so far as democracy is a demand not for goods but for machinery,

it is not purely democratic . . . . . . . . 245

The demands of the many are manipulated by the few . . . 245

Why, then, is democracy especially associated with the demand in which

its power is least? . . . . . . . . . . 246

Because it is the only sphere of activity in which the many can interfere

with the machinery of supply at all; . . . . . . 246

and they can interfere with it here because the effects of political gov- 
ernment on life are less close and important than the effects of business management on business; . . . . . . .

and in any case the apparent power of the many is even here controlled

by the few . . . . . . . . . . .

The power of the many is a power to determine the quality of civilisation and progress, not to produce them . . . . . . 248

\section{CHAPTER III}

\section{The Qualities of the Ordinary as opposed to The Great Man}

It will be objected that the conclusions reached in the last chapter derogate from the dignity of the average man . . . . . 250 But they do not really do so; . . . . . . . . 251

for since the great man, as here technically defined, is the man who in-

fluences others so as to promote progress, . . . . . $25 \mathrm{I}$

the ordinary man, as opposed to him, need not be stupid . . 252

$\mathrm{He}$ is merely the man whose talents do not increase the efficiency of

othermen . . . . . . . . . . . 252

Poets, in this technical sense, are ordinary men . . . . 252

So are the most skilful manual workers, . . . . . . . 253

for very great manual skill does not promote progress or influence

others, . . . . . . . . . . . . 254

unless it can be metamorphosed into the shape of orders given to

others . . . . . . . . . . . 256

Again, brilliance or charm in private life does not promote progress . 256

Therefore ordinary men, who do not promote progress, are not asserted

to be lacking in high qualities. $\quad$. $\quad . \quad$. . . 257

Indeed, what is really interesting in human nature is the typical part of

it, not the exceptional, . . . . . . . . 258

as we may see by referring to art and poetry . . . . . . 258

Average opinion also on social matters is for each class the wise

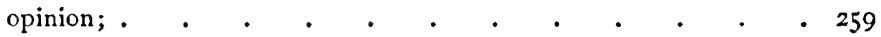

and the average faculties shared by all are in one sense the test of truth . . . . . . . . . . . 259

Therefore in denying to the average man the powers that promote progress . . . . . . . . . . . 260 
we are not degrading the average man. We are merely asserting that these powers form but a small part of life . . . . . 260

Socialists can object to this conclusion only because it establishes the claim of exceptional men to exceptional wealth . . . . 262

They cannot have any theoretical objections to it, for they are beginning to recognise the importance of the exceptional man themselves, . 263 and only obscure the fact for purposes of popular agitation . . $\quad 264$

So far, however, as the reasoning of this book has gone already, no claim has been made for the great man to which socialists need object; . . . . . . . . . . . . 264

for we have assumed that he keeps none of the exceptional wealth he makes, for himself, . . . . . . . . . . 265

but that he works exactly on the terms the socialists would dictate to him

It now remains to consider whether he would really do so . . 266

\section{BOOK IV}

\section{CHAPTER I}

The Dependence of Exceptional Action on the AttainaBility of Exceptional Reward, or the Necessary CorRESPONDENCE BETWEeN THE MOtIVES TO ACtION AND ITS RESULTS

Great men differ from ordinary men in degree only, not in kind, . $\quad 27 \mathbf{r}$ and the use of exceptional powers is conditioned like the use of ordinary powers . . . . . . . . . . 272

Now let us take the most universal powers possessed by man, viz. those used in acquiring the simplest food. . . . . . 272

Man's powers in agriculture would be latent unless man wanted food and the earth's surface were cultivable . . . . . $\quad 272$

Thus the exercise of the simplest faculties depends on the want of some certain object, and the possibility of attaining it . . . 273

If this is true of the commonest faculties, which aim at supplying necessaries, much more is it true of rare faculties, which aim at producing superfluities 
Society, then, if great men are to work in it, must be so constituted as to make the reward they desire possible . . . . . 274

In so doing society makes a contract with its great men; . . 274 and this is a contract which is being constantly revised . • . 275 The great men themselves are the ultimate fixers of their own price $\quad 276$ Here is the final proof that living great men, not past conditions, are

the causes practically involved in progress . . . . . 276

Thus living great men are masters of the situation . • . . 277 because no one can tell that they have exceptional powers till they

choose to show them . . . . . . . . . 277

They cannot, therefore, be coerced from without, like ordinary workers . 278

They must be induced to work by a reward . . . . . ${ }^{2} 278$

which they themselves feel to be sufficient . . . • . 279

Hence the great man's character and requirements impress themselves

on the structure of society . . . . . . . . 279

This is what socialists constantly forget . . . . . . . 280

and they propose to equalise matters by not offering great men any ex-

ceptional reward . . . . . . . . . . 28 r

They forget to ask whcther, under these circumstances, great men would

exercise or reveal their exceptional powers at all . . . . 281

Exceptional rewards are essential to exceptional action . . . $\quad 282$

We must inquire what the required exceptional rewards are . . $\quad 283$

\section{CHAPTER II}

\section{The Motives of the Exceptional Wealth-Producer}

Socialists, though often forgetting the necessity of exceptional motives, often remember it, . . . . . . . . . 284

and endeavour to show that socialistic society would have sufficient rewards to offer to its great men, . . . . . . . 284

such as the pleasure of doing good, of excelling, and of receiving honour . . . • . • • • • . . 285

The fundamental question is, will such rewards as these stimulate great men to wealth-production? . • . . . . . 285

Is the enjoyment of exceptional wealth superfluous as a motive to producing it? . . . . . . . . . . 286

If it is so, it is for the socialists to prove that it is so; . . . 286 
for they themselves admit that it has not been so in the past, and is not actually so now. . . . . . . . .

Are there any signs, then, that the desire for exceptional wealth is beginning to lose its power?. . . . . . . . 288

We shall find that the socialists themselves maintain just the contrary; . 288

for they appeal to the desire of each producer to possess all he produces as the most universal and permanent desire in man; . .

and never questioned this so long as they believed that the sole producer was the labourer . . . . . . . .

They questioned the doctrine only when they came to see that the great man is a producer also; and they confine their questioning to his case . . . . . . . . . . . .

But if the labourer desires to possess what he produces, much more will the great man do so; . . . . . . . . 290

for even if he gives away what he produces, he desires to possess it first 291

There is no sign, therefore, that the desire for exceptional wealth is losing force as a motive . . . . . . . . 292

Are, then, other desires acquiring new force as motives to wealth-production?. . . . . . . . . . .

Are the joys of excelling, of benefiting others, or of being honoured by

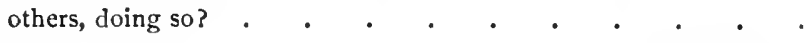

The desire of these joys is a motive to certain kinds of exceptional conduct .

It is a motive to benevolent action and religious work; . . . 293

But neither of these are the same thing as wealth-production . 294

It is a motive to artistic production, certainly, . . . . . 294

and also to scientific discovery; . . . . . . . . 295

and works of art are wealth, and scientific discovery is the basis of industrial progress; . . . . . . . . . 296

but great art forms but a small part of wealth, . . . . . 296

and artistic effort other than the highest is motived by the desire of pecuniary reward, . . • . . . . . . . 297

whilst scientific discoveries, though made generally from the desire for truth, are applied to wealth-production because the men who apply

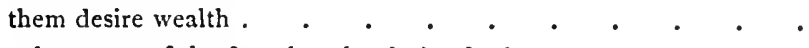

What, however, of the fact that the desire for honour makes the soldier work harder than any labourer? . . . . . . . 298

Why, the socialists ask, should not the same desire make the great wealth-producer work? . . . . . . . . . 299 
PAGE

Mr. Frederic Harrison has urged a similar argument . . . . 299

The answer to this is that the work of the soldier is exceptional; . . 300

and we cannot argue from it to the work of ordinary life . . . 301

The fighting instinct is inherent in the dominant races, . . . . 302

in a way in which the industrial instinct is not . . . . . 303

And even in war those who make the prolonged intellectual efforts

required, ask for themselves other rewards besides honour . . 303

Still more will the great wealth-producers do so . . . . $\quad 304$

There is therefore nothing to show that these other motives will supersede the desire of wealth . . . . . . . . 304

What they really do, and what socialists fail to see, is to mix with the desire for wealth, and add to its efficiency . . . . . 304

As the desire of wealth has mixed with other desires in men like Bacon,

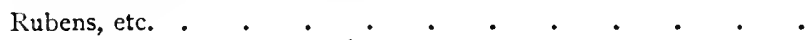

For in saying that the desire of wealth is essential as a motive to wealth-production we do not mean the desire of wealth for its own sake,

or for the sake of physical gratification . . . . . . . . 306

This forms a small part of its desirability . . . . . . 306

It is desired mainly as a means to power, and to those very pleasures which socialists offer instead of it . . . . . . 307

The great wealth-producers, susceptible to the motives on which socialists dwell, will desire exceptional wealth all the more because of them

It is argued, however, by semi-socialists that the actual producer may be allowed the income he produces, but that this must end with his life, and not be passed on to his family as interest on bequeathed capital . . . . . . . . . . . . . . 309

It is claimed that this arrangement would coincide with abstract justice, 3 IO for it is argued that all wealth which is not worked for must be stolen 310 This is utterly untrue, as the case of flocks and herds shows us; . . 3II but the chief producer of wealth that is not worked for is capital, which is past productive ability stored up and externalised . . . 3IX The dart of a savage hunter, . . . . . . . . . 312 the manure heap or cart horse of a peasant, . . . . . . 312 are forms of capital which actually produce, and the product belongs to those who own them . . . . . . . . .

The same is the case with such capital as engines and manufacturing plant 
These implements are like a race of iron negroes, and are producers as truly as live negroes would be. . . . . . . . . $\quad$. 314

Indirectly, wage capital is also a producer in the same way . . $\quad 314$

And indeed, till they saw that this argument could be turned against themselves, it was strongly urged by the socialists . . . . 315 Practically, however, the justification of income from capital . . . 316 rests on the fact that the power of capital to yield income is what mainly makes men anxious to produce it; . . . . . 316

since if income-yielding capital could not be acquired and amassed, wealthy men could make no provision for their families, . . 3I

nor could wealth give pleasure to those who might at any moment be beggars . . . . . . . . . . . .

Moreover, if incomes were not heritable, wealth would produce none of those social results, such as continuous culture, etc., which make it valuable . . . . . . . . . . . .

The wealth that ceased with the men that actually made it would produce a society of beasts . . . . . . . . . 319

Wealth is desirable because it is the physical basis of an enlarged life; . 320 and there must thus be continuity in the possession of wealth . 320 Hence the great wealth-producer demands the possession not only of what he produces directiy, but of what he produces indirectly through his past products . . . . . . . .

The majority not only may, but do, acquire a share of the increment produced by the great man; . . . . . . . .

but whatever this share may be, it can never be such as to make social

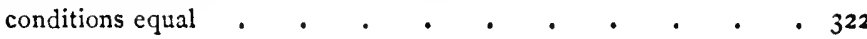

\section{CHAPTER III}

\section{Equality of Educational OpPortunity}

The wealthy class, owing to inheritance, is always much more numerous than the great men actually engaged at any given time in production

But though inheritance gives a certain permanence to the wealthy class, the families belonging to it are constantly, if slowly, changing, . . . . . . . . . . $\quad 325$ and new men are constantly forcing their way into it . . . $3^{26}$ 
Indeed the wealth of the country depends on the men potentially great

as producers actualising their talents and producing the wealth that raises them . . . . . . . . . .

It is therefore obvious that the wealth will increase in proportion as

these potentially great men have the opportunity of actualising

their productive powers . • • • • • • • • 327

It is impossible, however, to make opportunities absolutely equal . $\quad 328$

The question is how near we can approach to equality . . . $\quad 328$

In a country where these opportunities have been made artificially un-

equal there will be room for a great deal of equalisation . . .

But removing artificial impediments is only a negative kind of equalisation

It is probable, however, that for the development of genius of the high-

est order this is all that is needful, . . . . . . . 330

and will secure the development of all the genius of the highest kind

that exists . . . . . . . . . . . .

But genius of a lesser kind, which would else be lost, may, no doubt,

be elicited by positive educational help from the State; . .

though the amount of such genius is overestimated by reformers,

because they confuse talents rare in themselves with accomplish-

ments that are only rare accidentally . . . . . . 332

The latter can be increased indefinitely, the former not . . . 333

For real productive genius there is always room, . . . . 333

but the economic utility of mere accomplishments is limited by the con-

ditions of production at the time $. \quad . \quad . \quad . \quad$.

Thus to produce more possible clerks than are wanted merely lowers

the wages of those employed, without increasing the utility of those who are not employed. • . • . . • .

Still, within limits, educational help from the State does much to increase the supply of exceptional, though not great, talent . .

But the main difficulty involved in the equalising of educational oppor-

tunity is not the production of good results, but the avoidance of

bad . . . . . . . . . . . .

The bad results are the stimulating of discontent, not in average men,

but in men who are really exceptional . . . . . . 336

but those exceptional gifts are ill-balanced or have some flaw in them . 337

For if education sets free and stimulates sound intellectual powers, $\quad 337$

it will similarly stimulate intellects that are not sound, ..$\quad \cdot \quad \cdot 338$

or wills, with no intellect to match, and will generate a desire for wealth

in men who are not capable of creating it, . . . . . 338 
and thus will merely produce needless misery and mischief

Education, again, stimulates faculties that can really produce exceptional results, but not results that are complete

The progressive struggle requires that the intellects of some should be stimulated, whose efforts fail ..$\quad \cdot \quad \cdot c^{*} \cdot$

But those failures that promote progress are failures that partially succeed . . . . . . . . . . . . 340

But there are abortive talents which produce failures that have no relation to success. Those talents are purely mischievous; . . $34 \mathrm{I}$

for example, the failure of the would-be artist, . . . . $\quad 34$ I

or that of the man who popularises wrong medical treatment $\cdot \quad 342$

But the commonest example of this kind of man is the socialistic agitator, . . . . . . . . . .

who demands the redistribution of wealth, whilst absolutely powerless to produce it, . . . . . . . . . .

and who consequently invents false theories about its production, which do nothing but demoralise those who are duped by them . .

(though even these theories can be discussed with profit under certain circumstances)

Men like these embody the two chief dangers of the equalisation of educational opportunity, . . . . . . . .

namely, the rousing in the average man wants he cannot satisfy, and the stimulating of talents that are constitutionally imperfect . . $\quad 345$

The latter of these dangers is the source of the former . . . . 346

It cannot be completely avoided, but the present theories of education tend to heighten, not to minimise it . . . . . 346

The current theory that all talents should be developed is false, . $\quad 347$

so is the theory that all tastes should be cultivated in all alike. The education proper for the rich is not a type but an exception . • 347

These false theories rest on the false belief that equal education could ever produce equal social conditions . . . . . . 348

The majority of each class will remain in the class in which they were born . . . . . . . . . . . 348

Only the efficiently exceptional can rise out of their own class, . $\quad 348$

and it is the ambition of the efficiently exceptional only that it is really desirable to stimulate . . . . . . . . . 349

The average man should be taught to aim at embellishing his position, not at escaping from it . . . . . . . . 349 


\section{CHAPTER IV \\ Inequality, Happiness, and Progress}

The radical politician will object to the foregoing conclusions in terms with which we are familiar . . . . . . . .

The radical theorist will put the same objections more logically. If the desire of exceptional wealth is really the strongest motive, he will say that it follows that most men, since they cannot all be exceptionally rich, must always remain miserable $\quad$. . . .

Now the first answer to this is that the fact that all men will never be equally wealthy does not prevent the conditions of all men from improving absolutely . . . . . . . . .

Another answer is that if inequality in the possession of the most coveted prizes of life implies misery amongst the majority, this evil would be intensified rather than mitigated by socialists, who would substitute unequal honour for unequal wealth . . . . . . .

The final answer is that the unequal distribution of wealth has no natural tendency to cause unhappiness; . . . . . . .

for men's desires vary. There is equality of desire for the necessaries of life only; for this desire rests on men's physical natures, which are similar; . . . . . . . . . . . .

but the desire for superfluities depends on their mental powers, which vary . . . . . . . . . . . . .

The special appeal of luxury is mainly to the mind and the imagination - . . . . . . . . . . . $35^{8}$

the luxury, for instance, of a large house, . . . . . 359 or sleeping accommodation in a train . . . . . . . 359

Consequently the desire for luxury and wealth, like the pleasure they give, depends on peculiar mental powers or peculiar mental states . 360

Amongst most men the desire for wealth is naturally a speculative desire only

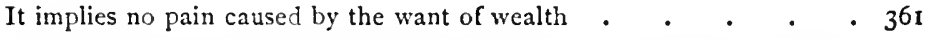

The desire ceases to be speculative and becomes a practical craving only when the imagination is exceptionally strong, and a strong belief is present that the attainment of wealth is possible . . . . 362

The desire for wealth, in fact, is in proportion to each man's belief that by him personally it is attainable . . . . . . 364 
This belief is naturally confined to men with exceptional imaginations and exceptional productive powers . . . . . . . 365

It only becomes general by the popularising of false theories which represent wealth as attainable by all, without exceptional talent or exceptional exertion . . . . . . . . . . 366

It is roused, for instance, in a man who suddenly is told that he has a legal right to an estate which previously he never thought of coveting . . . . . . . . . . . .

The socialistic teaching of to-day creates a spurious desire for wealth by its doctrines of inpossible rights to it . . . . . . 367

The practical craving for wealth is naturally confined to those who have some talent for creating it, and the pain caused by its absence is naturally confined to such men . . . . . . . 368

The socialistic theories merely cause a barren and artificial discontent, 368 which interferes with that harmonious progress on which the welfare of the many depends . . . . . . . . . . 369

These theories make enemies of classes who would otherwise be allies, and the cause of true social reform suffers incalculable injury . . 370

The object of the present work is to show the fallacy of the theoretic basis of existing socialistic discontent and socialistic aspirations; . 371

and to show that the many are not a self-existent power, . . . 372 but depend for all the powers they possess on the co-operation of the 373 few, . . . . . . . . . . . . 373 whose rights are as sacred, and whose power is as great, as their own - 375 The recognition of the fact that the relations and positions of classes can never be fundamentally altered . . . . . . . 376 (especially when we consider the facts of history to which Karl Marx drew attention) . . . . . . . . . 376

shows us not only how chimerical are the hopes of the socialists, but what solid grounds there are for the hopes of more rational reformers. 

BOOK I 


\section{CHAPTER I}

THE FUNDAMENTAL ERROR IN MODERN

SOCIOLOGICAL STUDY

THE interest with which the world in general, science during throughout the middle portion of this century, this century has watched the progress of the various positive interest mainly sciences, would, when we consider how abstruse on account of these sciences are, seem strange and almost inex- the doctrines of plicable if it were not for one fact. This fact is Christianity. the close and obvious bearing which the conclusions of the sciences in question have on traditional Christianity, and, indeed, on any belief in immortality and the divine government of the world. The popular interest in science remains still unabated, but the most careless observer can hardly fail to perceive that the grounds of it are, to a certain extent, very rapidly changing. They are its popularity ceasing to be primarily religious, and are becoming now is beginprimarily social. The theories and discoveries of on its bearing the savant which are examined with the greatest problems, but eagerness are no longer those which affect our 
Book I prospects of a life in heaven, but those which deal Chapter I with the possibility of improving our social conditions on earth, and which appeal to us through our sympathies, not with belief or doubt, but with the principles which are broadly contrasted under the names of conservative and revolutionary.

Science itself is undergoing a corresponding change.

Such being the case, it is hardly necessary to observe that science itself has been undergoing a change likewise. The character of the change, however, requires to be briefly specified. From the time when geologists first startled the orthodox by demonstrating that the universe was more than six thousand years old, and that something more than a week had been occupied in the process of its construction, to the time, comparatively recent, during which the genius of Darwin and others was forcing on the world entirely new ideas with regard to the parentage, and presumably the nature of man, there was a certain limit - a certain scientific frontier - at which positive science practically stopped short. Having sedulously examined the Its character- materials and structure of the universe, until on the istic aim during the middle of the century was to deal with physical and physiological evolution. one hand it reached atoms and molecules, it examined, on the other, the first emergence of organic life, and traced its developments till they culminated in the articulate-speaking human being. It brought us, in fact, to man on the threshold of his subsequent history; and there, till very recently, positive science left him. But now there are signs all round us of a new intellectual movement, analogous to that which accompanied the rise of Darwinism, 
and science once again is endeavouring to enlarge its borders. Having offered us an explanation of Book I Chapter I the origin of the animal man, it proposes to deal with the existing conditions of society very much as it dealt with the structure of the human body, to exhibit them as the necessary result of certain farreaching laws and causes, and to deduce our civilisation of to-day from the condition of the primitive savage by the same methods and by the aid of the same theories as those which it employed in deducing the primitive savage from the brutes, and the brutes in their turn from primitive germ or protoplasm. In other words, the great triumph of science during what we may call its physical Its characterperiod has been the establishment of that theory is to deal with of development which is commonly spoken of as the evolution Evolution, and the application of this to the problems of physics and biology. The object of science in entering on what we may call its social period is the application of this same theory to the problems of civilisation and society.

It is true that, if we use the word science in a certain sense, the attempt to treat social problems Social science scientifically is not in itself new. Political economy, wholly new. to say nothing of utilitarian ethics, is a social science, or it is nothing; and political economy had already made considerable advances when modern physical science had hardly found its footing. But before long physical science passed it, with a step that was not only more rapid, but also immeasurably firmer, and was presently giving such an example of what 
Book I accurate science is, that it was thought doubtful Chapter I whether political economy could be called a science at all. The doubt thus raised cannot be said to have justified itself. In spite of all the attacks that have been made against the earlier economists, their principal doctrines survive to the present day, as being, so far as they go, genuine scientific truths. But whenever the thinker, who has been educated in the school of modern physical science, betakes himself now to the study of society and human action, and begins to apply to these the developed theory of evolution, though he does not reject the doctrines of the earlier economists, he sees them in a new light, by which their significance is profoundly changed. The earlier economists took society as they found it, and they reasoned as though what was true of the economic life around them must be absolutely and universally true of economic life always. Here is the point as to which the thinker What is new is of to-day differs from them. He does not dispute the application to it of the evolutionary theory. the truth of the deductions drawn by them with regard to society as it existed during their own epoch; but, educated by the methods and discoveries of the physical and biological evolutionist, he perceives that society itself is in process of constant change, that many economic doctrines which have been true during the present century had little application to society during the Middle Ages, and that centuries hence they may perhaps have even less. Thus, though he does not repudiate or disregard the economic science of the past, he 
merges it in a science the scope of which is far wider and deeper. This is' a science which Book I Chapter I primarily sets itself to explain, not how a given set of social conditions affects those who live among them, but how social conditions at one epoch are different from those of another, how each set of conditions is the resultant of those preceding it, and how, since the society of the present differs from that of the past, the society of the future is likely to differ from that of the present.

What political economy has thus lost in precision This excites it has gained in general interest. So long as it gesting great merely analysed processes of production and dis- in the funture, tribution which it was assumed would always continue without substantial modification, political economy was mainly a science for specialists, and was little calculated to arouse any keen interest in the public. But now that it has been merged in that general science of evolution, which offers to an unquiet age what seems a scientific licence to regard as practically producible some indeterminate transformation in these processes, political economy has come to occupy a new position. Instead of being ignored or ridiculed by the more ardent school of reformers, and even neglected by conservatives as a not very powerful auxiliary, it has now been brought down into the dust of the general struggle, and is invoked by one side as the prophetess of new possibilities, and by the other as an exorcist of mischievous and mad illusions. And what is true in this respect with regard to political economy is 


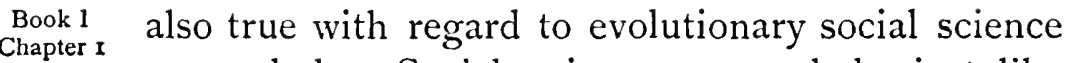
as a whole. Social science as a whole, just like this special branch of it, is being brought into vital contact with the lives and hopes of man, and is exciting a popular interest strictly analogous to that which had been excited by physical and biological science previously.

which will It is doing this in two ways, which, though
give a religious meaning to the closely connected, are distinct. In the first place, history of humanity, it is directing our attention to the human race as a whole, and is showing us how society and the individual have developed in an orderly manner, growing upwards from the lowest and the most miserable beginnings to the heights of civilisation, intellectual, moral, and material, and how they contain in themselves the potency of yet further development. It thus offers to the mind a vast variety of suggestion with regard to the significance of man's presence upon the earth, and is held by many to be supplying us with the materials of a religion calculated to replace that which physical science has discredited. The second way in which it excites or secure for popular interest is the way which has been just men now exist- illustrated by a reference to political economy. For practical social besides offering to our philosophic and religious advantages. faculties the vision of man's corporate movement from a condition of helpless bestiality towards some "faroff divine event," which glitters on us in the remote future, social science is suggesting to us changes which are of a very much nearer kind, and which appeal not to our speculative desire to discover some 
meaning in the universe, but to the personal interest which we each of us take in our own welfare - such,

Book I Chapter I for instance, as a general redistribution of wealth, the abolition or complete reorganisation of private property, the emancipation of labour, and the realisation of social equality.

This distinction between the speculative and practi- Men have thus cal aspects of social science has a special importance, for being interwhich will be explained and insisted on presently. But science, and it is here mentioned only to show the reader how strong sociologists a a combination of motives is impelling the present for studying it; generation - the conservative classes and the revolutionary classes equally - to transfer to social science the interest oncefelt in physical; and how strong is the stimulus thus applied to sociologists to emulate the diligence and success of the physicists and biologists, their predecessors. Nor have diligence, enthusiasm, or scientific genius been wanting to them. As has already been observed, they have transformed social science altogether by applying to it the doctrines of evolution which physical science taught them, and and it has attracted a have thus organically affiliated the former study to umber of men the latter. This is in itself a triumph worthy of the enterprise that has achieved it. But they have done or genius, who have applied to it the learned in the school of phyfar more than borrow from physics this mere general sical science. theory. They have established between physical phenomena and social an enormous number of analogies, so close that the one set assists in the interpretation of the other. They have borrowed from the physicists a number of their subsidiary theories, their methods of grouping facts, and, above 
Book I Chapter I

Yet despite their genius and their diligence, all parties complain that the results of their study are inconclusive.
Professor

Marshall and Mr. Kidd, for instance, complain of the fact, but can suggest no explanation of it.

all, their methods of studying them. In a word, they are endeavouring to follow the masters of physical science along the precise path which has led the latter to such solid and such definite results.

We have now, however, to record a singular and disappointing truth. Though men of science have, in the manner just described, been engaged for years in the field of sociological study; though the way was prepared for them by men like Comte, Mill, and Buckle; though amongst them have been men like Mr. Spencer, with capacities of the highest order, and though certain results have been reached of the kind desired, complaints are heard from thinkers of all shades of opinion that these results are singularly unsatisfactory and inconclusive when compared with the efforts that have been made in reaching. them, and still more when compared with the results of corresponding efforts in the sphere of physics.

No one complains more loudly of this comparative failure than some of the most distinguished students of social science themselves. Professor Marshall, for instance, who has done more than any other English author to breathe into technical economics the spirit of evolutionary science, admits that Comte, who laid the foundation of sociology, and $\mathrm{Mr}$. Spencer, who has invested it with a definitely scientific character, have brought to the study of "man's actions in society unsurpassed knowledge and great genius, and have made epochs in thought by their broad surveys and suggestive hints"; but neither of them, he proceeds to say, has succeeded 
in doing more than this. Mr. Kidd, again, whose work on Social Evolution, if not valuable for the conclusions he himself desires to substantiate, is curiously significant as an example of contemporary sociological reasoning, repeats Professor Marshall's complaint, and gives yet more definite point to it. Having observed that "despite the great advance which science has made in almost every other direction, there is, it must be confessed, no science of human society, properly so-called," he justifies this observation by insisting on what is an undoubted fact, that "so little practical light has even Mr. Herbert Spencer succeeded in throwing on the nature of the social problems of our time, that his investigations and conclusions are, according as they are dealt with by one side or the other, held to lead up to the opinions of the two diametrically opposite camps of individualists and collectivists, into which society is rapidly becoming organised."

Now what is the reason of this? Here is the what can the question that confronts us. That the methods be? adopted by the scientist in the domain of physics are applicable to social phenomena, just as they are to physical, has been not only established in a broad and general way, but demonstrated by a mass of minute and elaborately co-ordinated facts. Why, then, when we find them in the sphere of physics solving one problem after another with a truly surprising accuracy, do they yield us such vague and often contradictory results when we apply them to the solution of the practical problems of society? 
Book I

Chapter I

The answer will be found in the fact just referred to that social science attempts to answer two distinct sets of questions;

Those who complain so justly of the failure of social science and who yet show themselves altogether at a loss to account for it, might have seen their way to answering this question had they concentrated their attention on a point that was just now alluded to. It was just now observed that the problems which social science aims at answering, and is popularly expected to answer, are of two distinct kinds - the philosophic or religious, and the practi$\mathrm{cal}$; the former being concerned with the destinies of humanity as a whole, with movements extending over enormous periods of time, and with the remote past and future far more than with the present; the other being concerned exclusively with the present or the near future, and with changes that will affect either ourselves or our own children. and one set- Now it will be found that social science, whilst busy-

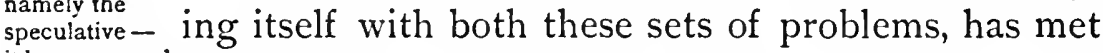
it has answered with the failures which are alleged against it, only
with great success; in dealing with the latter, and that, so far as regards the former, it has successfully reached conclusions comparable in precision and solidity to those of the physicists and biologists whose methods it has so conscientiously followed. Professor Marshall's own treatise on The Principles of Economics, and that of Mr. Kidd on Social Evolution likewise, abound in admissions that this statement of the case is correct. Professor Marshall's account of the rise and fall of civilisation as caused by climate, by geographical position, and the influence of one race and one civilisation on another, - an account of which he 
places in the very forefront of his elaborate work - is professedly merely a summary of conclusions Book I Chapter I already arrived at; and the manner in which he states these conclusions is itself evidence that sociologists, when dealing with certain classes of social phenomena, have given us something more than "surveys" and "suggestive hints." Social science, in fact, cannot be properly called a failure except when it ceases to deal with the larger it has failed phenomena of society, which show themselves only tempting to in the long course of ages, and descending to the answer practiproblems of a particular age and civilisation, endeavours to deduce, from the general principles it has established, propositions minute enough to be applicable to our immediate conduct and expectations. As practical inquirers, therefore, the real question before us is not why social science has failed, where physical science has succeeded, but why social science has succeeded like physical science in one direction, and, unlike physical science, failed so signally in another. If we concentrate our attention on the subject in this way, and thus realise with precision the nature of the failure we desire to explain, we shall find that the explanation of it is not only far simpler than might have been supposed, but also that the remedy for it is far more obvious and more easy.

It has been said that sociology has succeeded in dealing with those social phenomena which extend with which themselves through vast periods of time, and has successfully failed in dealing with those whose interest and ${ }_{\text {mena of social }}^{\text {are pheno- }}$ 


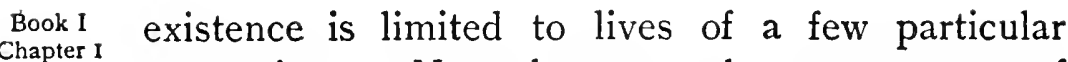
generations. Now between these two sets of phenomena, as thus far described, the most obvious difference is, no doubt, the difference in their magnitude. This difference, however, is altogether accidental, and does nothing to explain those curiously contrasted results which the study of one set and the other has yielded to the modern sociologist. The difference, which will explain these, is of quite another kind, and may briefly be stated thus. The larger social phenomena - those which interest the speculative philosopher, and with which sociology has dealt successfully, are phenomena of social aggregates, or masses of men regarded as single bodies; the smaller phenomena - those which interest the practical man, and with which sociology has dealt unsuccessfully - are essentially the phenomena not of social aggregates, but of various parts of aggregates.

Let us illustrate the matter provisionally by two rudimentary examples. As an example of the larger phenomena let us take the advance of man from the age of stone to the ages of bronze and iron. Of the smaller, we may take the phenomena referred to by Mr. Kidd - namely, the appearance in the modern world of the socialist or collectivist party, and the antagonism between it and the party of private property and individualism. Now the first of these two sets of phenomena - the use by men of stone implements, and the subsequent use of metal implements - consist of phenomena which, so far as the sociolo- 
gist is concerned, are manifested successively by humanity, or some portion of humanity, as a whole. They are not referred to individuals or small classes. No question is asked as to what particular savage may rightly claim priority in the invention of metal implements, or whether flint or bronze were the subjects of any prehistoric monopoly. Those races amongst which the use of the metals became general are regarded as a single body, which had made this advance collectively. They are, indeed, as we shall again have occasion to observe, habitually described under the common name of Man. But let us turn but the practito such phenomena as the antagonism between of to-day, with individualists and collectivists, and the case is wholly which it has different. It is true that here also, as in the case cessfully, arise we have just been considering, our attention is flict between called to a portion of the human race, namely, the of aggregates. Western or progressive nations, which we may, for certain purposes, regard as a single aggregate; but it is fixed, not on the phenomena which this aggregate exhibits as a whole, but on those exhibited by unlike and conflicting parts of it - the part which sympathises with individualists on the one hand, and the part which sympathises with collectivists on the other.

Thus the subject-matter of sociology, regarded as a speculative science, consists of those points in which the members of any given social aggregate resemble one another. The subject-matter of sociology, regarded as a practical science, consists of those points in which the members, or 
Book I certain groups of members, of any given social aggregate differ from one another. And here we come to the reason why sociology, as a practical Social success science, has failed. It has failed because hitherto has failed as a practical guide it has not realised this distinction, and has persisted because it has
not recognised in applying to the phenomena, involved in practical this distinc- social problems, the same terminology, the same
tion; methods of observation and reasoning, which it has applied to the phenomena involved in speculative social problems. By so doing, though it has dissipated many popular errors, it has, in the most singular manner, given a new vitality to others. It has indeed supplied a pseudo-scientific sanction to the most abject fallacies that have vitiated the political philosophy of this century; and it has thus been

and hence arise most of the errors of the political philosophy of this century. instrumental in keeping alive and encouraging the most grotesquely impossible hopes as to what may be accomplished by legislation, and the most grotesquely false views as to the sources of social and political power. To expose these fallacies, and the defective reasoning on which they rest, is the object of the present volume.

The nature of that peculiarity in the procedure of modern sociology which has just been described, and to which all its errors are due, forms a very curious study, and it will be essential to exhibit it with the utmost plainness possible. In the following chapter, therefore, the reader shall be presented with examples of it. 


\section{CHAPTER II}

THE ATTEMPT TO MERGE THE GREAT MAN IN THE AGGREGATE

LET us take any book we please, by any modern whatever may writer, who is attempting to deal with any social be done by writer, who is attempting to deal with any social some men, or subject scientifically, and whenever he is calling classes of men, attention to the great intellectual triumphs which at present have caused the progress of civilisation, or to any attribute to developments of human nature which have marked it, we shall find that these triumphs or developments are always attributed indiscriminately to the largest mass of people with whom they have any connection - sometimes to "the nation," sometimes to "the age," sometimes to " the race," and more frequently still to "man."

Reference has been made already to Mr. Kidd's Mr. Kidd's work on Social Evolution, which, on its publication, sion, for inattained an extraordinary popularity, and which, entirely on this whatever its value otherwise, is interesting as a procedure. $^{\text {. }}$ type of contemporary sociological reasoning. It is peculiarly interesting as illustrating the point which we are now discussing. Most of Mr. Kidd's reasoning, especially in the crucial parts of it, is not 
Book I
Chapter 2 terminology which refers everything to "the race," "the age," or "man." And it would be hard to find better examples in the works of any other writer of the condition of thought underlying the use of these phrases, and of the extraordinary consequences to which it leads.

He quotes with Three examples will be enough. The two first approval two
other writers shall be from two other writers, whom Mr. Kidd who have been
guilty of it, himself. We will begin with the following passage, taken from a contemporary economist, which Mr. Kidd singles out for emphatic approval as " $a$ very effective statement" of one of the truths of social science.

"Man," so the passage runs, "is the only animal whose wants can never be satisfied. The wants of every other living thing are uniform and fixed. The ox of to-day aspires no more than did the ox when man first yoked him.... But not so with man [himself]. No sooner are his animal wants satisfied, than new wants arise. . . . [He] has but set his feet on the first step of an infinite progression. ... It is not merely his hunger, but taste, that seeks gratification in food. . . . Lucullus will sup with Lucullus; twelve boars roast on spits that Antony's mouthful of meat may be done to a turn; every kingdom is ransacked to add to Cleopatra's charms; and marble colonnades, and hanging gardens, and pyramids that rival the hills, arise."

This passage is taken from Mr. Henry George. 
Our second example shall be a passage which $\mathrm{Mr}$. Kidd has borrowed from a far more educated

Book 1

Chapter 2 thinker-M. Émile de Lavelaye. Mr. Kidd quotes M. de Lavelaye as saying that the eighteenth century brought the following message to "man." "Thou shalt ccase to be the slave of the nobles and despots who oppress thee. Thou shalt be free and sovereign." But the realisation of the promise thus given has, in the present century, he goes on to say, confronted us with this strange problem. "How is it that the Sovercign often starves? How is it that those who are held to be the source of power often cannot, even by hard work, provide themselves with the necessaries of life?"

Now all these passages, if we consider them care- who both fully, will be seen to consist of statements, every one attribute to $^{2}$ what is of which is false to fact. To say that man's wants a dew men; are less stationary than those of the ox is not even rhetorically true, unless we mean by "man" certain special races of men; whilst the statements that follow are not true, rhetorically or otherwise, of any race at all, but only of scattered individuals. A really fine and discriminating taste in food is, as every epicure knows, rare even amongst the luxurious classes. Antony and Lucullus are types of what is not the rule, but the exception. So too are the individuals who either desire hanging gardens, or could design them; and more exceptional still are the individuals whose personal pride and power either desire or can secure the erection of pyramids for their tombs. 
Book I

Cbapter 2

and the consequences to their reasoning
are ludicrous.

In M. de Lavelaye's utterances there is an analogous misstatement and misconception of every fact with which he deals. The promises of political democracy, as he describes them, were never addressed to "man," nor ever professed to be. The whole point of them was that they were addressed to certain classes of men only; and that, as addressed to other classes, they were not promises, but threats. But a still graver confusion arises when the "Sovereign" is spoken of as starving. If by the "Sovereign" M. de Lavelaye really means "Man" as a whole, it is perfectly obvious that the "Sovereign" never starves. The statement is equally untrue if the Sovereign is taken to mean not man as a whole, but the immense majority of men; and to ask why the Sovereign often does something which it never does, is not to formulate an actual problem loosely, but to convert an actual problem into one that is quite imaginary. The actual problem is not why the whole or the immense majority of mankind often starves, but why there are nearly always small sections of men who do so, the majority all the while obtaining its normal nutriment; and the absurd result of confusing these two very different things is seen in the second form which M. de Lavelaye gives his question. "How is it," he asks, "that those who are held to be the source of power often cannot, even by hard work, provide themselves with the necessaries of life?" The answer is that the particular groups of workers who, at any given time, happen to be unemployed, 
were never held to be the source of power by anybody. M. de Lavelaye might as well take one

Book I Chapter 2 half of the passengers on a Dover packet, and treating them as identical with the British nation at large, ask how it is that those who are held to rule the waves can hardly set foot on a deck without clamouring for the steward's basin.

And now let us turn to Mr. Kidd himself. The Mr. Kidd's object of his book is to vindicate supernatural is not less religion by exhibiting it as advantageous to its fudicrt half. The possessors in the social struggle for existence. He $\mathrm{He}_{\text {that rentisis }}^{\text {argume }}$ endeavours to make good his position by two distinct prompts the lines of argument. The first of these is that the render advansocial struggle for existence, though it produces tages to the progressive communities, and communities fitted to if they chose endure, is injurious to the majority of those who at could keep. any given time are engaged in it, and benefits only a minority, described by him as "the power-holding classes." This minority, according to his account, could always, if it pleased, as it has pleased in all former ages, defend its position and keep the majority in subjection; but it is now beginning, under the pressure of a religious impulse, to surrender to its inferiors voluntarily advantages which they could never have extorted from it; and in this great fact our hope for the future lies.

Such is one of the two main portions of $\mathrm{Mr}$. The second Kidd's message to the world; and here follows the many at any other, which will be found to be fundamentally have taken inconsistent with it. "Man," if he had chosen to these advando so, Mr. Kidd maintains - and this assertion 
Book 1 is repeated by him with the utmost precision and emphasis - could at any period in his history

few, and that religion alone prevented them from doing so.
This contradiction is entirely due to the fact that, having first divided the social aggregate into two classes, he then obliterates his division, and thinks of them both as "man." have "suspended the struggle for existence" and "organised society on a socialistic basis"; and seeing that the struggle for existence, although essential to progress in the long-run, is injurious to the majority of each generation that takes part in it, man, if his chief guide had been reason or self-interest, would have been suspending this struggle constantly for the sake of his own present advantage, and leaving the future to take care of itself. Now, seeing that he does not, as a fact, pursue this obviously reasonable course, it follows that some power opposed to reason must have withheld him; and this power, argues Mr. Kidd, can be nothing else than religion. Here, he says, are the two functions of religion in evolution. It induces man to submit to the hardships of the evolutionary struggle, at the same time it redeems him from them by softening the hearts of the minority.

Now with Mr. Kidd's views about religion we have nothing to do here. We are concerned only with the extraordinary self-contradiction involved in these his principal lines of argument, and also with the cause which has led to it, and made it possible. At one moment he says that the majority in all progressive communities have been forced to submit to conditions of life that are prejudicial to them, by a powerful minority to whom these conditions are beneficial, and who, if they chose to do so, would still be able to maintain them. At 
another moment he says that this surprisingly patient majority could have easily "suspended these conditions" at any period of its history, and only failed to do so because religion prompted it to forbear. How a contradiction of this kind could have found its way into the reasoning of a really painstaking thinker, and been actually allowed to form the backbone of it, may at first sight seem inexplicable; but it is simply a typical result of the practice we are now considering - that practice, common to all our modern sociologists, of grouping the men they deal with in to the largest aggregate possible, and treating mixed classes of men as one single class - "man."

It is easy to see precisely how Mr. Kidd's mind has worked. In the first part of his argument he divides progressive communities into two sections, which he calls respectively "the power-holding classes" or the "successfuls," and the "excluded classes" or the "unsuccessfuls"; and he declares that the latter would naturally desire to suspend the conditions of progress, whilst the former would naturally desire, and are also able to maintain them. But when he pushes his argument farther, and advances to the proposition that if reason had been "man's" sole guide, the conditions of progress would have been suspended over and over again, he is enabled to take this extraordinary step only because his thought and his terminology undergo an unconscious metamorphosis. He forgets his original analysis altogether. He merges the two classes, so sharply contrasted by him, into one. He argues and 
Book I thinks about them both, under the single category
Chapter 2 of "man"; he builds up his conclusions by joining together the very things which, in arranging his premises, he had so carefully put asunder; and the result of his speculation reduced to its simplest terms is this - that "man" could have done, at any period of his history, and, if reason had been his sole guide, actually would have done, something that was against the interests of the stronger part of him, and beyond the power of the weaker.

Mr. Kidd's confusion is the result of no accidental error. It is the inevitable result of a radically fallacious method, and of this method the chief exponent is Mr. Herbert Spencer,

The reader will not find much difficulty in understanding that if sociologists persist in reasoning thus, they are hardly likely to arrive at any conclusion sufficiently definite to guide us in the practical difficulties of life. It may be urged, however, that such language as we have been considering, though used by scientific writers, is intended itself to be rhetorical rather than scientific, or that it betrays the inaccuracy of this or that individual thinker, instead of arising from a fundamental error in method. If any one thinks this, he shall soon be disabused of his opinion. The reader shall now be presented with a brief summary of the method deliberately followed, and of some of the conclusions arrived at by that distinguished thinker who has done more than any one else to impart to sociology the character which it at present possesses; and the error which lies at the bottom of the reasoning we have been just considering shall there be exhibited, systematically exemplified, and explicitly and elaborately defended. It is perhaps 
hardly necessary to say that the thinker thus referred to is Mr. Herbert Spencer.

Book I

Chapter 2

We will then follow Mr. Spencer's reasoning as a short from the beginning, as set forth in his works; and humsociological before consulting his monumental Principles of arguments will before consulting his monumental Principles of show.

Sociology, we will turn to his Study of Sociology, a smaller and preparatory treatise, in which the methods adopted by him in his main inquiry are explained. He opens this treatise with declaring that until recent years any scientific treatment of social phenomena was impossible; and it was impossible, he says, for two definite reasons. These were the prevalence of two utterly false theories, both of which precluded the idea that anything like law or order of a calculable kind were prevalent in the social sphere. One of these theories was "the theocratic theory," the other what he calls "the great-man theory."

The theocratic theory is that which explains all Mr. Spencer social change by reference to the direct and arbitrary starts with interference of a Deity; and if this be adopted, $\mathrm{Mr}$ chief impediSpencer has no difficulty in showing that anything science is the like a social science must be necessarily looked on the great-man as impossible: for the only thread by which social theory: phenomena are connected will in that case be hidden in the will of an inscrutable Being, which may indeed be made known to us by revelation, but which is not susceptible of being either observed or calculated. This theory, however, in its cruder form, at all events, is, says Mr. Spencer, being fast discarded by everybody - even by the theologically 
Book I orthodox; and the really important foe which social science has to fight against is the great-man theory, not the theocratic. Accordingly, it is by a criticism of the great-man theory that he introduces us to the theory of society, which is in his estimation true, and which alone presents social phenomena to us as amenable to scientific treatment.

The great-man theory is summed up by him in the following quotation from Carlyle: "As I take it, universal history, the history of what man has accomplished in this world, is at bottom the history of the great men who have worked here." "This," observes Mr. Spencer, "not perhaps distinctly formulated, but everywhere implied, is the belief in which nearly all are brought up"; and it is, he declares, as incompatible as the theocratic theory itself with any belief in the possibility of a social science, or any comprehension of what such a science is; for either the great man is regarded as the miraculous instrument of the Deity, a kind for if the ap- of "deputy-God," in which case we have "theothe great man cracy once removed"; or else his greatness, though progress, if it regarded as a natural phenomenon, is regarded as depends on must be one whose occurrence is so far fortuitous, that a him, must be also; great man of any given kind of greatness might appear in one age or nation just as well as in another; and in this case, if social changes depend on the great man's actions, these changes will be as fortuitous as the great man's own appearance, and will as little admit of any scientific calculation.

If, however, the great man is regarded as a 
natural phenomenon at all, if he is not to be looked upon as a species of incalculable angel, this idea of his fortuitous appearance is, says Mr. Spencer, but if the great plainly quite untenable. The great man, unless he miraculous differs miraculously from other men, is produced as apparition, he they are, in accordance with natural laws, and, like $\begin{gathered}\text { ness to causes } \\ \text { outside him- }\end{gathered}$ them, owes his greatness to his near and remote self; progenitors, just as a negro owes to his, his facial angle, his blackness, and his woolly hair. "Who would expect," Mr. Spencer asks, "that a Newton might be born of a Hottentot family, or that a Milton might spring up among the Andamanese?" The theory, then, which explains social changes by referring them to the great men whose names are connected with their initiation, will, unless it is regarded as a theory of perpetual miracle, be recognised as inadequate, even by those who have hitherto held it, when once they have realised the absurd supposition which it implies. The great man, whatever his seeming influence, is merely the agent of other influences which are behind him. He merely transmits a shock, like a man pushed. by a crowd. Even supposing what Mr. Spencer entirely denies to be the case, that he could really and it is these "remake his society," his society none the less must really produce have previously made him, and supplied him with which he is the those conditions which rendered his career possible; ; initiator. and therefore, of any changes which he may popularly be said to have caused, he is merely "the proximate initiator," not the true cause at all; and "if," says Mr. Spencer, "there is to be anything 
Book I like a real explanation of such changes, it must be sought (not in the great man himself), but in the aggregate of social conditions, out of which he and they have arisen." Except, perhaps, in the military struggles of primitive savage tribes, "new institutions, new activities, new ideas, all," he says, These effects, "unobtrusively make their appearance, without the
therefore, are therefore, are to bexplained aid of any king or legislator; and if you wish to by reference
not to the great understand the phenomena of social evolution, you man, but to wall not do it, should you read yourself blind over are behind the the biographies of all the great rulers on record,
great man. great man. down to Frederick the Greedy, and Napoleon the Treacherous." And he points his moral by observing, with a certain philosophic tartness, that there is no surer index of a man's "mental sanity" than the degree of contempt which, as a scientific thinker, he feels for the class of facts which the biography of individuals offers him.

Such, then, being Mr. Spencer's theory of the way in which social phenomena must be regarded, if we mean to make them the subject of anything like scientific study, let us turn to his magnum opus, The Principles of Sociology, and see how, and with what results, he puts his theory of study into practice. This immense work, full of encyclopædic detail as it is, contains certain general and comparatively simple conclusions, which can with sufficient clearness be expressed in a short summary, and which are typical of the character and the contents of Mr. Spencer's sociology as a whole. These general conclusions constitute in 
outline the entire history of human progress from the dawn of man's existence to the industrial civilisation of to-day.

The determining factors in all social phenomena Thetruecauses are, says Mr. Spencer, primarily of two kinds - the of all social "external" and the "internal." The former consist are, says Mr. of some of the various physical circumstances in physical enviwhich each community or collection of men is men's natural placed; the latter consist of the characters and constitutions of the men themselves. In the history of each community the chief of the external factors are these: the climate of the region which the community occupies; the cultivability of this region; its geological and geographical character; the way in which the fauna and flora natural to it are distributed; and the character of the other communities by which the community in question is surrounded. One of the first generalisations, says Mr. Spencer, to which social science leads is this - that progress can begin only in climates and physical cause regions where the production of the necessaries of an exceptional regions where the production of the necessaries of fertility of soil life is sufficiently easy to leave men leisure and energy available for other work; and all progress did as a fact begin in those parts of the earth where the maintenance of life was easy.

He goes on to show, however, that the initiation and an excepof progress does not require only that the men con- ing climate. cerned in it should inhabit a region in which the production of necessaries is easy and leaves them abundant leisure. It is equally essential that the men themselves should possess an energetic tem- 
Book I perament, which will not suffer them to devote their leisure to idleness, but will make it the startingpoint for some further activity. Now this energetic temperament is the special gift of climate. So, to a great extent, is the ease with which necessaries are obtained from the soil; but whilst the fertility of the soil is dependent on the climate being hot,

All the conquering races came from fertile and bracing regions.
There were other regions yet more fertile, but these were enervating; and here the inhabitants of the former enslaved the weaker inhabitants of the latter.

the requisite energetic temperament is dependent on the climate being dry. "The evidence," says Mr. Spencer, "justifies this inference. ... On glancing over a general rain-map of the world, there will be seen an almost continuous area, marked 'rainless district,' extending across North Africa, Arabia, Persia, and all through Thibet and Mongolia; and from within, or from the borders of this district, have come all the conquering races of the old World."

But the full operation of climate on human progress is not intelligible till a further climatic fact is considered. Though in hot and dry climates the production of necessaries is easy, in climates that are hot and moist their production is still easier. It is these last that are really the gardens of the world, and that offered to primeval man the easiest and most attractive homes. The original inhabitants, however, of these favoured localities not only profited by their conditions, but also ultimately suffered from them. Whilst the fertility of their habitat pampered them, its moisture destroyed their energy; and in process of time they were subjugated by other races, who, cradled in dryer climates, 
retained their energy unimpaired. In this natural descent of the stronger races on "the richer and Book I Chapter 2 more varied habitats" of the weaker, and the consequent super-position of one race over another, we see the origin of slavery, and of all the ancient civilisations that reposed upon it.

We have here the three essential elements to the union of which primarily all human progress has been due: Firstly, a race remarkable for its active energy; secondly, the appropriation by this race of some richer habitat than its own; and thirdly, the possession by it of an inferior race, as subjects, who are ready to work for its benefit, and are capable, when coerced and directed by it, of producing wealth indefinitely greater and more varied than they would or could have produced had they been left to their own devices.

And here we are brought to the threshold of a Again, division new order of facts. Industrial production, which is $\begin{gathered}\text { of labour, on } \\ \text { which indus- }\end{gathered}$ the basis of all civilisation, is not, says Mr. Spencer, trial progress started on its progressive career by the sudden caused by the orders of any one remarkable man, but by the the products spontaneous action of certain natural causes. It localities, must first be observed that its general character and its progress are always found to depend on the same thing. They depend on the division of labour. This, as Mr. Spencer says, developed in varying degrees, is the salient characteristic of every civilisation in the world. To what, then, is the division of labour, in the first instance, itself due? This is the opening question asked by Adam 
Book I Smith in his Wealth of Nations; and he seems to regard it as one which is more or less mysterious and recondite. The answer which he himself suggests is, that there exists in man " a natural propensity to truck, barter, and exchange." The answer given by Mr. Herbert Spencer is a curious illustration of how far, since the days of Adam Smith, social science has progressed.

Mr. Spencer shows us that the origin of the division of labour was no special propensity mysteriously innate in man. Its origin was the natural diversity of the various districts inhabited by the groups of men who originally took part in it.

Thus "some of the Fiji Islands," he writes, "are famous for wooden implements, others for mats and baskets, others for pots and pigments - unlikenesses between the natural products of the islands being the causes. . . So also .. . the shoes of the ancient Peruvians were made in the provinces where aloes are most abundant, for they were made of the leaves of an aloe called 'maguey.' The arms were supplied which led to by the provinces where the materials for making the localisation of industries. them were most abundant." Division of labour, in short, was primarily a localisation of industries, caused by the fact that a number of man's different needs were each supplied most easily by industry in some different locality.

By means of this explanation of the origin of the division of labour, Mr. Spencer proceeds to explain, in a way which would have astonished Adam Smith still more, other social phenomena of a kind which 
seem wholly different. He proceeds to show us that though increased production of commodities was the chief direct result of the localisation of industries, The localisacertain by-products resulted from it also, whose tries in its turn effects were not less important. These by-products led to roadwere roads. In the localisation of industries, he says, we have the true origin of road-making. The fact of industries being widely separated in place, required a constant interchange of the various sorts of goods; and the carriage of these goods to and fro between the same points first produced tracks, such as those made by animals, then paths, and at last regular roads. But to facilitate the movement and interchange of goods is not the only, or the highest, though it may be the first, function of roads. Roads facilitate two things of a yet more interesting and roads character - the movement of ideas and the central- the centraliisation of authority. They form, in fact, the great ${ }_{\text {authority and }}^{\text {sation }}$ physical basis of civilised human government, and interchange of of the development of the human intellect.

These examples of Mr. Spencer's conclusions Next, as to will be sufficient to show how he studies the pheno-men's natural will be sufficient to show how he studies the pheno- character. mena of social progress in so far as they are the ${ }_{\text {other cause of }}^{\text {which }}$ result of what he calls "the external factors" - progress, climate, locality, and the character of the other races with which each race that is studied happens to have been brought in contact. Let us now turn to what he calls the "internal factors," and consider the phenomena of progress which he explains by reference to these. He helps us here by providing us with a summary of his own, in which he calls the attention 
Book 1
Chapter 2 of his readers to the most important of his own conclusions arrived at in preceding chapters as to this section of his subject. Having reminded us of how he started with the "external factors," and how he had shown the ways - namely those we have just glanced at - in which they co-operated to produce civilisation, "our attention," he proceeds, "was then directed to the internal factors"; and what he had to tell us, he says, about the internal factors was as their primitive follows: "An account was first given of 'Primitive
character did not fit them to progress,

Man - physical', showing that by stature, structure, strength... he was ill fitted for overcoming the difficulties in the way of advance. Then examination of 'The Primitive Man-emotional' led us to see that his imprudence and his explosiveness, restrained but little by sociality and the altruistic sentiments, rendered him unfit for co-operation. And then, in the chapter on 'Primitive Man-intellectual', we saw that while adapted by its active and acute perceptions to the needs of a wild life, his type of mind was deficient in the faculties required for progress in knowledge." Then, having referred to the long explanation given by him of the rise of man's religious belief, Mr. Spencer goes on to say that these primitive human characteristics constitute the internal factors, with which sociology starts, and

till it was gradually improved by the evolution of marriage and the family especially of monogamy. that the business of this science is to explain the evolution of all those subsequent "phenomena resulting from their combined actions." Of these phenomena the chief, he says, are the following monogamy as evolved from polygamy, polyandry, 
and promiscuity; the higher family affections as developed by the monogamous family; and governmental and social organisation as developed in two ways - by the conduct essential to war and the conduct essential to industry. His conclusions, so far as possible, shall be given in his own words.

To begin with marriage: in the earlier stages of Monogamy society nothing resembling it existed. The nearest survival of the approach to a family was the mother and such fittest kind of children as could be kept alive without the help of the father; and as the children grew up, this rudimentary group dissolved. But "from families thus small and incohercnt" there naturally and inevitably arose, in accordance with the tendency to variation by which the human units are characterised, and which is the basis of all evolutionary selection, "families of divergent types" - families founded on unions of which some were more lasting than others, of which some were unions between one mother and many fathers, some between one father and many mothers, and some between one father and one mother. This last-named type of union, and the family life resulting from it, had many practical advantages, such as the production of closer bonds too-operation. between the several members of the family, and consequently the practice between them of more efficient co-operation. Accordingly, no sooner did monogamous groups appear than they exhibited a tendency to survive in the social struggle for existence; and monogamy affords, with the affections that have grown up under its shelter, the type 
Book I
Chapter 2 of marriage and family that prevails amongst the most advanced races of to-day.

The family being established, the nation gradually rose from it.

Next, as to the phenomena of governmental and social organisations: these arise only with the formation of groups larger than the family - of groups which we call communities, or nations, or social aggregates; and we have to consider how these larger groups rose out of the aggregation of the smaller. The process is explained, says Mr. Spencer, by the same few "internal factors." The nation sprang from the family by the following inevitable stages. Let us take any family group, sufficiently coherent to live together as a single household, and supporting itself on the produce of the land that surrounds its dwelling. Whilst this group is small, the acreage will be small also, which, as ploughland, hunting-ground, or pasture, is required to supply its wants; and each member of the group can easily reach his work, starting from the common home, and coming back to it in the evening. But as children grow, and children and great-grandchildren increased, and multiply, the land required by the household corregave rise to many families, which were obliged, in order to get food, to separate into different groups; spondingly grows in extent, and at last becomes so large that the whole of it cannot be utilised by a body of men living on the same spot. Hence, as Mr. Spencer expresses it, " a fission of the group is necessitated"; and this process is repeated till there are a multitude of groups instead of one. These groups, says Mr. Spencer, constitute the raw material of the nation. The nation is formed "by the recompounding of these units once again." 
And how is this process of "recompounding" Book I accomplished? Mr. Spencer answers it is accomplished by one means only, and that is the co- and the recomoperation forced on them by war for some common these groups, interest. Other tribes threaten to attack their for purposes of territory, or they are desirous of appropriating the $\begin{gathered}\text { aggression, } \\ \text { formed the }\end{gathered}$ territory of other tribes. Separately they are ration. powerless. The only course open to them is to band themselves together and submit themselves to a common leader. In cases where such wars are short, as observation of savage tribes shows us, the rudimentary nation with its rudimentary discipline dissolves and disappears as soon as the wars are over; but when the state of warfare is prolonged by $\underset{\text { being in its }}{\text { all government }}$ the rivalry of other societies, the military leadership origin military. develops into a permanent centralised authority; and from this military government, with its "coercive institutions," national existence and all forms of government spring.

And here Mr. Spencer's argument takes a new But as the arts departure and carries us on to the point where we industrygradushall be compelled to leave it. As governments ally emanciand civilisations have advanced, he says, they have from governtaken two forms - that in which the original military and becomes element still contin own master. element still continues to preponderate, and that in and also forms which the military element becomes gradually political desubordinate to the industrial. "The former," he mocracy. says, "in its developed form is organised on the principle of compulsory organisation, whilst the latter in its developed form is organised on the principle of voluntary co-operation"; and the latter 
Book I amongst civilised nations, always tends to supersede
Chapter 2 the former, in precise proportion as war tends to become less common. The industrial form, it may be observed, corresponds in a general way to the kinds of government commonly called "democratic"; but its emergence, says Mr. Spencer, has its most important effects in the sphere not of politics, but of economic production. Originally the conditions of industry were regulated by the dictates of the military and aristocratic ruler, as they are to-day in some savage communities, and as they partially were in France till towards the close of the last century. Under such a régime the very "right to labour" itself is regarded as belonging to the King; and he sells it to his subjects on such terms as he may choose. But as the military element in the government declines, not only does the character of governmental legislation change, but industry frees itself from governmental influence altogether. No king any longer arranges markets, fixes wages or prices, and settles what kind and quantities of commodities shall be produced. Industry becomes, as Mr. Spencer says, "substantially independent." He does not mean, however, that it needs no regulation. It needs as much as ever a constant and nice adjustment of the things produced to the current requirements of the community; but this adjustment is now secured not by the interference of a political ruler, but by a system which has spontaneously developed itself amongst the trading and manufacturing classes. It is a system, says Mr. Spencer, 
which we may call "internuncial, through which the various structures (i.e. manufacturing firms, etc.) received from one another stimuli or checks, caused by rises and falls in the consumption of their respective products. . . . Markets in the chief towns show dealers the varying relations of supply and demand; and the reports of these transactions, diffused by the press, prompt each locality to increase or decrease of its special functions. . . . That is to say, there has arisen, in addition to the political regulating system, an industrial regulating system, which carries on its co-ordinating function independcntly-a separate plexus of connected ganglia."

We have now looked at social evolution, as the Now, if we product of both those sets of causes - the "external these confactors" and the "internal" - by which Mr. Spencer Mr. Spencer's, explains it, and have followed it, under both aspects, from the earliest beginnings of progress to the dawn and development of civilisation, such as history knows it. Our account of Mr. Spencer's theory of the ascent of man and society is necessarily very incomplete; but the various conclusions mentioned we shall find in it may be said to be exhaustively typical of conclusions the conclusions of social science as Mr. Spencer about aggrethe conclusions of social science as Mr. Spencer gates as conceives of it.

And now let us consider what the nature of those of aggregates. conclusions is. We shall find that they are, one and all of them, conclusions with regard to aggregates. All the phenomena with which they deal are phenomena not of individuals, not of different classes, but of masses of men, communities, races, nations, 
Book 1 the units of which are regarded as being virtually so similar, that what is true of one is virtually true of all. This similarity certainly is not imputed to all mankind. Men are recognised as having been different in one epoch from what they become in another, and one race and the inhabitants of one climate as being different from other men differently born and circumstanced. The primitive millions who could hardly walk upright, and whose sexual

The only differences recognised by him between men are differences between one homogeneous aggregate and another, relations resembled those of the animals, are distinguished from their erect successors who married and lived in families; and the strong and energetic races are distinguished from their weaker contemporaries. But each of these aggregates is regarded as a unit in itself. The conquering race which has grown vigorous in dry regions, and the inferior race enslaved by it, which has lost its strength in moist regions, are contrasted sharply with each other; but neither is made the subject of any internal division, nor treated as though the units composing it were not virtually similar. Mr. Spencer of course admits (for this is one of the fundamental parts of his philosophy) that these wholes, these aggregates, progress through a constant differentiation of their parts, different functions being performed by an increasing number of groups; but the units who compose these groups, and whom he calls the "internal factors" are regarded by him as being congenitally each a counterpart of the others; and their different functions and their different acquired aptitudes are 
regarded as the result of different external circumstances which press into different moulds one and the same material. Thus when the single group from which the nation originally springs undergoes, as it becomes more numerous, what Mr. Spencer calls the process of "fission," and spreads itself in search of food over an ever-extending area, new groups separate not because they have different appetites, but because, having the same appetites, they must satisfy them in different places by the exercise of the same faculties. Division of labour, as we have seen, he explains in the same way; and not its origin only, but its latest and most elaborate developments. Of the manufacturing businesses of and differences to-day, for instance, with their promoters, managers, lar men who capitalists, and multitudes of various workmen, not happen to only is each business treated by him as a single differently. unit, but each of these units, or ganglia, is a unit which differs from the rest for accidental reasons only, as a gardener who happens to be digging may differ from a gardener who happens to be raking a walk; and he describes the whole as " $a$ plexus of ganglia connected by an internuncial system."

The use of this last phrase, and the physiological analogy suggested by it, illustrate yet more clearly the fact here insisted on - namely, that for Mr. Spencer the sociologist's true unit of interest is the social aggregate, as a whole, to the exclusion of the individual or of the class. The latter are merely the ganglia, or veins, or nerves, which are nothing 
Book I except as connected with the organism to which
Chapter 2 they belong. Each social aggregate, in fact, is a single animal; and whatever is achieved or suffered by any class or individual within it, is really achieved or suffered, in the eye of the Spencerian sociologist, not by the class or the individual, but by that corporate animal, the community.

Now a study of these phenomena of aggregates is, as has been said already, valuable for speculative purposes. It has led those who have pursued it to a variety of important conclusions which have largely revolutionised our conception of human history, and of the conditions that engender civil-

But, as has been said already, the social problems of today arise out of a conflict between different parts of the same aggregate; therefore the phenomena of the aggregates as a whole do not help us. isations or else preclude their possibility. It has shown us human life as a great unfolding drama, but it has hardly given us any help at all in dealing with the practical problems that belong to our own day; and the reason of this, which has already been stated generally, must be apparent the moment we consider what these practical problems are. Their general character is sufficiently indicated by such familiar antitheses as aristocracy and democracy, the few and the many, rich and poor, capital and labour, or, as Mr. Kidd puts it, collectivists and the opponents of collectivism. In other words, the social problems of to-day - like the social problems of most other periods - are problems which arise out of the differences between class and class. That is to say, they depend on, and derive their sole meaning from phenomena which are not referable to the social aggregate as a whole, but which 
are manifested severally by distinct and independent parts. The social aggregate, when regarded from Book I Chapter 2 this standpoint, is no longer a single animal, whose pains or pleasures reveal themselves in a single consciousness. It is a litter of animals, each of which has a consciousness of its own, and, together with its consciousness, interests of its own also, which are opposed to those of the others, instead of coinciding with them.

And now let us consider more closely out of what The confict this opposition arises. Mr. Spencer, as we have parts of the seen, in our rapid survey of his arguments, lays great arises from instress on the fact that as men rise into aggregates, position, they do so only on condition of submitting themselves to governors, military in the first place, and at a later stage civil. The truth, however, which he thus elaborates, whatever may be its speculative importance, fails to have any bearing on any practical problem, because it is not a truth about which there has ever been any practical disagreement. Aristocrat, democrat, and socialist all agree that there must be orderly government of some sort, and official governors to administer to it. The point at issue between them is not whether some must govern and others submit to be governed, but how the individuals who perform the work of government shall be chosen, and what, apart from their official superiority and authority, shall be their position with regard to the rest of the community. Why should they enjoy any special social advantage? Or if they are to enjoy it, why should they be usually 
Book 1
Chapter 2 drawn from a small privileged class, and not from the Chapter 2 masses of the community, sinking to the general level again when their tenure of office terminates? Such are the questions proposed by one party; whilst the other party replies by contending that the of which Mr. limited class in question can alone supply governors
Spencer's Spencer's
sociology takes of the required talents and character. Of this clash no account. of opinions and interests, which is as old as civilisation itself, though in each age it assumes some different form, Mr. Spencer's social science necessarily takes no cognisance, because the parts of each social aggregate have for him no separate existence.

The same criticism applies to his treatment of economic production. He explains, as we have seen, the origin of the division of labour, showing how "unlikeness between the products of different districts" inevitably led to "the localisation of industries," turning one set of savages - to use his own example - into potters, another into makers of baskets. But here again we have a truth which, whatever its speculative interest, has no bearing on any practical problem; for no one denies that division of labour is necessary, nor do any of the difficulties of to-day turn upon its remote origin. Socialists and individualists are alike ready to admit that different men must follow different industries. The point at issue is why, within the limits of the same industry, different men pursue it on different levels, some being masters and capitalists, some being labourers and subordinates. Here, just as in the sphere of political and military government, 
we have one class defending its existing position and privileges, and another class attacking or questioning them; and it is out of circumstances such as these, thus briefly indicated, that the practical social problems of the present day arise.

Now the question at the bottom of these can be Social probreduced to very simple terms. If all members of of the desire of the community were content with existing social those whose arrangements, it is needless to say there would be inferior to have no social problems at all. Such problems are due changed; entirely to the existence of persons who are not contented, and who desire that certain of these arrangements should be changed. It will be seen, accordingly, that the great and fundamental question which, as a practical guide, the sociologist is asked to answer, is whether or how far the changes desired by the discontented are practicable; and the first and the practical question is, step towards ascertaining how far the arrangements they desire step towards ascertaining how far the arrangements possible? in question can be turned into something which they are not, is to ascertain precisely how they have come to be what they are.

But this way of putting the case is still not sufficiently definite. Mr. Spencer himself has put it in somewhat similar language; and yet in doing so he has missed the heart of the problem. Mr. Spencer's speculative gaze, travelling over the past and present, sees one generation melting like a cloud into another, and takes no note of the individuals that compose each. The practical sociologist must adopt a very different method of observation. $\mathrm{He}$ must remember that practical problems arise 


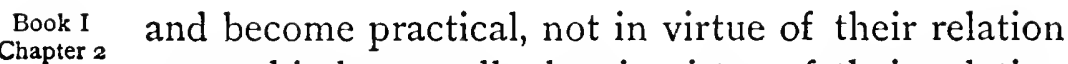
to mankind generally, but in virtue of their relation to each particular generation that is confronted by them; and a particular generation in any given community, and the different classes into which the community is divided, are made up respectively of particular men and women. In asking, therefore, To answer this how the social arrangements we have been consider-
question we quust examine ing have come to be what they are, we must not ask into the causes in vague and general terms why a portion of the
why such and in such individuals are in inferior. and others in superior positions. social aggregate occupies a position which contents it, and another portion a position which exasperates it; but we must consider the individuals of which each portion, at any given time, is composed, and begin the inquiry at the point at which they begin it themselves. "Why am I - Tom or Dick or Harry - included in that portion of the aggregate which occupies an inferior position? And why are these men - William or James or George - more fortunate than $I$, and included in the portion of the aggregate which occupies a superior position?" To this question there are but three possible answers. The inferior position of Tom or Dick or Harry is due to his differing from William or James or George in external circumstances, which theoretically, at all events, might all be equalised - such, for example, as his education; or it is due to his differing from them in certain congenital faculties, with respect to which men can never be made equal - as, for example, in his brain power or his physical energy; or it is due to his differing 
from them in external circumstances which have arisen naturally from differences in the congenital Book I Chapter 2 faculties of others, and which, if they could be equalised at all, could never be equalised with anything like completeness - such, for example, as the possession by William and James and George of leisured and intellectual homes secured for them by gifted fathers, and the want of such homes and fathers on the part of Tom and Dick and Harry.

The first question, accordingly, which we have to Are inequaliask is as follows. Taking Tom or Dick or Harry due to alterable as a type of those classes who happen to occupy an and acciinferior position in the aggregate, and comparing stances? him with others who happen to occupy superior positions, we have to ask how far he is condemned to the inferior position which he resents by such external circumstances as conceivably could be equalised by legislation, and how far by some congenital inferiority of his own, or circumstances naturally arising out of the congenital inferiority of others. Or we may put the question conversely, and ask how William and George and James have come to occupy the positions which Tom, Dick, and Harry envy. Do they owe their positions solely to unjust and arbitrary legislation, which a genuinely democratic parliament could and would undo? Or to exceptional abilities of their own, of due to conund equalities which no parliament could deprive them? Or to equalities advantages secured for them by the exceptional can ever do abilities of their fathers, which no parliament could interfere with, or, at all events, could abolish, without 
Book I entering on a conflict with the instincts of human
Chapter 2 nature, and interfering with the springs of all human action?

Social inequalities are partly due to

Now that external circumstances of a kind, easily aircumstances ; alterable by legislation, have been, and of ten are, responsible for many social inequalities, is a fact which we may here assume without particularly discussing it. The inquiry, therefore, narrows itself still further, and resolves itself into this: Do the congenital superiorities or inferiorities of the persons, or of parents of the persons, who at any given time are occupying in the social aggregate superior and inferior positions, play any part in the production of these social inequalities at all?

This question must plainly be the practical sociologist's starting-point; for if social inequalities are due wholly to alterable and artificial circumstances, social conditions are capable, theoretically, at all events, of being equalised; but if, on the other hand, inferior and superior positions are partly, at all events, the result of the congenital inequalities of individuals, over which no legislation can exercise the least control, then a natural limit is set to the possibilities of the levelling process; and it is the business of the sociologist, if he aspires to be a but most
people will practical guide, to begin with ascertaining what people will
adnit that con- these limits are. Are, then, the congenital ingenital inequalities in titlent have much to do with them. equalities of men a factor in the production of social inequalities, or are they not?

Now to many people it will seem that even to ask this question is superfluous. They will regard 
it as a matter patent to common sense that men's congenital inequalities are to a large extent the Book I Chapter 2 cause, in every society, of such social inequalities why then as exist in it; and they will possibly say that it is inst? a mere waste of time to discuss a truth which is so Because this self-evident. It happens, however, that the more fact is preself-evident. It happens, however, that the more cisely what our obvious it seems to be to common sense, the more sociologists $_{\text {conporaty }}^{\text {conter }}$ necessary it is for us to begin our present inquiry ignore, with insisting on it; and the reason is that, in spite of its being so obvious, the whole school of contemporary sociologists, with Mr. Spencer as their head, base their whole method of sociological study on a denial of it. By their method of dealing with social aggregates only, they deny not only the influence, but even the existence of congenital inequalities, and endeavour to explain them away as an illusion of the unscientific mind. They admit, indeed, as our quotation from Mr. Spencer showed, that the primitive man was congenitally different from man in later ages. They admit that the individuals reared in a dry climate, who formed the conquering aggregates, were congenitally different from the individuals reared in a moist climate, who formed the enslaved aggregates; but they absolutely refuse to take any account whatever of the congenital inequalities by which individuals within the same aggregate are differentiated.

In order to show the reader that such is literally the case, we need not rely merely on such inferences as have just been drawn from the manner in which Mr. Spencer applies his method, and from the 
Book I general character of his conclusions. We have the
Chapter 2 direct evidence of his own categorical statements. Let us turn again to the criticism with which, as Mr. Spencer as we have already seen, he prefaces his whole
shows us by his distinct series of sociological writings, and which may be assertions, as taken as his fundamental profession of faith - his well as by the character of his conclusions. criticism, namely, of what he calls "the great-man theory," his rejection of it as being a theory which would render all social science impossible, and his enunciation of the theory which he contends must take its place. It may seem to some readers that his rejection of the great man as a vera causa which will explain social phenomena amounts to no more than a rejection of that exaggerated view of history which expresses itself in the works of writers such as Froude and Carlyle, and which vaguely attributes all the progressive changes of humanity to the personality of rulers, of political and military autocrats - such as Henry VIII., Cromwell, and Frederick the Great of Prussia. And indeed, to judge by $\mathrm{Mr}$. Spencer's language, it is this exaggerated view which has been most frequently present in his mind, as we may see by referring to the passage already quoted, which concludes his demonstration that the "great-man theory" is false. With the sole exception, he says, of the military struggles of primitive tribes, "new activities, new institutions, new ideas, unobtrusively make their appearance, without the aid of any king or legislator; and if you wish to understand the phenomena of social evolution, you will not do it should you read yourself 
blind over the biographies of all the great rulers on record, down to Frederick the Greedy and Napoleon the Treacherous."

But Mr. Spencer, in rejecting the great "ruler Hiscondemnaand legislator" as a factor in social evolution un- great-man worthy of the attention of the sociologist, is really removal of all rejecting a great deal else besides. He is really congenital inrejecting every inequality in capacity by which $\mathrm{a}_{\text {study; }}^{\text {his field }}$ certain number of men are differentiated from, and raised above others. In order to show that such is the case, we will avail ourselves of his own words. We will, then, start with one casual remark out of many, in which Mr. Spencer, forgetting his own theories, slips into a method of observation truer than the one he advocates. "Men," he writes in his Study of Sociology, "who have aptitudes for accumulating observations are ravely men given to generalising; whilst men given to generalising are commonly men who, mostly using the observation of others, observe for themselves less from love of particular facts than from the desire to put such facts to use." Nothing can be clearer than the distinction here drawn. It is one of great importance in the elucidation of many social problems; and it deals not with the likeness, but with a congenital difference, which exists between men belonging to the same social aggregate. But now let us compare this with another passage, in which Mr. Spencer, returning again to his theory, explains how members of the same aggregate are to be treated by any sociologist who would claim to be a man of science. 
Book 1 "Amongst societies of all orders and sizes," he writes, "sociology has to ascertain what traits there are in common, determined by the common traits of human beings; what less general traits, distinguishing certain groups of societies, result from traits distinguishing certain races of men; and what peculiarities in each society are traceable to the peculiarities of its members." This is clumsily expressed; but its meaning, which is quite obvious, may be seen by taking, as a typical society, that of England. The sociologist, in explaining English society, will have to consider, according to $\mathrm{Mr}$. Spencer, first, what traits Englishmen have in virtue of being human creatures; secondly, he will have to consider what traits they have in virtue of being Europeans, not Orientals; and, thirdly, he will have to consider what traits they have in virtue of being Englishmen, not Frenchmen or Germans.

The reader will at once perceive the contrast between the spirit of these two passages. In the former Mr. Spencer notes, with great penetration and accuracy, a most important point of difference and he actually between two sets of men belonging to the same
defines an aggregate as being composed of approximately equal units. society. In the latter he deals with societies as single bodies, the members of which possess no personal traits whatever, except such as they all possess alike; and all the traits in which they differ from one another, such as the one just alluded to, of necessity disappear from the field of vision altogether. Should any doubt as to the matter still remain in the reader's mind, it will be dispelled by 
the quotation of one further passage. " $A$ true social aggregate," he says ["as distinct from a mere Book ! Chapter 2 large family], is a union of like individuals, independent of one another in parentage, and approximately equal in capacities."

Here is the case stated with the most absolute clearness. All congenital inequalities, as was said just now, between the various individuals who make up the aggregate are ignored; and it is upon this hypothesis of approximately equal units, acted on by different external circumstances, that he attempts to build up his whole system of sociology. $\mathrm{He}$ is, indeed, little as he himself may suspect it, reproducing in another form the error of Karl Marx and the earlier of the so-called "scientific socialists," who maintained that all wealth was the product of common or average labour, measured by time, and that hour for hour any one labourer necessarily produced as much wealth as another. The socialists of to-day are already beginning to see that this monstrous, though ingeniously advocated, His failure, doctrine is untenable as the foundation of economics; and thers, as and yet, strange to say, a doctrine strictly equivalent sociologists $^{\text {practical }}$ to it forms the accepted foundation of con- ${ }_{\text {their building }}^{\text {arises }}$ temporary social science. That science starts with on this false the hypothesis of approximately equal units, and ignores the congenital differences between the individuals who compose the aggregate. We shall find it to be ultimately from differences of this kind that all the practical problems which beset civilisation spring, and that the inability of the modern 
Book I sociologists, complained of by Mr. Kidd and
Chapter 2 Professor Marshall, to throw on these problems any definite light is simply the natural and inevitable result of excluding the differences in question altogether from their scientific purview.

We will, in the next chapter, consider the whole range of arguments used by Mr. Spencer and others in justification of this error. 


\section{CHAPTER III}

GREAT MEN, AS THE TRUE CAUSE OF PROGRESS

IT is evident that an error of the kind now in The ignoming question does not represent the carelessness of the of natural untrained thinker. It is nothing if not deliberate; ${ }_{\text {procedure. }}^{\text {a deliberate }}$ and indeed Mr. Spencer admits that it is altogether Let us see how in opposition to the opinions which men naturally hold. Accordingly, the arguments by which he and his followers justify it, and have actually imposed it on all the sociological thinkers of their generation, require, before we reject them, to be examined with Let us examine the utmost care.

Let us then turn our attention once again to the grounds on which Mr. Spencer refuses to admit the great or exceptional man as a true factor in the production of social change. If the reader will reflect upon the account that has been already given of Mr. Spencer's arguments in connection with this He defends it point, he will find that Mr. Spencer rejects the great man for two reasons, which are not only (I) by saying distinct, but are, when interpreted closely, not man does not entirely consistent with each other. One of these really do what entirely consistent with each other. One of these he seems to reasons is that the great or exceptional man does ${ }^{\text {do; }}$ 
Book I not really produce those great changes of which he Chapter 3 is nevertheless "the proximate initiator"; the other (2) by saying is that, outside the sphere of primitive warfare, he that what he seems to do is not really much. does not even proximately initiate any great changes at all. The first of these two contentions is expressed with sufficient clearness in his statement "if there is to be anything like a real explanation" of those changes of which the great man is the "proximate initiator" - changes, to quote an example which he himself gives, such as those produced by the conquests of Julius Casar - this explanation must be sought not in the great man himself, but "in the aggregate of social conditions out of which he and they (i.e. the changes commonly supposed to have been produced by him) have arisen." Mr. Spencer's second contention is expressed in the following passage, the concluding words of which have been quoted already, but on which it will be presently necessary for us to insist again. "Recognising," he says, "what truth there is in the great-man theory, we may say that, if limited to the history of primitive societies, the histories of which are histories of little else than endeavours to destroy one another, it approximately expresses fact in representing the great leader as all-important. But its immense error lies in the assumption that what was once true was true for ever, and that a relation of ruler and ruled which was good at one time is good for all time. Just as fast as the predatory activity of early tribes diminishes, just as fast as large aggregates are formed, so fast do societies 
begin to give origin to new activities, new ideas, all of which unobtrusively make their appearance withBook I Chapter 3 out the aid of any king or legislator."

It will be necessary to deal with these two He admits that contentions separately; and we will begin with the does do somesecond, as set forth in the words just quoted. We thing excepshall find it valuable as an example of that singular war; confusion of thought by which all the reasoning of our sociologists with regard to this question is vitiated. Mr. Spencer speaks of an "immense error" which he is pointing out and correcting. The "immense error" in reality is to be found in his own conception. It is hard to imagine anything more arbitrary and more gratuitously false than the contrast which he here draws between the actions but denies that of men in primitive war, for the success of which he does anyhe admits a great leader to have been essential, and ${ }_{\text {sphere of }}^{\text {tional the }}$ their various actions and activities as manifested peaceful prog. in peaceful progress, which, he contends, neither require leadership nor exhibit traces of its influence. We are at this moment altogether waiving the question of how far the great leader, when he is the proximate cause of the military successes of his tribe, is their cause in any deeper sense. It is enough for us now to take Mr. Spencer's admission that the leader is really the cause, in some sense or other, of the social changes connected with early warfare; and, keeping to this sense, let us consider in what possible way less causality can be attributed to the actions of great men and leaders in the sphere of peaceful progress. 
Book I

Chapter 3

But how does the great man fulfil his function in war? By ordering others.

"A primitive society," if it is to become powerful in war - this Mr. Spencer admits - must have a great leader to direct it. But what precisely is it that such a leader is and does? Such a leader leads, because he is one mind or personality impressing for the moment its superior qualities on many minds or personalities. He supplies the fighting men of his society with an intelligence not their own - often with a courage, a presence of mind, and a resolution. He dictates to them the directions in which their feet are to carry them; the manner in which they are to group themselves; the movements of their hands and arms. He gives the word, and a thousand men dig trenches. He gives the word again, and a thousand men wield swords; now he makes them advance; now he makes them halt; and the measure of his greatness as a leader is to be found in those results which, by directing the action of all these men, he elicits from it.

And now from the triumphs of war let us turn to those of peace. "These," says Mr. Spencer, "unlike the former, make their appearance unobtrusively, without the aid of any king or legislator." It may, no doubt, be true that they do appear unobtrusively in the sense that they are not accompanied by trumpets and drums and tom-toms. A factory for the production of toffee, or of trimmings for ladies' petticoats, does not require an Ivan the Terrible to direct it, nor are Mr. Spencer's sentences as he writes them punctuated by discharges of artillery. But if the essence of kingship and leader- 
ship is to command the actions of others, the larger part of the progressive activities of peace, and the arts and products of civilisation, result from and im- The great man, ply the influence of kings and leaders, in essentially precisely the the same sense as do the successes of primitive war, same thing. the only difference being that the kings are here more numerous, and though they do not wear any arms or uniforms, are incomparably more autocratic than the kings and Czars who do.

As a particularly clear illustration of this important truth, let us take Mr. Spencer himself, and place him before his own eyes as an autocratic king or ruler. In certain respects he is so; and it is only because he is so that he has been able to give, through his books, his thoughts and theories to the world. For let us examine any one of his volumes Mr. Spencer, and consider what it is, in so far as it differs from for example, any other volume - let us say from a treatise on the compositors any other volume - let us say from a treatise on the who put his cutting of trousers, or an attack on the Spencerian books into philosophy - which is printed in similar type on pages of the same size. It differs solely in the order in which the letters have been arranged by the hands of the compositors; and its value as a work of philosophy consequently depends altogether on a certain complicated series of movements which the hands of the compositors have made. And how has this prolonged series of minute movements been secured? It has been secured by the fact that Mr. Herbert Spencer, through his manuscript, has given the compositors a prolonged series of orders, which their hands, day after day, have been obliged to obey 


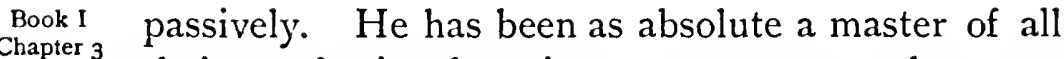
their professional actions as ever was the most arbitrary general of the professional actions of his soldiery; and there is absolutely no difference in point of command and obedience between the compositors who, at Mr. Spencer's bidding, put into type the words "homogeneity" and "the Unknowable," and the Guards who charged the French at the bidding of the Duke of Wellington.

The inventor orders the men by whom his inventions are manufactured.

Precisely the same thing is true of all scientific inventions - not indeed of inventions as mere ideas and discoveries, but of inventions and discoveries applied practically to the service of civilisation. The mere discovery of certain properties belonging to material substances, or the thinking out of some new machine or process, may be the work of one man, who has command over nobody except himself. But the moment he proceeds to make his machine or process useful - to apply it to the purpose of actual business or manufacture he is obliged to secure for himself an entire army of mercenaries, who act under his orders in precisely the same way as soldiers act under the orders of the military leader, or as the compositors act under the orders of Mr. Spencer. When the electric telegraph was supplemented by the invention of the telephone, telephones were produced, and could have been produced, only by a multitude of men performing a series of manual actions which were different in detail from anything they had performed before, and which, if it had not been for the inventor, would never 
have been performed at all. They filed or they cast pieces of metal into new shapes; with these Book I pieces of metal they connected in new order pieces of other materials, such as wood and vulcanite, the shape of these last being new and special also; and every piece of material shaped or connected with another piece was the exact resultant of so many manual movements made in passive obedience to the inventor's autocratic orders. It was only because his orders were obeyed with such humble fidelity and completeness that these movements resulted in telephones, enriching the world with a new convenience, and not in the old-fashioned telegraphic machines, or in penholders, or vulcanite inkstands, or even in useless heaps of shavings and brass filings. And the same is the case with every invention or contrivance which has helped to build up the fabric of modern material civilisation.

Civilisation, however, even in its most material sense, does not consist of contrivances and inventions only. "The one operation," says Mill, "of putting things into fit places... is all that man does, or can do, with matter. He has no other means of acting on it than by moving it." But valuable as this formula is, it is not sufficiently comprehensive; for there is another economic process which, to the The great man ordinary mind at all events, is hardly suggested by of business such a phrase as "to move matter."

The process referred to consists in the moving of men. What is meant by the distinction here drawn is this - that the industrial efficiency of a community 
Book I does not depend solely on the muscles of the manual workers being given a right direction, so that they shall shape material objects in such and such a way, but it depends also on the movements which are prescribed to the men being prescribed to the men best fitted to perform them, and being prescribed to them in such order that when each movement has to be made, the men told off to make it shall be ready to make it at the moment. Here we see part of the secret of the success of the great contractor.

The hotelkeeper orders his staff.

The importance of these considerations becomes all the clearer to us when we reflect on the fact that the mere production of commodities, and the production of the means of production, form but a part of the processes which advance, maintain, and indeed constitute civilisation. A part almost equally large consists in the rendering of various personal services, which often, no doubt, involve the utilisation of improved appliances, but which almost as often are neither more nor less than the performance of actions of a simple and ordinary kind, the merit and demerit, the wastefulness or the economy, of which depend on their being performed with absolute punctuality and despatch. A good example of this is the case of a large hotel. Whether a large hotel is carried on at a profit or at a loss depends almost entirely on this question of personal management. The success of a successful manager does not depend on his capacity for inventing new methods of waiting, of cooking, or of making beds. It depends on his 
capacity for organising his staff of cooks, waiters, and chamber-maids. This is well expressed by that most significant American saying, "He's a smart man, but he couldn't keep a hotel "; the meaning being that one of the most important, and at the same time one of the rarest, faculties required for maintaining a complicated civilisation like our own is the faculty by which, given a number of tasks, one man governs a number of men in the act of cooperatively performing them.

Examples of this kind might be indefinitely mul- All these men tiplied, but those just adduced are quite sufficient great military to prove the sole point insisted on at the present and if thelatter moment - namely, that whatever be the part (and is a social Mr. Spencer admits it to be "allimportant") which the former. the great man plays as a leader in primitive warfare, a part precisely similar in kind is played by other great men in the peaceful processes, and, above all, in the progress of civilisation.

And now, having dealt with this point, let us turn Next, as to the to Mr. Spencer's other contention - his contention the great man namely that, whatever the part may be, and however $r$ is the proxiseemingly important, which the great man plays in only, and not producing social changes, he is, in any case, nothing causebut their "proximate initiator"; - that "they have their chief cause in the generations he descended from"; - and that if there is to be anything like a real and scientific explanation of them, it must be sought in the aggregate of conditions out of which both he and they have arisen, and not in the great man's personality as revealed to us by any 
Book I records of his life, or by any analysis of his peculiar faculties.

We have already seen in a general way how this feat of merging the great man in "the aggregate of this, as Mr. Spencer and three popular writers of today show us, conditions out of which he has arisen" is performed by Mr. Spencer himself. Let us now turn for a moment to three other writers who, though differing from him as to certain of his conclusions, have with regard to this particular point done little else than popularise and apply his teaching.

"It needs only a little reflection," writes Mr. Kidd, "to enable us to perceive that the marvellous accomplishments of modern civilisation are primarily the measure of the social stability and social efficiency, and not of the intellectual pre-eminence of the peoples who have produced them. . . F For it must be remembered that even the ablest men amongst us, whose names go down to history connected with great discoveries and inventions, have each in reality advanced the sum of knowledge by only a small addition. In the fulness of time, and when the ground has been slowly and laboriously prepared for it, the great idea fructifies and the discovery is made. It is, in fact, the work not of one but of a great number of persons. How true it is that all the great ideas have been the products of the time rather than of individuals may be the more readily realised when it is remembered that, as regards a large number of them, there have been rival claims put forward for the honour of authorship by persons who, working quite independently, have arrived at like results almost simultane- 
ously. Thus rival and independent claims have been made for the discovery of the differential calculus, . . . Book I Chapter 3 the invention of the steam engine, ... the methods of spectrum analysis, the telegraph, the telephone, as well as many other discoveries." And then Mr. Kidd proceeds to quote with approval the following sentence from an essay which was written by an American socialist, Mr. Bellamy; and the sentence has been repeated with solemn and triumphant unction in half the socialistic books which have been given to the world since. "Nine hundred and ninety-nine parts out of the thousand of every man's produce are the result of his social inheritance and environment." "This is so," remarks Mr. Kidd, "and it is, if possible, even more true of the work of our brain than of the work of our hands." To these passages we must add one from Mr. Sidney Webb, who is, intellectually, a favourable example of a modern English socialist. Referring to the socialistic proposal that all kinds of workers, no matter what their work, should be paid an equal wage, "this equality," he says, "has an abstract justification, as the special ability or energy with which some persons are born is an unearned increment due to the effect of the struggle for existence upon their ancestors, and consequently, having been produced by society, is as much due to society as the unearned increment of rent."

Here we have then, in the words of these four resolves itself writers, Mr. Spencer, Mr. Kidd, Mr. Bellamy, and arguments: 


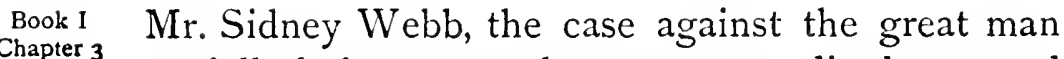
set fully before us; and we may accordingly proceed to analyse it. We shall find that it divides itself into four separate arguments, which are constantly recurring in some form or other in all the works of our modern sociological writers, and especially in the works of those who are democratic or socialistic in (i) That every their sympathies. Firstly, there is the argument first discovery involves all that have gone before it :

that in any advanced civilisation not one of the improvements made during any given epoch would have been possible if a variety of other improvements and the accumulation of various knowledge had not gone before it; and that thus the man who is called the inventor or author of the improvement is merely the vehicle or delegate of forces outside (2) that the himself. Secondly, there is the argument that the
discoverer's ability itself is the product of past circumstances; inventor or author of the improvement, even if we attribute to him some special ability of his own, is in respect of his own congenital energies merely the product and expression of preceding generations and circumstances. Of the four arguments in question, these are the most important; but they (3) that often are constantly reinforced by two others. One is the same dis-
covery is made drawn from the fact that several independent by several men workers often arrive simultaneously at the same
at once;

(4) that the difference between the great and the ordinary man is slight. discovery. The other is drawn from the factor what is alleged to be the fact - that the interval which divides even the greatest man from his fellows, alike in respect of what he is and of what he accomplishes, is really extremely slight, and not worth considering. 
For convenience' sake, we will deal with these two latter arguments first, and put them out of the way before we approach the others. We will begin with the argument drawn from the fact that the same discovery is often made simultaneously by independent workers. This would perhaps hardly be Book I Chapter 3 worth discussing if it were not used so constantly by such a variety of serious writers. The fact is true enough, but what is the utmost that it proves? If two or three men make the same discovery at once, this does not prove, as it is supposed to do, that all men are approximately equal, but that two or three men, instead of one man, are greater than the rest of their fellow-workers. If three horses at a race out-distance all competitors, and pass the winning-post within the same three seconds, this does not prove that a cart-horse is as swift as the Derby favourite. As a matter of fact, that more men than one should reach at the same time the same discovery independently is precisely what we should be led to expect, when we consider what discovery is. The facts of nature which form the subject-matter of the discoverer are in themselves as independent of the men who discover them as an Alpine peak is of the men who attempt to scale it. They are indeed precisely analogous to a peak which all discoverers are attempting to scale at once; and the fact that three men make the same discovery simultaneously does no more to show that any of their neighbours could have made it, and that it is made in reality, not by them, but by 
Book I their generation, than the fact that the three most intrepid cragsmen in Europe meet at last on the same virgin summit, which other adventurers had sought to scale in vain, would prove the feat to have been really accomplished by the mass of tourists at Interlaken, who had never climbed anywhere except by the Rigi railway, and whose stomachs would be turned by a precipice of twenty feet.

The extent of the great man's superiority depends on how it is measured.

Let us now turn to the argument that the inequalities between men's abilities are small, that the work accomplished by even the ablest is small also, and that the exceptional man as a separate subject of study may, in the words of a writer who will be quoted presently, be in consequence "safely neglected." The answer to this is that whether an inequality be great or small depends altogether on the point from which the total altitude is measured. If a child who is three feet high, and a giant who is nine feet high, are both of them standing on the summit of Mont Blanc, the difference between the elevation of their respective heads above the sealevel will be infinitesimal; but no one who was discussing the question of human stature would say that little children and giants were of approximately the same height. Similarly, if our object is to compare men in general with all other living creatures, no doubt the difference between the ordinary man and a microbe is incomparably greater than the difference between an ordinary man and Newton; but if our object is to compare men with men, in relation to this or that mental capacity - let 
us say the capacity for scientific and mathematical discovery - the difference which separates one Book I Chapter 3 ordinary man from another is insignificant when compared with the difference by which Newton is separated from both of them. And it is this latter sort of difference which alone concerns the sociologist. The difference which separates men from microbes is nothing to him. And what is true of what men are, is equally true of what they do. The addition made by any one great man to knowledge may be small when compared with the knowledge, regarded in its totality, which has been gathered together by all other great men preceding him; but It may be it may at the same tine blilosopher, it may at the same time be incalculably great when but to the compared with the additions made by the ordinary it is all- pran men, his contemporaries.

important.

Let us make this matter yet clearer by reference to one more authority, who, though endeavouring to confirm the very argument which is here being exposed, is, little as he perceives it, assassinated by his own illustrations. In Macaulay's essay on Dryden there occurs the following passage, a part of which anticipates the exact phraseology of Mr. Spencer. "It is the age that makes the man, not the man that makes the age. ... The inequalities of the intellect, like the inequalities of the surface of the globe, bear so small a proportion to the mass, that in calculating its great revolutions they may safely be neglected." The passage is quoted for the sake of this last simile. For those who study the human destiny as a whole - who 
Book I survey it as speculative and remote observers - the inequalities of intellect may, it is quite true, be neglected as safely as the inequalities of the surface of a planet are neglected by the astronomer who is engaged in calculating its revolutions. But because these latter inequalities are nothing to the astronomer, it does not follow that they are nothing to the engineer and the geographer. To the astronomer the Alps may be an infinitesimal and negligible excrescence, but they were not this to Hannibal or the makers of the Mont Cenis tunnel. What to the astronomer are all the dykes in Holland? But they are all the difference to the Dutch between a dead nation and a living one.

And the same difference, even in its most minute details, holds good between speculative, or as we may call it star-gazing, sociology and sociology as a practical science; for is it not one of Mr. Spencer's most important and interesting contentions that these very irregularities of the earth's surface - these lands, seas, plains, valleys, and mountains - which, when compared with the mass of the earth, are so absolutely inappreciable, constitute some of the most important of the "external factors" of human history and civilisation? And the same holds good of the inequalities of the human intellect. They may be nothing to the social stargazer, but to the social politician they are everything.

So much, then, for two of the most shallow sophisms that ever imposed themselves on presumably serious reasoners. We will now turn to 
those two other arguments in which the case Book I' against the great man finds its main support, and Chapter 3 which, however misleading they may be, must be examined at greater length. In both of these the As for the two distinctly exceptional character of the great man is other arguassumed, or at all events is not denied, but it is admit the great represented as being, if it exists, not properly the ness, but deny great man's own. The first argument refers it to own, aggregates of external conditions - the knowledge accumulated for the great man's use, the character of his fellow-citizens, who are ready to carry out his orders - and generally to what Mr. Bellamy calls his "social inheritance and environment." The second argument refers it to the great man's line of ancestors, insisting that he inherits from them his own exceptional capacities, which capacities his ancestors acquired by being members of society, and of which it is accordingly contended that society is ultimately the source.

Now on both these arguments, before we con- they are both sider them in detail, there is one broad criticism to true speculabe made, which applies to both equally. There is $\begin{gathered}\text { practically } \\ \text { untrue, or }\end{gathered}$ a certain sense - a remote and speculative sense - irrelevant; in which they are both of them quite true, and indeed are almost truisms; but for practical purposes they are either not true at all, or if true are altogether irrelevant; and it is necessary to show the reader, by a few simple examples, that in the doctrine that statements can be at once true and not true there is no philosophical hair-splitting, and no Hegelian paradox, but merely the assertion of a 
Book I fact which, when once attention has been called to it, Chapter 3 common sense will perceive to be as obvious as it is important.

It was just now observed that the same thing can be great and not great, according to the things with which we compare it. In the same way the same statement may be true or not true, according to the nature of the discussion on which it is brought

just as statements of averages and classifications of goods may be true and relevant for one purpose, and false and irrelevant for another. to bear. Let us take as an example those familiar statements of fact which are given in terms of averages. If the vast majority of any given population vary in height between the limits of five feet six and six feet, the statement that a man's average height is from five feet seven to five feet eight would be a truth most important to the producers of ready-made overcoats. But if half the population were two feet high, and half rather more than nine feet, to give the average stature as something like five feet seven would be for the coatmakers the most absurd misstatement imaginable, and would lead them to make, if they acted on it, garments that would fit nobody.

Let us turn from the question of the truth of a statement to the question of its mere relevance, and we can illustrate what has been said by an example equally homely. In the transference of goods by rail, these have to be sorted according to bulk, weight, shape, fragility, perishability, and so forth. In deciding which are to be sent by fast trains, and which by slow, the primary question will be that of perishability. When the perishable and 
the non-perishable shall have been separated, and they are being placed on the trains allotted to them, Book I the primary questions will be those of shape, weight, and fragility. But so long as the preparatory separation is in progress, to assert that the goods possess any of these latter characteristics will be wholly irrelevant, no matter how true. Boxes of fish will not be put with book parcels because neither of them are fragile, or because they are both oblong; and each characteristic, and every classification based on it, will be either relevant or irrelevant, full of meaning or meaningless, according to what question, out of a considerable series, has to be answered at the moment by the officials who superintend the business.

And now let us go back to the two arguments that are before us; and we shall be prepared to see how, though true for the speculative philosopher, they have no meaning, or only a false meaning, for any practical man.

We will first take that which is expressed with Thus the argusufficient plainness in the passage quoted from Mr. great man Sidney Webb, and which insists on the great man's owes his debt to society generally, not for his external circum- ${ }^{\text {ancestors, and }}$ through his stances, but for his personal character and capacities. ancestors to The idea involved in it is very easy to grasp. The which helped The m's conger his great man's congenital superiority is an inheritance ancestors. from his superior ancestors; but his ancestors would speculative $_{\text {sph a }}^{\text {the }}$ not have had it to hand on to him if they had not truism, been forced to develop such superiorities as they possessed by exerting them in a competitive struggle 
Book I with the great mass of their contemporaries. Thus the mass of their contemporaries formed a strop or hone on which the superior faculties of these men were sharpened; and the great man of to-day, to whom the superior faculties have descended, owes them accordingly, not to his own ancestors only, but to the mass of inferior men who struggled with them, and were worsted in the struggle. In other words, the greatness of the exceptional man has really been produced by the whole body of society in the past; and the results of it ought to be divided amongst the whole body of society in the present.

Now that the above line of argument has a

leads to nothing but absurdities if we apply it to practical life. certain kind of truth in it, it is hardly necessary to observe; and for biologists, psychologists, and speculative philosophers generally, such truth as it possesses may no doubt be of value; but that this truth has no relation whatever to practical life, and no applicability to any one of its problems, can be seen by considering the kind of results we shall arrive at, if, adopting the reasoning of $\mathrm{Mr}$. Webb and his friends, we merely carry it out to the more immediate of its logical consequences.

Let us begin with their reasoning, so far as it concerns the past. If the inferior competitors who were beaten by the great man's ancestors are to be credited with having helped to produce the talents by which they were themselves defeated, and must therefore be held to have had a claim on the wealth which these talents produced, which claim has descended to the inferior majority of 
to-day, the same claim might be advanced by any weaker nation which, after a series of battles, succumbs finally to the stronger. In the FrancoGerman war the French might have said to the Germans, "You acquired by fighting with us the faculties which have enabled you to conquer us. Your strength, therefore, in reality belongs to us, not you; and hence justice requires that you should give us back Alsace." In the same way it might be urged that all the idle apprentices of the past have, by the warning they afforded, stimulated the industry of the industrious, and therefore in abstract justice had a claim on their earnings.

Let us now take Mr. Webb's reasoning so far as For if the great it concerns the present, and we shall find that it workers owe results in similar fantastic puerilities. If the great ${ }^{\text {to tast sociele of }}$ man of to-day owes his greatness to society as a $a$ shirk work owe whole, it is to society as a whole that the idle man theiridlenessto owes his idleness, the stupid man his stupidity, the iformer id the dishonest man his dishonesty; and if the great man latter deserve who produces an exceptional amount of wealth can, ${ }_{\text {ment. }}^{\text {no punish- }}$ with justice, claim no more than the average man who produces little, the man who is so idle that he shirks producing anything may with equal justice claim as much wealth as either. His constitutional fault, and his constitutional disinclination to mend it, are both due to society, and society, not he, must suffer. And the same thing holds good of every form of economic incompetence.

The absurdity of Mr. Webb's position will be seen yet more clearly when we see how it looks 


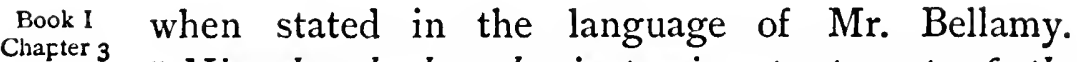
"Nine hundred and ninety-nine parts out of the thousand of every man's produce are the result of his inheritance and his environment." Now if this proposition has any practical application, it must mean that the whole living population - great men and ordinary men, labourers and directors of labour - who are commonly held to be the producers of the income of Great Britain to-day, really produce of it only one farthing in the pound; and hence, if we still persist in considering the proposition a practical one, we shall be forced to conclude that the whole of the living population might at any given moment stop work altogether, or fall into a trance like the Seven Sleepers of Ephesus, and the production would continue with hardly an appreciable diminution.

The same argument applies to morals; and if accepted, we should have to admit that nobody really did, or was really responsible for, anything.

Again, if the proposition has any practical bearing on economics, it must necessarily have a bearing precisely similar on morals. If a man of to-day produces only a thousandth part of what he seems to produce, it is equally evident that he does only a thousandth part of what he seems to do. Let us see, if we accept this theory, to what sort of conclusions it will lead us. One conclusion to which it will lead us at once is the following - that each of us is responsible only for a thousandth part of his actions; and from this will follow others more remarkable still. Since the holiest man has elements of evil in him, and the worst man elements of good, the good deeds for which we honour the saint may 
really be the result of his antecedents, and his few faulty deeds may be all that we are to attribute to Book 1 Chapter 3 himself ; whilst, conversely, the criminal's antecedents may have been the cause of all his crimes and vices, and he may himself have done nothing but some acts of unnoticed kindness. It will be thus impossible to form any true judgment of anybody; for the real St. Peter may have been merely a false and truculent ruffian, and the real Judas Iscariot may have been fit for Abraham's bosom. And yet even these conclusions deducible from the premises of Mr. Bellamy are sane when compared with those deducible from the premises of Mr. Sidney Webb; for Mr. Bellamy would allow a man to be responsible for a thousandth part of his actions at all events, whilst Mr. Sidney Webb would not allow that anybody either did or was responsible for anything.

And now, finally, let us turn to that other Finally, let us argument which seeks to eliminate the causality of ment that most the great man, not by proving that he owes his of what the superior brain-power to society, but by proving that depends on superior brain-power has little to do with his iesandachieveachievements, their principal cause being the ap- he does but pliances, the opportunities, and the accumulated knowledge at his command; and that these, at all events, are due not to himself, but others - to the efforts of past generations, and the legacy they have left to the present. This is the argument which is mainly relied upon by $\mathrm{Mr}$. Spencer. He insists on the fact that none of the great inventors or discoverers could have made their discoveries or 

Book I inventions if centuries of past progress had not
Chapter 3 prepared the way for them. " $A$ Laplace, for instance," he says, "could not have got very far with the Mécanique Céleste unless he had been aided by the slowly developed system of mathematics, which we trace back to its beginnings amongst the ancient Egyptians"; and his many other illustrations are all of the same kind.

If we consider the meaning of this argument carefully we shall see that its logical outcome is not to deny to the great man all superiority whatsoever, but to exhibit his superiority as being less than it is

If this argument means anything practical, it must mean that greatness is commoner than it is vulgarly thought. usually supposed to be. Laplace, Mr. Spencer would say, may have been personally a little above the level of his contemporaries, but he owed most of his elevation to sitting on the shoulders of his predecessors. Now if this reduction of the great man's reputed greatness to such very small proportions has any practical meaning, it must mean that greatness is not only less than it is supposed to be, but is also a great deal commoner, and more easily procurable. Whatever any particular great man has done, could have been done, if he had not done it, by an indefinite number of others. Let us then take as an illustration some definite task, and see how far such reasoning has any practical application. Our illustration shall be taken from the domain of art; for the great artist, according to Mr. Spencer's special statement, owes his greatness to the achievements of past generations, just as the great mathematician does, or the great thinker, or the great 
inventor. Let us suppose, then, that it is desired to decorate some public hall with pictures worthy of Book I Chapter 3 Titian or Michael Angelo, or to open some national theatre with a new play worthy of Shakespeare. Case? Does The great question will be where to find the artist debt to his or poet whose works shall even approximate to make Shakethese ideals of excellence; and any one who numerous? knows anything about either pictures or poetry will know that to find him is a well-nigh hopeless task. Now what conceivable help, what conceivable meaning, would there be in Mr. Spencer's coming forward and telling the public that the greatest poet or artist is the product of the same conditions that have produced any one of themselves? Mr. Spencer has actually made this precise statement. Let us therefore refer to the terms in which he has done so. "Given a Shakespeare," he says, "and what dramas could he have written, without the multitudinous conditions of civilised life - without the various traditions which, descending to him from the past, gave wealth to his thought, and without the language which a hundred generations had developed and enriched by use?"

Mr. Spencer could not have put his own case more clearly; and the more clearly it is put, the more easy it is to answer it, and to show that for practical men it has no meaning whatsoever. The answer to the question he asks is not only obvious, but contains at the same time the solution of the whole problem we are discussing. It will inevitably take the form of another question. Given the 

Book 1 conditions of civilised life, and the traditions of

England and its language, as they were under Queen Elizabeth, how could these have produced dramas like King Lear and Hamlet, unless England had happened to possess that unique phenomenon - a Shakespeare? Could a Bottom have written these dramas, or a Dogberry, or a Sir Toby Belch? Or could Sir Thomas Lucy, or any of the "poetasters" satirised by Ben Jonson? Or could the actors, Kemp, Jones, and Bryan, who assisted in the representation of these dramas upon the stage? The answer is, of course, No. And yet these men

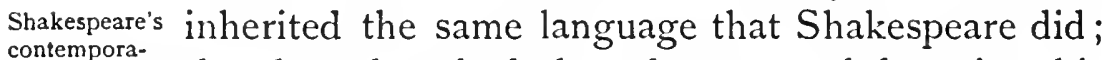
contemporaries had the same national antecedents that he had; but they could not do what he thi
did.

Men inherit the past only in so far as they can assimilate it. the three last had the advantage of knowing his finest passages by heart. The weaver, the bellowsmender, the constable, the Justice of Peace, had behind them the same traditions that Shakespeare had, and were surrounded by the same "multitudinous conditions" of civilisation. But out of these conditions one man alone was capable of eliciting the results elicited by Shakespeare. The real explanation of the whole difficulty - the difficulty involved in the fact that whilst the argument of Mr. Spencer and Mr. Bellamy is, in a speculative sense, not merely true but a truism, it is utterly untrue in any practical sense - is as follows: Every human being living at any given time is, as Mr. Spencer says, an inheritor of the past; but men inherit the past in very different degrees. They inherit the knowledge of the past only according to the degree to which they acquire it; the language of the past only according 
to their skill in manipulating it; the inventions of the past only according to their skill in reproducing Book I

Chapter 3 and using them.

The extraordinary confusion of thought in- Socialists say volved in Mr. Spencer's position is focalised in an once made argument constantly employed by socialists - that ${ }_{\text {mon property. }}^{\text {become }}$ "inventions once made become common property." Except the earliest and simplest of them, they no more become common property than the countless facts and figures buried in Parliamentary BlueBooks become the property of every new member of Parliament, or than encyclopædic knowledge becomes the property of every one who happens to inherit an edition of the Encyclopadia Britannica; or than the power of deciphering the hieroglyphics which are preserved in the British Museum becomes the property of every cabman who drives his vehicle along Great Russell Street. It is perfectly true that the discovery of each new portion of knowledge enables men to acquire it who never might have discovered it for themselves; but This is absoas the acquisition of the details of knowledge becomes facilitated, the number of details to be acquired increases at the same time; and the increased ease of acquiring each is accompanied by an increased difficulty in acquiring all, or even in assimilating those which are practically connected with one another. A mechanic, for instance, could with ten minutes' attention comprehend the principle involved in a cantilever bridge, but to design and construct a bridge such as that which now spans the 
Book I Forth, with its spans of six hundred yards and its altitudes of aerial steel, implies an assimilation of our multitudinous existing knowledge, such as is

The discoveries and inventions of the past are the property of those only who can absorb and use them.

hardly to be found in a score of engineers in Europe. Or to turn once more to Mr. Spencer's example of Shakespeare, whilst all Shakespeare's contemporaries had the same antecedents that he had, the same line of thinkers behind them, and the same developed vocabulary, Shakespeare's mind was capable of absorbing much of the national inheritance, whilst the great mass of his contemporaries could comparatively absorb very little.

Thus the intro- We are thus brought back to the point from
duction of the past into the which we set out - namely, the differences in capaquestion leaves the differences between the great man and others undiminished. city by which men are distinguished from one another; and we see that all the reasonings of our modern sociologists have, for practical purposes, left these differences undiminished. The difference between the great man and the ordinary man is not made less by the fact that they both of them owe much to a common past, any more than the difference between a hogshead of water and a wine-glass is made less by the fact that both have been filled from the same stream.

The conclusion, therefore, of the whole matter is as follows. In the first place, whatever may be the speculative significance of Mr. Spencer's contention, which Mr. Bellamy expresses with the arithmetical precision of an accountant, that each living generation does only a minute fraction of what it seems to do, or of arguments like Mr. Sidney Webb's, that 
each living generation does nothing at all of what it seems to do, the mass of living men at all events do something, in the very real sense that if they did not do it they would die; and the doing of this something is for them the whole of life, and all practical problems depend on the manner in which they do it. Such being the case, it follows, in the second place, that however much the ordinary man does, the great man does a great deal more. Therefore, if the ordinary man does any of the things that he seems to do, and causes any of the events that he seems to cause - if he ploughs the farm that he seems to plough, and lays the bricks that he seems to lay - indeed we may add, if he eats the dinners that he seems to eat - the great man in a precisely similar sense is the cause of those changes and of that progress which he seems to cause. Hence of these changes he is, for the practical sociologist, not merely the proximate initiator, whose action and and in practipeculiarities may be neglected, but a true and he is a true primary cause, on which the attention of the soci- sociologist. ologist must be concentrated; and just as in action it is impossible to do without him, so in practical reasoning it is impossible to go behind him.

The reader has now been shown the absolute futility of that train of reasoning by which even so keen a thinker as Mr. Spencer has persuaded himself that he can get rid of the causality of the great man, and in which every socialistic reformer who has risen above the level of a demagogue has attempted to find a scientific foundation for his im. 
Book I possible castle in the air. But the demolition and exposure of these mischievous and miserable fallacies shall not be entrusted only to the arguments that have been brought to bear on them. The validity of these arguments shall now be finally substantiated by direct appeal to a sociologist whose identity may surprise the reader. This is none other than Mr. Spencer himself, who, when he forgets to be the conscious expositor of his theory, and turns aside to illustrate some particular point by examples drawn from the experience of common life, is constantly contradicting, in a most remarkable but entirely unconscious way, the fundamental principle which he has deliberately set himself to establish.

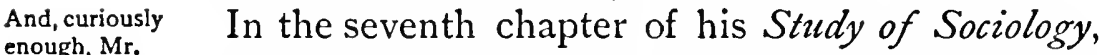
Spencer unconsciously admits this.

being incidentally concerned to insist on the iniquity and the mischievousness of war, he describes how Europe, during the earlier years of this century, was visited by certain disasters, far-reaching and horrible, from the consequence of which the world has hardly yet recovered. These disasters consisted of slaughter, plunder, pestilence, agony, rape, and ruin; and to say nothing of their results on those whom they left alive, they resulted in some two million He declares violent and unnecessary deaths. And how does Mr. that the Napoleonic wars were entirely due to the maleficent greatness of Napoleon.

Spencer explain these appalling phenomena? $\mathrm{He}$ who declares that we should learn nothing about social causation "should we read ourselves blind over the biographies" of all the great rulers of the world, explains them by tracing them to one sole and single cause; and this, he says, was the genius 
and personality of Napoleon. "Out of the sanguinary chaos of the Revolution," he writes, "rose a Book I Chapter 3 soldier whose immense ability, joined with his absolute unscrupulousness, made him now general, now consul, now autocrat. The instincts of the savage were scarcely at all qualified in him by what we call moral sentiments. . . And all this slaughter, all this suffering, all this devastation, was gone through - " Let us pause and ask why it was gone through, according to Mr. Spencer. Does he say it was gone through because of "aggregates of past conditions" and the influence of antecedent generations? Far from it. He says, "All this was gone through because one man had a restless desire to be despot over all men."

But perhaps Mr. Spencer may have a defence ready. He may tell us that the influence of Napoleon was merely that of a military leader, which influence he has excepted from his theory of general causes. To this it must be answered in the first place that Napoleon was at all events not a leader in "early" or "primitive" warfare, to which Mr. Spencer's exception is specifically and emphatically limited. Mr. Spencer consequently shows us, by his own practical reasoning, that this theoretical limitation of which he made so much cannot be maintained for a moment, and that whatever is true of great leaders in a primitive war, he himself recognises - all his theories notwithstanding - as equally true of them in the most advanced stages of civilisation. But a far more important 
Book 1 answer, and one taken from himself, is still in Chapter 3 reserve - an answer which clenches the whole matter, and shows us that Mr. Spencer, in his dealings with practical life, really recognises great men as exercising in the arts of peace precisely the same kind of causality which Napoleon exercised in war.

Let us turn to Mr. Spencer's treatise on Social Statics, and to the section of it in which he treats of patents - or as he himself describes them "the rights of property in ideas." He begins by complaining that the right of patenting "inventions, patterns, or designs" is not recognised as being based on any moral right at all, but is generally

He defends patents because they represent the v'cry substance of the inventor's oan mind; regarded as a kind of "privilege" or "reward." "The prevalence of such a belief," says Mr. Spencer, "is by no moans creditable to the national conscience. To think," he exclaims, "that a sinecurist should be held to have a 'vested interest' in his office, and a just title to compensation if it is abolished; and yet that an invention over which no end of mental toil has been spent, and on which the poor mechanic has laid out porhaps his last sixpence-an invention which he has completed entirely by his own labour and with his own materials - has wrought, as it were, out of the very substance of his own mindshould not be acknowledged as his property!"

Social Statics is one of Mr. Spencer's earlier works. Let us now consult his latest, the third and final volume of his Principles of Sociology; and here we shall find this same admission that the 
great man's achievements are wrought not out of aggregates of conditions, but "out of the very Book I Chapter 3 substance of his own mind," emphasised by him as a practical truth, with all the vigour of a practical man. In his chapter on the "Interdependence and Integration of Industrial Institutions" he dwells with and he attribmuch eloquence on the almost incalculable benefits modern imthat have resulted, and extended themselves through provement in the whole industrial world, from certain improve- ${ }_{\mathrm{H}}^{\text {facture to }}$ Sir ments introduced into the manufacture of steel. And to what were these improvements due? Mr. Spencer answers this question not merely by admitting, but by insisting with the fervour of a hero-worshipper, that they were due to the genius of one single man, namely Bessemer; and so obvious does this truth appear to him, that he devotes an indignant footnote to denouncing the governing classes for not being sufficiently alive to it, and for conferring on a man who, "out of the very substance of his own mind," had wrought such gigantic and universally beneficial changes, no higher reward than the title of Sir Henry Bessemer - "an honour" he says, "like that accorded to a third-rate public official on his retirement, or to a provincial mayor on the occasion of the Queen's Jubilee."

After this, what more need be said? Here we have Mr. Spencer himself, the moment he touches the practical side of life, contemptuously brushing aside the whole of his speculative theory and admitting, or rather insisting, with the most unhesitating and uncompromising vigour, that "the phenomena of 
Book I social evolution," even if they do not result entirely, as Carlyle would have it, from the actions of great men, yet cannot, at all events, be possibly explained without them; and that great men, their natures, and the details of their active lives are primary factors to be studied by every practical sociologist, and are not to be merged in "society," in "antecedents," and in "aggregates of conditions." So much, then, The practically independent character of the
being estab. lished, we must great man's causality will be yet more apparent consider two
difficulties at another stage of our argument, and we shall suggested by it. see that the whole structure of all civilised societies depends on it. But we may, for the present, regard it as being sufficiently established, and the absurd and unreal character of the attempts to get rid of it demonstrated. So much, then, being assumed, we will, in the following chapter, consider two objections of a character very different to any of those of which we have now disposed. They are objections which will very possibly have suggested themselves to the reader's mind, but which, instead of conflicting with the truth which has been just elucidated, will be found, when examined carefully, to emphasise and to enlarge its significance. 


\section{CHAPTER IV}

\section{THE GREAT MAN AS DISTINGUISHED FROM THE}

PHYSIOLOGICALLY FITTEST SURVIVOR

THE two objections to which reference has just been objected that made are connected with two doctrines, neither of modern sociolwhich has thus far been submitted to any detailed ${ }_{\text {as here as- }}^{\text {ogy does }}$ examination, and one of which has indeed been serted, neglect hardly so much as alluded to, but which are both for it adopts intimately associated, in the estimation of the world the survival of at large, with contemporary science, and more especially with contemporary sociology. One of these doctrines is that of the survival of the fittest. The other is that which, more or less distinctly, is suggested at the present time by the much-abused word "evolution." When the reader thinks of the doctrine of the survival of the fittest, when he reflects on the fact that Mr. Spencer is an avowed disciple of Darwin, and that Mr. Spencer's own disciples are constantly making allusion to "the rivalry of existence" and the "successfuls and the unsuccessfuls," he may be tempted to ask himself if it can be really true that Mr. Spencer has eliminated the great man from his system after all. On the other hand, when the reader thinks of evolution, 
Book I which, whatever it may mean, at all events means a progress essentially different from the achieve-

It may be asked, on the other hand, what place the great man has in an exclusively evolutionary theory of progress. ments of particular individuals, he may wonder in what way the doctrine of evolution can be reconciled with any doctrine which has the achievements of individuals for its basis.

We will take these two points in order. With regard to the survival of the fittest in the competitive struggle for existence, the great fact which it is necessary to make clear is as follows; and it is one which our contemporary sociologists have altogether The fittest sur- failed to perceive. In the evolution of societies,
vivor is not the same as the great man. just as in the evolution of species - in the evolution of man as a social being, as in the evolution of man as an animal - the struggle for existence has played an important part; but in social evolution the part played by it is very far from being that which is popularly supposed, nor does the survival of the fittest in any way correspond with the position and influence claimed for the great man. Certain of the

He plays a part in progress, but not the same part. phenomena of progress are no doubt produced by it, but they are as different from those which the great or exceptional man produces, as is the movement of the earth round the sun from its movement round its own axis. In order to understand this, let us first consider carefully how progress, as the result of the struggle for existence, is explained by our contemporary sociologists. The matter is put succinctly and very clearly in the following passage from Mr. Kidd's Social Evolution.

"Progress everywhere," he says, "from the begin- 
ning of life, has been effected in the same way, and is possible in no other way. It is the result of selection

Book I

Chapter 4 and rejection. In the human species, as in every other species which has ever existed, no two individuals of a generation are alike in all respects; there The fittest men, by suris infinite variation within certain marrow limits the general Some are shighthr aboue the average in a particular level of the Some are slightly above the average in a particular race, and prodirection, as others are slightly below it; and it is only in this only when the conditions prevail that are favourable to the preponderating reproduction of the former, that advance in any direction becomes possible. To formulate this as the immutable law of progress since the beginning of life has been one of the principal results of the biological science of the nineteenth century. . . . To put it in words used by Professor Flower in speaking of human society, 'Progress has been due to the opportunity of those individuals who are a little superior in some respects to their fellows of asserting their superiority, and of continuing to live and of promulgating as an inheritance that superiority."

The entire Spencerian position as regards the social struggle for existence is here given us in a nutshell. The competitive struggle is a process which produces progress by means of the manner in which it affects men in general. In any community the means of subsistence are being constantly appropriated by the members who are a little stronger than the rest, whilst those who are weaker have an insufficient portion left them. The latter therefore die early themselves; or breed no children; 
Book I or breed children who die early; whilst the former live long, and breed children who live likewise; and of these children there is always a certain percentage in whom are reproduced the superior qualities of their parents. Thus the weaker members of the community are always dying out, whilst stronger members not only become more numerous, but more efficient as individuals also. In other words, the Darwinian struggle for existence produces progress by raising the general average of efficiency. It has nothing to do with a few men towering over the rest. It works by producing a simultaneous rise of all. The superior "assert their authority" not by commanding their inferiors, but merely by "continuing to live" and having children as superior as themselves. In this way, to quote an illustration from Mr. Spencer, the progressive races of Europe have reached a stage of development which makes possible amongst them the appearance of men like Laplace or Newton, an event which could not occur amongst the Hottentots or the Andaman islanders. It will thus at once be clear that the theory of the survival of the fittest explains progress by reference The great man to an order of facts totally distinct from those promotes prog- involved in the influence claimed for the great man. superior to his contemporaries. Whilst the theory of survival is illustrated by the superiority of Europeans to Hottentots, the greatman theory is illustrated by, and depends on, the superiority of men like Newton to the great mass of Europeans.

What relation, then, do these two explanations 
bear to each other? In a direct way they are not related at all. They neither conflict with each other nor overlap each other. They are both of them The movement true; but true as explaining different sets of phe- of progress is nomena. One of the great errors of which our modern sociologists are guilty consists in their failure to perceive that social progress is not a single movement but the joint result of two, which differ from each other - to repeat what was said just now quite as much as do the two movements of the earth. The difference between them will become instantly clear to us if we will turn our attention merely to one morement the single obvious fact that the two take place at slow, the other different rates of speed, the one set of changes being rapid. slow, like the succession of years; the other set of changes being rapid, like the succession of days. The general rise in capacity which distinguishes the modern civilised nations from primitive man, or from the lowest savages of to-day, and which has been due to what Mr. Kidd calls "the preponder-The survival of ating reproduction of individuals slightly above the the fittest average," has been the work of an incalculable slow movenumber of centuries. It has been so slow that, in many respects at all events, it has been indistinguishable during the course of several thousand years. The great thinkers amongst the ancient Egyptians were not congenitally inferior to the great thinkers of to-day. The brain of Aristotle was equal to the brain of Newton; whilst the masons whose hands constructed the Coliseum and the Parthenon knew as much of their craft as those who 
Book I constructed the Imperial Institute. But with this
Chapter 4 slowness in the rise of the general level of capacity, let us compare the progressive results achieved within some short period. We cannot do better than take the past hundred years, and consider the progress made in the material arts of life. How the whole spectacle changes! Within that short period, at all events, no one will venture to maintain that the average congenital capacities of our own countrymen have been enlarged. We are not wittier than Horace Walpole, more polite than Lord Chesterfield, more shrewd and sensible than Dr. Johnson; whilst it is easy to see by reference to those trades, such as the building trade, which science and invention have done comparatively little to alter, that the natural efficiency of the average workman is no greater now than in the days of our great-great-grandfathers. And yet during that short period what an astounding progress has taken place! To sum it up in a bald economic formula, whilst the capacities of the average Englishman have remained altogether stationary, the economic productivity per head of the population of this country has during the past century trebled, and more than trebled itself.

This remarkable comparison between the rapidity of actual progress and the extreme slowness of the biological development resulting from the survival of the fittest in the Darwinian struggle for existence, will be enough to show anybody that progress is not one movement but two; and whilst the survival of 
the fittest explains the slow and almost imperceptible movement, the rapid and perceptible movement Book I is explained by the leadership of the greatest. It is with the rapid movement alone that the practical The rapid sociologist is concerned; and hence for him the movement is great man, not the fittest, is the important factor. great man.

Let us now consider what is meant by the process called social evolution, regarded as something distinct from those intentional advances made and maintained by the genius of great men. To understand this, we must consider what is meant by evolution generally. Mr. Spencer defines it in terms of "the homogenous" and "the heterogenous"; and from his own point of view we may accept his definition as correct. But facts have many aspects; and according to the purpose with which we deal with them they will require different definitions, which, though none of them are incompatible with the others, will have between themselves no apparent resemblance. Thus the biologist's definition of a man will be quite distinct from the theologian's; and the dangerous illness of a great party leader will be one phenomenon for his followers, and quite another for his doctor. In the same way $\mathrm{Mr}$. Spencer's definition of evolution, however admirable it may be from a certain point of view, is not exhaustive. It entirely leaves out of sight those characteristics of the process which it is necessary before all things that the practical sociologist should understand.

To reach a definition that will include these 
Book I let us begin by fixing our attention on that order of facts which formed the special study of Its great prac- Darwin, and in connection with which the theory istic, as put of evolution became first known to the world; Darward by ${ }_{\text {Darin that }}$ and let us ask what was the greatest and the it is opposed to most notorious effect produced by Darwinism on design, or divine intention; human thought generally. Its greatest and most notorious effect was to disprove, or rather render superfluous, the old theory which explained the varieties of organic life, by referring them to the design of some quasi-human intelligence. According to the old theory, every species of living thing, from the lowest to the highest, was produced by the power and purpose of one supreme Mind, who adapted the frame and faculties of each to a prearranged set of circumstances and the fulfilment of certain needs. According to the theory of evolution, associated with the name of Darwin, these results were accomplished by purpose and intelligent power likewise, only not by the power and purpose of one supreme external Mind, but by the power and and yet, ac- purpose of the living things themselves. Each

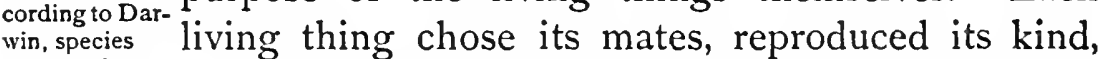
resulted from intention of hunted for food, fought with rivals, and either conlive and propa- quered or was conquered by them, in obedience to gate.

the promptings of its own instinctive purposes. These were the motive power of the whole evolutionary process. The variety and development of organic life, as we know it, did not result indeed from one great intention, but it did result from an infinity of little intentions. 
Now so far the theory of design and the theory of evolution very closely resemble each other; but here we come to the point of essential difference between Species, therethem. According to the theory of design, the varieties fore, according and gradations of organic life were not only the result tionist, is the of intention in the supreme Mind, but were also them- tion, but not selves the exact result intended. According to the intended. evolutionary theory, although they were the result of an infinity of intentions, not one of the living things, from whose intention they resulted, intended them. They were the by-product of actions undertaken for entirely different ends - that is to say, for the benefit of the individual creatures who undertook them. This is the essential and this is the peculiar character with which the theory of evolution invested them. It presented to the mind the extraordinary phenomenon of a single series of actions producing a double series of results - the intended and the unintended, the latter of which, though entirely different from the former, was Evolution, in equally orderly, equally reasonable and coherent. ract, is the Evolution, in fact, as revealed to us in the physio- sequence of the logical world, is, for the philosopher, neither more nor less than this - the reasonable sequence of the unintended.

But this definition of evolution does not apply This is as true only to development in that world of facts studied of social evoluby Darwinian science. It is equally applicable to biological the process of social evolution also. Indeed social evolution is even more strikingly, though not more truly, than physiological evolution, the reasonable 


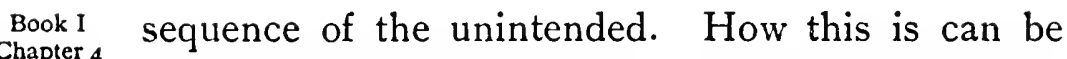
easily made plain; and when once the idea is grasped, which the definition embodies, it will be seen that social evolution, although it is no doubt different from all or from any of those changes deliberately produced by the agency of the great man, instead of excluding these changes, or eliminating the great man as the cause of them, is a process which depends altogether upon him and them, and that, instead of obscuring the great man's importance, it only exhibits it in a stronger and clearer light.

Many of the Let us take then our definition of evolution as social conditions of any age result from the past, but were intended by nobody in the past ; the reasonable sequence of the unintended, and apply the idea embodied in it to that aggregate of conditions, either in our own or any similar period. amongst which the great man works. All these conditions, such as the knowledge which he finds accumulated, the inventions which he finds in use, the political and the economic conditions of his country, are, taken as a whole, the result of no one man's genius. It is equally obvious that they do not, in their incalculably complex entirety, represent any one man's intention, or even the joint intention of any number of men acting in concert. Printing, for instance, for example, and railway travelling have produced a many of the
social effects of number of social results never dreamed of by the railways and
cheap printing. printing presses. Accordingly, when any great man of to-day initiates some fresh social change, whether as an inventor, a director of industry, a politician, or 
a religious teacher, a large part of his achievement consists in his manipulation and refashioning of results of past human action, which can be set down to the credit, or ascribed to the intentions, of no individual, and no body of individuals. The society produces some of the past intended these no more than the great tentionally he men of the past. They are results, that is to say, with uninwhich come all under the heading of the unintended. materials. But when we consider the great man's achievement thus, we shall not only witness the grouping of many of the factors essential to it into one heterogeneous but logically coherent class, as the unintended. When such a grouping has taken place, we shall see that there remains behind an equally coherent and equally striking residuum - namely, the social results and conditions that have been obviously and notoriously intended. These may not be found existing apart from the former; but though in conjunction or combination with them, they will be visible as a distinct and separate element, and their true importance as a factor in social progress will begin to be apparent to the mind the moment their specific peculiarity, as just described, is apprehended.

Let us take a few examples which, owing to their we can see magnitude and familiarity, will be at once intelligible. progicss of Our first shall be taken from the histories of art and dramatic art; of speculative philosophy. In each of these domains of human activity and achievement we find those phenomena of development to which it is now customary to apply the name of evolution. Thus we hear of the evolution of philosophy from the 
Book I crude guesses of Thales to the elaborate system of Aristotle. We hear of the evolution of the Greek drama from the exhibitions of Thespis with his cart to the tragedies of Eschylus and of Sophocles; and similarly we hear of the evolution of the English drama from such exhibitions as miracle plays or Gammer Gurton's Needle to tragedies such as Hamlet and comedies such as As You Like It. And to all such examples of development the word evolution is applied with perfect accuracy; for there is in each an obvious and orderly sequence of the

also in the progress of philosophy.
And yet in each case the intended elements equal or are greater than the unintended. unintended. Aristotle's philosophy was in part derived from that of his predecessors. He employed existing materials so as to produce a result which was not intended, indeed was not even imagined, by those who originally got them together and fashioned them, and which would never have been reached by Aristotle himself, if his predecessors had not thus unintentionally assisted him. None the less, however, does the Aristotelian philosophy, as its author gave it to the world, embody the deliberate intention of his profound and unrivalled genius; and it is only because it embodies this intended element that it constitutes an advance on the philosophies that went before it. Similarly, though Sophocles and Shakespeare, in constructing their dramas, each profited by the achievements of the dramatists who had gone before them, and though the art of each would doubtless have been more crude and imperfect had he come into the world a generation or two before he did, yet the part played 
by evolution in the production of Hamlet and Antigone is totally distinct from, and is altogether

Book I Chapter 4 dwarfed by, the part played by the genius and the intentions of their great authors.

Let us now turn to invention and applied science; we see the and the history of social progress, as connected the history of with and derived from them, will show the same printing press. two elements - the unintended and the intended, similarly related and similarly coexistent. A brilliant illustration of this fact is provided for us, in one of his books, by Mr. Herbert Spencer, though he himself, with a curious blindness and perversity, uses it not to illustrate but to obscure the point on which we are now dwelling. The illustration referred to is the history of the press by which The Times is printed, which implement, according to Mr. Spencer, is the result altogether of evolution. "In the first place," he says, "this automatic printing machine is lineally descended from other automatic printing machines ... each pre-supposing others that went before. . . . And then, in tracing the more remote antecedents, we find an ancestry of hand printing presses." $\mathrm{He}$ further points out that this press implies not only an ancestry of former presses, but also the existence of the machinery used in making it, and again how this machine-making machinery has a distinct ancestry of its own, which includes the fact of the abundance of iron in England. Geometry, physics, chemistry, also, he says, played their part in the process; and he winds up by referring to purely social causes. 


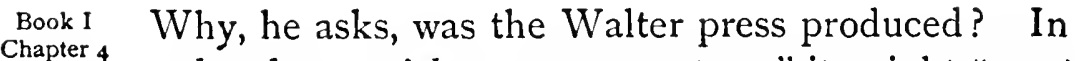
order that "with great promptness" it might "meet an enormous demand."

It is difficult to imagine a better illustration than this of the part played by evolution in the domain of mechanical invention. It is perfectly evident that the mass of discoveries and inventions which preceded and paved the way for the final invention in question were due to men who had no idea in their heads of such a machine as a steam-driven It was the printing press at all. When printing was first
result of many kinds of un- invented, steam-power was undreamed of. When intended progress, constantly recombined by intention. the steam-engine was being perfected as a means of driving machinery, the inventors had no specific intention of applying this force to the printing press. The men whose genius and energy in the seventeenth and eighteenth centuries laid the foundation of the English iron trade, and with it, as $\mathrm{Mr}$. Spencer says, the foundation of "machine-making generally," in all probability never even saw a newspaper, and could not have conceived the possibility of collecting enough news daily to fill as much as one page of The Times. The mathematicians and chemists to whose work Mr. Spencer alludes most probably never gave a thought to the practical application of their discoveries, and knew as little of the process of printing as they did of Chinese grammar. But let us give to these facts all the weight we can. Let us accept the antecedents that made the Walter press possible as not only sequences but also concurrences of the unintended; and yet the part played 
by the great man remains as essential, and remains as large as ever. The fact that the Walter press could never have existed unless Caxton's press had existed, and that Caxton never foresaw the future development of his apparatus, does nothing to disprove the fact that in the development of printing generally, genius like Caxton's was an indispensable agent, and one which stamped its character on the whole sequence of inventions which it inaugurated. Nor again does the fact that an invention like the Walter press implies not only a direct sequence of inventions and discoveries, but also a concurrence of many separate sequences, such as the invention and discoveries of chemists, of machine-makers, and producers of iron, do anything to disprove the importance and the necessity of the part played by the men to whose genius the press was directly due. For although the co-existence of the separate sequences referred to - the parallel march of progress in many separate arts and sciences - may have been altogether unintended by any of those concerned in them, what was emphatically not unintended was their final concurrence - the fact of their being brought together for one definite purpose. This was due to the deliberate intention of exceptional men with strong synthetic powers, who appropriated and connected the achievements of various other men. Chemistry, geometry, the production of iron, and the development of machinery for machine-making would never have worked together to produce an automatic

Book 1 Chapter 4 
Book I printing press had the immediate inventors of such
Chapter 4 an implement not coerced them into their service, and forced them to contribute to a deliberately planned result.

Evolution, in fact, is the unintended result of the intentions of great men.

The state of the case is this. Let us take any civilised society at any period we will, and examine it in the act of advancing to the next stage of its development. We shall find that its existing conditions consist partly of results intended by particular great men whose past actions have produced them, and partly of results neither foreseen nor intended by anybody. Thus at the present day amongst our social conditions we have the telegraph and the railway system - both of them results intentionally produced by individuals; and we have also a variety of new wants and habits, new methods of conducting trade and government, which have been produced by these, but which were neither intended nor even thought of by the inventors of the locomotive, or by Wheatstone and Cooke when their wires at last realised the long-forgotten dream of the Italian Jesuit Strada. ${ }^{1}$ Thus, though social conditions at any given time are a compound of intended results and unintended, and even though we may admit that at any given time these last are more widely diffused than the former, these last

${ }^{1}$ Strada, an Italian Jesuit, in the seventeenth century invented, or rather imagined, communication by electric telegraph; and his idea actually comprised the use of two needles moved by two magnets, these magnets being connected in such a way, that by the movement of either of them the needle, actuated by the other, could be made to point to such and such letters on a dial. 
are themselves the children of intention once removed. Great men may not have meant to proBook I duce them, but they have arisen from conditions which great men did mean to produce; and they could not have arisen in any other way. And here we are brought to a fact more obvious and more important still. Before any further advance in social civilisation can be made, other existing conditions, whether intentionally produced or not, require to be intentionally re-combined and acted on by men whose enterprise, whose intellect, and whose constructive imagination mark them out from their fellows as the pioneers of the future. We are thus once more confronted with the fact already insisted on that the social conditions of a time are the same for all, but that it is only exceptional men who can make exceptional use of them, and turn them into a stepping-stone on which their generation may rise higher.

Social evolution, therefore, in so far as it is other than biological, may be defined as the unintended result of the intentions of great men; and this definition at once brings us back to the truth which was urged in the first chapter as the starting-point of our argument, and which can now be put before the reader with an added force and clearness.

It was said in the first chapter that sociologists The uninhave succeeded in dealing with those wider social evolved phenomena which are exhibited by social aggregates element in as wholes, and which are interesting and significant 


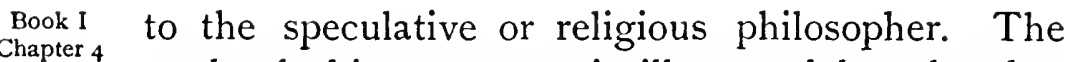
truth of this statement is illustrated by what has what concerns just been said about evolution. If evolved phenom-

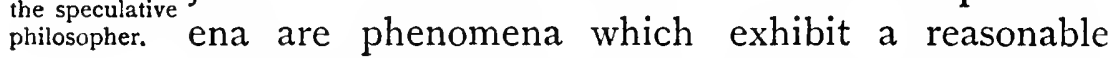
sequence, and have yet been intended by no animal or human mind, it is open to the thinker to argue that they must have been intended by the mind of some higher power; and a new gate is opened into the Eden of theological speculation, from which man was driven when he first ate of the tree of scientific knowledge.

The intended element, which originates directly in the great man, is what is of interest for practical purposes.

But whilst the business of the speculative philosopher is solely with the phenomena that have been unintended, the business of the practical sociologist is solely with the phenomena that have been intended. A moment's reflection will convince the reader that this must be so. The meaning of the words practical science is a science from which we can draw practical advice; but all advice implies an intended end; and every attempt to solve social problems scientifically must be concerned with results which we may deliberately set ourselves to produce, and not with by-products which, ex hypothesi, are beyond our calculation. We may study these by-products of intention as they have shown themselves in the past; but if we do this, it will be with the object of becoming able to foresee them in the future. So soon as we can foresee them, we shall be able to intend their production; and when this happens they will cease to belong to the unintended. The great man will then consciously aim at them, and 
not leave them to the incalculable chances of evolution. It may safely be said, no doubt, that, Book I Chapter 4 let us study human conduct as we may, unintended, or evolved phenomena, will always continue to form a large part of what we mean by social progress; but, as practical inquirers, we must put them on one side, and confine our attention to those factors in the problem which either embody some definite human intention themselves, or on which we can found, by studying them, some definite intention of our own. And of such factors the chief is the great man, whose importance is enhanced rather than dwarfed by the fact that his intellect and his energy are the causes not only of great results which he intends, but also of those others - wider, if not more important — which, though neither intended nor foreseen by himself or by anybody else, would, if it were not for him, never take place at all. 

BOOK II 



\section{CHAPTER I}

THE NATURE AND DEGREES OF THE SUPERIORITIES OF GREAT MEN

THAT great men are true causes of progress is The causality admitted by Mr. Spencer himself to be the natural of the great opinion of mankind. What has been done, then, in established, we the preceding book is not much more than this: a more precisely sound popular judgment, which is of the highest is. sociological importance, has been rescued from the discredit cast on it by the sophisms of modern theorists. These very theorists themselves, when they reason as practical men, have been shown to the reader blowing all their disproofs of it to the winds, and holding and appealing to it as tenaciously and as passionately as anybody; and it is consequently given back to us, with its old authority unimpaired. Sound popular judgments, however, are not science. They lack what is the essence of science - that is to say, analytical precision. We must now, therefore, take this judgment with regard to the great man, and endeavour to invest it with a meaning exact and full enough to enable us to apply it to the detailed phenomena of society.

And here Mr. Herbert Spencer shall once more 
Book II help us; for this remarkable writer, though he fails
Chapter I to recognise what he is doing, not only appeals on many critical occasions to the great-man theory as an explanation of the most important social phenomena, but he is repeatedly calling attention throughout his sociological writings to those facts of human nature of which the great-man theory is the expression. It will be sufficient to quote a few passages only.

Mr. Spencer will help us to a general

Let us turn, then, to the opening pages of Mr. definition of it. Spencer's Study of Sociology and consider what is contained in them. We shall find that they are entirely devoted to describing the abject mental condition of by far the largest portion of all classes of English society, from the labourer, the farmer, and the Nonconformist minister with his Bible, up to "men called educated" and the most illustrious of our historians and philosophers. All of them, says $\mathrm{Mr}$. Spencer, "are slaves to unwarranted opinions"; "proximate causes" are all that the majority of them are able to understand. Nor does he represent this as some accidental result, due to prejudices or deficiencies in education peculiar to our own country. He represents it as an inevitable result of the character of the human race. In his "Postscript" to the same volume he takes care to make his meaning plain. "Most people," he says, "conclude quickly from small evidence," and are incapable "of comprehending in their totality assembled propositions." Indeed, those whose mental constitution is such that they can take a 
rational view of "human affairs" are, he proceeds to say, merely "a scattered few." He elsewhere divides society into "the capable and the incapable," the "worthy and the unworthy"; and in the "Postscript" just alluded to he mentions as an admitted fact that in every social aggregate "the inferior form the majority." But a yet more caustic passage remains to be mentioned. In this same work, The Study of Sociology, he is ridiculing - and very justly - the socialistic idea that the State can He divides the human race
into the clever, be endowed with any talent or wisdom beyond what the ordinary, happens to be possessed by the individual functionaries who compose the State. These functionaries, he says, are merely " a cluster of men," which, like any other cluster taken at hap-hazard, will comprise "a few clever individuals, many ordinary, some decidedly stupid"; and he devotes pages to showing by means of multiplied examples, how incapable the ordinary statesman, to say nothing of the decidedly stupid, has been of promoting progress in even the simplest ways.

Mankind at large, then, according to Mr. Spencer, may, roughly speaking, be divided into three classes - the "clever" who are few, the "ordinary" who are the bulk of the population, and the "decidedly stupid" who form a considerable residuum; and it will appear from what he says of that representative "cluster," the State, that whilst all real progress is the work of the clever few, the "ordinary men" do nothing to promote it, and "the decidedly stupid men" impede it. 
Book II

Chapter I

Now if all the race were stupid, it is plain there would be no progress;

nor would there be any, if all the race were ordinary

Now it must be perfectly obvious to the reader that in this description of mankind we have the fundamental facts before us which the great-man theory formulates. For let us begin by supposing that the entire human race contained no individuals superior to the "decidedly stupid," who, whenever they are placed in official positions, do nothing, Mr. Spencer declares, but commit the most pernicious blunders, either by their irrational conservatism, or their still more irrational innovations. It is obvious that in this case the world would never have progressed at all. Let us next suppose that in addition to the "decidedly stupid" men, the human race comprises also a large proportion of "ordinary" men, but not a single man who deserves to be called more than "ordinary." Could social progress, as we know it, have taken place even then? Could thought, for example, ever have made any advances, had everybody been as incapable as Mr. Spencer's "ordinary" man is of taking a rational view of human affairs - had everybody been enslaved, like him, "to unwarranted opinions," and been, like him, entirely lacking in the faculty which enables a man to comprehend "assembled propositions in their totality"? Or to put the whole matter in terms of a single instance, could Mr. Spencer's own system of philosophy have been written if he himself had not been immensely superior not only to "ordinary" men, but even to those rival thinkers whom, in every one of his volumes, he treats with such supreme disdain? 
The answer of course is No. Under such conditions progress would have been quite impossible. Our simple argument will accordingly run thus. It is evident that those triumphs of thought, enterprise, and invention to which social progress is due could never have been made had the whole of each generation been as stupid and void of character as its lowest and weakest members. Therefore progress must be due to men who are superior to the "decidedly stupid." Here we have the great-man theory in embryo. But it is equally evident that we can go a step farther, and say that progress could never have taken place had there been no individuals who in will, originality, and intellect were therefore progsuperior to "ordinary menn." Social progress, there- due to the fore, must be due to this third class - the class which clever, who alone is capable of taking "a rational" view of a scancer says, things; but this class, as Mr. Spencer tells us, consists of a "scattered few," and here we have, in Mr. Spencer's own language, neither more nor less than the great-man theory developed. We have it developed in the form of a distinct general proposition that progress is due not to mankind at large, but to a minority of exceptional individuals, and in this form, which Mr. Spencer has assisted us in This is the giving it, it is brought into actual accordance with $\begin{gathered}\text { great-man } \\ \text { theory reason- }\end{gathered}$ the facts of social life, and, unlike the wild exaggeraably stated. tions of Carlyle, it will be found to accord the more closely with them the more fully it is analysed.

The error of writers like Carlyle was that they took a part for the whole. They recognised no 
Book II great men at all except great men of the greatest kind - heroic figures which appeared once or twice in a century; and as for the rest of mankind, they For great men treated them in accordance with Mr. Spencer's
are not necessarily heroes, as Carlyle thought, formula, as a mass of units, approximately equal in capacity. The truth of the case is, on the contrary, this:- that whatever is done by great men of the heroic type, something similar, if not so striking, is done by a number of lesser great men also; that whilst the action of the heroic great men is intermittent, the action of the lesser great men is constant; and that the latter, as a body, although not individually, do incalculably more to promote progress than the former.

Let us accordingly make it perfectly clear that when we describe great men as being a minority, or

nor divided absolutely from all other men. a "scattered few," we do not mean that out of every thousand men there are nine hundred and ninety-nine "ordinary" men and one genius; or that there are (let us say) seven hundred who can be described for all purposes as "ordinary," and two hundred and ninety-nine who can be for all purposes described as "stupid"; and that there is one "clever" or "great" man who towers over them like an oak tree over bramble bushes. Nor, again, do we mean that "greatness" is some single definite quality, which marks its possessor out like a white man amongst negroes. Believers in extreme democracy, who very rightly discern in the great-man theory the destruction of their favourite enthusiasms, will instinctively seek to attribute some meaning such as this to its exponents. But the great-man 
theory, when properly analysed and explained, will be found to comprise no such absurdities as the foregoing. When we speak of "greatness" we Greatness is mean a great variety of efficiencies, which, though in inind and grouped together because they are all exceptional degree, in degree, are nevertheless indefinitely various in kind; and, moreover, the degrees to which they are exceptional are indefinitely various also, the degree being in many cases so low that it is difficult to say whether it should be classed as exceptional at all. In short, there are as many degrees of greatness as there are of temperature; and it is as difficult to draw a line between ordinary men and men whose greatness is of a very low degree, as it is to draw a line between coldness, coolness, and low degrees of heat. But though it may be questionable whether we should call a day cool when the thermometer is at fifty-nine, and whether we should call it hot when the thermometer is at sixty-one, everybody admits that it is hot when the thermometer is at eighty-five, and cold when the ther-but, at all mometer registers twenty degrees of frost. In the a certain same way, though there will be a certain number of minority of people who may be classed as great by one judge semble each and classed as ordinary by another, there is a more efficient certain number whose capacities, however unequal majority. amongst themselves, set their possessors apart as indubitably greater than the majority; and we are speaking with sufficient, though we cannot speak with absolute, precision when we say that progress depends on the action of this minority. 
Book II Chapter I

We see this in poetry,

How great the inequality is between the natural powers of men is perhaps most clearly evidenced by the case of art, and more especially the art of poetry. In certain domains of effort it may be urged that unequal results are caused by unequal circumstances, quite as much as by unequal capacities. But about poetry, at all events, this cannot be said. Some of the greatest poets the world has ever known-it is enough to instance the cases of Burns and Shakespearehave been men of no wealth and of very imperfect education. Obviously, therefore, in poetry one man has as good a chance as another. It is no doubt often argued - and this argument has already been examined - that great poets, of whom Shakespeare is a favourite example, owe part of their greatness not to themselves, but to their age. But this does nothing to explain the differences between poets who belong to the same age, and who, all of them, in this respect, start with the same advantage. Let us confine our comparisons then to men who were each other's contemporaries, and ask what made Burns a better poet than Pye, Shakespeare a greater poet than the feeblest of his forgotten rivals, Pope than Ambrose Philips, Byron than "the hoarse Fitzgerald"? There is only one answer possible. These men in respect of poetry had been made giants by nature; those were condemned by nature to live and to die dwarfs.

And the same inequality that exhibits itself in the domain of poetry will be found in every other in singers, domain of human effort. What can be more 
unequal than the gifts of different singers? In every school and university we see multitudes of young men and boys whose opportunities of learn- in the scholaring are not only similar but identical, but of ship of boys at whom, in respect to assimilating what they are ${ }^{\text {school, }}$ taught, not one in ten rises appreciably above a certain level, and not one in a hundred rises above it signally. We have Virgil at one end of the scale, and Bavius and Mævius at the other; at one end Patti, and the other the vocalist of the street; at one end a Scaliger and a Newton, and at the other the idler and the dunce, who can hardly conjugate $\tau \dot{v} \pi \tau \omega$ or stumble across the Asses' Bridge. And in practical life the same phenomenon repeats itself. Let us take any department of social activity or production, on the results of which the welfare of society at any given time depends. Let us take, for instance, and similarly the work of government, or invention, or commercial in pa. enterprise. In each of these we shall find a large number of men, each doing what is in him to subserve some particular end; and we shall find a few producing results which are great both for themselves and others, and the many producing results which are uniform in their individual pettiness.

It is perfectly true that in these great departments of practical life there may not be so obvious or so widely-extended an equality of opportunity as that which prevails amongst poets, or amongst scholars in the same seminary, but in each department there will be a large number, at all

Book 11 Chapter I 
Book II events, whose opportunities are as equal as human ingenuity could make them. This is so in the Enoughmen, French army, in the English House of Commons, as it is, have equal opportunities, to show how unequal men are in their powers of using them. and in the world of business and industry; and yet of men thus equally placed we see some doing great things, and doubling their opportunities by using them; others doing little or nothing, and throwing their opportunities away. We have accordingly in every domain of activity a sufficient number of persons with the same external advantages, to show by the extraordinary difference between the results accomplished by them how great the natural inequality between men's capacities is, and how far the efficiency of a few exceeds that of the majority. It is therefore nothing to the purpose to attribute, as many reformers do, men's inequality in efficiency to the fact that equality of opportunity is not at present as general as it theoretically might be. To extend this equality further might produce good results or bad; but in neither case would it tend to make men's capacities equal. The utmost it would do in this particular respect would be merely to widen the area of their realised inequality - to increase the number of the mountains, not to produce a plain.

No doubt a man may be ordinary in one respect, and great in another:

It will doubtless be objected by those who would minimise natural inequalities that a man may be contemptible in one capacity, that of a poet, for instance, and yet be greater as a man than men who in one capacity are superior to him. It may, for example, be said that Frederick of Prussia, in spite of his 
bad poetry, was a greater man than Voltaire. This is perfectly true; but it is necessary to explain Book II Chapter I clearly that it in no way contradicts what is being here asserted. It is, on the contrary, part of it. It cannot be too emphatically said that greatness, in the only sense in which we are here considering it - that is to say as an agent of social progress is a quality which we attribute to a man not with reference to his whole nature, but with reference solely to the objective results produced by him, so that in one domain of activity a man may be great, in another ordinary, in another decidedly stupid. What, then, we here mean by a great man is merely a man who is superior to the majority in his power but the of producing some given class of result, whereas the majority are average man and the stupid are not superior to the ${ }^{\text {any. }}$ majority in their powers of producing any.

The reader must thus entirely disabuse himself The measure of the idea that greatness, as an agent of social greatness as progress, has any necessary resemblance to great- an agent of

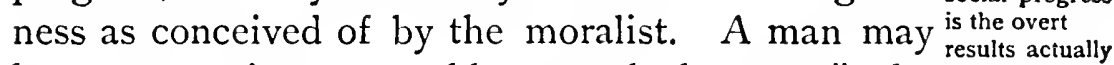
be a great saint or a noble "moral character" who produced by passes his life in obscurity, stretched on a bed of sickness, and incapable even of rendering the humblest help to others. He is great in virtue not of what he does, but of what he is. But greatness, as an agent of social progress, has nothing whatever to do with what a man is, except in so far as what he is enables him to do what he does. If two doctors were confronted by some terrible epidemic, and the one met it by tending the poor 
Book 1I for nothing, and died in his unavailing efforts to save his patients, whilst the other fled from the infected district, and, solacing himself at a distance with a mistress and an excellent cook, invented a medicine by which the disease could be warded off, and proceeded to make a large fortune by selling it, though the former as a man might be incalculably better than the latter, the latter as an agent of progress would be incalculably greater than the A selfish former. Again, if two doctors tried to invent such successful, is a medicine, and whilst the first succeeded the second greater than a failed, the second, though he might have exerted
devoted doctor, if unsuccessful. himself far more than the first, and have failed only owing to some minute flaw in his faculties, would be not only less great as an agent of progress than the first, but he would not be practically an agent of progress at all, any more than a man is an agent in saving another from drowning if he merely stretches a hand which the drowning man cannot reach, and actually himself tumbles into the water in doing so.

The fact that many men who produce no social results seem better and more brilliant than many men who do produce them makes some argue that these results require no greatness for their production.

This truth, which sounds brutal when plainly stated, but is really little more than a sociological truism, is constantly overlooked, and even indignantly denied, by thinkers whose emotions are more powerful than their minds. The way in which such persons reason is very easily understood. They see that a number of men by whom great social results are produced - men who make successful inventions and who found great businesses - are narrow-minded, uncultivated, and contemptible in 
general conversation, and that a number of other men who produce no such results are scholars, critics, thinkers, keen judges of men and things; and contrasting the brilliancy of those who have produced no great social results with the narrow ideas and dulness of those who have produced many, they proceed to argue that great social results cannot possibly require great men to produce them; or, in other words, that they might be produced by almost anybody.

But the whole of this class of objections will But the most altogether disappear when we more closely examine of of greatness what the qualities are on which the production of have often given social results depend. Let us take a few brilliant about of these results as examples. Let us take the formulation and the popularising of some particular political demand, by which the whole course of a country's history is affected, and the increasing and cheapening the supply of some articles of popular consumption - sugar, let us say, or workmen's boots and clothing. The persons who urge the objections we are now discussing assume that all greatness, other than physical strength and dexterity, must be necessarily ethical or intellectual, and be calculated to excite our ethical or intellectual admiration. But let them consider the qualities requisite to produce such results as have just been mentioned, and they will see that no assumption could be more wide of the truth.

A man who should, without underpaying his employees, succeed in manufacturing for the poorer 
Book II classes boots, jackets, or shirts better in quality Chapter I and very much less in price than those which

A lofty imagination is often the enemy to practical efficiency; they are accustomed to buy now, would probably have to devote a large part of his life to the consideration of a particular kind of seemingly sordid detail. To a man of wide culture and brilliant imagination, the concentration of his faculties on details such as these would be impossible; and if he wished to produce any of the results in question, he would soon discover that he could not. The men who do produce them are rendered capable of doing so, not by the width of their minds, but by the exceptional narrowness. The intellectual stream flows strongly because it is confined in a narrow channel, and thus what to the superficial observer seems a sign of their inferiority, is really, so far as the results are concerned, one of the chief causes of their greatness.

The mean man with the little thing to do

Sees it and does it;

The great man with the great end to pursue

Dies ere he knows it.

Robert Browning very tersely puts the case thus. We have only to alter his language in one respect. Seeing that the results we have now in view are realised results or nothing, the "mean man," as an agent of material progress, will be the "great man," and the "great man" will be the little.

So, too, with regard to the man who affects 
the history of his country by formulating and popularising some particular political demandthe secret of such a man's success, in four cases and great out of five, will be found to lie in the greatness, not officiency inof his intellect, but of his will - in an exceptionally exceptional sanguine temperament, in exceptional courage and intellect. energy, and very likely in an exaggerated belief in his own nostrums, which, instead of being a sign of great intellectual acuteness, is incompatible with it.

No doubt social progress, as a whole, has re- Intellect is quired and does require for its production intellectual proguired for powers of the highest and rarest kind. The point in invention; here insisted on is that it is not produced by intellectual powers alone, and that intellectual powers alone would be quite unable to produce it. Thus the sorrows and disappointments of the unfortunate inventor are proverbial; and the reason is that great inventive powers are frequently accompanied by a very feeble will and a fantastic ignorance of the world, the inventor, though strong as a mind, being pitiably weak as a man. He can do everything with his inventions except make them useful to anybody. He might be practically far greater were he to lose some of his intellectual powers, could he but the inthereby develop some of the humbler qualities in self is often which he is wanting. As it is, he resembles a chronometer which is without a main-spring, and which is useless when compared with a ten-andsixpenny watch. Hence the inventor has so frequently to ally himself with the man of enter- 
Book Il prise, and only becomes great, as a social force, by doing so. Such unions are often sufficiently strange and has to in appearance. We see some man whose intellect is with men whose exceptional gifts are unimpressive, and even vulgar. the finest machine imaginable, but he is only redeemed from absolute and grotesque uselessness by his partner, who is little better than an inspired bagman. But such a bagman's gifts, however the inefficient theorist may despise them, are, though less striking than the inventor's, often quite as rare. No doubt many great inventors have the practical gifts as well as the intellectual, and their greatness, in such cases, is comprehended completely in themselves. It remains, however, an equally composite thing, no matter whether it takes two men or only one to complete it; and exceptional intellect is only one of its elements. The other qualities with which it requires to be allied, and which alone give it its practical value, such as determination, shrewdness, and a certain thickness of skin, though often remarkable individually for the exceptional degree to which they are developed, just as often unite to produce practical greatness, not because of the exceptional degree to which they are developed, but of the exceptional proportions in which they are combined. Some of the most essential of them, indeed, need not be exceptional at all, except from the fact of their association with others that are so. Much greatness, for instance, of the most powerful kind consists mainly of very ordinary sense in conjunction with extraordinary energy; and energy is often, as has already been pointed out, in proportion 
to the narrowness rather than to the width of the

Book II imagination.

Chapter I

Greatness, in short, as an agent of social progress, Greatness is is in most cases not a single quality, but a peculiar but various combination of many; its composition varies combinations according to the character of the results in the production of which the great men are severally more efficient than the majority; and it often depends less on the extent to which any special faculty is developed, in comparison with the same faculty as possessed by ordinary men, than it does on the degree to which each faculty is developed as compared with the others possessed by the great man himself.

When we speak of greatness, then, in the sense Greatness, here attributed to the word - when we speak of then, is merely here attributed to the word which, in any great men as agents of social progress - we do not domain of mean that the world is divided into ordinary men ${ }_{\text {the few more }}^{\text {progres }}$ and heroes. The members of that minority whom efficient than we group together as great men, though some of the many. them are, no doubt, of noble and heroic proportions, are for the most part great in relation to special results only; even in relation to these special results they are great in very various degrees, and many of them in other relations may be ordinary, or even less than ordinary. It must therefore be clearly understood that greatness, as an agent of social progress, is not an absolute thing, and that to say of any one man that he possesses more greatness than another is a statement which, taken by itself, has no definite meaning. When we 
Book 11 Chapter I

The great-man theory, then, merely asserts that if some men were not more efficient than most men, no progress would take place at all.

say that a man is great we mean that he is exceptionally efficient in producing some particular result, which is either implied or specified - that he is great in commanding armies, or in managing hotels, or in conducting public affairs, or in cheapening and improving the manufacture of this or that commodity; and when we say that such and such a man possesses the quality of greatness to such and such a degree we mean that he produces results of a given kind, which are in such and such a degree better or more copious than results of the same kind which are produced by other people.

The inequality of men, then, in natural capacity being an obvious fact, and the nature and the degrees of their inequalities having been now generally explained, we may re-state, with a meaning more precise than was formerly possible, the fundamental proposition implied in the great-man theory, when that theory is raised from a rhetorical to a scientific formula. Progress of an appreciable kind, in any department of social activity and achievement, takes place only when, and in proportion as, some of the men who are working to produce such and such a result are more efficient in relation to that class of result than the majority; or conversely, if a community contained no man with capacities superior to those possessed by the greater But great men, number, progress in that community would be so
in spite of these slow as to be practically non-existent.

differences,

We must now go on to inquire what is the 
precise way in which the men who are superior to Book II the majority bring progress about; and we shall Chapter I find that however various they may be in other respects, they all promote progress in a way that is all promote fundamentally similar. 


\section{CHAPTER II}

PROGRESS THE RESULT OF A STRUGGLE NOT FOR SURVIVAL, BUT FOR DOMINATION

IT has already been explained that the great man, as here understood, does not in any way correspond with the fittest man in the Darwinian struggle for existence. The fittest man in the Darwinian sense merely promotes progress by the physiological process of reproducing his slight superiorities in his children, and thus raising in the slow course of ages the general level of capacity throughout subsequent generations of his race. The great man, on the contrary, promotes progress, not because he raises the capacity of the generations that come after him, but because he rises individually above the general level of his own. This, however, is only one of the differences by which the great man is distinguished from the fittest. There are two others, of which

In order to see how the great man promotes progress, we must consider that whilst the fittest survivor only promotes it the first that we must consider is as follows.

The fittest man, or the survivor in the Darwinian struggle for existence, is, so far as his own contemporaries are concerned, greater than his inferiors only in respect of what he accomplishes for 
himself, or for those immediately dependent on him. $\mathrm{He}$ is the man who lives and thrives whilst others

Book II

Chapter 2 die or languish, because whilst they can secure for by living themselves but little of what is requisite for life and whilst others health, he, by his superior gifts, is able to secure much. "Families," says Mr. Spencer, "whom the increasing difficulty of obtaining a living does not stimulate to improvement in production are on the high road to extinction, and must ultimately be supplanted by those whom the difficulty does so stimulate." That is to say, Mr. Spencer, and all our modern sociologists with him, conceive of the fittest as a man, or a man and his family, who fight for their food in isolation, like a lion and lioness with their cubs, and who affect their contemporaries only by being better fed than they, or as a race-horse affects its competitors only by being first at the winning post.

But the great man, as an agent of progress, the great man shows his greatness in a way precisely opposite to ress by help. that in which the fittest man shows his fitness. ing others to This it is that our contemporary sociologists all fail to perceive, and endless error is the consequence. The great man, unlike the strongest lion, promotes progress by increasing the food-supply not of himself, but of others; or if he increase his own, as he no doubt generally does, he does so only by showing others how to increase theirs. He is like a lion who should be better fed than the rest of the lions in his region, not because he took a carcase from them for which they all were fighting, 
Book II but because he showed them how to find others
Chapter 2 which they never would have found unaided, and took for himself in payment a small portion of each.

He promotes progress not by what he does himself, but by what be helps others to do.

We can see this by considering the progress of knowledge, which, as $\mathrm{J}$. S. Mill says, is the foundation of all other progress. The great man, in fact, as an agent of social progress, is great not in virtue of any completed results which he produces directly, by the action of his own hands or brains, or which he exhibits in his own person, but in virtue of the completed results which, by some simultaneous influence which he exercises over the brains or hands of others, he enables others to exhibit in themselves, or produce or do in the form of products or social services.

In order to realise this great truth, let us begin with considering that form of greatness which promotes social progress by supplying it with its first materials, and from which all other kinds of greatness draw some portion of their nourishment. It so happens that one of the most remarkable thinkers of this century, who, though he preceded $\mathrm{Mr}$. Spencer, belongs to the same school, is able to assist us here by a very apt and remarkable passage.

John Stuart Mill, in that section of his System of Logic to which he gives the title of "The Logic of the Moral Sciences," writes thus: "In the difficult process of observation and comparison which is required (for the purpose of obtaining a better understanding of the laws of empirical sociologv, and especially of social progress) it would evidently be a great assistance if it should happen to be the fact that one element in the complex existence of social man is pre-eminent over all the others, as the prime agent 
of the social movement. For we could then take the progress of that one element as the central chain, Book II to each successive link of which, the corresponding links of all the other progressions being appended, the succession of facts would by this alone be presented in a kind of spontancous ordcr, far more approaching to the real order of their filiation than could be obtained by any other merely empirical process. Now the evidence of history and that of human nature combine, by a striking instance of consilience, to show that there rcally is one social element which is predominant and almost paramount amongst the agents of social progression. This is the state of the speculative faculties, including the nature of the beliefs which by any means they have arrived at, concerning themselves and the world by which they are surrounded. Thus," Mill continues, "to take the most obvious case, the impelling force to most of the improvements effected in the arts of life is the desire for increased material comfort; but as we can only act on external objects in proportion to our knowledge of them, the state of knowledge at any given time is the limit of the industrial improvement possible at that time, and therefore the progress of industry must follow and depend upon the progress of that knowledge."

Any one who was inclined to be hypercritical might object, and object with justice, that the practical application of knowledge often lags behind the speculative attainment, and that material progress therefore, at certain times, depends on 
Book II some new state of the practical rather than of the
Chapter 2 speculative faculties; but apart from this not very important inaccuracy of expression, Mill's way of putting the case is admirable for its lucidity and for its truth; and we may, for our present purpose, be content to take it as it stands. All civilisation depends on the accumulation of speculative knowledge, and all progress in civilisation depends on an increase in speculative knowledge.

But all progress in knowledge is the work of "decidedly exceptional individuals,"

Speculative knowledge, however, does not increase of itself. It is not acquired without considerable effort; and people acquire it only because they strongly desire to do so. Such being the case, let us turn to another passage, taken likewise from the writings of Mill, and occurring in the very same chapter as that which has just been quoted. "It would be a great error," says Mill, "and one very little likely to be committed, to assert that speculation, intellectual activity, the pursuit of truth, is amongst the more powerful propensities of human nature, or holds a predominating place in the lives of any save decidedly exceptional individuals. But notwithstanding the relative weakness of this principle among other sociological agents, its infuence is the main determining cause of social progress, all the other dispositions of our nature which contribute to that progress bcing dependent on it for accomplishing their share of the work."

Now what does this passage mean? About its meaning, and the truth of its meaning, there can be no possible doubt; but it will be well to observe 
the extraordinary confusion in which Mill involves what he means by his perverse manner of expressBook II Chapter 2 ing it. In the first sentence of this last passage he tells us as clearly as possible that with regard to the pursuit of truth, and the power of discovering as Mill admits, and understanding it, mankind are divided broadly curiously coninto two classes - the great majority with whom fused language. the "pursuit of truth" and "intellectual activity" are "slight proponsities," and "the dccidcdly exceptional individuals" with whom these propensities are overmastering. But he has no sooner drawn this clear and all-important distinction between the two classes than he proceeds to undo his own work and mixes them together again in one unmeaning blur. He converts his statement that only "the decidedly exceptional individuals" desire truth with any great intensity, and have the faculties requisite for discovering it, into the statement that if we take "the decidedly exceptional individuals" and the majority together, and regard them as one body, which he calls "mankind," we shall find that the average desire for truth is lukewarm, and the faculties for discovering it insufficient. He might just as well group Shakespeare with a hundred ordinary men; tell us that Shakespeare could write the greatest poetry the world has ever known, and that the hundred other men could write no poetry at all, and then convert these statements into the following - that the one hundred and one men, Shakespeare included, could only write poetry of a very moderate quality. 
Book II Chapter 2

This confusion of statement, however, on the part of Mill, is merely mentioned here in passing, as one more example of the nature of that inveterate error - namely the ignoring of the differences between one class of men and another - which has made modern sociology so useless for practical purposes. The sole point which really now concerns us is this. In spite of the verbal, and indeed the mental confusion into which Mill lapses, the truth which he was struggling to express, and which no one, he says, would be likely to contradict, is not that, as he nonsensically puts it, the speculative faculties are weak in mankind generally, but that amongst the larger part of mankind they have hardly any efficiency at all, whilst "in decidedly exceptional individuals" they are intense, active, and conquering; and that consequently it is these "decidedly exceptional individuals" who practically constitute "the one social element which is predominant, and almost paramount, amongst the agents of social progression."

Now how do

Now such being the case, let us resume our the exceptional individuals, when they acquire know. ledge, promote progress by doing so ? present inquiry, and ask how do these individuals who alone strongly desire truth, and have the faculties for discovering it, perform the practical part which Mill so rightly assigns to them? By what kind of conduct do they become "agents of social progression," so as to raise communities from the level of helpless savagery and gradually endow them with all the resources of civilisation? One thing is perfectly clear. They do not so by the mere act 
of acquiring knowledge, by laying up this treasure in a napkin, or by showing it secretly to one another. They do so only by diffusing it, in such measure as is practicable, amongst a circle of men much wider than themselves. They do so, that is to say, by influencing the minds of others, by guiding their attention to this and to that fact, by providing, as it were, a go-cart for their weaker intellectual faculties, and compelling them to confront and assent to such and such propositions. All that mass of developing knowledge and expanding ideas which forms not only the basis but a part of all progressive civilisation, and is commonly called by the general name of enlightenment, is produced solely by the influence on average minds of the minds that are "decidedly exceptional." It is not produced by the fact that Theypromote the "decidedly exceptional" minds are stocked with conveying their such ideas and with such knowledge themselves, and imposing but by the fact that they communicate such a $a_{\text {clusions on, }}^{\text {their }}$ measure of these to average minds as average others. minds are severally able to receive.

To realise the truth of this we need do no more than consider for a moment the ordinary process of education. The schoolmaster and the college tutor, by the State or some other authority, are compelled to give their pupils instruction in certain subjects. But there is another kind of compulsion involved in the matter also; and this has to do not with the selection of the subjects that are to be taught, but with what is to be taught about them. The general progress of a community depends 
Book II primarily upon this; and what is to be taught about Chapter 2 them is determined not by the State, or by any other legally constituted body, but by the masters of speculative knowledge, by contemporary men of science, scholars, historians, and philosophers. Knowledge advances because these men are not only adding to it, but because they are perpetually assimilating the new discoveries with the old; and these men, by means of their comments on previous writers, or by new works of their own, often reproduced in the form of text-books, put the word into the teachers' mouths; and the teachers, like the prophet Balaam, are compelled to speak it. In other words, great speculative thinkers are great as agents of mental civilisation and enlightenment only because, and only in so far as, they settle for others what these others shall believe and think.

A similar thing And now let us pass from mental progress to is true of in-
vention, which material - that is to say, from speculative knowledge is knowledge applied. to applied knowledge; and the truth that is being here insisted on will become clearer still. The master of knowledge, as applied to production, is the inventor. Now the most perfect and important machines ever devised by man - let us say the steam-engine and the printing press - had they been planned by their original inventors in all their present completeness, but kept by the inventors to themselves in the form of working models, made by their own hands and shut up in their own rooms, would have left the arts of life totally unaffected; our fastest means of travelling would still be the stage-coach; 
our few books would be produced by the methods of the medixval scriptorium. These machines are Book 11 Chapter 2 instruments of social progress only because, and in so far as, they are multiplied and brought into use; and they could not be multiplied-as efficient implements, they could not be even made-without the co-operation of an enormous number of workers. It is probable indeed that in constructing the very model itself an inventor will have to employ some labour besides his own. Thus this first and preliminary step towards rendering his apparatus a moles progres factor in social progress he can take only by ine inventor influencing one or two other men, at all events - $\begin{gathered}\text { actions of the } \\ \text { workmen who }\end{gathered}$ artisans whose technical action he directs in such make and use a way that it produces something specifically different from anything which it had produced before; and as the apparatus is reproduced on a larger scale, put on the market, multiplied so as to meet a growing demand, and thus actually produces an effect on the arts of life, this practical result takes place only because, and in so far as, the number of artisans whose action is influenced by the inventor increases. The inventor, in other words, is an agent of "social progression" only because the particularised knowledge of which his invention consists is embodied either in models, or drawings, or written or spoken orders, and thus affects the technical action of whole classes of other men, just as Mr. Spencer affects, by means of his manuscript, the technical actions of the compositors who put his treatises into type. 
Book II

Chapter 2
The man of business ability promotes progress also only by so ordering others that the precise wants of the public are supplied.

Material progress, however, depends not only on the inventor and his machine. It depends also on the uses to which his machine is to be put. Here we shall find a new kind of greatness to be necessary - that which is called business ability; and we shall find that this operates precisely like the greatness of the inventor, through the influence which its possession exercises over other men.

All progress or development in commerce and in the arts of production is in proportion to the correspondence in every place and season of the goods brought into the market with the contemporary wants of the buyers. If it were not for this correspondence of the economic supply with the demand, progress in production would not be social progress at all; for just as a community does not become materially civilised by the mere act of wanting what it cannot get, so it does not become materially civilised by being presented with what it does not want - clothes, for example, which it could not possibly wear, and books in an unknown language, which it could not possibly read, or diminutive houses and furniture fit only for dolls. Now in any progressive community the wants of the buyers are in constant process not only of development but fluctuation, and are rarely quite the same in any two localities simultaneously. In order, therefore, that what is supplied may be in correspondence with what is wanted, it is necessary that in each industry the nature of the commodities produced be continually modified by men with a 
special sort of knowledge of the world; and also, since want, in the sense of efficient demand, depends Book II on the price at which these commodities can be supplied, it is necessary, just as it is in the case of the manufacture of machinery, that the army of men whose labour is involved in producing them shall be subject to men who, by their powers of industrial generalship, will be able to reduce the cost of reproduction to a minimum. Every business, in fact, and every industrial enterprise, succeeds or fails, not according to the amount of average labour involved in it, but according to the talents and energy by which this labour is directed. Thus in the economic domain, even more than in the intellectual, the great man is seen to be an agent of "social progression," in virtue not of the results which he himself produces by the direct action of his own hands or brain, but of the results which, being what he is, he causes to be produced by others.

And now having dealt with the great man as an And the same agent of speculative progress, which, as Mill says, obviously true is at the bottom of progress of all other kinds, and in the domains having dealt with him also as an agent of that and religion. manufacturing, commercial, economic, or material progress which Mill cites as the chief example of what practical progress is, and having shown how the essence of his greatness is his power of influencing others, let us illustrate this truth finally by a brief reference to three other kinds of human and social activity which exhibit it 
$\underset{\text { Chapter } 2}{\text { Bil }}$ in a light so obvious that it requires no explanation. These three kinds of activity are the military, the political, and the religious. The great soldier, as has been said already, is essentially the great commander - the man who makes others act and group themselves in a specific way. The statesman not only aims at benefiting his countrymen generally, but he achieves his aim by the same means as the soldier, namely, by influencing the actions of others in certain specific respects; whilst the man who is socially great in the domain of morals and religion is the man whose teaching and example affect the actions, and even the inmost feelings, of multitudes, or gives precision to their faith.

But here, having reduced to a truism this important truth that the great man, as an agent of social progress, is great only because he is able to exercise Greatness, a specific influence over others, it is necessary to however, is not turn our attention to a different order of facts altoequally beneficial.

gether. Greatness, as we have seen already, is of very many kinds. It is a varying compound of various and variously developed qualities; and its degree is measured by its efficiency in producing this or that result by which society is benefited. But greatness, in the sense of exceptional power of so influencing others that some given result shall be produced by them, has other varieties besides those that have been already mentioned. Each domain of progress has not only its own leaders, but it has leaders who desire to lead men in very different directions. There are scientists 
with conflicting theories, inventors with rival inventions, statesmen with rival policies. It follows accordingly that though all these men may be pos- The influence sessed of talents indefinitely above the average, they would not all of them, were their influence over other of some great men is more advantageous men equal, affect society in an equally advantageous others. that of way. Some men, indeed, whose talents are "decidedly exceptional" would, on account of some flaw or defect in their character, not promote, but, on the contrary, retard true progress, in exact proportion as they made their views prevail. Thus, though all progress is due to great men, all great men would not promote progress; or they would, at all events, not promote it equally. Progress, therefore, as Progress, then, resulting from the actions of great men, depends on involves a the degree to which certain of them make their own through which views prevail, and secure the rejection of others which are directly or indirectly opure influwhich are directly or indirectly opposed to them. ence over It depends, that is to say, on a keen competitive destroy the instruggle which is continually taking place within the fluence of the limits of the exceptional minority.

And here we come to that further point of We now come difference, which still remains to be noticed, point of differbetween the part played in social progress by the fittest great the great man, and the part in it played by the $\operatorname{man}$ and the fittest according to the Darwinian theory. Two points of difference between them have been noted and explained already, one being that the fittest man promotes progress only because he raises, by a physiological process, the average capacities of his successors, whereas the great man promotes prog- 
Book II Chapter 2

The social counterpart to the Darwinian struggle for survival is to be found in the struggle of labourers to find employment.

ress because he is himself more capable than his contemporaries; the other being that the fittest fulfils his social function by fighting for his own hand, without any reference to others, whereas the great man fulfils his solely by influencing others. We are now coming to a third point, which is, for practical purposes, even more important than the preceding.

The great-man theory, just like the theory of Darwin, involves a competitive struggle. This struggle is a struggle between great men; and its existence is a fact of too obvious a character to have escaped the notice of even the most inaccurate of our social evolutionists. But they one and all of them have completely misunderstood its nature. They have hastened to identify it with the Darwinian struggle for existence, from which it differs in the most vital manner conceivable; and, obscuring it thus by a loose and misleading analogy, they have managed to blind themselves to its entire practical significance. The Darwinian struggle for existence no doubt has its counterpart in the contemporary competition of labourers to find remunerative employment, and in the fact that those who are least successful in finding it would, if left to themselves, be continually dying off. In a progressive country there is, or there always tends to be, a larger number of would-be labourers than there is of tasks which at the moment can be profitably assigned to them. A struggle therefore is involved in obtaining work of any kind; and for the higher kinds of work the struggle is very keen. But this is not the 
struggle to which modern progress is due. Progress, in the sense of the rapid and appreciable Book II Chapter 2 movement which alone concerns us here, is - to confine ourselves for a moment to the domain of industry - not the result of a struggle to execute work in the best way, but is the result of a struggle to give the best orders for its execution. It presupposes the existence of a certain amount of skill; but it does not, except in its very earliest stages, depend on the struggle of so many thousand men, each to become individually a more skilful worker than his fellows. It is, on the contrary, when its earliest stages have been passed, so independent of But this is not any further increase of skill in the individual worker, to which histhat it continues its course whilst skill remains is due; stationary.

This is shown by the fact that some of the greatest advances ever made in material civilisation have been made during the active lifetime, and with the aid of the hands and muscles, of a single generation of workers, and has implied no improvement at all either in their acquired faculties or their inherited. Let us take, for instance, the introduction of the electric light, and the way in which it is superseding gas. The mechanics first employed to make the appliances for its production were none of them asked to perform any task which required on their part any new knowledge or dexterity. All they were asked to do, and all they did, was to submit their existing faculties to some new external guidance: and the electric light, in so far as it has superseded 
Book II gas, has superseded it not because it is the product of more skilful labour, but because it is the product

The progressive struggle in industry is confined entirely to the employers ;

of manual labour directed by a set of inventors and employers, who, so far as regards certain social requirements, direct it more successfully than another set. The struggle which it represents is a struggle between employers only. It does not, except by accident, represent any struggle between the employed.

And what is true of the struggle which produces and in every industrial progress, is true of that which produces
domain of progress it is confined to the leaders, not to the exclusion of those who are led. progress of all other kinds. Scientific knowledge increases in proportion as those exceptional individuals whose studies have brought them most near to the truth are able to fight down the opinions of the exceptional individuals who differ from them, and to impress their own undisputed upon the world. Such knowledge does not increase on account of any struggle amongst the learners, which causes some of them to become more and more apt in learning. It grows on account of a struggle between philosophers, each of whom aims at settling what the learners shall learn. And with regard to religion and politics the case is just the same. The progressive struggle is primarily between rival prophets and politicians. The spread of Christianity, for instance, was not brought about by Christian races exterminating those that were not Christians. It was brought about by Christian thinkers and teachers discrediting the doctrines taught by thinkers and teachers who were opposed to them. Free-trade, 
again, in this country has not triumphed over protectionism, because the mass of free-traders have Book II exterminated the mass of protectionists. It has triumphed simply because, in the eyes of the majority, one school of theorists has succeeded in discrediting another.

Now these facts, which, when once stated, are so In the proobvious, not only throw the Darwinian struggle for gressive existence altogether into the background as an between great agent in social progress, but they show that it pre- of the $\begin{gathered}\text { community } \\ \text { cons }\end{gathered}$ sents us with no true analogy to that kind of struggle play no part from which progress principally results. They show us, on the contrary, that the struggle which produces social progress, though it resembles the Darwinian struggle in one point, is in all other points contrasted with it. The struggle of one employer against another to direct labour in the most advantageous way, or the struggle of one politician or religious teacher against another to secure for his own views the largest number of adherents, is so far like the Darwinian struggle for existence, that it is a struggle in which individual is pitted against individual, and the gain of the successful is the loss of the unsuccessful. But the limits within which this struggle is confined are very narrow indeed; and the mass of the community takes no part in it whatsoever.

In order to show this with the utmost clearness possible, let us turn again to the domain of economic progress, which generally supplies the sociologist with his simplest and most luminous illustrations. 


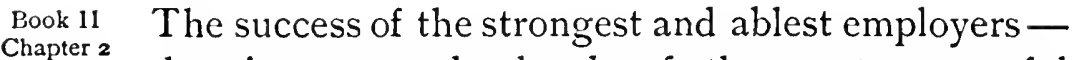
that is to say, the heads of the most successful Let us take, businesses - may involve, and does involve, their two rival hotel- selection for survival as employers, and does involve keepers.

the extinction, as employers, though not necessarily as men and parents, of their weaker and less able rivals; but it involves no struggle for existence with the men employed by them - that is to say, with the great masses of the community. Two men, we will say, start rival hotels, and each begins with a staff of a hundred persons. One of the two understands One becomes his business far better than the other. His hotel is
bankrupt, and the other takes over his hotel and his staff.

always full, whilst his rival's is half empty. The latter at last becomes bankrupt; the former buys his business, and together with his premises takes over his staff. He employs two hundred persons, instead of a hundred as at first; the hotel of the bankrupt, which the bankrupt ran at a loss, now yields the same profit as the other; and the aggregate takings of the two are thus increased largely. Here we have a community of two hundred and two persons offering a marked example of great material progress; and this progress has been the result of a genuine struggle for existence. But the struggle for existence has been between two persons only - that is to say, between the two hotel-keepers. As hotelThe sole
struggle here is between the struggling for, and the survival of the one has meant employers, not the disappearance of the other; but between them and the two hundred persons employed by them there has been no struggle at all. The achievement 
by the successful hotel-keeper of a fortune double that with which he started has not involved any diminution in the wages of his staff. It will, on the The staff of contrary, if we are to take the case now in question ful hotel-keseper as typical of the survival of the fittest employers $\begin{gathered}\text { gain, not lose, } \\ \text { by being em- }\end{gathered}$ generally, have not only not diminished their wages, ployed by the but very largely increased them. For here there is one further truth which naturally introduces itself to our observation. Whatever allowance it may be necessary to make for the lowest class or residuum of our modern populations, it is the most clearly proved and prominent fact in modern industrial history - and one which even socialists are now ceasing to deny - that along with the vast increase in wealth which the ablest employers have, by their struggle with rivals, secured for their own enjoyment, there has been not a corresponding diminution, but a corresponding increase in the means of subsistence that have gone to the population generally. The average income per head in this country of that class - composed mainly of wage-earners - which does not pay income tax has, in terms of money, nearly trebled itself during the present century; its purchasing power has increased in a yet larger ratio, and its increase will be found to have been most rapid and striking at periods when the struggle amongst the employing class has been keenest.

It will thus be seen that the struggle which pro- Historical duces economic progress - and progress of every results from a kind is produced in the same way - is not a general ${ }^{\text {struggle }}$ 
Eook II struggle which pervades the community as a whole; neither is it a struggle between the majority and an not for sub- exceptionally able minority, in which both classes
sistence, but fordomination. are struggling for what only one can win, and in which the gain of the one involves the loss of the other; but it is a struggle which is confined to the members of the minority alone, and in which the majority play no part as antagonists whatsoever. It is not a struggle amongst the community generally to live, but a struggle amongst a small section of the community to lead, to direct, to employ, the majority in the best way; and this struggle is an agent of progress because it tends to result, not in the survival of the fittest man, but in the domination of the greatest man. 


\section{CHAPTER III}

THE MEANS BY WHICH THE GREAT MAN APPLIES HIS GREATNESS TO WEALTH-PRODUCTION

THE whole secret of social progress, other than the most rudimentary, is summed up in the formula with which the preceding chapter has concluded. Progress is the result of the domination or the triumphant influence of the greatest. That is to All gain by the say, the civilisation of the entire community de-mination of say, the civilisation of the entire community de- the fittest, pends alike for its advance and for its mainten- except the few ance on a struggle which is confined within the secure power limits of an exceptional class; and the ordinary members of the community are connected with it only by the fact that when the fittest competitor achieves the domination for which he is struggling, they, instead of being defeated by him, share the advantage of his victory. When the scientific doctor discredits the theories of the quack, when the competent organiser of industry causes the ruin of the incompetent, when a good ministry drives a bad from office, when a great general supersedes one who is inferior, or when a true religious teacher destroys the influence of a false, the whole community gains, except the men who have personally lost 
Book II Chapter 3

We must consider, however, that the great men who struggle for domination would not do so without some strong motive : authority, and who share the merited fate of their own errors or deficiencies.

The progress and the maintenance, then, of civilisation in any community depends on its possessing a number of great men, of which number the greatest shall, by competition with the others, succeed in gaining a control over the beliefs and actions of the majority.

Here, however, we are introduced to two new sets of facts, which have not thus far come under our consideration at all.

In the first place, great men do not come into the world ready-made. Their greatness is potential only, or in other words it is practically non-existent, until it has been developed; and the process of developing it is in most cases extremely arduous. The philosopher, the soldier, the inventor, the statesman, the great merchant or manufacturer, achieve success only by prolonged and intense effort, by study, by concentrated thought, by action, by rude experience. Genius, indeed, has been defined as an infinite capacity for taking trouble; and the definition, though very incomplete, is, so far as it goes, true. No one, however, takes trouble without a motive; and a motive being some object of desire, such as money, rank, or pleasure, which a man hopes to attain by a certain line of action, it follows that if a community is to possess great men as actual agents of progress, and not merely as wasted potentialities, its social constitution must be such as to offer and make attainable positions, possessions, 
pleasures, or other advantages which its potentially great men will feel to be worth working for.

Book II

Chapter 3

In the second place, since the great man, as we and also that have seen, is an agent of progress and civilisation tominate only because he influences others - because he guides others except their speculative beliefs, and in certain respects ticular means. commands their actions - the society or community to which the great man belongs must be such as not only to supply him with a motive for exercising this influence, but also to enable him to secure for himself the means by which it may be exercised; and, furthermore, the means in question must be of a kind which will enable the rival great men to bring their respective capacities to a decisive practical test, so that the influence of the most efficient may establish itself, and that of the less efficient cease.

Now the whole question of motive we will deal Now the queswith later on. We will for the present put it we will treat altogether aside. We will assume a natural impulse of hereafter. on the part of all great men to develop their powers will confine to the utmost, and employ them in influencing the question of others, wholly independent of any other reward than such a minimum of sustenance and comfort as is physically essential to their efficiency; and we will confine our attention altogether to the question of the means by which the influence of the great men over the majority is obtained.

Human progress, however, being a complex thing, These vary in and taking place in different domains of activity, of social the means by which the great man influences others ${ }^{\text {activity. }}$ will vary with the nature of the results which his 
Book II influence aims at eliciting. The social activities on which progress depends, though they may be subdivided indefinitely, are reducible to five kinds intellectual, religious, military, economic, and political; and with regard to the two first, the influence of the great man exerts itself to determine what others shall believe and think; with regard to the three last, it exerts itself to determine what others shall do.

In some they are too obvious to need discussion.

Now out of these five domains of activity the three first - namely, the intellectual, the religious, and the military - are such that the means by which the great man makes his influence felt in them hardly require discussion. In the first place, they are obvious - there is no dispute about what they are; and, in the second place, the fact of their being what they are has no bearing, except such as is very remote, on any disputed question concerning the practical organisation of society. In the intellectual world thinkers, scholars, and men of science gain their influence by discussions, for the most part embodied in books, which discussions are carried on before a jury of expert critics, each man defending his own views against the views of those who differ from him; and the jury of experts ultimately gives its verdict, to which sooner or later the community at large submits. The religious leader gains his influence similarly. He gains it by arguments and persuasions, which are felt by a band of followers to touch the spirit more deeply than those of other prophets. He gives to his disciples, and his 
disciples give to the multitude. But these means are of so universal a kind, and have so little conBook II nection with any specific social arrangements, that none of the disputed points of social politics are involved in them; and we consequently have at present no occasion to discuss them. So, too, with regard to the military leader, though the means which are employed by him do, beyond a doubt, imply social arrangements of a very specific kind - namely, an iron system of discipline, with death and the lash to sanction it; yet these arrangements, however they may be denounced by sentimentalists, have always been found essential to the efficiency of every army; and though many worthy people would abolish military activity altogether, and whilst socialists especially express themselves anxious to do so, it is perfectly evident - nor would any socialist deny it - that a socialist State, if it had to fight for its existence, would be obliged to enforce the required military discipline by methods essentially identical with those of Cæsar or Wellington. It may, indeed, be disputed whether the great military leader is not a superfluous figure on the social stage; but so long as his greatness makes itself felt at all, it will continue to make itself felt by the same means.

The only domains of social activity, therefore, in we need con. which the means employed by the great man to are only in control the actions of others so that ordinary men ${ }_{\text {of politics and }}^{\text {the }}$ may be guided by the faculties of the exceptional - of wealth-prothe only domains of activity in which these means, 
Book II thus employed, really require minute and careful discussion, and have really a direct bearing on the practical problems of the day - are the domain of economic production and the domain of political government. These, indeed, may be said to contain between them the whole of the questions with regard to which parties are divided - with regard to which those who believe that the conditions of civilisation may be indefinitely improved but can never be fundamentally altered, are divided from those who believe them to be capable of indefinite metamorphosis.

The question is most important in its bearings on wealth-production.
This is specially true of the domain of economic production; for it is mainly on account of its connection with the production and distribution of wealth that political government excites so much popular interest and forms the subject of so much vehement controversy. And in every other domain of human activity equally, we shall find that the interests, the endeavours, and the disputes of men have an economic process as their basis, or economic progress as their object. The processes of production and commerce are, in fact, the central processes of every nation's life. Government exists to foster them, and changes its form as these processes develop, whilst fleets and armies exist mainly for their protection, and more and more depend on the progress that takes place in them. It is, in short, in the domain of economics that all the social problems of the day either begin or end; and consequently in examining the means by which the great man influences others, the question which it is 
really our first concern to examine relates to the means by which great men, whose greatness consists in the fact that they are exceptional in their powers of causing the production of wealth, and on whom consequently the wealth of the whole community depends, obtain a control over other men's productive actions.

This control can be secured in two ways only, The great man or else in some way that is a combination or modi- in wealth-profication of both. One of these ways is slavery; the influence the other is the capitalistic wage-system. Let us con-by two means other is the capitalistic wage-system. Let us con- only - by the sider how the two resemble each other, and also how slave-system they differ. and the wagesystem.

They resemble each other because both, in so far as they subserve progress, subserve it for precisely the same reason. They are both contrivances by which the superior few may secure, so far as industry is concerned, the implicit obedience of the many. On the private lives of the many their effects will be widely different; but so far as concerns their direct connection with industry - their operation on men obedience by during the actual processes of production - slavery wage-system and the capitalistic wage-system differ only in this: that the one secures the required industrial obedience by operating on men's fears; the other secures it by operating on their desires and wills. Thus the slaves who built the pyramids had each some specified task - the making of so many bricks, the cutting of such and such stones, or the fixing of bricks and stones in such and such situations - which had to be performed if the pyramids were to be built at all. So, too, if the Hotel Metropole at Brighton was to 
Book II be built at all, the bricklayers, masons, and other workmen who built it had to perform tasks of a precisely similar kind. But obedience to orders on the part of the Egyptian slave was secured by the knowledge on his part that disobedience would be punished by some form of chastisement, and very likely of torture, whilst obedience on the part of the Brighton workman was secured by the knowledge on his part that, unless he chose to yield it, one way, at all events, of earning a livelihood would be closed to him.

It is this latter method of securing industrial obedience that is made possible by the capitalistic wage-system; and it is primarily for this reason that what is called capitalism is an agent of progress, and has developed itself in progressive communities. As for capital itself, this, as we all know, performs part of its functions by assuming the form of machinery, buildings, bridges, railways, and a variety of structures and appliances which are grouped together under the general head of fixed capital by economists. But these structures and appliances are Wage-capital, themselves the result of the previous influence of
not fixed not fixed
capital, gives the primary power to capitalism as a progressive agent. great men on the industrial actions of the many; and as it was by means of wage-capital that this influence was secured, the primary and most essential functions which capital fulfils, and which really form the essence of the capitalistic system, are to be found by considering capital as employed in the payment of wages.

Now capital as thus employed consists of an 
accumulation of the necessaries and comforts of life, by the consumption and use of which men are able to Book II

Chapter 3 sustain themselves when engaged on works requir- Wage-capital ing a long period for their completion, which will is an accumuwhen completed be useful and produce much, but saries of life, which, until they are completed, will be of no use at all, and will consequently supply nothing to the workers when actually engaged on them. The simplest example of work of this kind is agriculture. The first man who saved sufficient food to support himself, whilst tilling the soil and waiting for his crops to ripen, was the first capitalist. But capital, when it takes the form of accumulated necessaries and comforts, though it now reaches the workers in the form of wages usually, need not do so of necessity. It need not do so when the work is extremely simple and the methods employed are rude. Whereever agriculture, for example, is in its earliest stages, every husbandman may be his own capitalist, and start with an accumulation of food in his own cottage which will keep him alive till his crops are ready for sale or for consumption. In cases such as these we have capital which, so far as its substance is concerned, is identical with wage-capital, but is not wage-capital nevertheless. In order to turn it into owned or conwage-capital it is necessary that these accumulations frow persons of food shall pass out of the control of the workers - such as the husbandmen just referred to - and be brought under the control of some other person or persons, who will dole them out to the workers on certain conditions only. The wage-system, in short, 
Book II does not represent capital as such. It represents Chapter 3 capital, in the form of the immediate means of subsistence, as owned or controlled by a small number of persons; and its efficiency as a productive agent resides in the bargain which it enables any great and appor- man possessing it to make with ordinary workers tioned by them a bargain, not that they shall work such and such a
amongst many, on certain conditions. number of hours (for that they would have to do were each man his own employer), but that they shall do their work in accordance with the great man's directions.

Now this fact that the wage-system represents the control of capital by the few - and this is its essential characteristic - is the fact on which, more than on any other, the socialistic opponents of the modern wage-system insist. They are never weary of insisting that it has its foundation in a monopoly. But though they perceive the fact, they entirely Karl Marx
entirely misunderstood what these

capitalists as a body of men who, so far as production is concerned, are absolutely inert and passive. Owing to a variety of causes, he says, during the past four hundred years all the means of production have come under their control, and access can be had to them only, as it were, through gates, of which these tyrants hold the key. Outside are the manual labourers, who are the sole producers of wealth, but who, without the means of production, naturally can produce nothing not even enough to live on; and the sole economic function which the capitalist fulfils is to let the 
labourers in every day through the gates, on the condition that every evening the unhappy men Book II render up to him the whole produce of their labours, except that insignificant fraction of it which is just necessary to fit them for the labours of the day following. Now it is no doubt theoretically possible that a society might exist, composed of a mass of undifferentiated and undirected manual labourers on the one hand, and on the other of a few passive monopolists who extracted from them most of what they produced, as the price of allowing them the opportunity of producing anything; but it is perfectly certain that a society of this kind would exhibit none of the increasing productive power which, as even Marx and his school admit, is one of the most distinctive features of industry under the capitalistic wagesystem. Under that system productive power has increased, not because capital has enabled a few men to remain idle, but because it has enabled a few men to apply, with the most constant and in- The essence of tense effort, their intellectual faculties to industry in $\begin{gathered}\text { these con- } \\ \text { ditions is that }\end{gathered}$ its minutest details. It has increased not because the many shall the monopoly of capital has enabled the few to say directed by the to the many, "We will allow you to work at nothing, unless you give us most of what you produce," but because it has enabled them to say to the many, "We will allow you to work at nothing, unless you will consent to work in the ways that we indicate to you."

The few, so far as our present argument is 

Book 11 concerned, may appropriate much of the gross product or little; or they may leave the whole of it to be divided amongst their employees. What

The question of how much the few appropriate of the product is a separate question altogether.

The corvée system or slavery would make wagecapital superfluous; and thus they show us what the essential function of such capital is.

they actually have done, or do, or may do, in this respect, is another question altogether, and will be discussed hereafter separately. The essence of the wage-system, in so far as it has influenced the actual processes of production, is in the power it gives to the few to direct the producers, not in the power it gives them to appropriate the products. It will indeed require very little reflection to show us that if the great men in the industrial world would only develop and use their faculties, without any motive of ambition or self-interest to stimulate them, - as indeed at the present moment we are assuming that they do - they could use the wagesystem for the purpose of directing industry merely by monopolising the control of capital without monopolising, and even without sharing in, its possession.

This truth will become plainer still when we reflect that if only certain conditions prevailed which in many civilised countries survived till quite recently, the whole process of production as we now have it might be carried on without any wagecapital at all. These conditions are those of the corvee system, under which peasants and others who owned the lands upon which they lived, and maintained themselves on those lands in a certain position of independence, were compelled to place their labour, for so many days a week, at the absolute 
disposal of this or that superior. Such a system, if applied to modern industry, would have, no doubt, Book II Chapter 3 many incidental disadvantages; but if only a number of independent peasant-proprietors could be forced to give half their time to the proprietor of a neighbouring factory, and during that time to work in it under his orders, the entire use and necessity of wage-capital would in theory, at all events, be gone. The same thing is also true of slavery, between which and the wage-system the corvee system stands midway. Like the peasant-proprietor, who is forced to give part of his labour to his over-lord, the slave is supplied with the necessaries of life independently of his obedience to the detailed orders of his task-master. The peasant maintains himself by tilling his own fields; the slave-owner feeds his slave just as he would feed an animal. In neither case is the giving or the withholding of a livelihood used as the motive or sanction by which industrial obedience is ensured. Obedience is ensured by the direct application of force, or the knowledge on the slave's part or the peasant's that force will be applied if necessary.

It will, no doubt, be urged by some that whatever So-called "coassistance is afforded by the talents of the few to the operation" industrial efforts of the many, may be secured by $\begin{gathered}\text { wagc-system } \\ \text { disguised. }\end{gathered}$ a third means, which is neither slavery nor yet the wage-system - that is to say, by what is called the system of "co-operation." Co-operative production, however, when it differs in anything except in name from production as carried on under the ordinary 


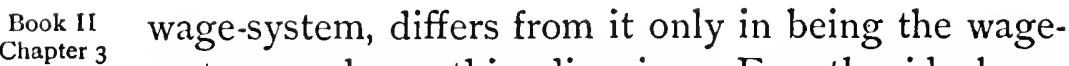
system under a thin disguise. For the ideal cooperative factory is simply a factory in which all the shareholders are workers, and all the workers are shareholders, and in which, being shareholders, they elect their manager. Under such conditions, each of these working shareholders may receive his remuneration under the form, not of wages, but of profits. But if any shareholder, or any group of shareholders, should systematically shirk working, or disobey the manager's orders, the whole or a part of the payment that would be otherwise due to him would be withheld; for unless some regulation of this kind were in force, it would be impossible to ensure any co-operation amongst the co-operators, or any order, or any equality of diligence. Each worker's profits, then, are in reality his wages, being essentially a payment which is made to him only on condition that he performs certain specified tasks in a certain specified way.

There are, then, only two We are thus brought back to the point from which alternatives - we started - namely, that there are two methods only the wagesystem and the slave-system; by which, in the domain of industry, the superior faculties of the few can direct the faculties of the many: firstly, the capitalistic wage-system, which is the method of inducement; secondly, slavery, complete or partial, which is the method of coercion. And of the truth of this assertion the reader shall now be presented with a highly interesting and curiously conclusive proof, taken from the very last quarter in which he would naturally expect to find 
it. This proof is afforded us by the schemes which, with ever-increasing clearness, have of recent years Book II Chapter 3 been put forward by all the more thoughtful socialists.

These enthusiasts, who are still careful to tell as we shall us that they regard the wage-system as the source sidering how of all social evils, have been slowly coming to can only perceive that the ability with which the labour is $\begin{gathered}\text { escape the } \\ \text { wage-system }\end{gathered}$ directed is as important a factor in production as the by substituting labour itself, which is directed by it. They propose accordingly to regenerate the human race by transferring the ownership of capital from private employers, not to groups of factory-hands, as the "co-operators" propose, but to the State; and by substituting for the private employers a hierarchy of State officials. Now these officials, so far as the wage-system is concerned, if they differed at all from private employers of to-day, would and could differ from them in the following way only. The present dispensers of wages assign the means of subsistence to each worker in proportion to the exactness, intelligence, and efficiency with which he obeys orders. The dispensers of wages under socialism would dispense these means daily to every worker alike, with no immediate reference to his industrial actions whatsoever; and the direction of his actions would be a second and wholly distinct process.

That such is the case is shown, and indeed distinctly admitted, in a preface to the American edition of Fabian Essays. It is there stated that 
Book II with regard to the apportionment of the means of subsistence, the only "truly socialistic" scheme is one which would "absolutely abolish" all economic distinctions, "and the possibility of their again arising, by making an equal provision for the maintenance of all an incident and an indefeasible condition of citizenship, without any regard whatever to the relative specific services of different citizens. For they would The rendering of such services, on the other hand, secure industrial obedience by coercion, instead of being left to the option of the citizen, with the alternative of starvation, would be required under one uniform law or civic duty, precisely like other forms of taxation or military service."

Such, then, is the most advanced socialistic programme - the programme of the men who have set themselves to devise an escape from capitalism. An escape from capitalism it may be; but it is an escape into complete slavery. For the very essence of the position of the slave, as contrasted with not through the wage-labourer, so far as the direction of his
the worker's own desire to earn his living. productive actions are concerned, is that he has not to work as he is bidden in order to gain his livelihood, but that, his livelihood being assured to him, he has to work as he is bidden in order that he may avoid the lash, or some other form of punishment; and amongst all the more thoughtful socialists there is now a consensus of admission that the socialistic State would necessarily have in reserve the severest pains and penalties for the idle and the careless and the disobedient.

Since, then - let us once more repeat it - the 
progress and maintenance of economic civilisation depend, as even socialists are now beginning to perceive, on the industrial actions of average men being subjected to the control of exceptional men, and since this control can be secured by two methods only - that of the wage-payer and that of the slaveowner - it is evident that all progress and civilisation implies the existence of either one system or the other, and that socialists accordingly, in proportion as they reject the wage-system, are obliged to replace it by what is essentially the system of slavery.

We have thus far, however, dealt with but one half of our subject. We have considered merely the Next let us means by which any one great man exercises indus- means by trial control over the actions of a number of ordinary ghich the men. We have still to consider the means by which of industry the most efficient of the great men get this control against one into their own hands, and take it out of the hands of the less efficient.

Under the regime of private capitalism this process Under capitalis simple. The fitness or efficiency of each great so, owing to man is according to the acceptability to the public the fact that of the goods or services which he offers them. If cannot direct the public are not pleased with these goods and ser- to please the vices, they do not buy or demand them; and the capi- public, loses tal of the man by whom they are offered, not being $\begin{gathered}\text { with it the } \\ \text { means of }\end{gathered}$ renewed by any money received, melts in his hands, direction. and with it his control over other men's labour. Meanwhile, by a converse process, the great men who offer goods and services which the public desire 
Book II

Chapter 3

The wagesystem is the only efficient means of com. petition of this kind.

The socialists, though they affect to be opposed to competition altogether, and find serviceable, renew and increase by their payments the capital which has been disbursed by him, and renew and increase his control over other men's labour along with it.

Now if the wage-system is the sole alternative to slavery as a means by which the great man controls the actions of the ordinary man, it is still more obviously the sole alternative to slavery as a means by which one great man, in controlling them, shall compete against another great man. Indeed, we may speak still more strongly. We may say not only that it is the sole alternative means, but that it is the sole efficient means. And if we desire a proof of this, all we have to do is to repeat our former procedure, and consider how the socialists propose to supply its place.

It is, no doubt, true that when we first begin this consideration it does not appear that we should derive from it much direct enlightenment; because, if we may go by what the socialists themselves tell us, one of their principal objects is to abolish competition altogether. Their protestations, however, with regard to this matter betray a most curious and most amusing confusion of thought. They declare that competition must be abolished because it inflicts misery on the majority - that is to say, on the weakest in what they call the "cut-throat struggle." But, as was shown at great length in the last chapter, competition means two, and two absolutely distinct things - one being a struggle to live, the other a struggle to dominate; and 
the effects of the two on the majority are altogether different. To this fundamental truth the socialists are completely blind. The struggle to live, or, in other words, the struggle to secure employment, no doubt, when it is severe, does entail suffering on the strugglers. But this struggle, though it often accompanies progress, under the capitalistic system is not essential to it - as is shown by the fact that when such progress is most rapid the struggle in question tends to disappear altogether; for the competition is then amongst the employers to find labour, rather than amongst the labourers to find employment. Now if the struggle for employment could be obviated by any kind of social reform, an indubitable benefit would, no doubt, be conferred on the workers generally. But just as this struggle for work or for existence - this struggle of one worker against another - is not essential to the capitalistic wagesystem, and certainly did not originate with it, and just as that system would not necessarily be abolished by its overthrow, so it is not the kind of competition against which the socialists direct their main attacks. Their main attacks are directed against the struggle between the wage-payers, not the wage-earners - that is to say, against the struggle not for existence, but for domination; and the struggle for domination has on the workers generally no evil effects at all, except such as are occasional and accidental. On the contrary, the workers are as much interested in its maintenance as anybody; for 
Book II not only does it inflict no injury on themselves, but to it that progress in the processes of production is due on which their own hopes depend, as much as do those of their employers. Accordingly, the socialists, profound thinkers as they are, propose to abolish the competition by which the workers benefit, because they confuse it with competition by which the workers suffer. The point, however, which concerns us here is not that they have made a blunder as to the kind of competition which they re-introduce it should attack, but that the kind of competition

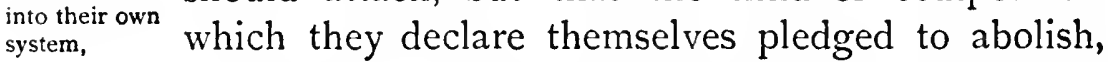
as a thing accursed, and the root of all social evils, they really reintroduce into their own programme, altered only by being associated with the system of slavery, and by being robbed of its practical efficiency, and robbed of nothing else.

the only change being that it is associated with the slavesystem, which is very cumbrous and inefficient.
For our contemporary socialists, who have at last come to perceive that the productivity of labour depends on the ability with which it is directed, perceive also the fact that, out of many possible directors, some would direct it far more efficiently than others. They also perceive the fact that the directors of labour, who, according to their proposals, would be officials of the bureaucratic State, could prove their efficiency only by practical experiment. Now if all capital were, as socialists propose it should be, owned by the State, and if all the means of subsistence were apportioned amongst the citizens equally, without reference to the work performed by them; and if all the directors of labour, whether inventors or business 
organisers, had to act as State officials, or else not act at all, the practical experiments necessary to Book 11 show which officials were the fittest could be brought about only by the State investing such and such of them with a quasi-military power over so many regiments of labourers for such and such a time, which power would be renewed if they could persuade the State to reappoint them, or taken from them if the State should be persuaded that some other men, their rivals, would employ this power more usefully. And this is precisely what the proposals of the socialists come to. The whole multitude of State officials who would direct socialistic industry would, according to every socialistic programme, be appointed, promoted, or degraded to the ranks of ordinary workers in accordance with the efficiency shown by them in the practical command of labour. Some socialists propose that these officials should owe their appointment to a central governing body; others propose that they should owe them to popular election; but, in either case, appointment, promotion, or degradation would necessarily and avowedly, if it did not depend on favouritism, depend on the practical results which the different men in question elicited from labour by their different methods of directing it. In other words, the whole system of socialistic production would involve and depend on competition; and the only essential difference between this bureaucratic competition under socialism and the competition of 
Book II capitalists which socialists so furiously denounce, is that whilst the capitalists obtain control over labour by means of wages, which control, by a natural and automatic process, is gradually extinguished unless it is used efficiently, the competitors for office under socialism would obtain the same control by compulsory powers with which the State would invest them, and which they would lose or retain at the pleasure of some more or less arbitrary authority.

Competition between employers, then, is a part of every social system that permits of progress,

Competition, then, between the directors of labour - or, as it is here defined, the struggle for industrial domination - is as much a part of the theoretical régime of socialism as it is a part of the actual régime of capitalism. The only differences between the two consist, firstly, in the means by which labour is directed, coercion being employed in one case, and in the other the inducement of wages; and, secondly, in the means by which the fittest director is placed in power, and the less fit deprived of it - an official body deciding the matter in the one case, and the mass of the consuming public deciding it in the other for themselves.

but since the
re-introduction Now we may safely say that the régime of

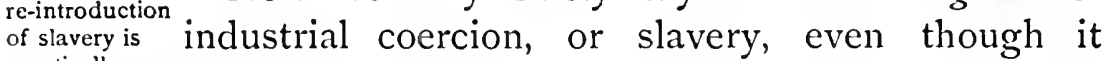
practically impossible, we must regard the wagesystem should bear the name of socialism, is not in these days possible. It is impossible for two reasons one, that it is out of harmony with the sentiments of the modern world; and the other-equally strong, though not so generally avowed - that it is an exceedingly clumsy and wasteful instrument of 
competition. We may, accordingly, dismiss it from our consideration; and such being the case, there remains for us the absolute certainty that if society is to make any further industrial advance, or if it is to a permanent feature of save itself from a relapse into industrial helplessness, societies. the capitalistic wage-system, and with it capitalistic competition, or, in other words, the competitive struggle for domination, must both of them be continued under some form or other; nor, although they may be modified in an indefinite number of their details, is there any apparent possibility of ever modifying them in any of their essentials. Indeed, the great moral to be drawn from the facts that have been here elucidated is that if any one institution in the modern world threatens to be permanent, that institution is the capitalistic wage-system ; and all proposed alterations in it we may set down as impossible in precise proportion as the socialists attach value to them. The foolish dreamers who imagine that they can overthrow it, consider only its outer aspect, and not the forces of which it is the expression. It is We might perfectly true that this system might at any given to ashes, but time, and in any given country, be paralysed or and capitalistic reduced to ashes; but the forces that would over- competition throw it would be essentially non-productive. The again out of men who destroyed it would find themselves powerless without it, and would be obliged to submit to, and assist in, its reconstruction. For the outer form of capitalism is not what capitalism is, any more than a painter's brush is the power that paints great pictures. Capitalism, in its essence, is merely

Book II Chapter 3 
Book II the realised process of the more efficient members of the human race controlling and guiding the less efficient; capitalistic competition is the means by for capitalistic which, out of these more efficient members, society competition means the domination of the fittest great men. itself selects those who serve it best; and no society which intends to remain civilised, and is not prepared to return to the direct coercion of slavery, can escape from competition and the wage-system, under some form or other, any more than it can stand in its own shadow.

With regard, then, to economic production, which, of all social activities, is for the practical sociologist incomparably the most important, what we have thus far seen is as follows. We have seen, not that it is impossible - for this question has been expressly postponed - that men may be made far more equal than they are now in respect of the possession of wealth; but that whatever degree of equality they may some day attain to in its possession, they can never be otherwise than unequal in the parts played The industrial by them in its production; that their inequality in the many to the few is the fundamental condition of progress. productive power is of such a kind as to render the industrial obedience of the larger number of them to the minority the primary and permanent condition on which economic progress is possible; that what feather-brained fanatics call "economic freedom" would be merely another name for economic helplessness; and that all the democratic formulas which for the past hundred years have represented the employed as the producers of wealth, and the capitalistic employers as the appropriators of it, are, 
instead of being, as they claim to be, the expressions of a profound truth, related to truth only as being direct inversions of it. Whatever appearances may Chapter 3 seem to show to the contrary, it is the few and not the many who, in the domain of economic production, are essentially and permanently the chief repositories of power. That this is so in the domain of intellect we have seen already. We will now turn our attention to the domain of political government, and consider the part played by the exceptional few there - the nature and origin of their power, and the means by which it is exercised. 


\section{CHAPTER IV}

\section{THE MEANS BY WHICH THE GREAT MAN ACQUIRED POWER IN POLITICS}

In discussing IN discussing, with reference to political govern-
the means by which the great ment, the means by which the great man controls the man wields actions of others, it will be found that the point on
power in politics the debatable which we shall have to concentrate our attention question differs differs somewhat from that which engaged it when
from the question raised by his power in industry; we were discussing the same question with reference to economic production. For all the points which, with reference to the directors of industry, it was necessary to establish in opposition to the sociological sophistries of to-day are, with reference to the political governor, admitted by all alike. Thus we shall find on reflection that the extremest democratic reformer, no less than the aristocrat or the for the points that are debated in the case of the great wealthproducer are admitted by al in the case of the governor. strict upholder of autocracy, admits, firstly, that satisfactory governors must be exceptional or great men; secondly, that the fittest great men can be secured by competition only ; and, thirdly, that however they are appointed, and whatever may be the principles on which they govern, their orders must in every case be enforced by virtually the same 
sanctions. The last of these three facts - namely, that the commands of the governor must be enforced by some system of restraint and punishment for the disobedient - is sufficiently plain to require no further notice; but the two others, obvious as they really are, are not perhaps generally realised, and it will be well to give a few words to them.

That the efficient governor, though he need not $\begin{gathered}\text { The greatest } \\ \text { democrats }\end{gathered}$ always be a genius, must in some respects, at all admit that the events, be a great or exceptional man, is of course governor admitted by the advocates of autocracy, aristocracy, ${ }_{\text {man, }}$ eptional or oligarchy. All that requires to be shown is that it is admitted also by the thinkers who are most opposed to them - by socialists and extreme democrats. This admission on their part is implied in the notorious importance attached by them to the machinery of popular election; for popular election is simply an elaborate means of expressing the opinion of the people that out of so many possible governors, this one or that one is endowed with greater capacity than the others. If the capacities of all were equal, or if exceptional capacity was not required, the personnel of the government might and also that be chosen by casting lots. Next, as to the question chosen by of competition, it must be obvious to every one that competition. the popular election of governors is not only an admission that some few men out of many are greater or more capable than the rest, but is also, on the part of the candidates for election themselves, competition in one of its intensest and most sharply accentuated forms. 
Book Il

Chapter 4

There is a competitive element even in autocracies,

Competition, indeed, is implicit in every form of government. Were it absent in any, it would be absent in complete autocracies; but even in these it is latent, and always ready to come into operation; for the most absolute autocrat, if he happen to make his rule sufficiently odious to a sufficient number of his subjects, - "postquam cerdonibus esse timendus coperat" - will, as history shows us, be assassinated or got rid of somehow, and some other candidate for power, probably an autocrat also, will be put in his place, and will either retain or lose it, according as experiment shows him to be a tolerable ruler, or the reverse. Here is political competition in its most rudimentary form; but it is competition none the less; and it generally involves a competition more advanced than itself; for the most absolute autocrat is obliged to govern through ministers; and these rise and fall according as experiment shows them to be fitter or less fit for the accomplishment of their master's purposes. If, then, even the power of the autocrat rests ultimately on competition and practical experiment, much more does the power of government, under aristocratic and oligarchic constitutions. Oligarchies invariably aim at ruling through their strongest members; and which are the strongest is shown by experimental competition

and democracies are essentially only; whilst political democracy, under all its forms, is experimental competition open and undisguised. competitive. A Gladstone remains in power because, as his years of office succeed each other, he satisfies the majority by the manner in which he governs them; and his 
power is taken from him when the majority cease to be satisfied, not only because they are of opinion that he governs badly, but because they are of opinion that a Disraeli will govern better. A democracy, in fact, and an oligarchy, so far as competition is concerned, differ merely in the way in which the competitors are admitted to the arena, and in the number and character of the jury which awards the prizes.

Since, then, with regard to the points just dealt All parties also with - namely, the necessity for great men as must be engovernors, for the selection of the fittest of them forced by pains by competition, and for the use of coercion and punishment as a means of enforcing orders - there is no essential difference between the most extreme democracy and its opposites, in what does that practical or theoretical difference between them consist, by which most undoubtedly the former is distinguished from the latter? The only essential point of difference between them lies, not in their respective schemes or theories of the machinery of government, or of their methods of electing governors, but in their theory of the powers which election com- Democrats are municates to those elected. An elected governor, their theory whether chosen from a large or a small class, is, greatness according to the aristocratic or oligarchic theory, their governor chosen because he is personally wiser than those is a perceptive who elect him; and it is theoretically his mission, ${ }^{\text {greatness, }}$ which will within very wide limits, to follow his own judgment, enable them to not that of the electors. The democratic theory spontaneous is the very reverse of this. The elected governor, many. 


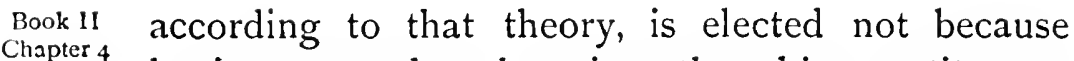
he is supposed to be wiser than his constituents, but because he is supposed to be exceptionally capable of understanding their precise wishes, and giving effect to each of them. In the first of these two cases the governor is like the physician whom the patient calls in, but whose orders he never thinks of disputing. In the second, he is like the professional Spanish letter-writer, whom the illiterate lover employs to put his passion for him grammatically upon paper.

This is the only point in which the democratic theory differs from the aristocratic.
The only point, then, in which democracy can claim to differ essentially, not only from autocracy, but from any form of oligarchy, lies not in its form of government, but in the power that is behind its government. This power, according to democratic theorists, is the power of the mass of ordinary men, as definitely opposed to exceptional men; and the exceptional men who are picked out as governors would necessarily, in an ideal democracy, be exceptional only for such qualities as practical activity and a quick apprehension of the wishes of other people, which would enable them to do what their manyheaded master bade them; but they would have to be wanting in any strength of mind or originality which might prompt them to acts out of harmony with their master's temper at the moment, or what is the same thing, to any acts beyond their master's comprehension, even although such acts might be for his future benefit. This is what the democratic theory, in its last analysis, means. All exceptional will 
is to be smothered or over-ridden by the average will, as is expressed clearly enough in the well-worn Book II democratic formula - every man's vote is to count for one in government; no man's vote is to count for more than one.

Now this theory of the relation of the great man to the many, so far as regards the conduct of civil government, is identical with the theory which, with a much wider application, Mr. Herbert Spencer enunciates as the foundation of his sociological system. As enunciated by Mr. Spencer we have already submitted it to examination, and we have shown that, in every practical sense, it is altogether fallacious, and that its acceptance renders all practical sociology impossible. We will now proceed to show that, as applied even to the most popular forms of government, it is as false as it is when applied to social phenomena generally.

That the essential principle of democracy, as The demojust described, according to which the brain of the cratic ruler is, ideal ruler is merely a balance for weighing the wills $\mathrm{a}$ weighing the of multitudes, which are dropped into one or other wills of the of its scales, like marbles - that this principle has ever yet been completely realised, no democrat will perhaps venture to maintain; but the whole democratic propagandism of the present day implies, before all things else, that its complete realisation is possible, and that every day "the peoples" are getting nearer to it. The facts, however, which are supposed to warrant this conclusion are to be sought, not in the sphere of official government, but 
Book II without it. They are to be sought not in the conduct of elected legislators, but in the machinery by which they are elected, and, above all, in those unofficial movements, meetings, and agitations by which the prophets of democracy affirm that the great mass of the people is learning to exert the power which was always latent in it, and to express its will with regard to every question of government as it arises, even if it has something yet to learn in the art of securing that its governors shall carry out its commands. It is this view of the situation which is expressed in the popular saying

or a machine for executing their "mandates "; and there are signs which might suggest that the few in politics are really becoming the mere instruments of the many. that a constituency has elected a member, or that the people has elected a parliament, with what is called a "mandate" to do some specified thing or things - to break up the United Kingdom, to disestablish the English Church, to penalise the drinking of a glass of beer on Sundays, or to deprive our soldiers of protection against the most malignant of contagious maladies.

Now the democrats, it must be admitted, are so far right, that a real political power has come into existence which has no constitutional connection with the men who nominally govern; and this is frequently used with such efficiency, and with such definite purpose, that official governors - men of most exceptional intellect - are compelled by it to use their intellect for ends which they themselves condemn. Here, then, in this external power, is to be found, if it is to be found anywhere, the will of the many, as conceived of by the theorists of democ- 
racy, exerting itself independently of any separate will of the few, and turning the powers of the few into its willing or unwilling instruments.

Now perhaps the question which will in this place most naturally suggest itself is whether this will of the many, however effectively it may be exercised, is really a power that makes for civilisation and progress, and whether it is not more likely to bring harm than benefit to those very collections of ordinary men who exercise it. And this question is, no doubt, extremely pertinent; but it is not one that need engage our attention now. The fact which alone we are now concerned to demonstrate is that the alleged will of the many is not what democrats conceive it to be, and that it is not really the will of the many at all.

For although there is much in the history of the But these signs present century to warrant the assumption that the are deceptive; political will of the many is at last emerging as a the will of the supreme and independent governing power, we depends on the shall find that these movements and opinions, which another seem, when viewed superficially, to result from the spontaneous actions and spontaneous thoughts of the many, really imply the influence of exceptional men, just as much as those movements which are avowedly aristocratic in origin; and that in the absence of these men the movements could never have taken place, nor the opinions have ever assumed any uniform and coherent shape.

To understand how this is, we need merely reflect upon the fact that masses of men, as masses, can 
Book II

Chapter 4

Opinions, to derive power from the numbers who hold them, must be identical:

but they seldom are identical till a few men have manipulated them.

only have a will at all when their judgments with regard to certain particular questions happen to be absolutely identical, and have thus a cumulative force, like that of weights piled on one another above some substance which it is desired to compress. Now, whatever may be the thoughts, wishes, or opinions which spontaneously shape themselves in the minds of any body of ordinary men - men various in training and temperament, and none of them remarkable for wisdom - these never take a shape which will give them any cumulative power unless amongst the ordinary men there is some man more active than the rest, who weighs them, compares them, eliminates what he thinks to be their discrepancies, adds what is in his opinion necessary to their logical completion, and clothes them in catching language, which appeals both to the mind and to the memory. Not till this is done do the mass of persons concerned realise how identical their opinions on a given question are; and they then perceive them to be identical for an exceedingly simple reason - that the exceptional man has made a mould for them, into which they have all been run.

It is then, for the first time, that the mass of ordinary men become conscious of corporate power; for then they become, with regard to a given question, conscious for the first time that their opinions are absolutely identical, and that in a certain given direction their power is consequently cumulative. But the opinion of these men, whose numbers give political force to it, is very far from representing 
the capacities of these men only. It represents the capacities, the character, and very probably the Book II Chapter 4 personal designs of the exceptional man who supplied that common mould to which the unanimity of the other men's opinions is due; and the one opinion which thus comes to be held by all of them will not be precisely the opinion that was originally held by any. The original opinion of each will have undergone some modification. It will have been softened, emphasised, developed, or other elements will have been added to it, which would never have entered the mind of the ordinary man naturally, and which even when admitted he does but imperfectly understand. Thus whilst a political Thus what opinion expressed, or a political demand made, by a opinion of the body of ordinary men thus absolutely unanimous many is seems at first sight a genuine expression of the will pendent on the and the capacities of the many, it always in part, few. and it very often mainly represents capacities and purposes belonging to one man alone, the many being practically little more than a phonograph, which repeats his words to the world through an enormous resonator.

Let us take, for instance, the two questions of The many, for Free Trade and Bimetallism. If any British Govern- never have had ment were to revert to the system of protection, it any opinions cannot be doubted that throughout the country there if a few men would be meetings and demonstrations, at which had not every throat would be unanimous in shouting con- them. demnation of their conduct. America has witnessed a precisely similar outburst in favor of a proposal 
Book II to remonetise silver. The issues raised, howChapter 4 ever, both by the free traders and the bimetallists, are of a kind so complicated that exceedingly few people would be able even to describe their nature clearly enough to satisfy the most lenient examiner who should set them a paper in economics. The majority of those who declared for bimetallism in America had as little to do with forming their own opinions as the little boys would have in a preparatory school who should shout their approval of some new emendation made by one of their masters of a corrupt passage in Pindar; nor does that British opinion in favour of free-trade principles which has caused our Government to adopt them, and would hinder or prevent their repudiation, rest in the minds of the majority of those who hold it, on any larger amount of original thought or knowledge. Ninety-nine free traders out of a hundred would never have been free traders at all if it had not been for the oratory of Cobden. The least educated portion of the citizens of the United States would never have howled themselves hoarse over an intricate financial problem if it had not been for the oratory and the singular activity of $\mathrm{Mr}$. Bryan. Indeed, what is oratory itself, which in all democracies, from that of Athens downwards, has been essential to the work of government, but an embodied expression of the fact that the many are powerless, unless here and there some thinker will think for them, and give them opinions which may form a mould or a nucleus for their own? Even a 
village meeting is never got together without the agency of some one who is slightly more efficient than the rest. He need not be wiser than they. He very frequently is not; but he has some gift or other which qualifies him for taking the lead. His temperament is more active, his words flow more freely, or he is hampered by less insight into his own ignorance or imbecility; and his opinions are the nucleus round which those of the rest form themselves, and which generally imparts to them something of its own character, as a vinegar plant does to the liquor in which it is immersed.

Without some such nuclei afforded to the many Popular by the few, popular thought is nebulous, and popular opinion requires excepwill unborn. An exceptional few are essential even tional men, as to those revolutionary movements which have the which to form destruction of the power of the few for their object. It is impossible for the many to attack one set of superiors, except by submitting themselves to the leadership or dictatorship of another set; and although these last may to a certain extent represent the multitude, it is usually just as true that the multitude represent them. The multitude cannot even unite to influence those exceptional persons to whom is entrusted the official work of government without placing themselves under the influence of another set of exceptional persons; and thus the extremest democracy will be found, if we only look below the surface, to be neither more nor less than an oligarchy disguised. It is, no doubt, true that those who actually govern do in a certain 
Book II sense derive their power from the many. They do so even in countries where the supreme governor is an autocrat. In countries with a popular constitution they derive their power from the many by an organised and conscious system; but even in the extremest democracies the average men can exercise their power only by constant processes of surrendering it into the hands of exceptional men. They

Thus even in what seems extremest democracy the few are essential.
Democrats, however, may argue that under democracy the few do, in the long the genuine wishes of the many. surrender it into the hands of the exceptional men for the simple and enduring reason that, with very few exceptions, which will be examined in another place, it comes into existence only in the very act of surrendering it; and the many accordingly place themselves in the hands of the few because, from the very constitution of human nature, they cannot avoid doing so.

We thus see that even in that sphere of political action in which, if anywhere, the many should be independent of the few, the many without the few would have no power at all.

The apologists of democracy, however, have another argument left them. They may contend that the exceptional men, who are necessary to the development of the collective powers of ordinary men, though each of them is constantly, with regard to particular questions, following his own devices rather than the instructions of the electorate, do on the whole, and in the long-run, substantially carry out the intentions and devices of those who are theoretically their masters; and that though they may do what their masters could never have thought of for them- 
selves, yet they can never continue to do anything of which their masters do not actually approve. Book II Chapter 4 Now even were this representation of the case true, it would leave untouched that broad and fundamental truth on which it is the primary purpose of the present work to insist. It would leave untouched Even were the truth that the great mass of human beings are true, the curhelpless without the assistance of a minority more of democracy efficient than themselves. If ninety-nine average would be false, men, through the aid of a hundredth man who is men would be exceptional, can develop and give effect to a col- executing the lective will, which is altogether their own, and equals. originates entirely with themselves, but if they can neither develop it nor give effect to it unless the hundredth man lends them his services, the power of this one man is as essential to the power of the ninety-nine, as it would be if the orders which he executes had been largely originated by himself; just as a lens is essential to the photographer's camera though its function is solely to focalise, not to colour, the rays transmitted by it. Accordingly, even on the above hypothesis, the modern democratic formula, which makes each man count for one, and nobody count for more than one, would, if judged scientifically, be absolutely and fundamentally false; for the power ascribed by it to the accumulated faculties of equals would be really the power of equals united with the power of a superior; and the difference between the equals and the superior would be at once apparent from this - that if one of the equals were subtracted, the power of the whole 
Book II hundred would be diminished by one ninety-ninth
Chapter 4 only; but if the one superior were subtracted, it would collapse altogether. Thus the presence of the superior, and the terms on which his services can be secured, would even in this case be subjects on which the sociologist would be bound to bestow the same attention as he bestows at present on the activities of the ordinary men; and unless he should do this, his conclusions would be wholly valueless.

Now in reality the few are never mere passive agents ;

As a matter of fact, however, the hypothesis that the superior few are ever the mere passive agents which the democratic theory assumes them to be is false; and it is as a rule false in exact proportion to the difficulty and importance of the cases to which it is applied. The qualities which enable men to organise the opinions of others are usually qualities which endow them with strong opinions of their own; and in addition to their own opinions, these men, with their exceptional vigour, have usually their own purposes also; and the popular will, as put into execution by them, is always modified, and very often metamorphosed, by what they themselves add to or subtract from it. Still it must be admitted that, in spite of their dependence on the few, the many can, and do to a great extent, impress their own

but nevertheless the many do impress their will on them to a great extent. genuine will - the will and wishes of the average man as distinct from the will and wishes of the man who is in any way exceptional - on the exceptional men to whom their power is surrendered. The acts of the governing few may never entirely represent 
the will and wishes of the average man, when these acts are considered as a whole; but they may be Book 11 Chapter 4 forced to embody, and they generally do embody, a certain element of what average men wish and will; and their character as a whole is profoundly modified in consequence. The question then is simply a question of degree. What is the extent - or rather The question is what is the utmost possible extent - of this genuine power of the many to make the faculties of the exceptional few their servants? Is it great or small?

The reader will perceive that when this question This intro- The reader will perces us to a is asked our inquiry is gradually taking a new new side of the turn, and that having started with asserting the extent of - the claims of the great man as the author and sustainer the powers of
the many. of both intellectual and economic progress, we are led, when we come to consider him as an agent in the domain of politics, to inquire into what is done by the average man, as well as into what is done by him. And the reason for this is that in the domain This is greater of politics the many, so far as direct and intentional in industry; influence is concerned, are actually capable of playing a far larger part than they are in the domain of speculation or of advanced economic production. A statesman like Mr. Gladstone might, without absurdity, maintain that he had a mandate from the many to grant home-rule to Ireland; but nobody could pretend that any body of mechanics had given Watt a mandate to invent the steam-engine, or that any one gave Newton a mandate to discover the law of gravitation. And yet the reflection will 
Book II Chapter 4

and yet when we think it over we shall see that it is great in most domains of activity.

probably force itself upon every reader that if the many play a part in politics which is commensurate with that of the few, they play a part in intellectual and economic progress also. It would be useless for the few to unfold their thoughts and their discoveries to the many, if the many were not, in various degrees, capable of assimilating and responding to them. Still less could the great man of industry realise his progressive inventions, or carry out his extending schemes of business, if it were not that an indefinite number of ordinary men - those "serviceable animals," as Mr. John Morley calls them - were endowed with capacities that enabled them to carry out his bidding. What would Mahomet have done if he had not had followers? What would Columbus have done if he had not had seamen? The reader, accordingly, will inevitably be led to urge that in attributing to the great men of the world the results which we have attributed to them, our statements are unmeaning, unless they are accepted as incomplete, and are understood to imply more than they have actually expressed. If no progress of any kind could have taken place without the many, surely, it will be argued, the many must have had some share in producing it; and unless we can assert and discriminate precisely what this share is - what are the phenomena of progress which are due to the activity of ordinary men - it is meaningless to assert that most of them are due to the activity of exceptional men.

And the larger part of this argument is perfectly 
true. In dealing with the activities of the few, we have taken those of the many for granted. This general assumption, however, though inevitable at we had to the beginning of our inquiry, has been provisional granted at only. To any scientific conception of what is done starting. exclusively by the few, an equally scientific con- examine it. ception of what is done by the many is essential. We must measure the former by the latter, as we measure mountains by their respective heights above the sea-level. That such a discrimination between the work of these two bodies is possible may be doubted by some; and accordingly before we actually proceed to undertake it, we will dispose of the arguments that will be, and actually have been, advanced in proof of its impracticability, and set forth the principles on which it must be, and obviously can be, made. 

BOOK III 



\section{CHAPTER I}

HOW TO DISCRIMINATE BETWEEN THE PARTS CONTRIBUTED TO A JOINT PRODUCT BY THE FEW AND BY THE MANY

In the first chapter of his Principles of Political Mill declares Economy Mill alludes to the question raised by agencies are certain thinkers, of "whether nature gives more essential to assistance to labour in one kind of industry than $\begin{gathered}\text { effect, their } \\ \text { respective }\end{gathered}$ another"; and he endeavours to show that the contributions question is useless and unanswerable. In every discriminated. industry, he says, there would be no product at all unless nature gave something and labour did something. Each is "absolutely indispensable," and the part played by each is consequently "indefinite and incommensurable." "When two conditions," he proceeds, "are equally necessary for producing the effect at all, it is unmeaning to say that so much of it is produced by one, and so much by the other; it is like attempting to decide which half of a pair of scissors has most to do in the act of cutting, or which of the factors five and six contributes most to the production of thirty." If this argument is applicable to nature and labour as agents in the 
Book III Chapter I

Mill argues thus with special reference to land and labour;

but he overlooks what in actual life is the main feature in the case.

production of commodities, it is equally applicable to the few and the many as agents in the production of social progress generally; and the crisp phrases and illustrations which Mill employs in formulating it, put in the clearest and most forcible manner possible the whole class of objections referred to at the close of the last Book.

Mill brings the argument forward with special reference to agriculture. Let us take, he says in effect, the products of any farm; and it is obviously absurd to inquire which produces most of it - the fields or the farm labourers. Now if all labour were equal, and if there were only one farm in the world, or if every acre of land, when the same labour was applied to it, yielded the same amount of produce, this would, no doubt, be true. The actual state of the case is, however, widely different. Acres vary very greatly in fertility; and if the produce of onethe least fertile - when cultivated by a given amount of labour, be symbolised by ten loaves, the produce of others, when cultivated by the same labour, will be symbolised by loaves to the number of twelve, fifteen, or twenty. Here, then, we have a constant quantity of labour, which produces ten loaves from each of the four acres in question; but when The labour applied to the first, it produces ten loaves only; remaining the same, the prod- when applied to the three others, it produces two, uct varies
with the quality or five, or ten loaves in addition. About the first of the land. ten loaves, in each case, it is not possible to argue. So far as they are concerned, the result is in each case the same; with regard to them we cannot 
make any comparison; and we must admit that the parts played by land and labour in producing them Book III Chapter I are "indefinite and incommensurable," precisely as Mill says they are. But the two, the five, or the ten extra loaves which result when labour is applied to the second, the third, and the fourth acre respectively, but do not result at all so long as it is applied only to the first, constitute phenomena of a different order altogether. The labour being in each of the four cases the same, and these additional loaves resulting in three cases only, these additional loaves are obviously not due to labour, but to certain additional qualities present in the last three acres and not present in the first. In other words, though Theextraprod. in producing the loaves, or, as Mill puts it, "the from labour effect," the parts played respectively by land and on superior labour are incommensurable so long as the land, the land, not the labour, and the effect remain the same, the parts become immediately mensurable as soon as the effect begins to vary, and one of the causes, and one of the causes only, varies also.

This truth can be yet further elucidated by This is easily means of Mill's two other illustrations. If the two proved by a blades of a pair of scissors were made of two analogous different materials, and the one blade were of such a nature that it was always of the same quality, and human ingenuity was not capable of improving it, whilst the qualities of the other blade varied with the skill devoted to its manufacture, and if one pair of scissors should cut twenty yards of cloth in a minute, whilst another cut only ten, the additional 
Book III Chapter I

efficiency of the more efficient pair would, it is perfectly obvious, be due to that blade in respect of which this pair differed from the pair which was less efficient, not to the blade in respect of which both pairs were similar. Again, let us take Mill's case of the two numerals five and six. If five is always to be the number multiplied, and six is always to be the multiplier, it is true we cannot say which does most in producing the result - thirty. But if the number to be multiplied remains always five, whilst the multiplying number varies, if it is in one case six and in another case ten, and if the result of the multiplication in the second case is not thirty but fifty, it is obvious that the additional twenty which results from our multiplying by ten is due not to any change in the number multiplied, but to the additional four introduced into the number muitiplying. To these illustrations we may add two others - the movement of a modern bicycle and the movement of a man running. A modern bicycle cannot be propelled without a chain; and if there were only one kind of bicycle in the world, Mill might fairly have said that it was meaningless and useless to ask whether the wheels or the chain contributed most to its velocity. But if there are two bicycles, with precisely similar wheels, but with dissimilar chains, and if the same man riding on one can accomplish ten miles an hour only, but on the other fifteen, the common sense of every bicycle rider in the world will tell him that the additional five miles are contributed entirely by the chain, and 
the patentees of the chain, we may be certain, will add their valuable testimony to the fact. So

Book III Chapter I with regard to running, Mill might fairly have said that if we consider it in an abstract and general sense, it is absurd to ask which contributes most to "the effect" - the ground or the man that runs on it, because the first is as indispensable to the man's movement as is the second. But if two men are racing each other over the same course, and one runs a mile whilst the other runs only half, it is perfectly obvious that the extra speed of the winner is contributed not by the ground, which for both men is just the same, but by certain qualities in the winner which the loser does not possess, or which the winner possesses in larger measure than he.

Now in all questions connected with progressive Mill errs by social action the effects which have to be considered ignoring the are not general effects, such as running at some character of indeterminate speed, each of which effects is considered as being single of its kind, and which, in consequence, cannot be compared with anything, but effects each kind of which exhibits many comparable varieties, such as the running of several men whose respective speeds are different. The whole error of Mill's argument depends on his failure to perceive this. He describes the result of man's labour applied to land $-\mathrm{a}$ result which we have for convenience' sake expressed in terms of loaves as "the effect." He says "nature and labour are equally necessary for producing the effect at all," as though the same amount of land and 
Book III Chapter 5

The case of labour directed by different great men is the same as the case of labour applied to different qualities of land. The great men produce the increment.

labour must always result in the production of the same number of loaves. To conceive and speak of the matter in this way is to ignore entirely all the phenomena of progress - all the phenomena which differentiate civilisation from savagery, and which it is the special function of economics and of sociology to explain. Rent, for example, the theory of which Mill states with extreme lucidity, and insists upon with the utmost emphasis, arises from the fact that one man and one acre of land, instead of producing something that can be described generally as "the effect," produce in different cases effects that are widely different - ten loaves when the acre is bad, twenty loaves when the acre is good: and, in a similar way, when the acres are of the same quality, twenty loaves will be produced by an acre if it is cultivated by the methods of civilisation, and only ten by an acre if it is cultivated by the methods of a savage. Now, just as agricultural rent arises from different qualities in the soil, so does agricultural progress arise from differences in the powers of the men. It is measured by, and it consists of, not "the effect," but a series of effects, similar indeed in kind, but continually increasing in degree; and it is their differences in degree, not their similarity in kind, that form for the economist the particular subject to be considered.

And what is true in this respect of production and progress in agriculture is equally true of production and progress generally. The former indeed are the simplest type of the latter, just as they are 
their original basis; and before we proceed farther, there is one fact more in connection with them on which it is necessary for the purposes of our present Labour, howargument to insist. Of soils the same as to area, held to probut not the same as to quality, some, it has been $\begin{gathered}\text { duce that } \\ \text { minimum }\end{gathered}$ said, will produce ten loaves, some fifteen, some necessary to twenty; and soils may exist, perhaps, which would labourers produce only five. But in order that any soil may be cultivated by human labour, it is necessary that the product should be at least sufficient to keep the men alive who devote their labour to cultivating it. No set of men, unless artificially subsidised, could continue to cultivate any region if the product of twelve months' labour would support them for only three months. It follows, therefore, from this truism that no soils can be cultivated which will not yield to labour a certain minimum product. Now, though this minimum is, in a certain sense, the product of labour and of land jointly, for all purposes of practical reasoning it is the product of labour alone. It is so because the sole object of practical reasoning about the matter is to determine the principles on which the product of the land is to be distributed; and with regard to that minimum there can be no doubt or question. It must go to the labourer, and it can go to no one else. The landlord, if there be one, cannot take any part of it; for if he did, the labourer would die, and there would cease to be any product to take. Labour, both in agrithen, in agriculture must be held for all practical purposes to produce the whole of that minimum 
Book III

Chapter I

resulting from its application to the least productive soils which the labourer can live by cultivating; and it is only in the case of soils which are more productive than these, and which yield to similar labour a product above this minimum, that land, apart from labour, can be said practically to produce anything at all.

and in all kinds Now just as we can argue with regard to land
of production. and labour, so can we argue with regard to the average men and the great men, and measure what they contribute respectively to any given civilisation; for just as a thousand men from some good soil will elicit twice the produce they would be able to elicit from a bad soil, so from a bad soil may a thousand average men manage to elicit, if directed by some agricultural genius, twice the product which they would elicit if left to themselves; and just as in the former case, according to the principles above stated, we shall ascribe the smaller product to labour without any reference to land, and ascribe to land the excess only of the larger product over the smaller, so in the second shall we ascribe the smaller product to the average men, and the excess of the larger product over the smaller to the great The great man man. We shall say, in fact, that the great man pro-
produces the increment that would not be produced by labour if his influence ceased.

duces so much of the product as comes annually into existence when he directs the others, and disappears as soon as he ceases to direct them.

Here, however, the original objection of Mill will suggest itself again, though in a somewhat different form; for in spite of all that has been 
said, it still remains certain that the great man could not produce this excess unless the average men were present to carry out his directions; and the Labour, it is reader will possibly be disposed to argue that the trua, is the the proaverage men may be as reasonably credited with duction of the the whole of the product, except that insignificant also; fraction which the great man could have produced without them, as the great man may be credited with the whole of the product except that which the average men could have produced without him.

Now this reasoning has a certain fanciful plausibility, but it is absolutely devoid of any clusions from practical meaning; and in order to show the the hypothesis reader how and why it is so, it will be necessary ing; to direct his attention to a certain fact which lies at the bottom of all practical reasoning, but which few practical reasoners ever consciously realise. All such reasoning is in its nature hypothetical, and can be reduced to a statement that if such conditions are present, such consequences will result; and that if existing conditions be altered in any specified way, the results will exhibit a specified and corresponding difference. If, however, this reasoning is to have any practical value, one thing is essential to it - namely, that the supposed alterations shall be at least approximately possible. No practical conclusion, for instance, could possibly be drawn as to machinery by considering what would happen if the properties of the circle were to be changed, and different parts of the circumference should be at different distances from the 
Book III centre. It is equally evident that no practical conclusion as to the claims and prospects of labour

for the could be drawn by considering what would happen labourers to if the labourers could live without food. Now since labour whether no food is producible without labour, a population
the great men were there or no.

which does not labour is just as impossible a conception as a population which does not require to eat; and no practical conclusions can be arrived at by supposing it to exist; but populations which have developed and submitted themselves to no great men, not only can exist, but have existed, and do exist to-day; and thus we are reasoning in a strictly practical way when we consider what would be produced by the average men if the great man ceased to direct them, but we are reasoning to no practical purpose at all by considering what would The cessation happen if the average men ceased to labour. The
of the great man's influence is a practical alternative; the cessation of labour is not: latter - or the majority of them - would have to labour in any case, whether there were any great man to direct their labour or no; and the supposition of their labouring is bound up with the supposition of their existence. The sole practical alternatives which can in the present case be conceived and reasoned from are average men labouring under the direction of the great man's talents, or the same men labouring blindly as best they can by themselves.

as we see by

These alternatives are being constantly exemplifrequent examples. fied in the actual life of communities. We may see men to-day, not only amongst savages, but amongst the peasantries of civilised countries, such as Russia, India, and parts of Ireland and the Scottish islands, 
who are still almost independent of any intellect superior to their own, and who maintain themselves by the exertion of man's commonest faculties only. We may see again populations who have been in the same condition, but who, under great men's guidance, become agents in producing a civilisation which they could by themselves not only not produce, but could, by themselves, hardly even imagine; and again we may see how in more than one country the energies of the great man, having worked these wonders for a time, become paralysed by insecurity under a barbarous and predatory despotism, and how, as his action ceases, the masses relapse again into their former condition of relative inefficiency.

Accordingly, though the productivity of the average men, as distinct from the great men, will be different in one race or region from what it is in another, just as their diet will be and the other necessaries of existence, yet within each community experience furnishes us with comparisons which show us, roughly at all events, how much the average men produce without the aid of the great men, and how much the great men, by directing the average men, add to this. ${ }^{1}$ To calculate these amounts

1 It is, of course, true that in densely populated countries and in certain industries the average workmen, if left to themselves suddenly, with no man of business ability to guide them, would be unable to produce anything. But so long as the man of exceptional talent employs them to produce anything, they contribute something to the result, and must, for practical purposes, be held to produce so much of it as will provide them with the means of living. If it happens, as is sometimes the case, that the total value of the profit 
Book III Chapter I

with any approach to exactness will, no doubt, be more difficult in some cases than others, just as is the case with book-keeping in various businesses. But it is enough to have shown the reader that, despite Mill's contention to the contrary, the calculation is one which is based on the simplest Thus the great and most indisputable principles, and that not only most practical in a theoretical, but in the most strictly practical sense, produces what labour would oproduce in operate with average men by directing them, is labour would oproduce in operate with average men by directing them, is sense, what great men produce, when they cohis absence. the amount or degree in which the total result produced exceeds or excels that which was produced by average men when unaided, and would be again produced by them were the great man's aid withdrawn. An analysis of The absolute validity of this method of argureasoning as to ment and calculation will be yet more apparent causes generally will show us the truth of this.

to the reader when we pursue a step farther our analysis of reasoning generally as applied to practical matters, and consider it especially when it takes the form of a direct discussion with regard to causes and effects. In the strictest sense of the word it would plainly be quite impossible to specify fully the causes of even effects of the simplest kind. The motion, for instance, of a ball when a cricketer hits it, would, in any discussion of the game, be said to have been caused by

is less than the workmen's wages, the employer must either alter the character of his product, so as to meet the public demand, or he will otherwise be crushed out of existence as an employer, and his workmen will pass under the control of some more able rival. 
the cricketer; but the entire antecedents and conditions which have rendered this effect possible Book III Chapter X comprise not only all the incidents of the cricketer's past training, but the history of cricket itself, and half the properties of matter. It would be impossible and useless to specify all these. When we say that anything is the cause of anything else, we are always selecting that cause out of an indefinite number, on which, for the purpose on hand, it is practically important that we should insist; and the cause on which it is important that we should insist for For practical practical purposes will be found to be always one cause of an which, under the circumstances in view, may or effect is that may not be present, ${ }^{1}$ - which a careless person may which may or neglect to introduce, or an ignorant person be present; persuaded to take away; whilst those other causes whose presence is assumed by all parties to the dis-

1 It was his complete neglect of these considerations that enabled Karl Marx to impose on himself and others his doctrine that the value of commodities depended on the amount of average labour embodied in them - a doctrine which is the most remarkable intellectual mare's nest of the century. It is perfectly true that if all other circumstances were always equal - the demand for the commodities in question, the ability with which average labour is directed, and the assistance which the genius of the great inventors gives to it - it is perfectly true that then the amount of average labour embodied in various commodities would be the measure of their value; for labour in that case would be the only variant. But, in reality, the important variants are not average labour, but the ability by which labour is directed. The efficiency of labour itself is practically constant; and for the student of wealth-production the principal force to be studied is the ability of the few, by which the labour of the many is multiplied, and which only exerts itself under special social circumstances. 
Book III cussion, and which no one proposes to take away, or which no one is able to take away, or whose number, if they were mentioned, would make all discussion impossible, are passed over in silence, for there is no need to mention them. Thus we

as we see when men discuss the cause of a fire,

all know that when a house is burnt to the ground the causes of the phenomenon comprise the inflammable nature of timber, and indeed the whole chemistry of combustion; but if an insurance office is disputing the owner's claim to compensation on the ground that the owner set a light to it purposely, whilst the owner maintains that the scullerymaid set it alight by accident whilst reading in bed a novel of Belgravian life, the only causes that will be put forward by the litigants will, let us say, be a candle alleged by the owner to have ignited the scullery-maid's pillow-case accidentally, and on the other hand a match which is alleged by the agent of the insurance office to have been applied by the owner to the drawing-room curtains intentionally. Or again, let us take the case of a ship's chronometer.

or of the accuracy of a chronometer,
The reliability of a chronometer, any practical man will tell us if we ask him about the matter, depends on the balance and the escapement. It is the perfect "compensation" of the latter and what is called the "detachment" of the former that differentiates the chronometer from the ordinary lever watch; and these are rightly said to be the causes of the chronometer's superiority as a time-keeper. But a balance and escapement of themselves will not keep time at all. They are useless without a main- 
spring and a train of intervening wheel-work. But if any one were explaining the causes of a chronometer's exceptional accuracy he would never think of mentioning these last at all. He would not dwell on the properties of the coil of elastic steel, or on the interaction of the ordinary toothed wheels, or on the steel axes which make their interaction possible. And why would he omit these causes? He would omit them because they would be assumed, because there would be no discussion about them, and because they are implied in the existence of all watches and chronometers equally. If, however, the case were reversed - if all escapements and all balances were alike, and there was no room for superiority except in the main-spring and the wheel-work - the latter would be dwelt on, and the former would be passed over, in any discussion that turned on the causes of accurate timekeeping.

Let us take one case more. A man is hanging by or the causes a rope, which is fastened to a spike of rock, and is man who is looking for samphire or birds' eggs on the face of a hanging on to sheer cliff. It is suddenly perceived by some of his friends on the summit that the rope is frayed a yard or two above his head. They are anxious for his safety; and if any one asked them why, they would answer, Because his life depends on the rope not breaking. Let us suppose, however, that the rope is perfectly strong, but that the spike of rock it is attached to shows signs of being about to fall. The man's friends in that case will explain 
Book III
Chapter $\mathbf{x}$ their anxiety by saying that his life depends not on the rope but on the rock. In either case it would literally depend on both, and on a thousand other things besides; but in either case one cause only is mentioned, or calls for mention, and that is the cause whose cessation or continuance is doubtful. For similar reasons, and in a similar sense, great men are said to be the causes of all that is done or produced in the communities to which they belong, beyond a certain minimum which, even when not insignificant, is stationary; for though the efforts of the average men are essential to the production of this addition to the minimum, just as they are to the production of the minimum itself, there is no question of their efforts coming to an end unless the men come to an end also; whereas the activities of the great men require special circumstances for their development, and constitute the only productive force which modern democratic activity practically tends to paralyse, or at all events diminish or impede.

But there is another means But there is yet another method, still more necesof discriminat- sary to be described, by which we are able to differing between
the products of entiate the respective products of these two classes exceptional
men and of men - a method which will assist us not only to ordinary men. assign to each a certain portion of one joint effect, but also to particularise many of the elements of which each portion is composed. This method will be explained more fully in the following chapter, but it will be well to give a general and preliminary explanation of it here. It is founded on the two 
following propositions, which, when once they have been considered, will be seen to be self-evident. Whatever the many contribute to the social con-This is by an ditions of a analysis of the ditions of a community, either in the way of faculties industrial production or of the formation of habits pressary to and sentiments, consists of effects produced by those ${ }^{\text {product. }}$ traits or faculties of human nature in which all members of that community are approximately and practically equal. Thus the fact that all men are alike obliged to eat, and that all parents as a rule have a preference for their own offspring, are facts Are these which determine much in the conditions of all possessed by societies. On the other hand the social effects $\begin{gathered}\text { all, or by a } \\ \text { few only? }\end{gathered}$ which are produced exclusively by the few are effects produced by certain traits and faculties which, though possibly possessed in a rudimentary state by all men, are appreciably and efficiently developed in the persons of the few only. The dramas of Shakespeare, though in a sense they are eminently national, could never have been produced had Shakespeare possessed no gifts except such as were possessed at the time by the English nation at large. The discoveries of Newton, the inventions of Watt and Stephenson, similarly were produced by powers that were indefinitely above the average. It is needless to say that they could not have been produced otherwise. If we will but reflect carefully on obvious truths like these, we shall see that civilisations are woven out of two kinds of materials, the one originating in traits common to the community generally, the other in traits confined to a 

Book III more or less numerous minority; and even when the two are most closely woven together we shall be able to follow out and identify the different threads, which never can lose the trace of their different and opposite origins. 


\section{CHAPTER II}

THE NATURE AND SCOPE OF PURELY DEMOCRATIC ACTION, OR THE ACTION OF AVERAGE MEN IN CO-OPERATION

THE great-man theory as held by the conventional Carlyle was historian, and expressed by Carlyle and others in claims for the those vehement formulas which have so justly $\begin{gathered}\text { great man } \\ \text { because he }\end{gathered}$ excited the ridicule of Mr. Herbert Spencer, errs failed to note not because it emphasises the fact that the great were connot because it emphas ditioned by the man is the sole cause of progress in the sense that capacities of no progress could have taken place without him the ordinary but because it ignores the fact that the ordinary by him. men of his time, being the tools with which he works, or the instrument on which he plays, the result is conditioned not only by his capacities, but by theirs; just as the kind of music that can be produced by a pianist is determined not only by his own skill, but by the character of the piano also. Writers like Mr. Spencer, on the other hand, and with him the whole school of socialists, impressed because, seeing by the obvious fact that the many do something, do something, never pause to inquire what they do, or how much they argue that they do, or how little, but rush to the conclusion that thing. 
Book III the many do everything. This conclusion is even more meaningless than the doctrine which it is intended to contradict. The many do something, and they do what is of extreme importance; but its importance is strictly limited, and is indeed only intelligible through its limitations, just as the character of a profile is intelligible only through its outlines. The object, therefore, of the sociological inquirer must be to discover precisely what these

What the many do is limited. We must see precisely what the limits are. limitations are. The methods by which the discovery is to be made have been already indicated. Let us now go on to apply them. They are of two kinds. One consists of an examination of what, in any domain of activity, the many would produce, if the influence of the few were absent. The other consists in an examination of the kind of faculties which the production of such or such a result implies. If these faculties are common to all, we say the result is produced by the many; if the faculties are rare, we say it is produced by the few.

If a Russian The practical validity of both these kinds of conspirator employs a hundred workmen to dig what they think is a cellar, reasoning is shown by the following imaginary but not impossible case. A hundred Russian workmen, all of them loyal to the Czar, are employed by a citizen of Moscow to enlarge a subterranean cellar, and another hundred are employed to fill it with heavy wine-cases. A week after the work is completed the Czar is driving outside, and, as he passes the citizen's house, is killed by an explosion but is a mine from below. The so-called cellar was a mine, the for blowing up wine-cases were filled with dynamite. Now if all
the Czar, 
those who were concerned in the production of this catastrophe were tried it is perfectly evident that Book III the part played by the workmen would be sharply separated from that played by the man employing them; and that, though they no doubt would have contributed something to the result, they would have contributed nothing to its essential and criminal elements. It is equally evident that if the designed the conspirator and attained result had been not criminal, but entire criminal beneficent, the elements in it that made it glorious character of would be the product of the man who planned and intended it, and not of the workmen who blindly obeyed his orders, neither knowing nor caring what the result would be. Let us take another case of a somewhat different character. When a spontaneous cheer bursts from a thousand people, the volume of sound is obviously the unadulterated product of the many. On the other hand, when a thousand peo- When a choir ple with ordinarily good voices are so trained and music, Handel organised as to sing a chorus out of Israel $I n$ contributes the Egypt, the peculiar qualities which render the acter of the sounds produced by them valuable, obviously imply by them. the existence of the musical genius of Handel, or in other words faculties which belong to hardly one man in a million, and are thus the product not of the many, but of one.

And now let us turn to the actual facts of life, and Let us turn to the kinds of activity on which progress and civilisa- social progress, tion depend, and let us apply our two analytical methods to these. It is needless to repeat, after what has been said in a previous chapter, that it is 
Book III impossible, in a case like this, to examine social activity as a whole. Such activity is of various kinds, and each must be dealt with separately. Let us begin, then, with two - the activity of economic production, and the activity which results in the growth and begin with of speculative knowledge. The first affords us the
economic progress and progress in knowledge. clearest illustration of how to discriminate the product of the many by considering what it would shrink to were the influence of the few absent. The second affords us the clearest illustration of how to discriminate the product of the many by considering the nature of the faculties which the production of the result implies. In the case of To begin with production, then, let us take the
economic progress we must apply the method of inquiring what is produced by labour with and without the assistance of the great man. case of the United Kingdon, and consider the amount per head that was annually produced by the population a hundred years ago. This amount was about \&14. At the present time it is something like $£ 35$, and the purchasing power of money has so increased with the cheapening of commodities, that the excess of the latter sum over the former is far greater than it seems. Now, if we attribute the entire production of this country, at the close of the last century, to common or average labour (which is plainly an absurd concession), we shall gain some idea of what the utmost limits of the independent productivity of the ordinary man are; for the ordinary man's talents as a producer, when directed by nobody but himself, have, as has been said already, not appreciably increased in the course of two thousand years, and have certainly not increased 
within the past three generations. The only thing that has increased has been the concentration on the ordinary man's productive talents of the productive talents of the exceptional man. The talents of the exceptional man, in fact, have been the only variant in the problem; and, accordingly, the minimum which these talents produce is the total difference between $£ 14$ and $£ 35$. This sum is no mere piece of fanciful ingenuity. Parts of it are being done daily before our eyes, and its practical character is being shown in the most conclusive manner, when the profits of a business decline on the death of some head or partner, or when some declining town is restored to its old prosperity by some man of industrial genius, who starts in it some new manufacture.

And now let us pass from industrial activity to To the intellectual, and apply to this our second method prestress in of analysis. Of purely intellectual results, or, as Mill $\begin{gathered}\text { knowledge } \\ \text { must apply }\end{gathered}$ calls them, "advances in speculative knowledge," the method of the most striking examples are to be found in faculties are the mathematical sciences. To the advances made in these it is not only certain but obvious, that the many have contributed nothing, because even of that section of mankind which has some mathematical aptitude the majority are unable even to appreciate them completely when they are made; much less do they possess the powers to make them. No one would contend that the books of Euclid are These are the result of the faculties possessed by every average faculties school-boy, or of the kind of man into which the fined to the average school-boy grows. We may indeed dismiss 


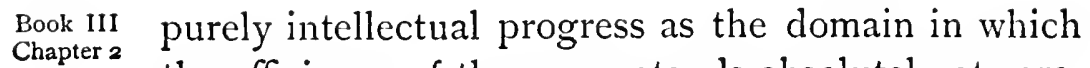
the efficiency of the many stands absolutely at zero.

Let us pass now to the domain of political government, and consider to what extent the And now let faculties of the many, as distinct from those of us turn to political government. the few, are capable of operating there. This inquiry resolves itself mainly into the question of how much the many can do to direct the activity of the few, the activity of the few being presupposed; but it will be well to consider first how much, if anything, the many can accomplish, or

What can the faculties of average men do when left to themselves?

They can accomplish only the simplest actions, the faculties of ordinary men can accomplish, without any assistance from exceptional faculties whatsoever. In the domain of politics, which is here meant to include all organised action of a public and political character, as well as the making and the administration of laws, the only positive functions or actions which can be performed by the co-operation of the average faculties of men, or by absolute and unadulterated democracy, are very simple destructive actions and the formulation of and the insistence on, very simple demands. Of the destructive actions referred to we shall find an excellent example in the lynching of a negro who has outraged some white American girl, or in such an act as the burning of the Tuileries by the communists. In each of these actions the feelings of those who take part in it are as nearly as possible identical. In the first, all of the men are equal in their sense of righteous indignation; in the second, they are all equal in their feeling of blind rebellion; and no special skill is in either case 
required by any one of them. It is true that even in such cases as these there will most probably be Book III Chapter 2 leaders, of some sort, but they will be leaders by accident, and the others will be their comrades rather than their subordinates. Of the simple demands which the many can formulate and insist and formulate upon unaided we may take as an example a demand simplest for the abolition of a tax which distresses in an obvious way multitudes of men equally; or a demand for the continuance of a war, in which the issues at stake are sufficiently apparent to anybody who can read a newspaper. The protest against the tax by the multitudes of men whom it harasses, and the national demand, when it arises, for the continuance of such a war, are phenomena which are absolutely democratic. They are each the sum of a number of spontaneous feelings and reasonings. They do not require any leader to stimulate them; and all who contribute to their force do so in an equal degree.

But the moment we come to cases of any com- The moment plexity the situation changes. If the negro's guilt matters at all could be established only by inference, the lynchers $\begin{gathered}\text { complex, the } \\ \text { faculties of the }\end{gathered}$ would have to be convinced of it by some clever exceptional advocate. If the lynching itself were a matter of required. extreme difficulty, the lynchers would require to be commanded by the boldest and shrewdest of their number. If the tax protested against were indirect, if its injurious effects were hard to detect and realise, and if it were capable of being represented as less injurious than any other, men of exceptional 

Book III activity and exceptional sharpness would be required to rouse the sufferers to a perception of what caused their suffering. In other words, democracy, the many, or the faculties possessed by the many, are incapable of initiation in any complex matter, or of carrying out any course of complex action when initiated; and we may sum up the case by saying that all corporate action in politics is less and less purely democratic in proportion as the questions dealt with are less and less simple.

Now in any civilised country few governmental measures are really simple.

Exceptional men must simplify them for the many.
Now, as a matter of fact, in any civilised country the majority of the measures which the Government has to devise and carry out, however simple in appearance, are very far from simple in reality. Even when their details are few, the good or the bad effects of them are certain to depend on a great variety of circumstances, with regard to which ordinary faculties can form no independent judgment; and if ordinary men are to express any judgment on such measures at all which is not put into their mouths by others and then uttered by rote, these measures must be placed before them by talented interpreters and advocates, who will reduce the details to a real or apparent simplicity and invest their alleged results with charm and an air of certainty. ${ }^{1}$ Accordingly, when we approach the

1 This truth is strikingly illustrated by the history of the Home Rule agitation in Ireland. Whether Home Rule would be advantageous for the British Empire or for Ireland is a very complicated question, and the demand for it consequently never became genuinely popular until it was identified with the simplest of all aspirations - the non-payment of rent. 
question from the point of view of the many, we do nothing but arrive at the same conclusion to which Book III Chapter 2 we were brought when we approached it from the point of view of the few. We arrive, that is to say, at the conclusion that, if we mean by government the devising, the passing, and the administration of this and of that measure, the genuine power of the many, even under the most popular constitution, becomes less and less in proportion as the greatness Thus the voice and the civilisation of the country increases. The in all complex voice of the many is heard as loudly as ever; but the voice of what guides the voice is not the personality that the few. seems to utter it. What guides it is a handful of men, exceptionally active, though not always exceptionally wise. The voice is the voice of Jacob, but the hands are the hands of Esau.

And here before pursuing the subject farther let us look back for a moment, and consider the point in our argument at which we have now arrived. We have seen, then, that in the domain of modern industrial activity the many, if we estimate the total produced in terms of value, produce only an insignificant portion of the total. We have seen that in the domain of intellectual and speculative progress the many literally produce or achieve nothing. We have seen that in the devising and administration of governmental measures the many are powerful in proportion as the issues are exceptionally simple - that is to say, in proportion as they are few and far between.

Now the reader may think that this brings us to 
Book 111
Chapter 2 the end of our inquiry; but it only brings us to the beginning of what is really the important part of it. This, however, For though these conclusions, so far as they go, are is not the end of the matter, absolutely true, they by no means dispose of the whole question which is before us, nor do they really reduce the social power of the many to such small dimensions as they at first sight seem to do. Thus speculative knowledge, though the many contribute nothing to its progress, itself contributes nothing to progress until the many are affected by it, and respond somehow to its stimulus; economic production, when regarded merely as an affair of quantity or as an accumulation of values - a process in which the part played by the many is humble -

for the details of governmental measures are not the whole of government. does not represent that process in its true social entirety; nor is civil government wholly an affair of measures which are devised, discussed, amended, demanded, opposed, carried, or rejected from year to year. We shall find, accordingly, that, in spite of what has just been said, there is room in social life for the operation of the genuine will of the many of pure, spontaneous, and unadulterated democracy. We shall find that the power of this will, though it is in certain directions incalculably less than it is at present generally believed to be, is paramount in domains where its action is not generally recognised The true at all; and the nature of its action here will throw
power of power of to be seen in religion and in a remarkable light on the nature of all action which is in a true sense democratic. Of the domains of activity here referred to, the most important are those of religion and family life. 
Every religion, regarded as a body of doctrines and observances, with the special habits of mind and dispositions of the heart which are appropriate influence of to them, which has ever influenced great masses of the great man mankind, is mainly a result of pure democratic action. enormous, It is true that in the establishment of the great religions of the world another agency has played a great part also. In no other sphere has the influence of great individuals been so vast and so far-reaching as in this. The mere mention of such personages as Christ, Buddha, and Mahomet will make us realise that such is the case; and to these we may add the missionaries, saints, and theologians who have spread yet religions and explained the respective gospels entrusted to gave only them, and given by their saintly lives examples of endured bethe value of their teaching. But whilst nowhere is $\begin{gathered}\text { touch the heart } \\ \text { of the average }\end{gathered}$ the power of the few - of the very few - more man. conspicuous than in the domain of religion, nowhere is the power of the many more conspicuous also. No religion has ever grown, become established, and influenced the lives of men unless its doctrines and its spirit have appealed to those wants of the heart and soul which have been shared, to a degree approximately equal, by all members of the communities, nations, or races amongst whom the religion in question has become established.

The truth of this statement is not in the least Christianity invalidated if we apply it to a religion which we as- this fact; sume to have been supernaturally revealed. Indeed, the clearest example of its truth may be found in the phenomenon of Christianity. Whether we attrib- 
Book III ute the doctrines of Christianity to a natural or a supernatural source, it will be equally plain in either case that they have found acceptance amongst men because there was something inherent in the nature of each individual Christian which naturally responded to them. Even the staunchest Protestant who takes his stand most exclusively on the Bible will be unable to deny that Protestant Christianity, as it exists, represents not merely an assent to a number of bare propositions uttered by Christ, or made with regard to Him by His disciples, but also the subjective interpretation given to these by each believer as he assents to them. Thus the doctrine of the Atonement would never have been accepted by men, it would never even have conveyed any meaning to them, if there had not been something in their nature corresponding to a sense of $\sin$; and the universal effect which, for a time at least, this doctrine had on all the Western nations and on all classes alike, showed that this something which corresponded with the sense of $\sin$ was one of those characteristics in which all men were approximately equal, and that the acceptance of the doctrine was therefore a true act of democracy.

and especially Catholicism.

But the clearest illustration of the truth thus insisted on is to be found, not amongst the varying and conflicting doctrines of Protestantism, which represent theoretically the direct result of the revealed truths of the Bible on each believer individually, but in Christianity as represented by the Church of Rome. According to ordinary Protestant opinion, 
the doctrines of the Church of Rome represent a structure built up by the misguided ingenuity of priests, and imposed by them on a credulous and passive laity; but so far, at all events, as the more important doctrines are concerned, the very reverse is the case really. It has been the world of ordinary believers that has imposed its beliefs on the priests; not the priests that have imposed them on the world of ordinary believers. Let us take, for instance, the Catholic doctrine of the Eucharist, or the beliefs implied in the cultus of the Virgin Mary. That the sacramental elements were actually the body and blood of Christ, that the Redeemer who died on the cross for each individual sinner entered under the form of these elements into each sinner's body - entered bearing the stripes on it by which the sinner was healed, and mixing with the sinner's blood the divine blood that had been shed for him - this was the belief of the common unlettered communicant long before priests and theologians had, by the aid of Aristotle, explained the assumed miracle as a process of transubstantiation; and longer still before their philosophic explanation was, by the ratification of any general Council, given its place amongst the definite teachings of the Church. Similarly, the devotion to the Virgin Mary first sprang up amongst the mass of believers naturally, because the idea of God's mother, with all her motherly love, with all her virgin purity, and with all her human sorrows allied so closely to omnipotence, touched countless hearts

Book III Chapter 2

The doctrines formulated by the aristocracy of Popes and Councils originated amongst the mass of common believers. 
Book III

Chapter 2

Theologians and Councils merely reasoned on the materials thus given them.
Catholicism shows the great part played by the many so clearly because the part played by the few is defined by it so sharply.

in a way which was in all cases practically similar; just as the offer of a helping hand would make a similar appeal to each one of a multitude of men drowning. The official teaching of the Church with regard to the Virgin's sinlessness, and the degree of worship which is her due, has been the work, no doubt, of the few, not of the many - of priests, of theologians, of Councils, of the spiritual aristocracy; but the doctrines which they have thus defined have been no more fabricated by themselves than the wines, good or bad, which a peasantry have made for centuries, are made by the chemist of to-day, who at last undertakes to analyse them.

It has been said that the part which democracy plays in the development of religion is shown us by the Church of Rome with greater distinctness than it is by any other great communion of believers; and the reason is that no other great communion of believers shows us with so much precision the part played by an aristocracy, and thus leaves the part played by democracy with so sharply defined a frontier. The Roman Church alone is in possession of a complete machinery by which all the pious opinions of the whole body of its members - the opinions which have spontaneously shaped themselves in the minds of innumerable Christians as the result of a multitude of independent spiritual experiences, and which, when sufficiently manifested, have been studied by various theologians, and reduced by them to logical and coherent forms - shall be finally submitted to one great representative 
Council. This Council considers how far they are consistent with doctrines already defined, and with Book III one another, and how far, explicitly or implicitly, there is any warrant for them in the Scriptures. It ends with rejecting some, whilst others are reconciled and affirmed by it; and then these last are added to the authoritative teachings of the Church. But the Council, with the Pope included in it, is nothing more than a lens by which the rays originating in the democracy of the faithful are focalised and made to transmit a clear and coherent picture; and the Roman Catholic religion, regarded as a body of doctrines which have actually influenced the spiritual lives of men, is a magnified picture, projected, as it were, upon the sky, of those secret but common elements of the human mind and heart, in virtue of which all men are supposed to be equal before God, and which unite the faithful into one class, instead of graduating them into many.

This analysis of what may be called the natural Catholicism, history of Catholicism may be thought, perhaps, only alluded to to have little appreciable connection with those illustrates the social or sociological problems which at present of truly demoagitate the world, and give to the theory of de-craticaction. mocracy its main practical interest. But neither Catholicism nor religion at large has been referred to here for its own sake. They have been referred to because the case of religion affords a singularly clear illustration of the essential nature of democratic action generally, because it helps us to understand that action in the affairs of ordinary life, and 


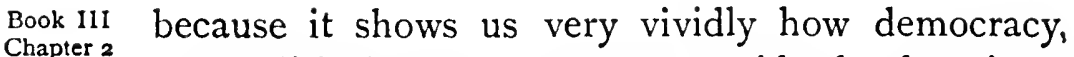
as a political power, operates outside the domain to which it is popularly supposed to be confined. ${ }^{1}$

Thus en-
lightened by it And now let us turn again to a nation's family lightened by it,
let us turn back to family Catholicism throws on the question of what,
life. essentially, democratic action is. The religious life of a Catholic is meritorious only when the beliefs and dispositions of heart which his religion requires of him are spontaneous. No doubt they may have been developed in him by some stimulus from without, but it is essential that, when once present in him, they should draw their life from himself. A saint may rouse a sinner to repentance, but the repentance in its minutest details must be the sinner's own work. He must be his own overseer, he must be his own taskmaster. In economic production this is not so. A bricklayer may contribute to the building of some exquisite cathedral without any sympathy with the architect's intentions, and indeed without any knowledge of them; but a man cannot be a true Christian unless Christ's will becomes his, and unless the beliefs suggested from without are seized on by his own soul, and made a part of himself by his soul's spon-

1 The political power of the religious beliefs of a community can be seen at a glance when we consider our own government of India. Our government there, in the ordinary sense of the word, is a government of the few, not a government of the many; and yet the religion or religions of the many impose limitations on our legislators as stringent as any that could be imposed on them by any number of formal mandates. 
taneous workings. Thus the common religious opinions of the mass of devout Catholics are, theoretically at all events, the sum of a number of independent opinions, which agree because they result from a number of similar but independent experi- Catholicism ences. Here we have the essence of democratic democracy is a action - namely, a natural coincidence of conclu- natural coincisions, which happen to be identical, not because clusions. those who hold them have allowed their thinking to be done for them by the same thinkers, but because with regard to the points in question they naturally themselves think and feel identically.

Now the home or family lives of the citizens of The home life any race or nation owe their points of identity to depends on essentially the same causes. They result from incidence, or propensities in a vast multitude of men which, on spontanealthough they are similar, are independent. The propensities. structure of the family differs amongst different races. Amongst some it is based on polygamy; amongst others on monogamy; but no matter what its details in either case may be, the government, however autocratic, accommodates itself to the family life of the people, not the family life of the people to the laws and the dictation of the government. It will be enough to confine ourselves to the Western or progressive races, amongst whom family life has its basis in monogamy. Advocates of socialism often distinctly say, and the principles of socialism beyond all doubt require, that the family, as now existing, shall be practically broken up; and that whilst the union of the parents is 
Boak III Chapter 2

made terminable with an ease unapproached at present, the multiplication of children shall be regulated by State authority, and that the children themselves shall be reared by the State rather than by the parents. For both these arrangements there are many obvious arguments, which are from the point of view of the socialist quite unanswerable. If the State binds itself to provide for all the children that are born, it is bound to claim some control over the number of them that shall be thrown on its hands. If the State is to be the sole employer and sole director of labour, it must settle the number of children that shall be educated for each branch of industry. If the solidarity of feeling requisite to make socialism possible is ever to be obtained, it can be obtained only by fusing into one those family groups now so obstinately separate. But here the socialists encounter one of their great stumbling-blocks. ${ }^{1}$ In theory the advocates of the extremest and most complete democracy, they are baffled by the habits and character of the very masses to whom they address themselves. There may be unhappy homes, and there may be unnatural parents, but the masses, as a whole, will not listen to any proposal for invading the privacy of the home or for tampering with the parental tie. Any average

${ }^{1}$ The Italian socialist, Giovanni Rossi, who attempted in 1890 to found a socialistic colony in Brazil (an attempt which completely failed), attributes his failure largely to the tenacity with which his followers clung to family life. "If I had the power," he writes, "to banish the greatest afflictions of this world, plagues, wars, famines, etc., etc., I would renounce it, if instead I could suppress the family." 
mother would, when it came to the point, tear out the eyes of any socialist legislator who, under pretext of increasing her weekly wages, should seriously attempt to snatch her children out of her arms. Similar resistance would be offered to any attempt to modify, beyond certain limits, the institution of marriage, or to interfere in any way with the habits of a people's home life. These habits give This truly rise to legislation by the few, but they do not comocridence originate in it. The legislation of the few, on the forces all contrary, has so to shape itself as to protect those to accommomodes of life and institutions which these habits selves to it. naturally produce; and the laws that do this, no matter who devises and administers them, come into being under genuinely democratic dictation. It is a genuinely democratic power which maintains them unaltered, or imposes its own limits on any modification of them which may be made.

The effects, however, of the natural similarities The same of men's family lives are not to be found only in power deterthe domain of laws and government. They confront ${ }_{\text {structure of our }}^{\text {mines }}$ us even more openly in the material surroundings houses, of our existence, especially in the structure of the dwellings of all classes except the lowest. The detached cottage as well as the large mansion, the row of cottages each with its separate door, and the tenement of three rooms, are in one respect all alike. They are constructed and arranged in accordance with those propensities which keep the members of the family group united, and each family group separate from all others. Nor do matters end here; 


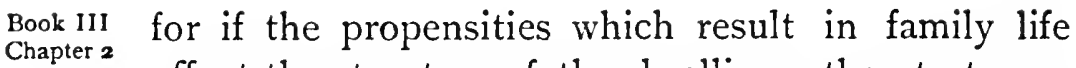
affect the structure of the dwelling, other tastes or propensities equally spontaneous determine what commodities shall be put in it. It is true that these tastes are different in different social classes; it is

and the furniture and other commodities in them;

and indeed on all economic products. true also that they have not, so far as their details are concerned, as deep a root in our nature as the propensities which give its character to the family. They are stimulated, sustained, and modified by constant suggestions from without, by circumstances, and by tastes which, within limits, vary greatly; but they are all alike in this, that when they become efficient, or, in other words, take definite shape as a want, the want has become a part of the man who feels it, and is for the time as spontaneous as are the family instincts themselves.

The influence, however, of men's spontaneous wants is not confined to the house and household appliances, but extends itself over the whole domain of economic products. And here we are brought back again to another portion of the ground which we have already traversed. We are brought back to the domain of economic production, but brought back with eyes opened to a new order of facts.

Now before we proceed to a consideration of these, let us recapitulate what has been said with regard to this subject already. The main fact which was dwelt upon in our previous examination of it was the fact that in wealth-production all but the earlier advances are due, both in their achievement and their maintenance, to the few, 
and to the few alone. The practical validity of this reasoning has been shown in the preceding chapter, Book III Chapter 2 and defended against the common objections sure to be brought against it; and just now it was reinforced incidentally when we were considering the influence of the many on the doctrines of the Church of Rome; for whilst the essentially democratic origin of these doctrines was insisted on, it was shown that the religion of the Catholic democracy could have no organic growth, no definition nor cohesion, without the aristocracy of theologians and the machinery of popes and councils. It was further pointed out For though in that if even in the development of religion the production many are dependent on the exceptional powers of dependent on the few, in the process of economic production the few they are incalculably more dependent. For whilst Catholicism represents the ideas of the multitude, analysed, perfected, and carried out by the few, advanced economic production, such as the production of a beautiful cathedral, represents the ideas of the few carried out in partial or complete ignorance by the multitude.

Attention must now be called to certain further facts which constitute the final evidence of the truth of the same conclusions.

The facts now referred to are those of con- (a fact which temporary trade unionism. These are supposed by trade unionism many of the trade unionists and their sympathisers do but make many of the trade unionists and their sympathisers more to show the growth of democratic power in the apparent). domain of production generally. What they do in reality is to exhibit its essential limitations. They 


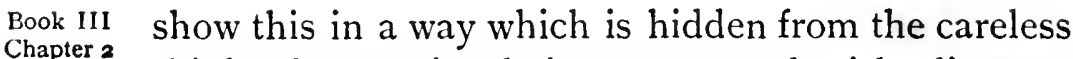
thinker by a curiously inaccurate and misleading use of language. Trade unionism is constantly described as the organisation of Labour. In reality it is nothing of the kind. It is an organisation of labourers; and that, as we shall see, is a totally different thing; for where labourers are spoken of under the collective name of Labour, they are so spoken of with special and exclusive reference to the phenomena which they manifest when actually exerting themselves in production. Were the same men organised for some ethical or religious purpose, they would be spoken of not as Labour, but as the National or Popular Conscience. The organisation of Labour is the setting men to perform a large variety of correlated productive tasks, and prescribing to each man what his own task shall be. But the organisation of labourers that has been brought about by trade unionism is of a precisely opposite kind, and has a precisely opposite end. Its end is not production, but the cessation of production; not the prescribing, the devising, and the allotting of tasks, but the taking men away from them. In a word, it is the organisation not of production, but of obstruction ; nor does the fact that the trade unions have succeeded in organising the latter give so much as a hint that they would be able to organise the former. Even if they could do so, it would be the leaders, not the men, that performed the feat - a new race of employers separating themselves from the body of the employed; and this fact is oddly enough acknowledged 
by the very men who are apparently most blind to it. For one of the arguments most frequently used Book III Chapter 2 to show the practicability of industrial democracy is based on the unusual ability manifested by the officials of the trade unions in managing strikes and great demonstrations of strikers. Must not these men, it is asked, have very exceptional capacities who can gather together their thousands at the shortest possible notice, and march them into Hyde Park through the crowded thoroughfares of London? And it is perfectly true that many of the trade union leaders are, in their own way, men with remarkable and exceptional characteristics. But, in the first place, the more that their admirers magnify them, the more do they detract from the democratic character of trade unionism; and in the second place, if a man is necessarily exceptional because he can so far organise some thousands of men as to march them occasionally into an enclosure where they walk about sucking oranges, how much more exceptional must be the abilities that can organise similar men, day after day, for the performance of the most intricately adjusted tasks, in such a way that their efforts shall result in an Atlantic liner! Trade unionism, then, whatever the ability of its leaders, does not represent democratic action in the actual process of economic production at all ; and instead of pointing to any development of such action in the future, merely helps to show us that no such development is to be looked for.

Such being the case, then, the facts that now 


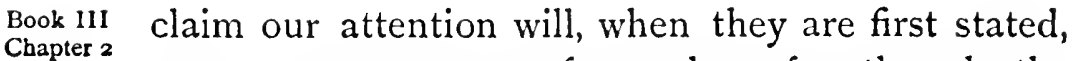
wear an appearance of paradox; for though the power of democracy, in the advanced processes of production, is smaller than it is in any other kind of social activity, abstract thought and discovery alone excepted, yet it exercises an influence on production none the less, which is as purely democratic in character and as far-reaching in its consequences as that which it has ever exercised over the doctrines of any religion.

yet it is the wants and tastes of the many which determine what shall be produced;

For what is the object of production? It is the satisfaction of human wants, which begin as needs, and gradually develop into tastes. The multiplication of these needs, together with the satisfaction of them, is what civilisation means; and though material wealth may increase, as it does in many new countries, without any concurrent development of civilisation in its higher forms, civilisation in its higher forms cannot increase, and certainly cannot diffuse itself throughout the community at large, without a development in the means of material production. Books, for example, though they are vehicles of mental culture, are themselves economic commodities, and depend for their accessibility to the public on the same kind of industrial agencies as do cotton, sugar, tobacco, and that comforter of the nations - alcohol. Refinement of taste and feeling, again, is largely diffused by pictures; but the accessibility of any great picture to the vast majority of any nation depends on the industrial processes by which it can be cheaply and faithfully reproduced - 
processes which have only of late years reached any sort of perfection.

Book III

Chapter 2

But all the industrial ingenuity that great men have ever possessed would be absolutely futile unless the commodities they were employed in producing, or the services they were employed in rendering, sat- and though isfied tastes and wants existing in various sections of elicit these the community. The eliciting of these wants, or the wants by first development of these tastes, depends often on the them, previous supply of the products or services that minister to them. Thus the introduction of railways, of the electric telegraph, of the telephone, of the electric light, preceded any popular demand for them; and many a great writer, according to the well-known saying, has to create the taste by which he is to be appreciated. But he could not create the taste, or, in other words, make it actual, unless it existed already in human nature as a potentiality, any more than the producers of electric light could make the general public anxious to have it in their houses if mankind at large entertained no wish whatever to do anything but sleep between the hours of sunset and sunrise. The wants and tastes; then, to which all production ministers, whether the wants common to all men, like the desire for food, or must be laten: developed by influences from without, like the desire of the nature for telegraphic accommodation, are, when once they and when are in existence, essentially democratic in their are essentially nature. They are not like the movements of a phenomena. mason, who constructs under an architect's order a cathedral with the design of which he has nothing at 
Book III all to do. They represent the uncontrolled promptChapter 2 ings of the individual's own nature, and they affect production, and dictate to the producers what they shall produce, because they represent a spontaneous similarity of taste amongst a multitude of individuals living under similar circumstances. Here we have the reconciliation of the seemingly contradictory facts, that the power of the many over production is at once paramount and small.

Thus, though economic supEconomic demand, though it owes most of its ply is aristocratic, eco-
nomic demand is purely democratic. development to the few, is yet, when its development has taken place, fundamentally democratic in its nature. But, on the other hand, economic supply, which not only ministers to existing wants, but elicits new ones, tends ever more and more as civilisation advances to depend on the action of the few. For as wants increase there is required, in order to satisfy them, a growing elaboration in the methods and organisation of supply; and in proportion as supply becomes more and more elaborately organised, it becomes, from the necessities of the case, less and less democratic. In the Middle Ages, for instance, the only rich supplying class consisted of merchants, because the exchange of commodities, and the bringing them in the required quantities to the proper markets, was a process more complicated than the original processes of producing them. Production has now become quite as complicated as commerce; and a manufacturing aristocracy has developed itself equal in wealth to the commercial. 
But though supply thus depends on the domination of the few, and rises and falls with the ability with which that domination is exercised, The most it is itself at the same time under the domina- cannot make tion of the many. Some industrial genius may drink beer make a colossal fortune by directing the labour of likey do not some thousands of men to the production (let us say) of a new species of beer; but his enterprise will succeed only because millions of men like the beer, and demand it under the direction of their own taste alone. The tastes of the many, of course, exhibit many varieties. Where a million men demand beer, another million will demand whiskey; and there are many commodities, such as guns, golf balls, and cricket bats, the demand for which is confined to comparatively small classes. But the point here insisted on is, not that every member of the community demands the same commodities, but that whatever commodities are demanded, are demanded in each case in accordance with the spontaneous wishes of individuals, and that the total force of the demand is the cumulative result of a number of actions and desires which happen to be spontaneously similar. The commodities supplied to them have, in other words, to be accommodated to a genuinely democratic order; and if the consuming democracy does not consider them suitable, it virtually, by refusing to buy them, condemns them to be destroyed. Thus if we direct our attention to consumption, the few - the directors of industry are the servants of the many; though if we direct 
Book III

Chapter 2

our attention, as we did previously, to production, the many, in the capacity of workers, are the servants or subjects of the few. Now in politics And now let us turn back to the domain of
also there is a similardemand

but the truly democratic demand in politics is not for laws.

politics. We shall find that we do so possessed of a new clue to the true nature and extent of the powers of the many there. For we shall find that in civil government, just as in economic production, the process involved is a process of supply and demand; and that whilst there is a certain kind of political demand in respect of which the many are paramount, and act as a true democracy, their power in the business of supply is never more than partial, and is in most cases illusory.

The first point of which we must here take notice is this - that though the analogy between economic production and civil government is a genuine one, it is not to be found in the phenomena in which we should naturally be tempted to look for it. What we should naturally be inclined to do would be to take the demand for laws and policies as the counterpart to the demand for commodities, and the framing of such laws and the carrying out of policies as the counterpart to economic supply; the first of these, like the demand for commodities, being simple and spontaneous; the second difficult, like the manufacture of them. But in arguing thus we should be wrong.

The demand for laws and policies is, as we have seen already, by no means a simple thing, like the demand, let us say, for a particular kind 
of beer; nor is it the true counterpart to such a demand; for the beer is demanded for its own sake, but laws and policies are not. They are The demand demanded for the sake of certain results on social the counterlife which, by various processes of reasoning those part of a life which, by various processes of reasoning, those demand for who demand them have been led to believe that commodities, they will produce; and it is the results of laws and ties are demanded for policies, not the laws and policies themselves, which their own are in the political sphere what commodities are in sake, laws for the economic, and for which alone the demand is purely and genuinely democratic. The multitudes of men who were led to demand the abolition of the corn laws were not led to do so because the actual process of abolishing them was profitable or pleasurable in itself, but because they believed it would mean a larger loaf on their breakfasttables. It was in the demand for the loaf that the many were spontaneously unanimous, and expressed their own views, not those of anybody else. Their unanimity in demanding the measure was produced by the arguments of an intellectual oligarchy, and could not have been produced without them. Thus whilst the demand for the larger loaf was The demand equivalent to a demand for a particular kind for laws is like becr, the demand for the law was cquivalent to ammodities beer, the demand for the law was equivalent to a commodities demand that the brewer should employ some novel made by some appliances for brewing, with the merits of which machinery. they were acquainted only through the puffs and explanations of the patentee.

There is therefore a great difference between political demand and economic. Economic demand 
Book Iil is single; political demand is double; and whilst one part of political demand - namely, the demand No one makes for social results - corresponds with economic de-
this latter demand. mand, or the demand of the consumer for comEconomic de-
mand is single; modities, the other part of political demand political
demand is namely, the demand for particular measures - does double. not correspond with economic demand at all, but is, on the contrary, in contrast to it. For when workmen's wives buy some particular make of calico for their husband's shirts, or when cyclists buy some particular kind of tyre for their bicycles they do so because they approve of the qualities which those goods manifest when in use, not because they approve of the machinery by

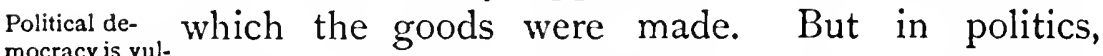
morrycy is vulitied although there is likewise a demand for political with the demand, not for social goods, but for machinery.

goods, as such, - for social security, personal prosperity, and so forth, - of which each man is naturally his own judge, just as those who use them are of the tyres or calico, and although statesmen and governments are frequently supported by the nation, not because they have carried this measure or that, but because the political goods supplied by them are on the whole satisfactory, yet the political demand which is supposed to be the special characteristic of democracies is not a demand for the completed goods, but a demand that this or that patent shall be used in the hope of producing them.

Now political patents are most of them highly complicated devices; the action of all of them is dependent on a complication of circumstances; and they 
are always the work of a special class of inventors. They never represent the spontaneously similar ideas Book 111 Chapter 2 of the mass of ordinary men, any more than the But in so far machinery used in a great brewery represents the is a demand spontaneously similar ideas of the happy and united but for goods customers whom a spontaneously similar taste $\begin{gathered}\text { machinery, it } \\ \text { is not purely }\end{gathered}$ leads to the same tied house. All that the many democratic. can do with regard to these political patents is to listen to the accounts of them given by the patentees, their agents, and their travellers, and to make the best choice they can between a number of different contrivances which they have had no share in devising, and which they only partially understand. They are, indeed, in much the same position in which that portion of the public would be placed which travels habitually between London and Glasgow, if it were asked to decide by its votes which of five kinds of reversing gear should be made use of on the London and North Western engines. If this question had really to be decided by vote, the public might so far instruct itself by lectures from the competing inventors as to give The demands votes for this contrivance or for that; but the very of are manipugrounds on which its choice was formed would be lated by the obviously supplied to it by others; its choice would be limited by the number of the contrivances before it, and the part spontaneously played by it in the whole transaction would be small. And yet, as has just been said, it is the making of a choice of this kind that is regarded as being, in the domain of politics, typically, if not exclusively, the exercise of 
Book III
Chapter 2 the power of the many. The result is that, whilst the many do in reality exert, through their spontaneously similar demand for certain social results, an influence on legislation which in certain respects is paramount, the political theorist, neglecting this fact altogether, confines himself to asserting their Why, then,
is democracy specially asso- of demand in respect of which they are most ciated with the influenced by others.
demand in

which its power is least?

Now what, let us ask, is the explanation of this fact? How does it come that in government a power is attributed to the many which is, even by recent socialists, not attributed to them in economic production? The reason is that over the processes of economic production the many can exercise no control at all, but that over the devising of governmental measures they can exercise some, which, though absolutely small, is yet, by comparison, large.

Because it is the only sphere of activity in which the many can interfere with the machinery of supply at all;

Thus, for instance, though the structure and manufacture of watches is in one sense determined by the many, because the manufacture of those watches only can be continued permanently which satisfy the many, and which the many will consent to buy, it would be impossible for any watchmaker to produce good watches at all if his workmen were constantly required to be altering or readjusting the escapements in order to introduce some "dodge" devised by any man in the street. But in politics this is not the case. The influence of the men in the street, though it can exert itself through 
exceptional men only, and is consequently not wholly their own, does continually make itself felt in law-making as it does not make itself felt in watchmaking; and yet the conduct of government is not rendered impossible, whereas the making of the watches would be. Indeed, in very many cases is not even rendered unsatisfactory.

For this peculiarity in politics there are three and they can reasons. One is that the connection between meas- it here because ures and the general welfare of the community is the efficects of by no means so close or immediate as the con- government on nection between a watchmaker's tool and the wheel close and less or pinion to which he applies it. Social effects the effects of follow on measures slowly, and the tendencies of bad management measures are neutralised by other causes. The on business; second reason is that, as Mr. Spencer rightly insists - agreeing in this judgment with the wisdom of Dr. Johnson - the social ills which governments "can cause or cure" are far less numerous than many thinkers imagine; and the third reason is one with which we are already familiar, that the power of the many in determining what measures shall be adopted is, although not an illusion, less considerable than it appears to be. But whatever their power in this respect, the great point to and in any remember is that it cannot exert itself or exist parent power for any practical purpose unless the few provide of the many is it with the means of doing so, any more than $\mathrm{a}_{\text {felled }}^{\text {trolled the }}$ rudder has power to guide a ship unless some other power shall have set the ship in motion. The popular demand for measures, or the popular 
Book III Chapter 2

The power of the many is a power to determine the quality of cıvilisation and progress, not to produce them.

choice between them, alike presupposes the few who will make the supply a possibility.

And if the power of the many over supply is thus limited even in the domain of politics, in the domain of economic production it is more limited still, and in the domain of intellectual progress it is absolutely non-existent. Their true power is in their demand for completed results - for knowledge which they can assimilate, for dogmas logically stated, which reveal to them clearly what they already believe dimly, for food they can enjoy, for clothes that please their eyes, for commodities and appliances that minister to their comfort and convenience, for social security, for freedom, and for personal and national prosperity. In other words the truth, when properly understood, is a truism. The many are all powerful in determining the quality of progress and civilisation because it is their own tastes and wants to which civilisation must minister, and their own qualities which civilisation must draw out; but of initiating civilisation, of advancing it, or even maintaining it, the many are absolutely incapable unless they have the few to guide them. They contain within themselves the things that have to be developed, but they cannot themselves provide themselves with the conditions of their own development. Without the few to assist them they could no more progress than a train of railway carriages could progress in the absence of the locomotive.

It is impossible, however, to state these conclu- 
sions plainly without realising that in some quarters violent objections will be taken to them; nor is it difficult to see on what grounds the objections will rest. These shall accordingly be discussed in the next chapter; and it shall be shown that the conclusions to which our inquiry has brought us thus far really contain in them nothing inconsistent with the sentiments, or incompatible with the objects, of even those extreme reformers who will certainly feel impelled to attack them. 


\section{CHAPTER III}

THE QUALITIES OF THE ORDINARY, AS OPPOSED TO THE GREAT, MAN

It will be objected that the conclusions reached in the last chapter derogate from the dignity of the average man.

THE objections which will be taken to the conclusion arrived at in the preceding chapter resolve themselves into two groups, one of which rests on general and more or less sentimental considerations, the other on practical. We will deal with the former first.

This group of objections will, by those persons who entertain them, be probably first expressed in an outburst of fine indignation at the wrong which the conclusions just epitomised do to the average man; for such persons will at once take them as implying that the average man is a miserable and helpless creature with only enough intelligence to carry out blindly the orders which his betters are condescending enough to give him; and this implication will strike them as a wanton insult. They will think over various men in private and humble life who were never thought by themselves or others to be above the average level, but who yet were gifted with intelligence, 
taste, and skill equal to any possessed by the men who are called great. They will reflect that these Book 111 Chapter 3 men represent not the few, but the many; and they will angrily reject a theory which frankly denies to the many any of those forces which specifically make for progress.

But this class of objections, which was already But they do briefly glanced at when we were considering the so; precise points by which the great man is distinguished from the average man, will disappear altogether when we take the matter conversely and consider the precise points in which the average man differs from the great man.

In any discussion that aims at scientific precision for since the it is necessary to give to the principal terms used a $a$ here technifar more definite meaning than is given to them cally defined, is when they are used ordinarily; for most words when influences used ordinarily have several meanings, but when used to promote technically they must have only one. Any term, then, when used technically will of necessity specifically exclude a number of ideas - and it may be very important ones - which are frequently attached to it when it is used in conversation or general literature. This observation, as the reader will readily perceive, has a special application to our use of the term great man. The greatness of the great man, regarded as an agent of progress, is a quality, as has been said, which is to be measured by its overt results; and its overt results consist of, and are brought about by, not what he does in his own person, but what he makes others do. It is needless to insist upon 


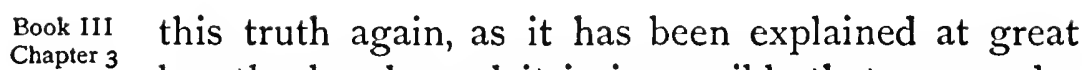

length already, and it is impossible that any reader can misunderstand it. What it is necessary for us here to explain and insist upon is its converse the ordinary namely, that if the essence of technical greatness is man, as
opposed to him, need not be stupid. so to influence the actions or thoughts of other men that the productivity of human labour is increased or the scope of human thought enlarged, no man is technically great who is not in this way influential.

When we come to reflect closely on this definition, some of the results will strike us as not a little curious; for if we exclude from the class of great He is merely men and relegate to the class of ordinary men all talents do not those whose greatness begins and ends with themincrease the selves, and does not tend to communicate itself to
effiency of other men. any one beside themselves, so as to make others think or act more efficiently than they would unaided, ordinary men, or the many, in our present technical sense of the words, will include a number of men of the most brilliant capacities and accomplishments.

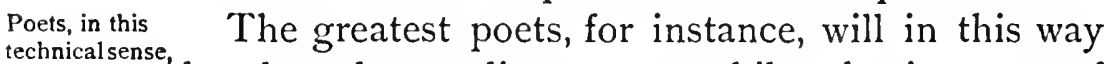
are ordinary be classed as ordinary men, whilst the inventor of men. machinery for making good boots cheaply will be classed as a great man. And the reason is as follows. A great inventor is great as an agent of progress because when the apparatus invented by him is in process of being manufactured, and a thousand workmen are shaping or multiplying its separate parts, or again, when ten thousand other workmen are using the machines when completed, he makes each workman do precisely what he would 
do himself if he were performing their several tasks actually with his own hands. But a great poet Book 111 Chapter 3 let us say Shakespeare - could not in a similar way so influence a thousand ordinary writers that they should all of them be producing plays like Macbeth or Hamlet. Indeed, the greater the poet is, the more absolutely incommunicable is his gift. Shakespeare may have so far contributed to progress as to have aided in the development of literary English generally, but he has not, in the course of some three hundred years, brought into existence one dramatist comparable to himself. ${ }^{1}$ In art, in fact, after a certain point has been passed, it can hardly be said that there is any progress at all.

It is still more important to observe that what is Soare the most ofkilful manual true of the arts is also true of the crafts, or, in other workers, words, those kinds of manual work whose special characteristic is rare personal skill. Manual skill, though essential to material progress no less than unskilled labour is, does not, except during the earlier stages of civilisation, itself constitute an actively progressive principle. That is to say, at a very early stage in the development of productive industry manual skill reaches its utmost limits, and thenceforward remains stationary, whilst industry continues to progress. Thus the skill which is evidenced by the

1 Of course the great poet, like the great religious teacher, may have an effect on the thoughts and imaginations of his readers, and he may be a great man or an agent of progress in this way. But he is not, in the technical sense of the word, a great man in reference to his own art. He does not promote progress amongst other poets. 


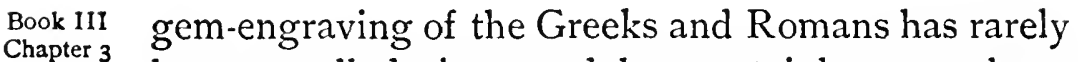
Chapter 3 been equalled since, and has certainly never been surpassed. But we need not stop short at the antiquity of the Greeks and Romans. Many of the implements made by the prehistoric lake-dwellers could not, so far as mere manual workmanship is concerned, be better made by any workman or mechanic of to-day. Indeed, so far is the progress of material civilisation from depending on or coin-

for very great manual skill does not promote progress or influence others, ciding with any progress in manual skill, that it actually depends on a getting rid of the necessity, not certainly of all skill, but of skill of the rarer kinds. If any machine, for example, depended for its successful operation on an accurate finish in certain essential parts which only one workman in half a million could give, such a machine would be practically almost worthless. A productive machine is of use in the service of society generally in proportion as the machines or processes by which it is itself manufactured obviate the necessity for any skill in manufacturing it beyond such as can be obtained with considerable ease and constancy.

Many sentimentalists - and it is difficult not to sympathise with them - regret the manner in which manufacture is thus superseding craftsmanship, or that kind of production in which the beauty or excellence of the product is the direct result and expression of the skill of one producer. But this natural regret, though most frequently expressed by socialists, is defensible only on grounds of the narrowest social exclusiveness. That the artist- 
craftsman who gives his talents directly to each particular commodity in the production of which he is concerned - a silver cup, or a lamp, or a curiouslydesigned carpet, or a printed volume - will produce objects having a charm which is wanting in similar objects produced by the methods of the manufacturer is, no doubt, true. But great artist-craftsmen being few in number, the beautiful objects they make by the craftsman's methods are few in number also, and are consequently obtainable by a few persons only; whilst the objects inferior, but approximately similar to them, which the great manufacturer multiplies in indefinite quantities, are accessible to the many, who, under any social system, must either have these or have nothing of the kind at all. An artistcraftsman, for example, such as the late $\mathrm{Mr}$. William Morris, or a transcriber and illuminator in a mediæval monastery, could produce a volume indefinitely more beautiful than any product of the steam printing-press; but a book which the methods of the manufacturer would admit of being sold for sixpence might cost, if produced by the craftsman, twice that number of pounds; and it is easy to see that, supposing a study of the Bible to be desirable, a village comprising four hundred and eighty families would be benefited more by each family having a sixpenny Bible of its own than it would by the existence of one sumptuous copy chained to a desk in the village church or reading-room.

Rare manual skill, in short, does not promote progress, or help to maintain civilisation at any 
Book III Chapter 3

unless it can be metamorphosed into the shape of orders given to others.
Again, brilliance or charm in private life does not promote progress.

given level, unless it can metamorphose itself as in many cases it can do by means of patterns or otherwise - into a series of orders which men who have less skill can execute, and thus affects commodities not directly, but indirectly. So long as it resides in exertions of the craftsman's hand, applied directly to each commodity produced, it has on the progress of the arts generally no effect at all. The man or men who invented the slide rest communicated a new power to every one of the innumerable artisans now using it; but an artisan who should produce exceptionally accurate work, owing to the exceptional accuracy and steadiness of his own hand, could no more add anything to the faculties of even one of his fellows than a beautiful woman can, by means of her own beauty, improve the eyes, nose, or hair of her plainer sisters. Material progress, then, as has just been said, is so far from being dependent on the growth of rare manual skill that it takes place in proportion as the necessity for such skill is eliminated.

And now let us turn from the consideration of human capacities, as applied to and expressing themselves in the production of particular commodities or results, and consider them as they reveal themselves in ordinary life and conversation. We shall find ourselves confronted by a similar set of facts here. We shall see that many of the talents and qualities which, when possessed by our friends or by ourselves, elicit our strongest admiration, and give an interest to human nature, do nothing to 
advance or to maintain civilisation at all. No one, for example, who knows anything of English society Book III will deny that conversational wit is one of the rarest faculties to be met with in it, and earns for its possessor the reputation of an exceptionally brilliant man; but its possession by one man does not cause its existence in others. The wit leaves the rest of society precisely where he found it. The same is the case with private goodness and wisdom. They may indeed affect an exceedingly small circle, but there is in their influence nothing certain or lasting. The most highly moral parents have often the most dissipated sons; it requires almost as much wisdom to take sound advice as to give it; even if the sensible and the excellent exert a good influence on their own friends, they have no tendency to inaugurate any general moral advance; and a man whose life is rendered interesting by an exceptionally romantic passion may illustrate the capacities of human nature, but he does nothing to expand them.

It will thus be seen that when we describe the Therefore the majority of mankind as being so far passive with who do not regard to the production of progress that unless ${ }_{\text {gress are not }}^{\text {promot }}$ there were a minority of men with faculties which asserted to be the majority do not possess, no progress or civilisa- qualities. tion would take place at all, we are not declaring that the larger part of mankind are stupid, foolish, unskilful, or void of resource, or that human nature as exemplified in the normal man or woman is not often noble and beautiful, and is not always interesting. On the contrary, the very reverse is the 
Book III Chapter 3

case. What is really interesting in human life and in human nature is the universal and typical elements in it, not the exceptional; and we can show ourselves the truth of this in a very convincing way by looking into the mirror that is held up to nature by art. Indeed what is The most famous and interesting characters to be really interesting in human nature is the typical part of it, not the exceptional, found in fiction or in the drama, though they may have been invested by their creators with exceptional circumstances and endowed with exceptional gifts, have interested and appealed both to the world and their creators through the qualities and experiences which they share with human beings generally, not through those which may incidentally make them peculiar. Very few men, for example, are as intellectual as Hamlet; but Hamlet has interested the world because, as has been well said of him, he is not "a man," but "man." If a great dramatist or novelist makes his heroes exceptional, he does so only because he can, by this device, more easily give a magnified representation of what is universal; and

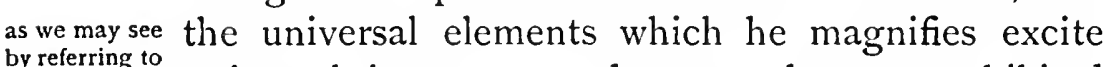
by referring to
art and poetry. universal interest, not because they are exhibited on more than a common scale, but because they are thus exhibited with a more than common clearness. What are the most beautiful love-poems that have made their writers immortal but an expression of what is felt by millions, though it can be expressed only by a few? Why is there life still in the two marriage songs of Catullus, if it were not for the living strings in the normal human heart which the magic of his hand still touches? 
But not only is the normal man the type of what is interesting and important in humanity. $\mathrm{He}$ is Book III Chapter 3 also the type of wise conduct in life, and secures amongst men in general a conformity to this conduct, not by means of advice given by exceptionally excellent individuals, but by the purely democratic pressure of cumulative class opinion. The force which this opinion exercises is commonly called "The World." The details of its injunctions and prohibitions are different in different classes; and Average opinion also on when it is called "The World," reference is usually is for each being made to the pressure exercised by it in opinion; the highest classes only. But this limitation of meaning is altogether arbitrary. Every class is "The World," so far as regards itself. It has its own standards of manners, honour, prudence, dress, and also of moral judgment as applied to social conduct; and it is in respect of all of them incalculably wiser than most individuals who differ from it. In social life even the greatest genius is ridiculous, in so far as he is unusual in anything except his greatness.

It is, moreover, the same cumulative common and the sense, the same spontaneous identity of perception average faculon the part of ordinary men, that forms, as Aristotle by all are in says, the fundamental test of what is real. The test of truth. world of reality is distinguished from the world of dreams because the former is the same for all men. It is $\delta \pi \hat{\alpha} \sigma \iota \delta o \kappa \epsilon \hat{\imath}$. The same fact is the foundation and the justification of trial by jury - an institution in which, as Sir Henry Maine has observed, we 
Book III have the very abstract and essence of all practicable
Chapter 3 democratic government.

Therefore in denying to average men the powers that produce progress,

we are not degrading the average man. We are merely asserting that these powers form but a small part of life.
It is true that even here we are brought sharply back again to those limitations by which the powers of the normal man are surrounded. The jury, who represent the normal man's intelligence, require, as Sir Henry Maine points out, to have the facts on which they are to base their judgment, in exact proportion as these are obscure or complicated, reduced to order for them by advocates whose powers are more than normal. It is also true that, though it is the identity of ordinary men's perceptions which shows the reality and the qualities of external objects, ordinary men's perceptions would never have sufficed to show us that the earth was not the centre of the universe, and that the sun did not move round it. But the true moral of all that has been just insisted on is, that in denying to the masses of mankind those special powers which actively initiate and actively promote progress, and actively sustain the fabric of advanced civilisation, we are not denying to the masses of mankind great moral and great intellectual qualities generally. We are not asserting that the normal, the average, the ordinary man is incapable of being developed into a creature endowed with beliefs, thoughts, and feelings which are not only noble and correct, but which expand and improve as civilisation advances. We are merely asserting that the ordinary man, or the masses of mankind, which are simply the ordinary man multiplied, cannot provide themselves 
with the conditions of their own progressive development; or, to put the matter in a still more comprehensive way, we are merely asserting that that particular form of greatness which improves those conditions or sustains them, by influencing, or compelling, or enabling masses of men to act or think as they would not act or think otherwise, constitutes a very small portion of human activity, and a still smaller portion of human life.

This truth has been lost sight of because modern social philosophers, led astray by political and other passions, have confused two distinct things - man as a moral being, moving in a circle of prescribed duties, and man as a being capable of public or social initiative; and the more we study the ordinary man, and the more fully we appreciate the varied possibilities of his nature, the more clearly shall we see, and the more ungrudgingly shall we recognise, how absolutely he is, so far as civilisation is concerned, dependent on the exceptional man for even those very powers in virtue of which the action of the exceptional man is controlled by him.

The general or the sentimental objections, then, which might not unnaturally arise in the minds of many when the claims of the great man to be the sole agent of progress are first broadly asserted, are found to disappear altogether when the meaning of these claims is more fully considered. But sentimental objections, as has been said already, are by no means the only objections which these claims have 


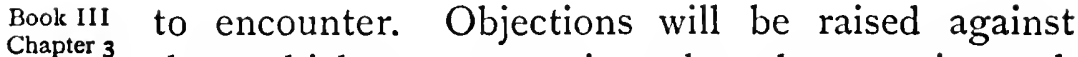
them which are economic rather than sentimental, and which, moreover, - this is a still more important fact, - rest solely upon a practical, and have no theoretical, basis.

Socialists can object to this conclusion only because it establishes the claim of excepexceptional wealth.

In order to see what these objections are it will be well to consider them in their extremest and most uncompromising form. We will accordingly consider them as put forward by the socialists. That the objections of the socialists to the claims made for the great man are not grounded in any theory that consistently disallows them, is sufficiently shown by the fact that even the most extreme socialists, no less than the members of every other militant party, are always extolling the exceptional qualities of their own leaders. Agitators, thinkers, and writers like Karl Marx, Lassalle, and Engels have been extolled by their followers as though in their own way equal to Cæsar and Napoleon, to Aristotle, Galileo, and Bacon; and their works are continually called "marvels of reasoning," and described as evincing "such powers of thought as are given to only a few men in the course of five hundred years." The arguments, therefore, which are employed by socialistic thinkers to convince them that the great man is not essential to social progress, and plays no real part in it - those arguments to the examination of which the first chapters of this work were devoted, do not really convince even those who lay most stress on them, so far as they are applicable to social progress generally. For the 
socialists in practice are forced to limit the application of them to two kinds of social action only; and these are social activity in the domains of political government and of wealth-production. They are, moreover, applied to the latter of these with so much more strictness than to the former, that the objections to the special claims of the great man as a Theycannot wealth-producer are the only ones that here require have any our attention. objection to it, for they are

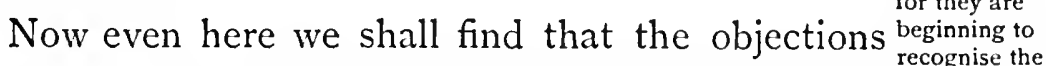
in question are originated not by theoretical, but by importance of practical considerations only; for one of the most man themcurious features in the history of socialistic thought, selves, from the time when socialists claim that it first began to be scientific till to-day, has been the unwilling replacement, in their theory of production and progress, of that factor or element - and this factor is the great man - which Karl Marx, with his doctrine of labour as the sole creator of value, had eliminated. Under one disguise or another the great or exceptional man, as distinct from the average labourer whose productivity is measured by time, has been put back in the place from which the theory of Marx had ousted him; and the inventors, the men of enterprise, the organisers and capitalists of to-day - or, as Mr. Sidney Webb calls them, "the monopolists of business ability," - are given back to us in the guise of officials of the bureaucratic State, armed by the State with the industrial powers of slave-owners. It is true that socialistic theorists still do their utmost to hide from themselves and their followers the nature 
Book III of this change, by means of those curious arguments which find their chief exponent in Mr. Spencer, and which have rendered sociology thus far so useless as a practical science. But the change is but partly hidden, nevertheless, even from themselves.

and only obscure the fact for purposes of popular agitation.
So far, however, as the reasoning of this book has gone already, no claim has

Why, then, should they endeavour to hide it at all? Why should they shrink from a perfectly frank avowal - an avowal which they are constantly compelled to make by implication - that the great man's power in wealth-production is what has been described, and that every increase in the wealth of civilised communities is due to him? They shrink from making this avowal for one reason only. This reason is that their main practical object is to represent the possessions of the great man, or of the few, as a treasure to which the few have no theoretical right, and which can be, and ought to be, divided amongst the many. They are therefore compelled, by the necessities of popular agitation, to obscure the part that the few have played in producing it, and to pretend, so far as possible, that it is produced by the undifferentiated many. If it were not for its promise to the many of some indefinite pecuniary gain, it may safely be said that socialism would have been never heard of ; and if this pecuniary promise were made good, the demands of the socialists, as a practical party, would be satisfied.

And now having considered this, let the reader look back at the claims that have, in our present argument, been advanced for the great man thus far. It will be seen that not a single claim has been 
advanced on his behalf to which, on practical grounds, any socialist could object. We have not assumed that out of all the wealth he produces he shall take a been made for larger, or even so large a share, as the least efficient to which of his workmen. On the contrary, we have assumed ${ }_{\text {object; }}^{\text {socilis }}$ that his contributions to the national wealth find their way in to the pockets of those around him, and that for him nothing is left but the bare means of subsistence. It has indeed been shown that he must necessarily have the control of capital, and be free to use it in the way that he thinks best; but this is only because the control of capital affords the sole means by which, amongst free men, industrial discipline can be enforced and the productive genius of the few be communicated to the muscles of the many. For all that has been said thus far to the contrary, the great man himself may derive from his control of it no advantage whatsoever. We have assumed only that for we have by his use of it he shall concentrate his exceptional he keeps none faculties on the practical business of wealth-produc- of the exception with as much intensity and devotion as he he makes, for would do if the whole of what he produced were to go into his own coffers. We have, in fact, been regarding the great man as being socially the servant of the ordinary men, though in technical matters he is their master.

So far, then, as our argument has up to this point proceeded, we have merely in our theory assigned to the great man functions which are implicitly assigned to him in the reasonings of the more recent socialists themselves, whilst in practice we have 
Book III Chapter 3

but that he works exactly on the terms the socialists would dictate to him.
It now remains to consider whether he would really do so. assumed the realisation of the very conditions at which socialism aims. For let us consider very briefly what these conditions are. The more carefully the theoretical admissions and the practical promises of the more recent socialists are examined, the more clear does it become that the sole essential change which socialism would introduce into the existing economic régime would consist not in getting rid of the great man, but in securing his activity on totally new terms. The socialists aim, in fact, at securing the best industrial masters and treating them like the worst servants. This, as social reformers, is their fundamental peculiarity. For whilst they propose to secure an equal distribution of products, they implicitly admit that the producers may be divided into three classes - the men of exceptional ability who produce an exceptional amount of wealth; the mass of average men who produce a normal amount; and the idle, the refractory, and the worthless, who produce less than the normal amount; and they propose accordingly to apportion the products as follows. To the average man they would give twice as much as he produces; to the idle and the worthless man they would give a hundred times as much as he produces; and to the great man, on whose talents the fortunes of all the others depend, they would give from a hundredth to a thousandth part of what he produces.

Now, whatever the reader may think of this economic programme, there is nothing in the present work, thus far, to show that it is impossible; and if 
the object of socialists is to level social conditions, to abolish all differences of rank, and to confiscate Book III all exceptional incomes, this book up to the present point might be accepted as a handbook of socialism. For the reader will recollect that when it was said that the great man's activity involved the existence of motives which would lead him to develop his faculties, and that without such motives these faculties would be practically non-existent, the question of what these motives were was for the time altogether waived, and we assumed the development and the subsequent exercise of his abilities as something that would take place no matter under what conditions. The question, however, which we then put on one side must now be taken up and submitted to a careful examination. It being granted that the activity of the great man is necessary, on what conditions can his activity be secured? Can it be secured on the conditions that are proposed by socialism, or on any others that even remotely resemble them? 
BOOK IV 


\section{CHAPTER I}

THE DEPENDENCE OF EXCEPTIONAL ACTION ON THE ATTAINABILITY OF EXCEPTIONAL REWARD, OR THE NECESSARY CORRESPONDENCE BETWEEN THE MOTIVES TO ACTION AND ITS RESULTS

IN entering on the inquiry which now lies before Great men us it is necessary to recall to the reader, and to insist ordinary men with renewed emphasis, on a fact which has been ex- in degree only $_{\text {nind; }}$ plained with the utmost fulness already. This is the fact that those exceptional efficiencies of the few on which the initiation, the progress, and the maintenance of civilisation depend, and which in a technical sense we have here described as greatness, do not consist of qualities which are unique in kind, or which are not possessed in some measure by the masses of ordinary men; but that they are made up of ordinary faculties magnified or mixed together in unusual proportions. For although, as George Eliot observes in a striking passage, the faculties of all men are the same in kind, they manifest themselves in different men in such very different degrees that a faculty or feeling which in one man has the power and dimensions of a tiger, may never in another man outgrow 

Book IV those of a weasel. Greatmess, then, is simply the possession and exercise by such and such a person, in an exceptional degree, of some faculty or assortment of faculties, the rudiments of which are possessed by all. And the reason why it is necessary to insist on

and the use of exceptional powers is conditioned like the use of ordinary powers.

Now let us take the most universal powers possessed by man, viz. those used in acquiring the simplest food. this fact here is that, as a consequence of it, the use which the great man makes of his exceptional powers - or, in other words, their whole efficient existence-depends on certain causes which are relatively, though not absolutely, similar to those on which depends the use which the ordinary man makes of his.

Let us, then, consider the powers of the ordinary man first, and let us take as examples of them those powers or faculties which are most universally distributed amongst the human race - ramely, the powers by which the rudest populations obtain enough food to live upon. Now such faculties, practically universal as they are, would be potential only, not actual, if it were not for two things. These are certain appetites or desires, having a physiological origin, on the one hand, and the external conditions on the other, which make the satisfaction of those appetites, or the fulfilment of those desires, a possibility. Thus if men could live without eating, and had no desire for food, those special faculties would

Man's powers in agriculture would be latent unless man wanted food and the earth's surface were cultivable. be dormant which are now exercised in agriculture; and this means that for all practical purposes they would not exist at all. These faculties would also not exist at all, no matter what men's desire for food might be, if the whole of the earth's crust had 
happened to be cast-iron, and if tillage were consequently impossible, and there were no seeds to sow. Book IV Chapter I In other words, the very commonest and very simplest faculties which human beings possess have a practical and a universal existence in those beings, only because, in the first place, they minister to universal wants, and because, in the second place, Thus the exercise of the the earth is so constituted as to supply the materials simplest facul on which these faculties can operate. Or, to put the on the want matter in more general terms, the very commonest and simplest faculties are not practically self-existent, of some certain the possibility of attaining it. except as mere barren potentialities; and as practical forces they exist only in the degree to which they are evoked by external things and circumstances by some external object, such as food, which excites and will satisfy desire, and by external circumstances which make the object obtainable.

Now if this be true of those faculties of the com- If this is true monest kind ministering to the needs which all men of the commonest kind, ministering to the needs which all men monest faculinevitably feel alike, and which they always must ${ }_{\text {at supplying }}^{\text {ties, whim }}$ feel so long as they remain alive, it is yet more necessaries, obviously true of those higher and rarer faculties it true of rare ministering to needs which are so far from being acum at produch inevitable, that whole races have existed and do ex- ing supeist without any conscious knowledge of them. The great inventor, the great director of industry, will not develop or use his exceptional latent faculties unless by the use of them he can achieve some object which he desires; and this must be something which the community has to give, or the possession of which it will secure to him if it be something which he himself 
Book IV Chapter I

Society, then, if great men are to work in it, must be so constituted as to make the reward they desire possible. the great men shall think worth working for, their exceptional faculties will remain potential only. That is to say, their faculties will be practically non-existent, and the community will be as helpless as it would be if it had no great men at all.

In so doing society unconsciously makes a social contract with its great men;

produces. Columbus, for instance, as the records of his life show us, would never have braved the Atlantic if the society of his time, though in the end it rewarded him ill, had not rendered an enormous reward both in money and rank possible - a reward which he specifically bargained for in the event of his enterprise being successful. And similarly in the case of great men in general, unless society is so constituted as to render some reward or other the natural or possible result of the exercise of certain exceptional faculties, and unless this reward shall be one which Now here we have what is virtually a genuine social contract. It is not, indeed, such a contract as Rousseau dreamed of. It was never made deliberately at any period of history by two independent parties coming together for the purpose. It was the result of a gradual and quite unconscious process. Ordinary men, having experienced the advantages of being directed by great men, submitted instinctively to such conditions as the great men demanded, and instinctively offered them, or allowed them to retain possession of, such rewards as were necessary to stimulate them to further action. But these proceedings were a bargain, a social contract, none the less, although they were not recognised as such; and they constitute a bargain still - a bargain which is continu- 
ally being renewed, and the terms of which reformers are continually trying to alter. Thus the socialist's Book IV Chapter I proposal to take from the founder of a new industry all the wealth that his exceptional faculties have created, and pay him, as they propose to do, with the paper money of honour, is merely an attempt to make a new bargain with the great man, which shall secure his services on cheaper terms for the little men. Similarly, all encouragement offered to art and science by the State is a bargain offered to a number of unknown persons, who are presumed to be the possessors potentially of artistic and scientific faculties, the State engaging to give them certain opportunities and rewards, if they on their part will make their potential faculties actual.

Now with regard to this bargain or contract and this is a which the community has not only made, but is is being conalways remaking and revising with its great men, stantly revised. we must observe that it is a bargain which, from the necessities of the case, is made by the community solely with individual great men who are living. It is not a bargain offered to the great men of the past, no matter how much of his greatness the living great man may owe to them. It is impossible to bargain with the dead, and therefore to the present question the claims of the dead are as irrelevant as the claims of protoplasm. The present question is how shall such and such living people be induced to develop certain superiorities which are latent in them, or to use to the best advantage superiorities which have been developed already. And 
Book IV the answer depends on these men themselves. It depends on the characters which they personally possess, and not on the parents or ancestors from whom their characters have been derived. We can no more go behind the personality of the great man in bargaining with him, than we can go behind the personality of the dipsomaniac in attempting to cure him. We may excuse the failing of the latter as something which he has inherited from his ancestors; we can cure it only as something for which he is himself responsible. If civilisation, therefore, depends The great men on the great man, no community can become or themselves are the ultimate fixers of their own price. remain civilised which does not so arrange itself as to accord to its living great men such rewards as they themselves feel to be a sufficient inducement firstly to develop their faculties, and secondly to employ them to the utmost. Here is the Here, then, we have a new and final verification
final proof that living great of that truth which has already been established men, not past conditions, are the causes practically involved in progress. against the arguments of Mr. Spencer-namely, that the great man is a vera causa of progress, and that no explanation of progress has any practical value which does not base itself on an examination of the great man's character. And that such is the case will become yet more apparent when we take into consideration the following additional facts, which are quite distinct from any we have yet touched upon, and which practically have an equal, or perhaps even a superior, importance.

If the exceptional faculties of the great man were so far like the faculties possessed by all men, 
that by looking at him we could tell that he was a potential inventor, or organiser of industry, or philosopher, as easily as by looking at a common man we can tell that he can trundle a wheelbarrow, the entire force of the foregoing argument would be lost. The community would then know what each great man could do for it, and could force him to do it by flogging or starving him if he refused. The ordinary faculties - the faculties of manual labour - can be made to exert themselves precisely in this way. A large number of the great works of antiquity were due to labour successfully stimulated by the whip. But it is only a man's commonest faculties that can be called into action thus; and they can be called into action thus only for this reason - that those who coerce him know that these faculties are possessed by him, and they also know the task which they wish to make him accomplish. But in the case of the great man both these conditions are wanting. It is impossible to tell that he possesses any exceptional faculties till he himself chooses to show them; because no and until circumstances supply him with some motive one can tell for exercising them, he will probably be hardly aware texceptional that he possesses such faculties himself. Moreover, they choose to even if he gives the world some reason to suspect their existence, the world will still not know what he can do with them, and will consequently not be able to impose on him any task until he himself chooses to show of what he is capable. Any farmer by looking at Burns could have told that he had the makings of a ploughman in him, and have forced 
Book IV him, under certain circumstances, to do so much ploughing daily; but no one could have told that he was a poet if he had not of his own free will revealed the fact to the public; and even when the public were aware of it, no one could have forced him to compose The Cotter's Saturday Night. A press-gang could have turned Columbus into a common sailor, but not all the sovereigns of Europe could have forced him to discover a new hemisphere. On the contrary, it was he who had to force sovereigns into the reluctant belief that possibly there

They cannot, therefore, be coerced from without, like ordinary workers. was a new hemisphere to discover. The great man, therefore, is lord of his exceptional faculties in a way in which the common man is not lord of his common faculties. The existence of the latter faculties cannot be concealed; the kind of work that can be accomplished by them is known to everybody; and therefore the community by the exercise of mere force can command the average man, and make him work like an animal. But over the exceptional faculties of the great man it has no command whatever, except what the great man gives it; for it neither knows that the faculties exist, nor what things the faculties can do, until the great man elects to reveal the secret. He cannot be made to reveal it, he can only be induced to do so; and he can be induced to do so only by a community which offers to exceptional faculties some assured and exceptional They must be reward, just as a reward is offered for evidence induced to work by a reward against an unknown murderer. Moreover, just as in the latter case it very often happens that the re- 
ward originally offered has to be raised several times before a sum is reached which will induce the witness

Book IV Chapter I to come forward, so must any community, as the condition of becoming civilised, raise the rewards of which they greatness to such a figure that the possessors of to be sufficient. latent superiorities will be induced to develop and use them. And hence the great man not only causes progress by what he does, but he influences also the entire structure of society, by his character, which regulates the terms on which he will consent to do it.

This is the point at which the science of sociology Hence the primarily comes in contact with the practical prob- character and lems of to-day. That all progress is due to the impress them. efforts of the superior minority is a truth which, selves on the taken by itself, and apart from other truths allied to it, society. we can merely recognise and assent to. We can do nothing to alter it; nor will the fact of our recognising it, if taken by itself, tend to alter or guide our conduct. We are not even able to settle the number of males and females which shall be produced in each family. Still less can we settle or increase the number of individuals who shall bring into the world with them talents more than ordinary. But though no community can do anything to settle or alter the per centage of potential greatness that will be born into it from generation to generation, it can settle or alter the social conditions and rewards by means of which this potential greatness shall be developed and enabled to use itself; and a very large part, though not the whole, of political wisdom 
Book IV Chapter I

This is what socialists constantly forget,

will thus consist in arranging these conditions and rewards, so that from each potentially great man, whatever degree or kind of potentiality may be his, the community may elicit the highest and most farreaching efforts of which he is capable. It will, of course, be to the interest of the community to secure this result by offering the great man the smallest and least costly reward, the desire of which will induce him to develop and exert himself to the utmost; but the ultimate fixer of the great man's price - let it once again be said - is not the community, but the great man himself.

It is this sociological and psychological truth that even the clearest-headed amongst the socialists are continually forgetting. They perceive it at one moment, at the next moment they entirely forget it, and solemnly proceed to build up their visionary polity on foundations which their own arguments had previously condemned. A curious example of this "inability," as Mr. Spencer calls it, "to comprehend assembled propositions in their totality" is to be found in a remarkable passage by Mr. Sidney Webb. Having observed that "socialists would nationalise both rent and interest by the State becoming the sole landowner and capitalist," he goes on to acknowledge that great fundamental fact which it is the main object of the present work to elucidate. "Such an arrangement, however," he says, "would leave untouched the third monopoly, - the largest of them all, - the monopoly of business ability." In these last words he appears to be like a Daniel 
come to judgment. He recognises in the fact that the few have a natural monopoly of faculties, the Book IV Chapter I exercise of which is required for the progressive and they well-being of all, a genuine and a formidable diff- equalise culty in the way of the realisation of socialism; but matters by not now comes the passage for the sake of which these menany exothers have been quoted. Great as this difficulty reward. is, he tells us, "the more recent socialists" have devised a way for getting over it. And what does the reader think this way is? It has at all events the merit of being very simple. "The more recent socialists," says Mr. Webb, "attack this third monopoly also by allotting to every worker an equal wage, whatever may be the nature of his work."

It has been thought worth while to quote Mr. They forget to Sidney Webb because he is an exceptionally favour- under these able specimen of the modern socialistic theoriser. It grcat men is therefore interesting to notice the hiatus that here $\begin{gathered}\text { would exercise } \\ \text { or reveal }\end{gathered}$ yawns in his argument. The entire question which their excepis really at issue is begged by him. His allies, he tional powers tells us, though they cannot destroy the monopoly which the few possess of exceptional business powers, will destroy the effects of this monopoly by taking away from the few nearly all the wealth that their exceptional powers produce. It never seems to occur to him to ask whether, under these circumstances, the few would develop or exercise their exceptional powers at all. And yet the whole problem for him, as a socialist, lies here, and lies nowhere else. For from the very fact that these powers are admittedly a monopoly of the few, it is 
Book 1V Chapter I

Exceptional rewards are essential to exceptional action.

evident that their existence cannot be assumed in anybody unless he exerts himself to give some sign of their presence. External authority, therefore, can compel nobody to use them who does not put himself at the mercy of the authorities by letting them know he has them; and thus "the more recent socialists," in attacking "the third and greatest monopoly," are really themselves at the mercy of the very monopolists whom they propose to attack. It is true that if a socialistic revolution could be brought about suddenly, existing great men known to have certain talents, which had been already developed and exercised under conditions which the revolution destroyed, might be seized on by the State, in its capacity of universal employer, and forced to continue something of their former voluntary activity by threats of torture or some similar method of coercion. But even granting this to be possible, it would only solve the problem for a moment ; for as these men died and some of them would be dying daily - new talent would be wanted to take the place of the old; and though the State might coerce such talent as was already developed, it could not by coercion secure the services of the new, because threats of coercion would never tempt new talent to discover itself, but would, on the contrary, drive it yet deeper beneath the surface.

Exceptional potentialities can be called out and realised only by a kind of action which is the very antithesis of coercion, and which is analogous to that of sunshine on buds, or flowers or fruits 
- namely, the penetrating, the warming, the stimulating action of the hope of certain personal advanBook IV Chapter I tages on the mind of the exceptional man, which advantages he will not only covet as advantageous, but will recognise as the natural result of the exercise of his exceptional faculties, and as a result attainable by the exercise of these faculties We must inonly. What these personal advantages are, the quire what the desire of which, coupled with their attainability is exceptional necessary to stimulate men who have more than ordinary potentialities, to do greater things by developing them than are done by ordinary men, must be determined by reference to the actual facts of life, the records of which are ample, and the details of which, though numerous, can by careful analysis be easily reduced to order. 


\section{CHAPTER II}

\section{THE MOTIVES OF THE EXCEPTIONAL WEALTH-}

PRODUCER

Socialists, though often forgetting the necessity of exceptional motive, often remember it,

IN spite of their frequent forgetfulness of the fact just insisted on, that the development and exercise of exceptional faculties can be secured only through the influence of some exceptional motive, this is not a fact which socialists theoretically deny. On the contrary, often as they forget it, with curious consequences to their reasoning, yet just as often, when they happen to be directly confronted with it, they are loud in declaring that they recognise it quite as clearly as their opponents; and a considerable portion of their more modern writings consists of a setting forth of the various exceptional rewards which will, according to them, in the socialistic State, and endeavour elicit from exceptional men the exercise of their to show that socialistic society would have sufficient rewards to offer to its utmost powers. Moreover, the rewards on which the socialists principally insist are rewards, the desire of which is admitted by all parties to be an actual great men, force in society as at present constituted, and in fact to have been, ever since the dawn of history, the motive to which much activity of the highest kind 
has been due. These rewards have been defined in a recent Handbook of Socialism as the pleasure of "excelling," "the joy in creative work," the satisfaction which work for others brings to "the instincts of benevolence," and, lastly, "social approval," or the homage which is called "honour."

Book 1V

Chapter 2

If the socialists, however, confined themselves to maintaining that the desire of such rewards as these constitutes a sufficient motive to exceptional activity of certain kinds, they would not only be asserting what nobody else would deny, but they would be putting forward nothing which, as socialists, it is their interest to assert. The ultimate proposition which, as socialists, they aim at establishing is not that certain kinds of exceptional men do certain kinds of exceptional things, in obedience to the motives in question; but that because some excep- The fundational men, endowed with certain temperaments, tion is, will are motived by them to activities of certain specific such rewards kinds, other exceptional men will be motived by stimulate them with equal certainty to other activities of a wealth-prokind totally different - and more especially to the duction? activities which result in the production of wealth.

Here is the fundamental point on which the socialists join issues with their opponents. Their opponents, they say, assume that the sole reward or advantage, the desire of which will stimulate the monopolists of "business ability" to exert that ability in the production and augmentation of wealth, is a share of wealth for themselves proportionate to the amount produced by them - an 
Book IV amount which will separate their lot from that of the majority of their fellows. Now if this should be really the case, as the socialists are coming to perceive, the fact would be fatal to the entire ideal of socialism. They are consequently now directing the best of their ingenuity to showing that the Is the enjoy- desire of possessing exceptional wealth is altogether
ment of exceptional wealth superfluous as a motive to producing it ? superfluous as a motive for producing it, and that the great producers of it, when all chance of possessing it is taken from them, will find in the pleasures of the strain which the productive process necessitates - especially if these are supplemented by the inexpensive thanks of the community - a more powerful inducement to exertion than is the prospect of the largest fortune. If it is so, it is
for the socialists to prove

Now in endeavouring to make this peculiar that it is so; position good, it is evident that the burden of proof lies with the socialists themselves; for although the doctrine that all exceptional exertions in wealthproduction are motived solely by an avidity for exceptional wealth as such - and this is the doctrine which the socialists set themselves to controvert - is a very imperfect rendering of what their opponents actually maintain, it embodies an assertion which the socialists themselves declare to have been true of all exceptional exertion in wealth-production hitherto. No one declares this more passionately and more persistently than they. For what, as political agitators, has been their chief moral indictment against the typical great men of industry - the organisers of labour, the introducers of new 
machinery, the pioneers of commerce? Their chief moral indictment has been this: that these men, Book IV Chapter 2 instead of labouring for their fellows, or for the for they themsake of any of those rewards which the socialists declare to be so satisfying, have been motived that it has not been so in the solely by the passion of selfish "greed." Its hideous actually so influence, they say, is as old as civilisation itself, and the "monopolists of business ability" in Tyre and Sidon were as much its creatures as are their modern representatives in Chicago. And this assertion, unlike many made by the socialists, has the merit of being, so far as it goes, true. Greed, of course, is a word which, in addition to its direct meaning, carries with it an accretion of moral insult; but putting aside this, it means in the present connection merely a desire on the part of the great wealth-producer to enjoy an amount of wealth proportionate to the amount produced by him: and from the dawn of civilisation up to the present time all great wealth-producers, whether merchants, manufacturers, or inventors, have had the desire of enjoying such wealth as their motive. The desire has been connected with the activity just as universally and closely as the desire of water is connected with the act of drinking it, or the desire of winning a woman with the act of making love to her. If the socialists, then, would persuade us that a motive so universal as this can be now superseded by others of an entirely opposite character, they can do so only by adducing the clearest evidence that, on the one hand, this motive itself is losing its old power, and 
Book IV that other motives, on the other hand, are actually acquiring and exercising it.

Are there any signs, then,

Let us first, then, consider the passion of greed that the desire itself, and ask whether there is anything in its confor exceptional wealth is nection with wealth-production hitherto which may beginning to lose its power? lead us to think that in spite of its universality in the past, it is merely a transitory propensity from which exceptional men will free themselves, instead of being a propensity rooted in the very constitution of human nature.

We shall find that the socialists themselves maintain just the contrary;

And here again the socialists will be amongst our most important witnesses; for just as they, of all writers and thinkers, have done most to call attention to the fact that up to the present time greed has been the main motive by which the exceptional wealth-producers have been actuated, so they, of all writers and thinkers, have done most to call attention to another fact as well, which shows the motive in question to be as permanent as it is universal. For that very desire of the producer to possess what he himself produces, which, when found in the exceptional man, they denounce as greed, and which they tell us that the exceptional man will get rid of in the course of a year or two, is the very desire which, as existing in the common man, they have assumed to be the foundation of his whole industrial character; and to it have all their most fervid and powerful appeals been made. The socialists, in their attempts to excite the masses against the existing order, have relied less on rhetorical declarations that the labouring man gets 
very little, than on the quasi-scientific assertion that he gets less than he produces, and that consequently

the wealth of his employers is merely his own for they appeal wealth stolen from him. "All wealth is due to each producer labour; therefore to the labourer all wealth is due" to possess all has formed from the first, and still forms, the text the most and from which the socialists always preach when permanent addressing the labouring classes; and the use of this text as the watchword of popular agitation is obviously an admission that, as a producing agent, man is motived so exclusively by the desire to possess what he produces, or else its fair equivalent, that he naturally resents the idea of producing anything merely in order that others may take it away from him. Indeed, this doctrine that the desire for the product, and the producer's sense that he has a right to it, form the only motive for production possible for a free man, formed the unquestioned basis of the entire socialistic psychology so long as the theory of Marx was held by the socialists to be unassailable, according to which wealth was the product of average labour, and the common or average labourer was the sole true producer. It was only as time went on, and the socialists were and never slowly compelled to recognise the few to be pro- thestionsolong as ducers of wealth just as truly as the many, that they believed the socialists began their attempts to get rid of the producer was doctrine which a very little while ago they regarded as axiomatic - the doctrine that each producer has a right to his own products, and that his hope of possessing it is his principal motive for its produc- 
Book IV tion. In making these attempts, however, they Chapter 2 have, with a judicious eclecticism, been content to They ques- apply them to the exceptional man only; and the trine only when common man and his motives they leave undis-

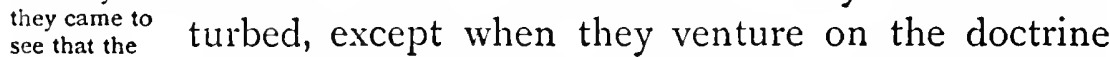

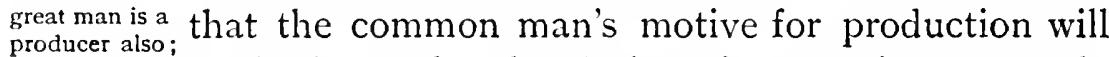
and they con- in the future be the desire of possessing, not only fine their questioning to all that he produces, but all that he produces and a his case.

But if the labourer desires to possess what he produces, much more will the great man do so; great deal else besides.

If, then, it is unlikely that this desire to possess the product will cease to be operative as the motive to production amongst the masses, that it will cease to be operative amongst the few is more unlikely still; for the man who is possessed of average powers only cannot hope to produce more than the average man requires, and his object in producing tends to represent itself to his mind in terms of the comfort which he hopes to experience, rather than in terms of the value of products which he hopes to possess. But the exceptional man, whose peculiarity as a producer is this, that he produces not only as much as the average man requires, but an indefinite amount in addition to it, is constantly balancing his products not with his immediate wants, but with the amount of intellectual effort which he has expended in the process of production. Indeed, the more closely we consider the matter, the more strongly we shall be convinced that the desire of possessing wealth proportionate to the amount produced by them becomes as a motive to production stronger in men, not 
weaker, in exact proportion as their productive powers are great, and the amount produced by them appeals to their intellects rather than to their necessities.

So far, then, as a study of this motive itself can inform us, the socialistic idea that it will ever cease to be paramount has no foundation whatever, and is contradicted even by the socialists themselves. The only fact connected with this motive directly which wears so much as a semblance of serious evidence in their favour is the fact often dwelt on by emotional writers like Mr. Kidd, that many men who have made enormous fortunes have given away a large part of them for what he calls "altruistic" purposes; and writers of the kind in question take this fact for evidence for even if he that the desire of possessing great wealth is ceasing $\begin{gathered}\text { gives away } \\ \text { what he pro- } \\ \text { ducs }\end{gathered}$ to be the motive for producing it. But those who duces, he allow themselves to argue thus, show a curious ${ }^{\text {possess it first }}$ carelessness in their examination of human action; for the fact referred to, so far as it proves anything, negatives rather than supports the conclusion they seek to draw from it. It is perfectly true that many men of great industrial ability have produced large fortunes and given them away afterwards. But in order to give, a man must first possess ; and it is in the act of giving magnificently for some specified purpose that many men most fully realise the power with which wealth endows them. Thus the fact that many men will produce in order that they may have the delight of giving is no more a proof that they would produce under the régime of social- 
Book IV Chapter 2

There is no sign, therefore, that the desire for exceptional wealth is losing force as a motive.

Are, then, other desires acquiring new force as motives to wealth-production?

ism, which would aim at depriving them of anything that they might possibly give, than the fact that a man would with pleasure give five shillings to a beggar is a proof that he would be equally pleased if the beggar were to pick his pocket. Even the men who produce wealth - and no doubt there are such - without any conscious sense that they produce it because of their desire to possess it, would show that such was their motive by their instinctive and indignant refusal to go on producing it, if they knew that it would be forcibly taken from them.

And now, since we have seen that "greed" as a motive to wealth-production shows no internal tendency to lose its old efficiency, let us turn to those other motives which the socialists tell us are to supersede it, and ask whether there is anything in their known operations hitherto which indicates that in the domain of wealth-production they will acquire an efficiency similar to it. This is not an inquiry which is very difficult to pursue, for the motives in question are of a very familiar kind, and the kinds of activity which they have produced hitherto are notorious.

What these motives are has been sufficiently shown already in language borrowed from the socialistic writers themselves - the pleasure of "excelling," the "joy in creative work," the pleasure of doing good to others, and, lastly, the enjoyment of the approbation of others, or of the yet more flattering tribute commonly called "honour." Now these motives, it will be seen, are of two distinct kinds, the first three 
being based exclusively on some pleasurable condition of mind, which is independent of anybody except the individual who actually experiences it; Are the joys of the two last being besed on a pleasurable condition excelling, or of the two last being based on a pleasurable condition benefiting of mind, which is directly dependent on the actions $\begin{gathered}\text { others, or of } \\ \text { being hon- }\end{gathered}$ or the attitude of other people. We may therefore oured by others reduce these motives to two - namely, self-realisation, in the first place, and recognition by others, in the second. This classification will be not only shorter, but more comprehensive than the other; for self-realisation will include not only the joys of self-improvement and artistic creation, but those of the pursuit of truth and the performance of religious duty, and will distinguish the pleasure of doing good to others from the pleasure of being thanked or praised for it.

And now let us consider what those kinds of The desire of exceptional activity are, in the production of which motive to one or other of these motives, or both of them, certain kinds have played, hitherto, any considerable part. We conduct. shall find them to be as follows: heroic conduct in battle, or in the face of any exceptional danger; artistic creation; the pursuit of speculative truth; what theologians call works of mercy; and, lastly, the propagation of religion. This list, if understood in its full sense, is exhaustive.

Now of these five kinds of action we may dismiss It is a motive the last from our consideration, not because it has action and not a most important influence on civilisation, but religiouswork: because it has no direct connection with any of the processes of wealth-production, except in so far as it 
Book 1V tends to divert men's attention from them. And with Chapter 2 regard to the works of mercy something similar must be said also; for though they undoubtedly have a close connection with wealth, they do not aid at its production, still less at its increase, but merely at the distribution of portions of it, which have been produced already, amongst persons whom it would otherwise not reach. The love for others, for example, by which works of mercy are motived, may prompt a man to send London children for a holiday into the country by train, but it would never have prompted him to invent the locomotive engine. It may prompt him to secure for a youth an education in

but neither of these are the same thing as wealth-production.

It is a motive to artistic production, certainly, modern science, but it would never have prompted him to write the treatises of Professor Huxley. All activity of this kind, then, whatever form it may take, is, in a sociological sense, essentially parasitic. It implies the previous exercise of another set of faculties totally distinct from those directly implied in itself, and, together with other faculties, other motives belonging to them. It has, then, with the actual process of wealth production as little to do as has religious propagandism itself; and, like religious propagandism, we may dismiss it from our consideration here. The only forms of activity with which we are called on to deal with here will thus be artistic creation, the pursuit of speculative truth, and military or quasi-military feats of heroism.

As to artistic creation, it is, no doubt, perfectly true, as is proved by the efforts of countless devoted amateurs, that men with artistic powers will 
often do their utmost to develop them, merely for the sake of the pleasure which the exercise of these Book IV Chapter 2 powers brings with it; whilst literature is even more obviously than painting cultivated by men who devote themselves to it solely as a means of selfexpression. Indeed, it might reasonably be contended that finer books and paintings would be produced if it were impossible for painters and writers to make money by producing them, than are now produced with a view to captivating the public purchaser.

So, too, the pursuit of scientific and philosophic and also to truth - arduous though it is - is generally under- coveryi taken by men whose principal motive is the pleasure their work brings them.

A watcher of the skies,

When some new planet swims into his ken,

may well be supposed to find in that thrilling moment a reward sufficient to compensate him for all his pains in arriving at it; and most branches of science would yield us similar illustrations. Indeed, the career characteristic of scientists and philosophers generally is a conclusive proof that the principal motive of their activity is not the desire of any extrinsic reward, the amount of which they will balance against the amount or the quality of their efforts, but a passion for truth as truth, which they indulge in for its own sake only.

Now granting all this, what will its bearing be on the question of whether the pleasures of pure selfrealisation will suffice to stimulate those exceptional 
Book IV faculties whose function it is to maintain and increase the production of wealth? With regard and works of to artistic creation, we are certainly bound to and scientific admit that great works of art are wealth of a highly

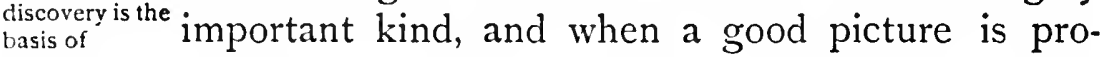
industrial duced, as it often is, solely in obedience to the
progress; painter's artistic impulse, we have a genuine example of wealth produced in obedience to that kind of motive whose efficiency the socialists desire to establish. Further, with regard to the pursuit of truth, as Mill points out in a passage that has been already quoted, progress in speculative knowledge is the basis of all other progress, and notably of progress in the arts and processes of wealth-production. It must, accordingly, be admitted that in a certain sense all progress in wealth-production has for its basis a kind of disinterested activity with which the desire of possessing wealth has nothing at all to do. And yet in spite of this, neither the case of the artist nor of the philosopher warrants the inference that the motives which are sufficient for them will ever have a similar effect on the faculties of the great wealth-producers. The evidence, in fact, as soon as we have fully examined it, will be found to point in a direction precisely opposite.

but great works of art form but a small part of wealth;

For, to begin with the case of the artist, it must be remembered, in the first place, that works of art, such as pictures painted by the artist's hand, form a very small, though an important part of wealth, and that they are hardly wealth at all from the 
point of view of the many, unless they are reproduced and multiplied by adequate mechanical processes. Now, though it is quite conceivable that a painter might paint a Madonna solely because the realisation of his own ideas delighted him, it is hardly to be expected that other men will rack their brains to devise blocks, presses, and preparations by which copies of it may be made and multiplied, solely for the pleasure of reproducing ideas which are not their own. It must further be added that delight in creation for its own sake can be attributed as a sufficient motive to the highest class of artists only. As for the men whose artistic and artistic powers are true, but qualify them only for decorative, than the not for creative work, - the men, for example, who hoshest is design beautiful stuffs and furniture, - though the ${ }_{\text {pecuniary }}^{\text {desire of }}$ exercise of their power may be doubtless itself a reward; pleasure to them, they are certainly as a class not given to exercising them without the expectation of some proportionate pecuniary reward. Indeed, in exact proportion as artistic creation assimilates itself to the processes by which wealth in general is produced, the mere pleasure of the work itself ceases to be a sufficient motive for it.

Next, with regard to the pursuit of speculative whist scientific knowledge, though this, and more especially pure discoveries. scientific discovery, may form the basis of all pro- $\begin{gathered}\text { generally from } \\ \text { the desire for }\end{gathered}$ ductive effort, it is very far from being a form of truth, are productive effort itself. It has, on the contrary, no wealth-producnecessary connection with it. It does not even the men who belong to the region in which such effort operates. $\begin{gathered}\text { apply them } \\ \text { desire wealth. }\end{gathered}$ 
Book IV Scientific truths, as apprehended by the mere seeker after speculative knowledge, are like powerful spirits secluded in some distant star; and, for any effect which they have on the processes of economic production, they might just as well have never been discovered at all. Before they can be applied to practical purposes they have to be mastered and digested by a new class of men altogether, who value them not for themselves, but solely for the use they can be put to. Thus, in order that speculative truths may be connected with productive effort, they must pass out of the hands of the men who first discovered them, and be made over to men whose motive in acquiring them will emphatically not be desire of the mere pleasure of intellectual acquisition, but the desire of some marketable products with a calculable pecuniary value, in the production of which a knowledge of the truths in question will help them. Thus speculative activity, just like artistic creation, in exact proportion as it connects itself with the ordinary processes of wealth-production, ceases to find its motive in the desire of self-realisation, and claims to be rewarded by the possession of the objective results produced by it.

What, however, of the fact that the desire of honour makes the soldier work harder than any labourer?

And now let us turn from the motives which consist in the desire of self-realisation to those which consist in the desire of the approbation or the homage of others. This desire, which exercises a great influence on the artist, and often also on the seeker after speculative truth, concurrently with the 
desire of pure self-realisation, exhibits its force most signally when it is the motive of military heroism; Book IV Chapter 2 and the readiness with which a soldier will risk his life for honour - honour which brings with it nothing besides itself, excepting perhaps a medal and a why, the scrap of ribbon - has been said by socialistic writers should not the to afford a conclusive proof that any practical work, $\begin{gathered}\text { same desire } \\ \text { make the great }\end{gathered}$ no matter how laborious, and more particularly the wealth-prowork of the great wealth-producer, will be willingly undertaken for the sake of the same reward. "The soldicr's subsistence is cortain," writes a well-known contemporary enthusiast. "It does not depend upon his exertions. At once he becomes susceptible to appeals to his patriotism. He will dare anything for glory, and value a bit of bronze which is 'the reward of valour' far more than a hundred times its weight in gold." The implication, of course, is that what men will do in war they will do in peaceful industry; and the writer adds, in order to point this moral, "yct many of the private soldiers come from the worst of the population." This passage is quoted with rapture by another socialistic theorist, who exclaims, "Let those especially notice this last point who fancy we must wait till men are angels before socialism be practical." And even so well-trained a thinker as Mr. Frederic Mr. Frederic Harrison has argued, from the readiness with which Hurrison has men die in battle for their country, that they will be argument. equally willing to deny themselves or suffer martyrdom for universal humanity.

To all these ideas and arguments there is one 
Book IV answer to be made. They are all founded on a failure to perceive the fact that military activity is The answer to in many respects a thing apart, and depends on work of the soldier is exceptional; psychological, and indeed on physiological processes which have no counterpart in the domain of ordinary effort. That such is the case can be seen very easily by following out the train of argument suggested by Mr. Harrison. Mr. Harrison sees that in ordinary life a man will not deliberately run the risk of being killed except for the sake of a cause or person to which or whom he is profoundly and indescribably attached. Indeed his attachment is presumably in proportion to the risk he is prepared to run. And such being the case in the field of ordinary life, Mr. Harrison assumes it must be the case on the field of battle also, and that the soldier's willingness to risk death in fighting for a cause or country proves that this cause or country is inexpressibly dear to him. And in certain cases - when a country is in desperate straits, and everything hangs on the issue of a single battle - this inference would be doubtless just; but that it is not so generally is shown by the notorious fact that some of the bravest and most reckless soldiers ever known to history have been mercenaries who would fight as willingly for one country as for another. Thus until Mr. Harrison can show us that men in ordinary life will wear themselves out for either of two opposed objects indifferently, or that they will risk death as willingly for a plain woman as for a pretty one, it is obvious that men's willingness to risk death in war implies no corresponding 
willingness to risk it cutting trousers, and is for certain reasons a phenomenon standing by itself.

Book IV

Chapter 2

That this is so is shown even more strikingly by the fact to which the two other writers just and we cannot quoted point with so much complacency. This fact to the work of is the soldier's undoubted willingness to pursue ordinary life. his calling for pay which seems strikingly incommensurate with his risks. His conduct in this respect is, no doubt, remarkable, especially when compared with that of men in the domain of peaceful industry. When any industrial occupation is in question a workman will expect special wages if it is one which presents a likelihood of his often hurting his thumb; but soldiers will risk the probability of being tortured and blown to pieces for wages which would hardly induce a peasant to hoe a turnip-field. This is no indication of any abnormal poverty amongst the classes from whom the army is mainly recruited, for the same phenomenon is constantly observable amongst men who are not under the necessity of working for their living at all. Amongst such men are numbers who in time of actual war will eagerly give up a life of leisure and luxury for the certainty of hardships and the probability of death - men who for the sake of anything else but fighting would hardly, without a struggle, run the risk of a bad dinner. But what these facts really suggest to us is not the insane conclusion that because soldiers act differently from other men, other men may be counted on to act like soldiers. On the contrary, what they suggest is the question 
Book IV why men will do as soldiers what no one will do in any other capacity, and what soldiers themselves will cease to do as soon as they become commissionaires. The fighting For this peculiarity in the soldier's conduct there
instinct is inherent in the are three separate reasons. One is the strictness of dominant races, military discipline, which socialistic reformers would hardly find popular if they tried to introduce it into factories and contractors' yards. A second is the peculiar character of the circumstances in which the soldier is placed when his courage is most severely taxed - circumstances which render the attempt to evade peril almost as difficult, and often more perilous, than facing it, and which in ordinary life would be intolerable if they did not happen to be impossible. But the most important reason is this - and the others without it would be non-existent - that the instinct of fighting is inherent in the very nature of the dominant races, and it will always prompt numbers to do for the smallest reward what they could hardly, in its absence, be induced to do for the largest. This immemorial instinct has been wrought into our blood and nerves by the innumerable thousands of years that have made us what we are; and all the battles of their fathers are pulsing in men's veins to-day. These instincts, no doubt, are more controlled than formerly, and not so frequently roused; but they are still there. They are ready to quicken at the mere sound of military music; and the sight of a regiment marching draws cheers from the most democratic crowd. Here is the 
reason why the soldier, though he submits himself to the most direct coercion, never considers himself, Book $1 \mathrm{~V}$ Chapter 2 and never is considered, a slave; and military activity will always be a thing apart, and for in a way in purposes of argument will never be comparable to industrial industrial, till human nature undergoes so radical ${ }^{\text {instinct is not. }}$ a change that men will as eagerly risk being killed by unfenced machinery in a cotton-mill as they will being killed by a bullet or a bayonet on the field of battle. Here again the facts for which the socialists reason are indubitable; but the inference which the socialists draw from them is altogether illusory.

It remains, however, to add that the desire of And even in mere honour - of honour unaccompanied by any make the proextrinsic advantages - has an efficiency which is longed intelstrictly limited in the domain even of military required, ask activity itself. It may move men, in the act of wards besides fighting, to the highest and most heroic actions; mere honour. but history shows us that it has not been found sufficient to elicit the sustained intellectual efforts of the General, bent on achieving some great and monumental conquest - efforts in which all the excitement of the actual fighter is wanting, and in which the coolest calculation plays as large a part as courage. The Cresars and Napoleons of the world have certainly not, as a rule, been content, when they have crushed their enemies and augmented the magnificence of their country, with the gift of a medal or two, and the privilege of ending their days in the modest uniform of commissionaires opening 
Book 1V shop doors. If, then, the mere honour of being
Chapter 2 a great conqueror is insufficient to stimulate the Still more will activities by which great conquests are achieved, a the great wealth-producers do so. man is hardly likely to consecrate his entire faculties to wealth-production merely that he may enjoy the honour of being known as the proud producer of so many miles of calico, or millions of pots of jam.

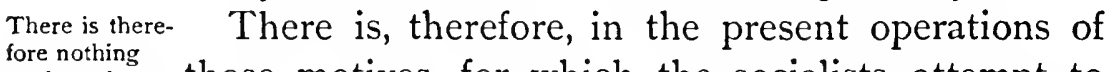
to show that these other motives will supersede the desire of wealth.

What they really do, and what socialists fail to see, is to mix with the cesire for wealth, and add to its cfiliciency; those motives, for which the socialists attempt to claim a universal efficiency, as little to suggest that as motives to exceptional wealth-production they will ever supersede the desire of exceptional possession, as there is in the present operations of the desire of exceptional wealth-possession to show that it is losing its power, or is at all likely to be superseded. The final demonstration of this truth, however, yet remains to be given.

The socialists, in dealing with this question of motive, have been led into the curious blunders which have just now been exposed by their singularly childish conception of what men's actual motives are. They divide motives into various wellknown classes, and, so far as it goes, their procedure is here correct. Their error is that they conceive of man as a being on whom these motives, as a rule, act separately; whereas in reality the very reverse is the case. Acts which are due to any single motive are not the rule, but the exception. For instance, even though artistic creation and the pursuit of truth are motived in the case of many men by the pleasure which the work brings them, some of the greatest 
artists and thinkers, with whom this motive was certainly powerful, have been motived by the desire of pecuniary reward also. It is enough to mention the names of Bacon and Shakespeare, Rubens, Turner, and Scott. And with the desire of honour the desire of pecuniary reward is found to mix itself yet more often and readily than it does with the mere passion for artistic or for speculative work itself. The psychological fact, however, which we must here notice is this - that the pecuniary reward, though it seems theoretically to be in contrast to any genuine desire for other men's approbation, or for the pleasure brought to the worker by the work itself, instead of destroying the force of those other motives, increases it, just as the admixture of a certain amount of alloy makes gold and silver more valuable for artistic purposes. And now, having observed this, let us turn back to the consideration of the desire of pecuniary reward as the principal motive of wealth-production, and endeavour to make our analysis of it more complete.

As the reader will recollect, the doctrine that all For in saying exceptional exertions in wealth-production are of wealth is motived solely by the desire of exceptional wealth essential as a as such, although it is the doctrine imputed by the wealth-prosocialists to their opponents, has been said already not mean the to be a very imperfect rendering of any doctrine as forits own to the subject which their opponents would actually maintain; and the reason why it is imperfect is simply that wealth as such is not the object for which wealth is really sought by most of those men whom the 
Book IV desire of it most powerfully influences. For wealth as such, in the ordinary sense of the phrase, is wealth or for the sake regarded as a means of personal self-indulgence. It
of physical gratification.

This forms a small part of stands for the finest wines, the richest food, the softest beds, the most luxurious furniture - for everything that can caress the senses and enervate the mind and body. And no doubt its power of securing all these things to its possessors is one of the qualities which render it an object of desire. But it is only one; and though it is the most obvious of them, it is not the chief. The subordinate place which it occupies is conclusively shown by the fact that a very few thousands a year would suffice to provide a man with every pleasure or luxury that his own its desirability. senses could appreciate; and yet men are often more eager, after these few thousands have been secured by them, to pass this point of opulence than they ever were in reaching it. Many men, moreover, who have surrounded themselves with pomp and splendour are indifferent to the gratification of their own senses altogether. Though their luncheon tables may groan under every imaginable delicacy, they will themselves eat a slice or two of cold ham, no better or worse than would have been secured them for a shilling in a cheap restaurant. Their own beds will be no softer than those of prosperous clerks; and, surrounded by cushioned sofas, they will sit upon straight-backed chairs.

The principal reasons for which wealth is sought are not pleasures of the senses, but pleasures of the mind and the imagination; and of these pleasures 
there are three principal kinds. One of them is the pleasure of power, which in their analysis of human motives the socialists conveniently overlook; and $1 \mathrm{tis}$ desired the two others happen to be the very pleasures means to by the desire of which the socialists themselves de- power, and to clare the exceptional the socialth-producers are to be pleasures clare the exceptional wealth-producers are to be which socialprincipally marked in the future - namely, the pleas- ists offer inures of self-realisation and the pleasures of social honour. Wealth is coveted by all really great wealth-producers, not in preference to these, but as a means to all or one of them. To many of our great wealth-producers, with their strong practical faculties, wealth would be nothing if it brought to them no accession of influence; to many it would be nothing if it did not bring them the means of indulging their tastes, as distinct from their physical appetites; to nearly all it would be nothing if they did not, or if they did not hope it would, secure for them the approbation and the respectful homage of others.

The only alternatives, then, which we have before us are as follows: - If the great wealth-producer is a man of such coarse fibre that none of those desires just mentioned are really his - neither the desire of power, nor the desire of social honour, nor the desire for that larger development of taste and moral activities which is rendered possible by the possession of exceptional wealth - then it is obvious that the sole motive left to him will be the gross or unreasoning desire for the possession of wealth as such; and we are brought back to the original 
Book IV proposition which the socialists set themselves to annihilate. But if, on the other hand, the great The great wealth-producer is really capable of those higher
wealth-producers suscep
tible to the motives on which the socialists dwell will desire exceptional wealth all the more because of them. desires which the socialists assure us will shortly become so strong in him, the desire of exceptional wealth, instead of being superseded by these, will be stronger beyond calculation than it ever could be without them.

And it is, as a rule, the latter of these two suppositions which practically represents the truth. Exceptional wealth is desired by the men who produce it not for itself, but for its results; and in proportion as the man who desires it possesses a lofty character, his desire for it, being merged in the thought of the uses to which he desires to put it, will itself become equally lofty also. But none the less will the desire of the material wealth form the physical basis in which his loftier desires inhere, just as the impulse of sex remains the physical basis of the deepest and tenderest love which a man feels for a woman, or as the brain is the physical basis of every thought that a man can think. Thus the arguments of the socialists recoil upon their own heads; and instead of tending to show that the desire of possessing exceptional wealth will ever cease to be indispensable as a motive to exceptional production of it, they have merely succeeded in calling attention to the facts on which the indispensable character of this motive depends.

We have not, however, finished with this question yet. There is a further set of objections still 
remaining to be considered which, whilst based on an admission that wealth-production is motived by the Book IV Chapter 2 desire of wealth, aims at showing that this fact does not necessarily result in more than a fraction of the consequences which have up to this time flowed from it, but merely shows in reality that those consequences are unalterable, and adds new force to the arguments that have just been urged with regard to them.

The objections referred to are those embodied in It is argued, the well-known contention that though the posses- semever, by sion of exceptional wealth must be allowed to the producer may exceptional men who are actually engaged in pro- be allowed the ducing it, and the exercise of whose business ability duces, but that is just as essential to the country's prosperity as to with his life, their own, yet this possession of wealth should be passed on to limited to themselves personally, and should not be ${ }_{\text {interest on }}^{\text {his amily }}$ allowed to distribute itself amongst their idle and bequeathed inefficient families. In other words, it is urged that capital. whilst the founders and conductors of businesses are entitled to the incomes, no matter how large, that are due to the exercise of their own powers, these incomes should cease with the cessation of the powers that caused them, and should not be allowed to perpetuate themselves, as they do now, in the shape of interest paid to the passive owners of capital. Such an arrangement, it is maintained by those who advocate it, would at once coincide with the dictates of abstract justice, and whilst securing to the exceptional wealth-producer, whose services society requires, the full reward and motive necessary to ensure his activity, would enrich the community at 
Book IV large by distributing amongst it an enormous income,
Chapter 2 which at present, instead of stimulating anybody to any useful exertion, merely keeps a number of men in idleness. And this contention at first sight does It is claimed not lack plausibility either in respect of the question that this arrangement would coincide with abstract justice : of abstract justice which it raises, or of the practical consequences which, according to it, the arrangement in question would produce. When we examine it closely, however, the plausibility vanishes, and abstract justice and practical reason alike condemn the appeals thus made to them as founded entirely on misconception.

Let us deal with the question of abstract justice first. Those who denounce interest or unearned income as unjust, invariably state their case in the following simple form. There are only two ways, for it is argued they say, in which a man can become possessed of
that all wealth which is not worked for wealth - either by producing such and such an mort be stolen. amount himself, or by appropriating such and such an amount that has been produced by another person; or, as they frequently put it, with an air of solemn sententiousness, " $A$ man can get an income only by working or by stealing: there is no third way!" Now one conclusive answer to this puerile, though popular, sophism has, strangely enough, been given by Mr. Henry George, who, though eager to adopt any argument that could be used to assail the rich, was, nevertheless, not taken in by this. Mr. George pointed out that one kind of wealth, at all events, - and we may add that in this we have wealth in its oldest form, - consists of 
possessions which have been neither made by the possessors nor yet stolen by them. That is to say, Book IV Chapter 2 it consists of flocks and herds. Mr. George pointed out also that whole classes of possessions besides are, for by far the larger part of their value, equally independent of either work or theft. Such posses- This is utterly sions are wines, whose quality improves with time, untrue, as the and whose value, consequently, whether in exchange and herds or use, is increased from year to year by the secret operations of nature. But Mr. George, though his arguments were true so far as they went, did little more than touch the hem of the question; for flocks and herds, and commodities that grow valuable as they mature themselves, form but a small, though they do form a typical, portion of wealth that may come to a man without his having produced it himself, and without his stealing it from any other human producer. And this is the wealth which is actually produced by capital.

In order to show the reader that capital is an but the chief actual producer, in as true a sense as labour is, or wealth that is the ability by which labour is directed, let us begin not worked for by considering fixed capital as distinct from wage which is past capital, and by considering it in its simplest forms. ability stored By fixed capital is meant any tools, machines, or externalised. materials by which man's efficiency as a producer of wealth is increased; and we will take as examples of these the three following things - a dart or missile by which game may be killed; a heap of manure by which a peasant's field may be fertilised; and a horse which a peasant uses for ploughing and 
Book IV kindred purposes. Now let us imagine a race of savages who use no missiles at all, but catch their game merely by sleight of hand. If a man is entitled to such game as he catches, the exceptionally dexterous hunter who catches most will be necessarily the rightful possessor of more game than his fellows. This will be granted by those who admit that work constitutes a true, and the only true title to possession. The dart of a Such being the case, then, let us alter our sup-
savage hunter, position somewhat, and suppose that the hunters, instead of catching the game with their hands, kill it with wooden darts; and that the amount of game which each hunter will secure in a day depends not on the skill with which the darts are thrown, but on the skill with which the darts are made. Under these circumstances, the hunter who secures most will not be the man who is quickest in seizing the quarry with his hands, but the man who makes the darts that will reach their mark most certainly; and yet no one would say that he was less entitled to what he took, because his exceptional skill, before it could become effectual, was obliged to become embodied in some object external to himself.

the manure heap or cart horse of a

In the same way, if two peasants are cultivating similar fields, and one, by sheer hard work, raises a larger crop than the other, his right to his larger crop would not be denied by anybody. Let us suppose, then, that instead of working harder than his neighbour he works more intelligently, that he saves and stores up as manure materials which his 
neighbour wastes; and that every year, through the powers accumulated in his manure heap, he can raise a larger crop than his neighbour, though he are forms of actually works less. Would any one affirm that the capital which man lost his right to his extra produce because he produce, and produced it indirectly by the external agency of belongs to his manure, and not directly by overstraining his them. muscles? Or again, if one of the peasants raised a larger crop than his neighbour because, whilst his neighbour spent all his money in drinking, he himself saved it and bought a horse, would any one maintain that the extra crop due to the work which the horse performed for its owner did not belong to the owner, but was stolen by him from the other man?

No one would put forward an argument so absurd The same is as this. And yet the wooden darts of the savage such capital as and the manure heap and the horse of the peasant are manufactory neither more nor less than portions of fixed capital, ${ }^{\text {plant. }}$ just as a steam engine is, or a cotton mill with all its plant. Fixed capital is merely productive ability which, instead of acting directly in the production of goods for the consumer, stores itself up in externalised means of production, so that it may, with accumulated force, produce such goods indirectly; and the additional wealth which a man produces by a new machine is just as much produced by himself as is the additional crop which he raises from a patch of land by the employment of a horse which he has bought, or manure which he has himself concocted. Indeed, fixed capital may be compared to a breed of artificial horses, or if we like the simile better, to 
Book IV

Chapter 2

These implements are like a race of iron negroes, and are producers as truly as live negroes would be.

a race of iron slaves. The amount of wealth which the employment of a machine adds to the amount that would be produced without it by a given number of labourers, is produced by the machine itself just as truly as it would be if the machine, instead of a structure of wheels and framework, took the form of a gang of artificial negroes, who only betrayed the fact that they were not human by the heat of their breath, an occasional unearthly whistle, and the different language in which they required to have their orders given them. The machine produces this increment, but certain men produced the machine; and therefore the increment is in reality produced by the men, just as truly as when a murdered man has been killed by a bullet from a rifle, his death has been caused by the murderer who aimed and discharged the weapon.

Indirectly, wage capital is And what is true of fixed capital is true of wage also a producer capital also; for fixed capital, such as machines, in the same way. buildings, or railways, is the result of wage capital, as employed to direct labour, and is therefore wagecapital externalised in the objective results of its employment. But fixed capital, or a man's productive power externalised, differs from his productive power when exercised by himself through wage capital. It is a part of his power which he can separate from his own personality, and which he can make over to others, just as a slave-owner might make over a body of slaves; only these are slaves whose enslavement does them no wrong, and who belong 
by right to the men whose enterprise and whose intellect created them.

Capital, then, as such, is as true a producer of And indeed wealth as the men were who in the first instance that this arguproduced it; and when one of them passes a ment could be portion of it on to his son, and with it the income ${ }_{\text {was strongly }}^{\text {themser }}$ that results from it, this income is nothing that is urged by the stolen from other men, but is simply a part of the product produced by the artificial slaves, the use of whom other men for their own advantage borrow, and who rightly belong to the lender because he has received them from his fathers, who created them. And should any socialist quarrel with this reasoning, it will be sufficient to point out to him that it is neither more nor less than the reasoning which, till only a few years ago, the leaders of socialism themselves were never weary of employing. Capital, said Lassalle, is merely labour fossilised: and so long as labour was held to be the only wealthproducer, the socialists urged that capital belonged to the labourers, because it represented the labour of their fathers, whose heirs they were. But with the gradual disappearance of the doctrine that labour is the sole producer, it is becoming more and more evident that capital is not what Lassalle thought it was - that it is not fossilised labour, but fossilised business ability. In other words, it does not, except in its earliest stages, represent on the part of producers a process of exceptional saving. What it does represent is a process of exceptional production. Since then the labourers, as labourers, 
Book IV would have been the rightful heirs to all capital, Chapter 2 if all capital had been produced by the common labour of their parents, those who have actually inherited it must be its rightful owners in fact, because in fact it has been produced by the ability of the exceptional men who left it to them.

Practically, But the whole of this argument, based on the however, the justification of income from capital

claims of abstract justice, would avail very little to defend the income of the mere owner of capital if his position rested upon its abstract justice only, and if his right to his income did not form a part of the very conditions that render the production of wealth possible. The part which the right to income from capital plays when the ownership of the capital is divorced from any active employment of it, depends on the fact that the right to income of this kind is what gives to wealth the larger part of its value, and renders the desire of it efficient as a social motive.

The ways in which it does this are many and various; and because it is impossible to indicate them in any simple or single formula, certain people may imagine that they have no importance. Such people might as well argue that no complicated process is an important process, or that no results are necessary when many causes combine to produce them.

rests on the fact that the power of capital to yield

The most obvious of the reasons why the right to income from capital forms in the eyes of the income exceptional wealth-producer a principal element in the desirability of the wealth produced by him has 
its root in the facts of family affection. In spite of the selfishness which distinguishes so much of human Book IV Chapter 2 action, a man's desire to secure for his family such is what mainly wealth as he can is one of the strongest motives of anxious to prohuman activity known; and the fact that it operates duce it ; in the case of many who are otherwise selfish shows how deeply it is engrained in the human character. It may, indeed, be regarded as a kind of selfishness itself; and the vigorous and practical men who have exceptional faculties for wealth-production are precisely those in whom it is strongest and most persistent. Men like these would never for a moment tolerate an arrangement which permitted the head of the family to keep his wife and children since if inin luxury so long as he lived, but would condemn capitat could all of them, the moment he happened to die, to be and be amassed turned by the butler and footmen into the street as queathed, beggars. It has been said that this family feeling on the provision for wealthy men could make no part of the great wealth-producer may be regarded as a species of selfishness; and there is nothing very recondite in the process by which it comes to be so. Such a man, no matter how selfish, values his family because it happens to be his own. His own importance is enhanced by the success and brilliancy of its members; and the possession of a fashionable wife, and a popular and well-bred son, reflects almost as much credit on him as the possession of a gentleman for his grandfather. For this reason, if for no others, he will do for them everything that exceptional wealth will enable him to do. Wealth, 
Book IV however, depends for its effects on those who enjoy Chapter 2

it, not merely on its present enjoyment, but on the prospect of its continued possession; and unless the man who is making a fortune by his ability may bequeath to one of his children, at all events, a position similar to his own, and something exceptional in the way of wealth to all, the money which he spends on them during his own lifetime will be wasted. The whole social importance which

nor would wealth give pleasure to those who might at any moment be beggars. wealth might have given them would be gone. The tastes and the peculiar cultivation which wealth is capable of securing for those who are from their earliest years surrounded with it, they would under such circumstances neglect to acquire at all; or, if they did acquire them, they would be living in a fool's paradise, for when their father died, and their wealth consequently vanished, they would be infinitely worse off than those who had never possessed it. They would resemble nothing so much as plants that had been grown in a conservatory, merely that, when on the point of flowering, they might be bedded out in the frost.

If, then, for the selfish, or even the heartless parent, wealth would in most cases lose the larger part of its attractions unless it could be accumulated and bequeathed to others in the shape of incomeyielding property, for the normally affectionate parent its attractions would be reduced yet further.

But the full part which heritable incomes play, in rendering wealth desirable in the eyes of exceptional men, is not to be understood by considering such a 
man and his family singly. For the life and the ambitions of a family are not self-contained. They Book IV Chapter 2 imply and depend upon relations with other families; and these other families will be valued, and intercourse with them will be rendered possible, not by the Moreover, if bare fact that they are the possessors of so much incomes were money, but by the fact that they have the habits and interests which result, and result only, in the social atmosphere created by a number of assured incomes, wholly independent of any daily struggle to make not heritable, wealth could produce none of those social resuits, such as them. It is easy to see that no rich society would be culture, etc., endurable if the only men in it were men who had just made their fortunes, and if, on their deaths, their families disappeared from it in the gulfs of destitution. Anything more exquisitely ludicrous than the socialistic proposal that great wealth-producers should be allowed large incomes to spend, but that they must not on any account be allowed to invest any part of them, or use it in a way by which more income may result from it - anything more ludicrous than this it is not possible to conceive. It is - to recur to an illustration used already - like proposing that a peasant who is more industrious than his neighbours shall be allowed all the money which the sale of his extra produce brings him, provided only that The wealth he spends it on brandy, or beer, or absinthe; but with the men that if he saves it up and buys a useful horse with made it would it, his purchase shall be confiscated by the State, society of because a horse is productive capital. This pro- beasts. posal, however, is not only ludicrous in theory, but it would, if put into practice, result in a sort of 
Book IV society more vile and bestial than anything which the world has ever known. For the sole advantage which in that case wealth would bring to its producer would consist in the meat and drink and other means of physical pleasure which he and his family could consume or enjoy during his lifetime - before he retired to the grave, and his wife and children to the workhouse.

Wealth is desirable because it is the physical basis of an e larged life ;

The main value of wealth in the eyes of the great wealth-producer does not consist in its ministering to brief spasms of self-indulgence, but in the fact of its being the foundation of an equable and sustained life, in which the physical pleasures are refined rather than intensified, and the time employed by the majority in producing the necessaries of existence is given not to sloth, but to other kinds of exertion. A life of this kind is impossible except in a society of which a large section not only and there must possesses wealth, but is accustomed to its possession,
thus be continuity in the possession of wealth. and is characterised by accomplishments, tastes, principles, and kinds of knowledge, which can be developed and acquired only when the continuance of its possession is assured. In other words, those men on whose exceptional business ability the productive processes of the entire community depend, and who are the cause of growth in the incomes of the mass of the community, just as truly as they are the producers of their own fortunes, are motived to activity less by the desire of the wealth which comes to them day by day through their own direct exertions, and which would cease instantly 
when these exertions were suspended, than they are by the desire of wealth that shall come to them Book IV Chapter 2 indirectly, not as the product of their exceptional exertions in the present, but as the product of the accumulated product of their exceptional exertions in the past - the product of those stored-up forces with which they have enriched the world, and which, whilst rendering help to thousands of men besides, great wealthwill continue to render a tribute to their creators producer and their creators' children.

Thus, to express the matter in brief and familiar only of what language, the sustained development and exercise directly, but of ex of exceptional ability in wealth-production implies duces indithe possession by those who monopolise this ability, his past not merely of that portion of those products which are called the wages of superintendence, but also to that portion which is called interest on capital. For just as the control of capital affords the only means by which, under free institutions, the great man can apply his faculties so as to increase the production of wealth, so does the right to interest, or to the products of the capital accumulated by him, constitute the chief reward by the desire of which the exercise of his faculties is stimulated.

There is a further point, however, which now remains to be noticed. When it is said that the great wealth-producer is motived mainly by the desire to enjoy an amount of wealth proportionate to what is produced by him, it is not asserted that in order to gratify this desire it is necessary that he should be able to appropriate the whole of what 
Book IV
Chapter 2 is produced by him. On the contrary, of that constantly growing product which is added by the

The majority not only may, but do acquire a share of the increment produced by the great man;

great man's faculties to the product of ordinary labour, and out of which the income of the great man comes, a portion is capable of being appropriated by the ordinary labourers themselves. Indeed, the masses of the community are partakers in material progress, and have an interest in material progress solely because, as an actual fact, a considerable percentage of this added product goes to them; and though few of our so-called "labour leaders" recognise this truth, all the hopes of enrichment which they hold out to their followers imply nothing whatever beyond the securing a larger amount of an increment which is produced not by themselves but others. An important question, therefore, arises in this way as to how far the product of the great men can be taxed and handed over as a bonus to average labour without weakening the

but whatever this share may be, it can never be such as to render social conditions equal. motives which prompt the great men to produce it. This is a question to which, by à priori reasoning, it is absolutely impossible to give any definite answer. It is a question that can be solved only by cautious practical experiment; and the answer will vary constantly with times, places, and circumstances. All that can be asserted here, and it is all that requires to be insisted on, is that the amount of wealth which the exceptional wealth-producer can secure must be proportionate to what is produced by him, however far short of the whole of it; and that it must not be diminished to such an extent as 
will render it less exceptional as the object of an ambitious and strenuous man's desire.

In other words, that graduation of social circumstances, those differences in ways of living, in habits, manners, accomplishments, and social functions, which have their physical basis in varying degrees of wealth, and give to civilised society what is its present, as it has been its past character - these graduations of social circumstances, which it is the cherished dream of the socialists to do away with, are indestructible so long as civilisation lasts. If they perish, civilisation will perish also; when civilisation is restored they will reappear along with it; and however they may be modified or adjusted, they can never be even approximately effaced.

It is the facts briefly indicated in the present chapter which the socialists of to-day are principally distinguished by ignoring; and it is these facts which render socialism for ever impossible.

This truth, when once generally recognised, will lead to many practical consequences, of which the most immediately important will be dealt with in the following chapter. 


\section{CHAPTER III}

\section{EQUALITY OF EDUCATIONAL OPPORTUNITY}

THE two great facts, then, that have been elucidated by our inquiry thus far, are these: in the first place, all progress and civilisation, and more especially all production of wealth, results from a complicated process in which, man for man, a minority plays a part incalculably greater than the majority; and consequently, in the second place, the minority, man for man, possess wealth that is correspondingly greater than the wealth of the majority, likewise. In addition to these facts a third has been elucidated also, to which it is desirable that we should give renewed attention. Since great men not only proThe wealthy duce wealth directly, but produce it indirectly by
class, owing to class, owing to inheritance, is always much more numerous than the great men actuproducing wealth which produces it, and which they are enabled to hand on to their children, the wealthy class is at any particular moment always ally engaged at more numerous than those members of it who are any given time in production.

engaged actually in production. In Great Britain, for example, it has been estimated that two-thirds of the aggregate income that pays income tax is rent or interest on capital, and that one-third represents 
the direct products of work. We may therefore here adopt the rough hypothesis that out of each generation of our wealthy class a third part is enriching itself by the process of direct production, and two-thirds are living on the products produced for them indirectly by the capital or the means of production which were created by their fathers and their grandfathers. Now such being the case, what we have to notice is as follows. Though the mem- But though bers of the wealthy class are not always changing, gives a certain as they would be were no saving of capital, no in- the wealthy terest, and no bequest allowed, they are still chang- class, the ing gradually from generation to generation, so that longing to it whilst the class, as a class, always postly, whilst the class, as a class, always possesses a nucleus if slowly, of families with whom wealth and the traditions of changing. wealth are hereditary, a number of individuals born in it are constantly disappearing over its borders, and a number of other individuals are constantly passing into it. ${ }^{1}$

1 The most permanent form of hereditary wealth is land; but only a small minority of our existing landed families existed as landed families at the time of the last Heralds' visitation. Thus, though the estates of this country are as old as the country itself, the actual possession of a large proportion of them by their owners, at any given time, represents their purchase by wealth recently created, and is, in fact, recent wealth converted into another form.

And if there is a change like this in the possession of landed wealth, there is a still more rapid change in the possession of commercial capital. One of the many childish assumptions of Karl Marx was the assumption on which a good deal of his reasoning rests - that the English middle classes of the present century owed their capital and positions to social opportunities which had come to them as the heirs and descendants of the merchants and wealthier 
Book IV

Chapter 3

and new men are constantly forcing their way into it.

Thus in spite of the permanence which interest gives to wealth, the families that live merely on interest are constantly tending to disappear, and their places are being taken by the men whose exceptional faculties, whose business ability, whose enterprise and strenuous will, actually contribute most to the productive forces of the country. It was observed by J. S. Mill with regard to political government that this "is always in, or is passing into, the hands" of the men who are at the time the true repositories of power. In the same way the wealth of any progressive country is always in, or is passing into, the hands of the men who by their own abilities are engaged actively in producing it.

sheep-farmers who began to make fortunes four hundred years ago. As a matter of fact by far the larger part of the great commercial businesses and commercial fortunes now existing in this country have been founded during the past hundred, and many within the past fifty years, by men who were the sons of ordinary wage-paid labourers, and who were no more heirs to the men who formed the middle class under the Tudors than they were to the merchants who are celebrated in the Arabian Nights. That such is the case is shown with sufficient clearness by the following figures, which refer to commercial incomes during the thirty years which followed the first Great Exhibition. During these years, whilst the population increased by about thirty per cent, fortunes of over ten thousand a year were multiplied by 100 per cent, fortunes of from five to ten thousand by 96 per cent, and fortunes of from five to six hundred by 308 per cent. It is obvious, then, that when a class is augmented in one generation by a number of new members from three to ten times as great as its natural increase would account for, most of its new members must have come to it from some class outside, and have gained their place in it solely by their own exertions. 
Such being the case, then, the material civilisation of a country - the wealth of the few or the progressive comfort of the many - depends on the ex-Indeed the tent to which its potentially great wealth-producers, country deas they come into the world, generation after genera- $\begin{gathered}\text { pends on the } \\ \text { men potentially }\end{gathered}$ tion, are induced by circumstances to develop their great as proexceptional talents, and devote them to the main- ising their tenance and improvement of the productive process. producing the For those, therefore, who regard the material wel- waises that fare of a community as the test and basis of its welfare in all other ways, the abiding social problem is always this: how to adjust circumstances in such a way that the smallest possible number of these potentially great wealth-producers may be wasted, and the largest possible number may be induced to exert themselves to the utmost.

One set of conditions essential to this result has It is therefore been described already - those, that is to say, by wealth will which the possession of wealth is secured to the increase in proproducers of it, and the persons to whom they leave great men have $_{\text {grially }}$ it. But to these must be added another set of an theopportunity en actualising entirely distinct character - that is to say, the con- their producditions which, the motive to exertion being given, shall render exertion of the kind required possible for the largest number who happen to be theoretically capable of it. Now modern democratic thinkers have supplied the world with a formula by which, in their judgment, these conditions are sufficiently indicated. This formula is "equality of opportunity," and we cannot begin our consideration of the question better than by taking this as a starting- 
Book IV point, and asking what truth is contained in it. We
Chapter 3 may at once admit, then, that if it is taken in an abstract sense, it sums up a truth which is, beyond doubt, indisputable; for if each individual having exceptional potentialities as a wealth-producer, which require nothing but the favour of circumstances to ensure their being turned into actualities, could be provided with circumstances so nicely adapted to his idiosyncrasies that these potentialities might be developed to the utmost extent possible, the productive powers of the community, it is almost needless to observe, would be raised in that case to their utmost possible efficiency. Such an ideal

It is impossible, however, to make opportunities absolutely equal. condition of things as this, however, is impossible for the following, if for no other reason. Successful parents as a rule will employ part of their wealth at all events they will employ the positions which they have won by their own ability - to provide opportunities of a special kind for their sons; therefore, whatever the State might do for its youths and young men in general, exceptional parents for their sons would be able to do something more. Equality of opportunity, therefore, represents an The question is ideal condition which we never can reach, but to how near we can approach which we can only approximate; and the only practical questions for us are accordingly these: how far towards this ideal can political action carry us, and what results are to be anticipated from our nearest possible approach to it?

Now the answer to both these questions will very largely depend on the existing conditions of the 
community with reference to which they are asked. For though men's powers of equalising opportunities are limited, their powers of making them unequal In a country may be said to be indefinitely great; and the more there opporunequal they have been made at the time when we artificially ask our questions, the greater will the progress be unequal therc which there will be room for us to make towards for a great deal equalising them, and the greater will be the social advantages which we may hope to secure by making it. In France, for example, before the first Revolution, the laws affecting industry had almost ruined the nation, not because by unduly favouring one class they led to wealth being concentrated, but because by unduly hampering other classes they prevented its being produced; and the sweeping away by the Revolution of the old feudal inequalities, though it had none of the millennial effects which the Revolutionists themselves hoped for, has had others equally striking, though of a very different kind. It has not made men equal in point of wealth, but it has increased to an astonishing extent the wealth of all classes alike. And the way in which it has done this has been by removing artificial impediments to the development and free exercise of exceptional productive talent; or in other words, by an equalisation of economic opportunities.

But the kind of equality that has thus been But removing reached may be described as being of a negative pediments is rather than a positive kind. It depends on the only a negative absence of artificial impediments to production, equalisation. rather than on the supply of any artificial helps to 
Book IV it; which means that it depends on the absence of everything that might obstruct the strong, rather than on measures or institutions that should artificially lend strength to the weak. Now, so far as industrial ability of the highest kind is concerned, it is probable that this negative condition of things, which is merely the complete embodiment of a policy of laisser-faire, represents the utmost that, in any civilised country, can be done by the process of equalisation with any beneficial result. For in wealth-production the men whose capacities are It is probable, really of the first order will, when not positively for the develop-impeded, make their own opportunities for themment of genius selves; and the genius who is born with every
of the highest

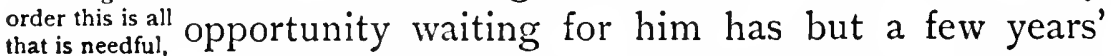
start of the genius who is born with none. That such is the case is abundantly illustrated by history. If we consider the most famous of the men whose originality of mind and extraordinary spirit of enterprise have been chief amongst the forces which have enriched the civilised world, we shall find that those whose names most readily occur to us have had no opportunities save such as their own genius made for them. Arkwright, Cartwright, Watt, Stephenson, the intrepid and enduring adventurers who, in the teeth of prolonged opposition, laid the foundations of the modern manufacture of iron; Columbus, who gave to Europe a new hemisphere - all these have been men born amongst social circumstances which conspired to deny them rather than to provide them with opportunities. And if we turn from 
Europe to new countries like America, and consider the leaders of economic production there, we shall find that the histories of these men have been similar. Nor, indeed, in this fact is there anything to be wondered at. In the sphere of industry, just as in the sphere of art, the greatest men will never be suppressed. They are always sure to assert themselves, and the struggle with adverse circumstances will, instead of crushing, strengthen them.

It may therefore be safely said that no equalisation of opportunity which goes beyond the abolition of arbitrary and unequal impediments would tend to increase the number of those exceptional men whose produc- and will secure tive faculties are really of the first order. And this ment of all the inference is supported by a large number of analogies $\mathrm{g}$ henius of the drawn from domains of activity other than economic. that exists. Any workman's boy, for example, who has any taste for books has now in England, before he is fifteen, more educational opportunities than Shakespeare had in all his lifetime. But the number of Shakespeares has not appreciably increased. Again, popular education has given to the whole French army advantages confined to a few at the time of Napoleon's boyhood. Every private carries the marshal's bâton in his knapsack. And yet democratic France, with all its equalisation of opportunity, has not produced a series of new Napoleons. On the contrary, the mountain, after years and generations of labour, does nothing at last but give birth to a Boulanger.

Though faculties of the first order, however, are 
Book IV

Chapter 3

But genius of a lesser kind, which would else be lost, may no doubt be elicited by positive educational help from the State;

independent of artificial assistance, many of an inferior, but still of an exceptional kind, are not; and it cannot be doubted that the supply of these last will depend very largely on the degree to which facilities for self-development are given by the State to those who desire to take advantage of them. Thus, though the spread of education in this country has not increased the number of Shakespeares, it has enormously increased the number of those who can write good English. And no doubt in the domain of wealth-production it has had an analogous effect. This effect, however, though real, has been enormously exaggerated; and it has been exaggerated for a particular reason. Social reformers have confused two things together. They have confused talents which are exceptional in their very nature,

though the amount of such genius is overestimated by reformers, because they confuse talents rare in themselves with accomplishments that are only rare accidentally. with accomplishments which are exceptional only because they are not universally taught. Thus reading and writing, for instance, were rare accomplishments once. Of all accomplishments they are the most universal now ; and there is not the least doubt that there are very many others which, with equal opportunities, might be acquired by almost anybody, but which yet, as a matter of fact, are still confined to a minority. In this fact that education may increase the accomplishments of a community, social reformers have fancied that they discovered an indication of the extent to which education could elicit exceptional talent. But to call into practical activity by means of external help exceptional faculties, of which the supply is necessarily limited, is a very 
different process from evoking by similar means faculties which are potential in everybody, and the Book IV Chapter 3 supply of which can be increased indefinitely; and The latter can it is a process, moreover, which produces very different results. Let us consider how this is.

For productive faculties of the highest order, For real prowhich not only minister to progress, but initiate it, there is always and which make, as if by a conjuring trick, the hands of the average labourer produce new commodities of which he never would have dreamed himself - for faculties such as these, the demand is always unlimited. There are productive faculties also, exceptional although they are inferior, the demand for which is usually greater than the supply. But with regard to those faculties or accomplishments which are only exceptional accidentally, and which might be, like reading, conceivably made universal, the case is precisely opposite, and it is so for two reasons. In the first place, these accomplishments, which anybody might conceivably acquire - knowledge of French, for instance, or of book-keeping - though they may minister to the business of wealth-produc- but the tion, yet have no tendency in themselves to make utility of mere the business grow. The number of persons, then, accomplishpossessing these accomplishments who at any given by the conditime can put them to a productive use is limited by duction at the the condition in which production at that time is. Thus the number of clerks which a mercantile firm can employ is limited by the business which the firm happens to be doing; and though this business might be enlarged by the enterprise of one new 
Book IV

Chapter 3

Thus to produce more possible clerks than are wanted merely lowers the wages of those employed, without increasing the utility of those who are not employed. partner, it would not be enlarged, when there were no letters to copy, by the accession of ten young men who could copy letters beautifully. In the second place, even at times when the national business is growing, and the demand for these accomplishments is for the moment greater than the supply, any attempt by the State to make their development general would produce a supply indefinitely greater than the demand. Thus to multiply the number of labourers' sons possessing accomplishments that would fit them for the work of clerks would not be to increase the number of young men who would wear black coats, and sit on stools in offices, instead of working in factories, or laying bricks, or ploughing. Instead of raising the position of the ploughboy to the same level as the clerk's, it would lower the clerk's salary to the level of the plough-boy's wages; and clerk and plough-boy would be alike sufferers by the process.

The beneficial effects, then, to be looked for from an equalisation of opportunity have been exaggerated by democratic thinkers because they have failed to perceive those facts. They have confounded the development of accomplishments which might conceivably be acquired by all with the development of faculties which, even potentially, are possessed by a few only. They see that education can increase the number of possible clerks, and they have therefore imagined that it can, with similar ease and certainty, increase the number of efficient men of genius. It must, however, be distinctly stated that 
the error in their conclusion is one of exaggeration only. There is much exceptional talent which, though not of the highest order, will, when oppor- Still, within tunity is given it, increase the wealth of the com-tionai help munity, but which will, without the educational does much to help of the State, be lost; and it may frankly be $\begin{gathered}\text { increase the } \\ \text { supply of }\end{gathered}$ admitted that, within certain limits, the equalising exceptional, of educational opportunity plays a very important great, talent. part in supplying the community with exceptionally efficient citizens.

But the main difficulties involved in the artificial But the main equalisation of opportunity are not concerned with volved in the the problem of how to produce good results by it. equalising of They are connected with the problem of how to opportunity is avoid producing bad results. Let us consider what duction of the possible bad results of it are.

In a general way they are indicated, or indirectly good resuits, but the avoid. ance of bad. implied, in the saying so dear to the sterner and more thoughtless of the Conservatives - that popular education does nothing but promote discontent. Sweeping statements of this kind, however, though they may have an element of truth in them, are valueless till they have been carefully qualified; for what we have to ask about them is not whether they are true, but how far they are true, and in what precise senses. Thus, though it is true that the danger of diffusing education lies in the discontent that may thereby be promoted, some kinds of discontent are not dangerous - they are beneficial; therefore the danger of diffusing education lics in its tendency to promote not discontent generally, but 
Book IV discontent of certain special kinds; and it is
Chapter 3 necessary to discriminate carefully what these kinds are.

The bad results are the stimulating of discontent, not in average men, but in men who are really exceptional ;
Now the kind of discontent which Conservatives generally have in view, when they denounce education because they think it tends to promote it, is by no means that from which danger really arises. What they generally have in view is a discontent with his circumstances which they think education will produce in the average working man. In reality, however, the primary danger of education is not to be looked for in its effects upon average men at all. It is to be looked for in its effects upon men who are distinctly exceptional.

In order to understand how this is, let the reader reflect once more on one of the main truths that have been insisted on in the present volume - namely, that though all progress is the work of great or exceptional men, all great or exceptional men do not promote progress equally, and some of them indeed do not promote it at all. Progress results from the victory of the fittest of these over the less fit in the struggle to gain dominion over the thoughts and actions of others. Let the reader reflect also on the analysis that was given of the various qualities which go to make up greatness - that is to say, the qualities by which dominion over others is obtained. It was pointed out that greatness is a highly composite thing; that it need not necessarily imply any moral, nor indeed any intellectual superiority; and as an illustration of this it was mentioned that many most 
important political movements have been produced by men whose greatness consisted merely in ordinary sense joined to, and made efficient by, an extraordinary strength of will. It is necessary now to but whose follow this line of observation farther, and to point giffs are illout that if extraordinary strength of will can pro- balanced or duce beneficial effects when allied with ordinary flaw in them. sense, it is equally capable of producing effects that are mischievous when allied with stupidity, or with that kind of imperfect intellect which is as quick in defending and popularising, as it is in being duped by fallacies. And with these latter qualities it is allied as often as with the former. It is a great mistake to suppose that even the most false and foolish opinions which have influenced multitudes to their own detriment have been originated and promulgated by men who were altogether weak and inferior. On the contrary, most of the follies which have disturbed or retarded civilisation have been due to the influence of men who, though morally or intellectually contemptible, have possessed a vigour of character far beyond what is ordinary.

Now, if education has the effect attributed to it For if educaof liberating the will and developing the intellectual and stimulates powers of men in whom the intellect is really acute sound inteland sound, there is an obvious danger of its having the same effect on men whose intellect is unbalanced and imperfect. To some of such intellects, no doubt, it may give clearness and equilibrium; but there are it will similarly others for which it does nothing, except to increase intellects that their powers of reasoning wrongly; and when an lectual powers, it will similarly
stimulate
intellects that
are not sound, 
Book IV intellect of this kind is allied with a naturally strong will, the effect of education is to let loose a wild horse, merely in order that it may run away with a lunatic. or will that has It must be remembered that the strength of a
no intellect to match, and will generate a desire for wealth in men who are not capable of creating it, man's will, though depending as a potentiality on the character with which he happens to be born, depends as an actual force on his desire for certain objects or results, coupled with the belief that he can attain these by action. Now, when a man's powers of action are capable of realising his desires - as when a man who desires to be wealthy has the talents that produce wealth, or when the man who desires to be Prime Minister has the talents of a great statesman - his career satisfies himself, and is presumably serviceable to his country. In many cases, however, desire is exceptionally great, and generates also a strong impulse to act, but the capacity for that kind of action by which the desired object might be obtained is small. Thus many men desire exceptional wealth, but find themselves incapable of the peculiar kind of action that produces it. Their will, accordingly, if it makes them act at all, is like a steam-engine which merely puts useless machinery into motion; or if it fails to make them act, as it very often does, it shakes them to pieces with a kind of intellectual retching. These unhappy persons owe the condition in which they find them-

and thus will merely produce needless misery and mischief. selves mainly to an over-estimate of their own powers; and this over-estimate is generally the direct result of education, which, by making them 
falsely imagine themselves capable of attaining wealth, actualises a fruitless desire for it, which might otherwise have remained latent. When education has this effect on a man it is an unmitigated evil for himself, and very frequently for others.

Again, education, besides actualising exceptional Education, desires which are wholly unaccompanied by any ex- ataies, ftimuceptional faculties that correspond to them, actualises that can really desires accompanied by faculties which are really tional results, exceptional, and which produce results undoubt- that are edly more than ordinary, but are nevertheless incacomplete. pable of complete development. Many men, for instance, have gifts for music and poetry which, though genuine so far as they go, have yet some fatal defect in them, and will never produce, however devotedly they are exercised, any results possessing artistic value. Now the fact that progress is caused by a struggle between exceptional men of course implies that some of them shall be less efficient than the others. It is by struggling with the less efficient that the superiority of the most efficient is realised; and in order that it may be found who the most efficient are, the inferior as well as the superior must put their capacities to the test. It is therefore unavoidably one object of education to stimulate the activity of some exceptional men whose own efforts are foredoomed to ultimate failure. Failures, however, differ in degree and kind. Some men fail because they can accomplish nothing of what they The progresattempt, like the dreamers who have wasted their requires that 
Book IV lives in trying to make perpetual motions. Some fail Chapter 3 because, though they accomplish something, others the intellects accomplish more; and the production of what is the of some should be stimulated whose efforts fail. best makes the second best valueless. Thus nine inventors might produce nine motor-cars, each of which worked well enough to command a considerable sale; but if a tenth inventor was to produce another which was faster, simpler, more durable, and cheaper than any of these, all the rest would drop out of use altogether, and be practically as valueless as the mad aggregation of wheels by which the seeker for the perpetual motion endeavoured to accomplish the impossible. Between the men who fail, however, because they succeed less than others, and the men who fail because they do not succeed at all, there is a great practical difference. The men who fail only because others succeed better

But those failures that promote progress are failures that partially succeed. than they do, contribute to the very success of the men by whom they are defeated; for they raise the standard of achievement which these men have to overpass. But the men who fail because they accomplish nothing waste their own lives without benefiting anybody. In the domain of economic production the truth of this is obvious. It is not less so in the domain of speculative thought. Scientific theories are constantly put forward which, though not true, are sufficiently near the truth to have some definite relation to it; and those who actually reach it find in errors of this kind an indispensable assistance. Nothing gives to truth so keen and clear an outline as the refuted errors of really powerful thinkers. But 
there are errors, on the other hand, which, though it may be necessary to refute them because they have imposed themselves on a number of ignorant people, do nothing to advance the discovery of truth whatever, and the activity of those who originate them is altogether mischievous. Thus whilst the reasonings of heretical thinkers like Arius, by the controversy they provoked, were very largely instrumental in advancing orthodox theology to really logical completeness, the philosophy of religion owes absolutely nothing to Joanna Southcote or the American prophet Harris. Accordingly, whilst it is But there are impossible to say with precision where the line is which produce to be drawn between the exceptional talents which, failures that if developed, would be of use in the progressive ${ }_{\text {success. }}^{\text {relation to }}$ struggle and those which are so defective that These talents their influences would be merely mischievous, it is mischievous; obvious that talent of this latter kind is sufficiently plentiful to render its development dangerous.

History teems with examples of this fact, and so for example, do the unwritten annals of the social life around us. the would-be Henri Murger in his studies of Bohemian Paris bears eloquent witness to the tragic absurdity of the results caused by the development of imperfect artistic talent, and the miserable endings of men who, if they had not tried to be artists, might have lived and thriven as honest and healthy ouvriers; whilst, according as we hold vaccination to be a blessing to the world or a curse, we must necessarily hold that it would have been far better for everybody or that of the if the talents of the men who invented it, or else mapularises 
Book IV those of the men who now oppose it, had been Chapter 3 killed by the frosts of ignorance, and never allowed $\begin{array}{ll}\text { wrong medical } & \text { to blossom. }\end{array}$

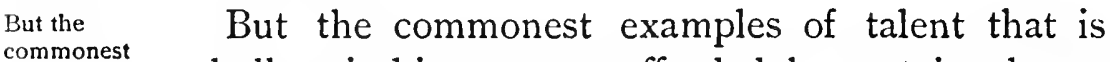
example of this wholly mischievous are afforded by certain classes kind of man is of politicians and social agitators. There is a agitator, large number of men whose potential activity is considerable, and whose intellect has a natural nimbleness which will enable them, when stimulated by education, to seize on plausible fallacies and impose them both on themselves and others. Politicians of this class are familiar figures enough. The social agitator, whose mental equipment is similar, is more familiar still. Many attempts have been made to give a scientific explanation of those constant attacks on the existing organisation of society which are common to all civilised countries, and go by the name of socialism. Socialism is said by some to be the protest of increasing poverty against increasing wealth; by some to be the natural voice of highly organised labour, which has come at last to be capable of selfgovernment; and by some to be an embodiment of the esoteric philosophy of Hegel. In reality it is the embodiment of the results of indiscriminate education on talents which are exceptional, but at the same time inefficient. The avowed object of socialism is a redistribution of wealth; but the most striking characteristic of all the socialistic leaders has been an incapacity to produce the thing which they are so anxious to distribute. The wish to re- 
distribute it in some of them arises from sentiments of benevolence; in some from fallacious reasoning; Book IV Chapter 3 and in some from personal envy; but in none has it been accompanied by those particular faculties on which the actual production of wealth in large quantities depends. Socialism, therefore, so far as it is a serious theory, is essentially an attempt on the part of men who are themselves economically impotent to prove that they, and others like them, have some reasonable right to possess and divide amongst themselves what they are constitutionally powerless to make for themselves.) The result has been the elaboration of a theory of production which sometimes declares that wealth is produced by "aggregates of conditions," or "social inheritances" or "environments," as Mr. Spencer, Mr. Bellamy, and Mr. Sidney Webb tells us; and sometimes that it and who conis produced by "average labour measured by time," invents false as Karl Marx tells us, - the one doctrine being that theories about wealth is produced by nobody, and that one man which do nothhas thus as good a right to it as another; the other alise those who has thus as good a right to it as another, the other are duped by being that it is produced in equal quantities by them everybody, and that everybody on that ground has a right to an equal quantity of it. Both doctrines agree in this, that they altogether miss and divert the attention of the mind from the forces and conditions on which wealth-production depends in reality.

Now if the elaboration of these fallacies had been confined to men who were capable of presenting them in a really arguable form, and if they had been (though even promulgated only amongst classes who were capable can be dis- 
Book IV of passing a scientific judgment on them, they might have played - and within limits they have

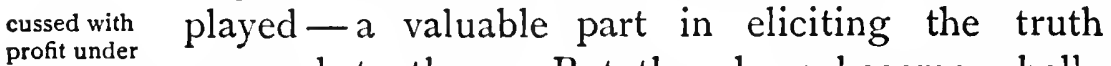
profit under
certain circum- opposed to them. But they have become wholly stances). mischievous when, through the agency of indiscriminate education, they have influenced men who, whilst wanting in intellectual judgment, are nevertheless endowed with a potential activity of character, and who, when this is developed, at once become powerful agents in disseminating fallacies amongst others even less capable of criticising them than themselves. Thus many of the leaders of the "new unionism" in England are to be credited with energy of a really remarkable kind; but unfortunately the energy is united to such defective intellectual powers, that the more vigorously these are employed, the more mischievous and absurd is the result. The general resolutions that have been passed at Trade Union conferences declaring that no progress is possible till all the means of production shall have been nationalised, or the doctrine of the "new unionists" that wages control prices, are all results of the exercise of faculties which, though in some respects doubtless superior to those of the average man, had far better have never been developed at all.

Men like these It is men like these - the men with ill-balanced embody the
two chief or abortive talents - the men with strong wills and dangers of the artificial equalisation of educational opportunity, defective intellects, the men whose ambition is developed by the smallest educational stimulus, but who have no talents proportionate to it which any 
education could develop - it is men like these who invest with its principal dangers the equalisation of Book IV educational opportunity; and if education, as so many Conservatives say, really does nothing but promote popular discontent, it promotes discontent amongst the great masses of the population less from the manner in which it affects the average man directly, than from the manner in which it affects men who are inefficiently exceptional, and who, not having the gifts that would enable them to rise in any society, endeavour to persuade the masses that society, as at present constituted, is an organised conspiracy of the few to keep everybody else down.

The equalisation of educational opportunity has, therefore, two dangers - the danger of developing wants in the average man which could never be generally satisfied under any social arrangements, and the danger of developing the talents of a certain class of exceptional men which are naturally incomplete, and which the more fully they were developed, would only become more mischievous both to their possessors and to society.

And these dangers correspond with the two objects namely, the for the sake of which the equalisation of educational average man opportunity is advocated. One of these objects is wants which the raising the condition of the average man; the satisfy, and the other is the securing, alike for himself and for talents that are society, the full benefit of the potential gifts of the imperfect. exceptional man. The average man, however, is not made better or happier by being filled in early life with importunate wants and propensities which 
Book IV he will, when he comes to maturity, be unable to gratify; nor is any one made better or happier by the development of gifts which, however exceptional, can, by reason of their incompleteness, do nothing but give currency to error, or initiate abortive action.

The latter of these dangers is the source of the former.

It cannot be completely avoided, but present theories of education tend to heighten, not to minimise it.

The current theory that all talents should be developed is false;
It is the latter of these dangers that is practically the source of the former. The average man would, as has been said already, probably suffer little from over-development under existing systems of education if it were not for the effects of these systems on inefficiently exceptional men whose superiorities ought never to be developed at all. It is doubtless impossible to avoid this danger completely. If educational opportunities are to be of a kind that will enable the efficiently exceptional to work their way to the top, and advance or maintain civilisation by their influence or domination over others, it is inevitable that a certain proportion of the inefficiently exceptional will be induced to develop their unhappy capabilities also; but the number of these may, at all events, be reduced to a minimum. The fundamental fault of contemporary educational theories is, that in proportion to the completeness with which they were carried out, they would tend to raise the number of these men to a maximum. And the reason why they would have this tendency is that they are founded on two absolutely false principles. The first of these principles is, that whatever potential talents any man may possess, it is desirable to assist and encourage him to develop them to the utmost. The second is that the type of educa- 
tion and culture to which education generally should, so far as is possible, be assimilated, is the kind of Book IV education and culture that is actually prevalent amongst the rich.

It is impossible to meet these principles with too emphatic a negative.

The first of them is false because, as has just been shown, there is a large amount of really exceptional talent which, if developed, would work nothing but mischief, and which ought, consequently, for the sake of everybody, not to be developed, but suppressed. The second is false so is the theory because all tastes and talents are good or bad, should be useful for a man or useless, according to the con- cultivated in ditions under which his life will be passed; and education the conditions of the rich are altogether exceptional. rich is not a Societies have existed in which they have been exception. enjoyed by nobody. It would be impossible to construct a society in which they should be enjoyed by more than a few. The attempt, therefore, to give to everybody a rich man's education is like including skating in the curriculum, and fur coats in the wardrobe, of a thousand boys, when nine hundred of them are to spend their lives in the tropics.

Both these false principles rest on that radically These false false theory of society which it is the principal object the false belief of the present volume to expose - the theory that education civilisation is the product of men approximately could ever proequal in capacities, and that in proportion as these social condiequal capacities have equal opportunities of development, there will naturally be an approximation to an 
Book IV equality of social conditions. The facts of the case are precisely the reverse of these. Civilisation originated in, and is still maintained by, men whose capacities are unequal to those of the majority; and just as there is no tendency towards equality in capacity, so, for reasons which have been explained in the last chapter, there is no tendency towards equality in social conditions. Inequalities of condition may at some times be greater than at others, but the fact that at times they show a tendency to become less is no more a sign that they have any tendency to disappear than the fact that an economy has been effected in the consumption of coal on board a steamship is a sign that steam has a tendency to be generated without fire. It is therefore a scientific certainty that of each generation of children in

The majority of each class will remain in the class in which they were born. every civilised country the majority will, throughout their subsequent lives, occupy positions very different from those of the few. Most of the members of each class will remain in the position in which they were born; but there will be a gradual descent from the upper classes of their weaker members into the lower, and amongst the stronger members of the lower classes there will be a constant potential desire

Only the efficiently exceptional can rise out of their own class; to push their way into the upper. Some of these last are strong in potential desire only. With others the strength of desire is accompanied by corresponding talent, by means of which, if developed, the position which they desire will be obtained. It will be obtained by the talent of these men, because the talent of such men is creative; and when it is 
developed it renders those who possess it actual additions to the civilising forces of the community.

With regard, then, to exceptional men, the object of education should be to stimulate the ambitions of and it is the those of them whose talents are efficient, whilst dis- efficiently couraging the ambitions of those whose talents are oxceptionat it is inherently defective. The stronger the ambitions of really desirable the former are, the better for themselves and for the community. Men like these are the true gold-mines of their country. The stronger the ambitions and the larger the opportunities of the latter, the more will the health and strength of the social organism be interfered with.

With regard to the average man, the object of The average education should be to develop in him such tastes or taught to aim accomplishments as will assist him in the work by his position, which he is to live, and enable him to make the most not at escaping of such means of enjoyment as are within his reach, whilst leaving him untormented with a desire for enjoyments that are beyond it; and the crucial fact on which it is necessary to insist is that the circumstances of different classes are permanently and necessarily different, and that for the average man of each class the education that will make the most of his life is necessarily different also.

In other words, the only true equality of educational opportunity is an equal opportunity for each, not of acquiring the same knowledge or developing the same faculties, but of acquiring the knowledge and of developing the faculties which, given his circumstances and given his natural capacities, will 
Book IV do most to make him a useful, a contented, and a happy man.

Unfortunately these conclusions, simple and obvious as they seem, run directly counter to that entire theory of society which, with more or less consciousness, and with more or less precision, is held by the school of writers, reformers and politicians, who suppose themselves, in some exclusive sense, to have social progress at heart; and also to that mass of diffused sentiment which, though not expressing itself formally in any theoretical propositions, has that theory as its foundation, and bears to it, as a political force, the same relation that vapour bears to water. These conclusions, therefore, which imply inequality in capacity as the cause of social progress, and inequality in social circumstances as the necessary and permanent conditions of it, are, like most of the other conclusions put forward in this work, certain to be met with objections of the most vehement kind, which it will now be necessary for us fairly and carefully to consider. We shall find that, as we do so, the entire arguments of the present work are summed up and brought together before us; and however incompatible they may be with the false conception of progress, of class relationships, and of the structure of society generally, which are at present mischievously popular, they form the foundation of hopes, for all classes, far more solid than those, the fallacy of which they aim at demonstrating. 


\section{CHAPTER IV}

INEQUALITY, HAPPINESS, AND PROGRESS

MAN does not live by wealth alone, and progress is not concerned solely with the production and the distribution of it. But the processes involved in the production and distribution of wealth, though far from being coextensive with all social progress, are typical of it. They form, moreover, the subject with regard to which contending politicians The radical and reformers practically join issue; and it is object to the mainly because inequality in the possession of foregoing conwealth is affirmed to be a permanent and necessary terms with feature of civilisation, that the conclusions here put familiar. forward will be attacked.

The objections that will be brought against them will take two forms: one being the form which will be given them by the radical or socialistic politician; the other the form which will be given to them by the radical or socialistic theorist.

The radical or socialistic politician, whether he is journalist or popular orator, will express them by asserting, in a tone of contemptuous irony, that these conclusions, whilst highly satisfactory to 


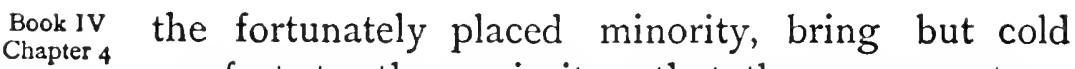
comfort to the majority; that they represent an attempt "to put the clock of progress back," and that the masses of mankind are not very likely to accept them. He will probably go on to say that they are merely a prose rendering of the well-known lines which the sarcastic radical loves -

God bless the squire and his relations, Teach us to know our proper stations;

which last request to the radical seems to be the very height of absurdity; and he will end his attack by appealing to our electioneering instincts, asking us, if we take away the hopes to which at present the masses cling, what new hopes or promises we propose to put in the place of them?

The radical or socialistic theorist, as distinct from the militant politician, will express these same objections in a more logical form, thus: He will remind us

The radical theorist will put these same objections more logically. If the desire of exceptional wealth is really
the strongest motive, he will say that it follows that most men, since they can. not all be exceptionally rich, must always remain miserable. that in our analysis of social action we represent the attainment of an exceptional position, and more especially of an exceptional amount of wealth, as the sole motive that can be counted on to induce exceptional men to develop and use their powers. Now this, he will urge, is tantamount to declaring that exceptional wealth is naturally regarded by men as the main condition of happiness; and since it is obvious that exceptional wealth can be possessed by the few only, we are, he will say, convicted of teaching that social progress involves a denial of happi- 
ness to the vast majority of those amongst whom social progress takes place; which, the critic will go on to say, is absurd.

Now even if the conclusions we are discussing did involve in reality all those consequences which would be so depressing to the majority of mankind, yet to prove the conclusions depressing would not be to prove them false; and few enthusiasts will deny that the object of sociological inquiry is not to reach conclusions which are inspiriting, but to reach conclusions which are true. As a matter of fact, however, the conclusions now in question have by no means that depressing tendency which the radical and the socialist will impute to them.

For, in the first place, none of the arguments Now the first contained in the present work have been invoked is that the to prove, or have any tendency to prove, that the $\begin{gathered}\text { fact that all } \\ \text { men will never }\end{gathered}$ many, as distinct from the few, in any progressive be equally country, may not reasonably look forward to a not prevent continuous improvement in their condition - to $\mathrm{a}_{\text {of }}^{\text {the conditions }}$ greater command of the comforts and luxuries of ing improvlife, together with a lightening or a lessening of the labour necessary to procure them. On the contrary, the majority may look forward to an improvement in their circumstances which it is as impossible for us to imagine distinctly at the present time as it would have been for our grandfathers to imagine the telephone or the phonograph. All that has been urged in this work is as follows: That whatever may be the new advantages which the majority of mankind attain, they will attain them 
Book 1V Chapter 4
Another answer is that if inequality in the possession of the most coveted prizes of life implies misery amongst the majority, this evil would be intensified rather than mitigated by socialists, who would substitute unequal honour for unequal wealth. not by any development in their own productive powers, but solely by the talents and activity of an exceptionally gifted minority, who will enable the ordinary man to earn more whilst labouring for fewer hours, because they will, by directing his labour to more and more advantage, secure from equal labour an ever-increasing product. The conclusion, therefore, is not that the majority in any progressive community may not look forward to indefinitely better conditions, but merely that their condition will not depend on themselves, and that, though the conditions of all may be bettered, they will never be even approximately equal.

What, then, of the argument that, however conditions may be bettered, yet if exceptional conditions are still objects of exceptional desire, the want of these objects of desire will cause a sense of privation amongst the majority?

To this really important question there are two answers.

The first is, that the conclusion now before us - the conclusion that certain of the most coveted prizes of life will always be for the few only - is, whatever may be its consequences, true; and that its truth is nowhere more clearly evidenced than in the ideal State, as presented to us by the extremest socialists. For we shall find that whatever in the way of equalised incomes these statesmen of cloudland promise to their imaginary citizens, they do not even suggest that the most coveted social prizes shall be distributed more equally than they are at 
the present moment. They, as has been said already, though they consider themselves the apostles of equality, recognise that the prosperity, and, above all, the wealth of the community, will depend on their securing the very ablest of their citizens as members of the bureaucracy by whom all labour will be directed; and they recognise that these able men, like the present race of employers, will not develop their ability without some special inducement. They accordingly propose to reward them, not by allowing them to retain any exceptional portion of the wealth which they are instrumental in producing, but by investing them with exceptional honour; and the desire for such honour, say the socialists, as a motive to exceptional effort, "will be incalculably more efficacious" than the desire for wealth. Now if those who make this assertion attribute to it any serious meaning, they must mean that men like honour much better than they like wealth - that they covet it more keenly, that they will struggle more desperately to win it, and are more exasperated at not possessing it. If, however, great wealth is possible for the few only, and if the majority of mankind are for ever destined to be without it, such, with regard to honour, is the case even more evidently. For honour is more essen. tially confined to the few than wealth is. We can, at all events, conceive a community composed wholly of millionaires, supported in luxury by battalions of labouring automata; but it is impossible to conceive a community wholly composed of men on whom 
Book IV honour is conferred as the choicest prize of life, and all of whom - the exceptional and the ordinary enjoy it to the same degree. The essence of honour is distinction or differentiation; and it forms a motive for the exceptional actions of the few only because it is withheld from the many whose action is not exceptional. Either, then, in the socialistic State the honour that is to form the reward of exceptionally able men will fail to stimulate their abilities and attract them into the ranks of the bureaucracy because it is not of itself so keenly desired as wealth is; or if, as the socialists say, it is desired even more keenly, and if it consequently does stimulate exceptional men to struggle for it, the socialistic bureaucracy, with its honours, will excite amongst the mass of the citizens incalculably more envy than the rich excite amongst the poor; and the millions of average men will be rendered by the want of honour incalculably more miserable than they could be by want of wealth. If, therefore, inequality in the possession of external goods, for which many men struggle, and which only a minority can secure, necessarily means unhappiness for the larger part of the community, this evil at all events is not due to the existing structure of society, but is, on the contrary, so rooted in the constitution of human nature, that even the wildest and completest schemes of social reform are unable to offer us so much as a mitigation of it.

The second answer to the objection, however, is of quite a different, and of a far more reassuring, 
character. It is that the entire supposition on which the objection rests is untrue. The external prizes of Book IV Chapter 4 life, of which exceptional wealth is the type, though struggled for by many with every faculty they possess, though valued by those who achieve them, distribution of and though recognised by men in general as some- natural tenthing of which everybody would choose to be the unhappiness; possessor if he could be, do nevertheless amongst average human beings not cause any unhappiness by their absence at all corresponding to the satisfaction which they cause notoriously by their presence. Such an assertion will to many people probably seem self-contradictory. But if it does so, this will simply be owing to the fact that the whole science of the subjective conditions of happiness has been utterly neglected by sociological writers hitherto. The assertion here made, however paradoxical it may sound, embodies one of the most important truths which can claim the sociologist's attention; and though it cannot be called self-evident, every student of social science should be familiar with it. It forms, indeed, the pons asinorum of all social psychology. A brief elucidation of it will be enough for our present purpose.

There is a certain minimum of external goods, the for men's desire for which has a physiological basis, and causes there is when unsatisfied, misery, disease, or death. Chief equality of when unsatisfied, misery, disease, or death. Chief desire for the amongst such goods are food and, in most climates, life only; for clothes and shelter. So far as this minimum is con- this desire cerned, the desires of all are practically equal; and physical they are equal because they arise out of that physical natures, which 

Book 1V constitution which we cannot alter, and in respect of which we are all similar. But for external goods but the desire for superfluities depends on powers, which vary.

that are beyond this minimum men's desires vary indefinitely; and they vary because they depend on the action of the imagination and the intellect, which varies in different men, and in the same men under different circumstances.

In civilised countries the minimum of goods desired is practically not limited to the bare necessaries of existence, and it is difficult to define it with anything like absolute precision. But without any formal definition of it, it is at all events sufficiently

The special appeal of luxury is mainly to the mind and the imagination distinct to enable us to place in contrast with it those obviously unnecessary goods which make up wealth and luxury. Now luxury is very commonly supposed, in contradiction to what has just been asserted, to represent materialism in its most exaggerated form, and thus to offer a contrast to competence or modest comfort. And it does, no doubt, rest on a material basis; but competence and modest comfort do so likewise. An arm-chair which costs perhaps thirty shillings is as material as one which, on account of its artistic workmanship, costs four or five times that number of pounds. But so far as wealth and luxury transcend comfort and competence, and possess those peculiar qualities which are held to render them enviable, what they appeal to, and what they are measured by, is not their effect upon the senses, but their appeal to the imagination and the mind. We can easily see this by considering very simple examples, which will show us that the 
same external things are luxuries or not luxuries according to the way in which the mind regards them. Thus a man will be called luxurious if his house is of palatial proportions, if he lives under the luxury, for lofty ceilings and treads upon shining floors. But large house, the luxury which the owner finds in existing amongst these surroundings consists not in any physical effect which they produce upon his senses as he moves amongst them, but in a great variety of complicated relations which exist between them and his own life, past and future, and of which the senses take no account at all. Were this not so the poorest and most destitute might daily enjoy a luxury superior to that of the millionaire by strolling through the halls and corridors of our great public institutions, of which many are far finer than the most magnificent private houses. A man, again, $\underset{\text { accommo- }}{\text { accoping }}$ will be thought, and will think himself, luxurious if dation in a he travels from Paris to Monte Carlo in a sleeping train. compartment with sheets and pillows; and passengers who have ordinary places, if they are sensitive to social contrasts, will glare through the windows enviously at the occupant of this paradise, who has probably had to pay a hundred francs to enter it. But let us only imagine that the sleeping compartment is taken off its wheels and is permanently planted by the side of some street or road. It will then form a bedroom which the owner of the pettiest villa would hardly venture to assign to a maidof-all-work; whilst if three workmen had to sleep in it instead of three first-class passengers, the agitator 


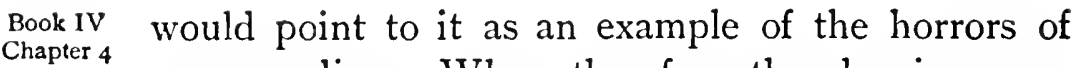
overcrowding. When, therefore, the sleeping compartment is admitted - as it is admitted - to be a luxury, it is admitted to be so because it is regarded in relation to a variety of circumstances to which the senses are quite blind, and which are realised by acts of the mind and the imagination only. And with all wealth and luxury the case is just the same. Like comfort and competence, they have material things for their foundation; and the material foundation that supports them is no doubt necessarily larger. But what renders them more desirable is not the additional material in itself, but the qualities with which it is invested by the subtle craftsmanship of the mind.

Consequently the desire for luxury and wealth, like the pleasure they give, depends on peculiar mental powers or peculiar mental states.
Just, then, as wealth and luxury depend on the intellect and the imagination for the larger part of the pleasure which they give to those who possess them, so does the desire for them amongst men in general depend on the action of the intellect and the imagination also. Hence, though a desire for wealth is popularly supposed to be universal, and in a certain sense is so, it is a desire the non-satisfaction of which causes a sense of privation only when the imagination and the intellect work in an exceptional way. Let us take, for example, some community on the outskirts of civilisation which continues to maintain itself in rude plenty and comfort, but to which wealth and luxury are merely remote ideas. If a stranger suddenly came within its borders carrying a bag which had in it a hundred thousand pounds, and if 
he placed this bag on the summit of a neighbouring mountain and promised to give it to the first man who should get hold of it, every member of this simple community who was not lame or bed-ridden would start for the mountain as fast as his legs could carry him, and the slopes would soon be the scene of a mad and breathless scramble. But if no such stranger came bringing the image of wealth close to them, or if instead of placing his bag on the summit of a neighbouring mountain he showed it to them through a telescope hung up in the moon, not a single heart amongst them would beat quicker at the thought of it or suffer a single pang from the knowledge that it was unattainable.

The reason of this is as follows: Amongst the Amongst most great masses of mankind the desire for wealth is a men the desir is speculative desire only. They give, if we may naturally a borrow an expression from Cardinal Newman, only desire only. a "notional assent" to the fact that it is desirable. Wealth means for them no special pleasure which they have experienced, or can represent to themselves, and the repetition of which they crave for; nor does it mean the satisfaction of any importunate wants. It does not mean for them what a shilling would mean for a starving man. For him the shilling would mean the food for which his stomach clamoured; and he would feel the want of It implies no it as keenly as he would value its possession. So, the want of too, a poor youth separated from his family may wealth. crave for a five-pound note, and be miserable at not possessing it, because this will represent the possi- 
Book IV bility of spending Christmas with them. But no
Chapter 4 ordinary man, unless he has lived amongst the very rich, and his entire view of life has been practically identified with theirs, has any similar craving for a hundred thousand pounds, or for a million; for he has no personal experience and no detailed knowledge of the peculiar conditions of life which require such sums to purchase them. Wealth is to him little more than a name for a power which would secure for him, if he possessed it, an indefinite number of indefinite things, if he wanted them; but he is under ordinary circumstances no more troubled by its absence than he is by the fact that he has not a fairy for his godmother, or that he does not happen to be the owner of Aladdin's lamp.

How, then, does it come to be the object of that keen hunger which is the strongest motive to activity amongst the men who are the chief producers of it? What are the exceptional circumstances which convert it from a remote something, held in a passionless and speculative way to be desirable, into a near something, craved for, and

The desire ceases to be speculative and becomes a and becomes a ing only when the imagination is exceptionally strong, and a strong
belief is present that the ettain- any given individual that wealth is a thing which ment of wealth
is possible. 
efforts, of which he believes himself to be capable. In cases where the necessary efforts are recognised

as long and arduous, and the coveted reward as being consequently far distant, the belief of the individual that it is really possible for him to attain it will require the aid of an exceptionally powerful imagination to rouse it into activity, and to keep it alive when roused. In cases where the necessary efforts are obviously extremely slight, and the individual believes that wealth is almost in his hands already, the belief will stimulate his imagination, however feeble it may be naturally, instead of requiring that his imagination should sustain or stimulate $i t$. Thus the attainment of wealth being under ordinary circumstances difficult, and requiring intense, anxious, and prolonged effort, a keen desire for it is not ordinarily felt except by men whose strength of imagination amounts almost to genius, and in whom a belief, whether true or false, is developed, that they are capable of creating for themselves this prize which they see so clearly. Warren Hastings, for instance, if his imagination had not been exceptional, would never have had that vision of the past glories of his family which made the desire of restoring them the main motive of his career; and again, on the other hand, if some sudden and exceptional circumstance, such as the advent of an imaginary stranger with his bag and his hundred thousand pounds, should present every member of a community with a chance of acquiring wealth instantly, the feeblest imaginations would be 
Book IV stimulated to such a degree, that all would find
Chapter 4 themselves craving for the possible prize equally.

The desire for In converting, then, a mere notional assent to wealth, in fact, is in proportion the proposition that wealth is desirable into an to each man's belief that by him personally actual hunger for it, which is painful if not it is attainable. satisfied, the essential cause is a belief that the desired wealth is attainable; and the intensity of the hunger is in proportion to the vitality of the belief. This important psychological truth is very easily demonstrable by a kind of experience sufficiently familiar to most people. If a man who has perfect taste, and a few thousands a year, is buying furniture for his house, and is anxious that every room shall be as beautiful as it is in hower to make it, we all of us know with what eagerness day after day he will stare into the windows of the dealers in old furniture and bric-à-brac, and how quickly he will take note of any object that his taste approves. Now if such a man, having admired a cabinet or a piece of tapestry, finds that the price of it is a hundred or a hundred and fifty pounds, he will feel perhaps that it is a little beyond his means; but he will dream of it, long for it, and will never know a moment's peace till he has so arranged his expenditure as to enable him to complete the purchase. But if the price of the cabinet or the tapestry, instead of being a hundred or a hundred and fifty pounds, had been a thousand or fifteen hundred, he would have recognised that the objects were totally beyond his reach, and though they still excited admiration in him, they would 
excite no desire. Here is the great difference between the necessaries of life and the luxuries. Men crave for the former, whether they are able to procure them or no. They crave for the latter only in proportion as they feel them to be procurable. A starving boy does not want a bun the less because he has not a penny to buy it with. A man of taste, with only a hundred pounds to spend, does not crave for a piece of tapestry at all, if he knows that the lowest price for it would be not less than a thousand.

Now under normal conditions the belief that exceptional wealth is procurable by them is confined to men with exceptionally vivid imaginations and with certain exceptional talents and energies that This belief is correspond to them. They crave for wealth, in fined to men fact, because they believe themselves capable of with excepcreating it, and their craving keeps pace with their tions and belief in the range of their capabilities. The more productive wealth they can create, the more they desire to powers. create. Their desire for wealth, in fact, unlike their desire for necessaries, is proportionate not to their natural wants, but to the extent of their natural powers. It follows what may be called the law of expanding desire. Here, then, is the explanation of the fact which is at first sight so paradoxical - that whilst the desire of wealth is the strongest of all motives amongst a minority, the absence of wealth is not felt as any privation by the majority; and so long as the normal conditions that have just been indicated prevail, and the men who 
Book IV can really produce exceptional wealth are the only
Chapter 4 men who believe it to be a thing attainable by them, and are consequently the only men who feel any actual craving for it, all goes well and healthily, and the desire of all classes may be at least approxi-

It only becomes general by the popularising of false theories which represent wealth as attainable by all, without exceptional talent or exceptional exertion.
It is roused, for instance, in a man who suddenly is told that he has a legal right to an estate which previously he never thought of coveting. mately satisfied. Unfortunately, however, the belief that wealth is attainable, though it is naturally confined to men who have exceptional powers of creating it, is capable of being implanted under certain circumstances artificially in men who possess no exceptional powers at all.

A familiar case like the following will show how this is effected. A man, we will say, occupies an ornamental cottage, which is beautiful in itself, is embowered in beautiful gardens, and also commands views of a picturesque and magnificent park, into the glades of which one of the gates of his garden opens, and which the owner allows him to use precisely as if it were his own. All his friends tell him, and tell him truly, that there is no such place of its size within fifty miles of London. They envy him his dainty drawing-room, his verandah festooned with roses, his prospect of the timbered park, and his free access to its solitudes. His friends envy him, and he feels himself that he is enviable. One morning, however, he receives a lawyer's letter, which gives him to understand that he is really the legal owner, not of his cottage only, but of the park and property adjoining, and that with adequate legal assistance he could certainly substantiate his claim to them. In an instant his whole 
temper of mind with regard to his surroundings is changed. His pride in his cottage is gone, and its Book IV Chapter 4 place is taken by indignation at having been kept out of possession of the park, and by a feverish craving to acquire it. He goes to law. The case is long and difficult. He lives for months distracted by fear and hope; and when the case is finally given against him, he comes back to his cottage with his mind unhinged by the shock, contemptuous of the dwelling which was once a source of pride to him, and cursing the prospects which once were his daily pleasure.

Now this craving for wealth, by which the man's life is blighted, has been produced, precisely as such a craving normally is, by the belief on his part that certain wealth is attainable; but the belief here does not rest on a consciousness that he is able by his own abilities to create or earn it for himself; it rests on his intellectual assent to a delusive proposition that he has a legal right to it, or, in other words, The socialistic that the law will make him the possessor of it day creates a without any exceptional productive effort of his for wealth by own. And here we have a counterpart to the its doctrines socialistic teaching of to-day. It excites, or aims at rights to it. exciting, an artificial craving for wealth in men who would not naturally trouble their heads about it, by teaching them that they have a right to it, which is wholly independent of any exceptional productive power in themselves, or in any ancestors from whom they might claim to inherit. The only difference between men who are thus deluded, and 
Book IV the claimant to the park and estate whose case we have been just imagining, is that whilst the latter is deceived into expecting that he individually can be made rich by a law-suit, the latter are deceived into expecting that they all can be made rich by legislation.

The practical craving for wealth is naturally confined to those who have some talent for creating it, and the pain caused by its absence is naturally confined to such men.

The desire for wealth, as something distinct from competence, is a desire which normally affects men only in proportion as they believe themselves to be possessed of power by which they may individually earn it; and so long as men recognise the truth that, apart from rare chances, the powers that earn wealth are the exceptional powers that create it, the craving for wealth which makes the non-possession of it a pain is confined to a minority composed of exceptionally constituted individuals. The absence of wealth amongst the majority causes unhappiness only when false theories with regard to its attainability and men's natural rights to it have produced in the average man an artificial and diseased sensitiveness. There is no surer means of exaggerating inequalities in happiness than the false and pestilent teachings which encourage equality of expectations.

The socialistic And not only do these teachings, so far as they theories merely cause a barren
and artificial discontent, have any effect at all, create private unhappiness and multiply private disappointments, but they give rise amongst masses of men to an impracticable temper, which is the source of many of the difficulties confronting us in the domain of politics, and most of those confronting us in the domain of industry. 
The crude and childish philosophy which socialists and so-called labour-leaders endeavour to diffuse amongst the great masses of the population rests, so far as the masses of the population understand it, on the theory that society is composed of "approximately equal units," and that whatever is produced within a community is produced by that community as a whole. Hence the members argue, and the socialists distinctly tell them, that property and capital are merely accidental possessions, which give to those who possess them a purely adventitious power. These teachers add that such possessions, in abstract justice, should be taken from their present possessors and divided amongst the community at large; and from this it follows that all claims to the profits of capital, as put forward by its present possessors, are, in an abstract sense, unjust. The consequence is that the employed, when stimulated in to conflict with the employers, enter on the conflict in a temper which forbids them to be satisfied with any immediate result of it, however favourable to themselves. Whatever advance in wages, or reduction in hours, the employers may have conceded, the employed - so far as they are influenced by the socialistic fallacies of the day - consider themselves still wronged almost as much as ever, so long as the employers continue to exist at all ; and thus any cordial understanding between the two classes is made impossible. When the employed strike or agitate for higher wages, they may be compared to a man who maintains that his tailor's bill is ex- 
Book IV orbitant, and desires to have a certain portion of the total deducted. Now if the tailor is reasonable and agrees to take off something, the matter may be easily adjusted to the satisfaction of both parties; for though the customer may think that the tailor has claimed too much, he admits that to a certain sum the tailor has an undoubted right. But if the customer were a madman, who believed when he ordered his clothes that in abstract justice he ought to be charged nothing for them, and that any claim on the tailor's part was in reality robbery and oppression, whatever deduction the tailor might consent to make, the customer's grievance against him would remain the same as ever. It is possible for customers and tradesmen to come to some satisfactory understanding, so long as the demand of the former is that their bills shall not be too high. No satisfactory understanding could be arrived at between them possibly - there would be nothing but friction, constant dunning, and writs - were it known that the customers entertained and meant to act on These theories the theory that they ought not, in abstract justice, to make enemies of classes who would otherwise be allies, and the cause of true social reform suffers incalculable injury. pay their bills at all. Now such is the labourleader's theory with regard to the employing classes. For a time some part of their bills must unfortunately be paid - that is, some part of their profits be allowed them. But to these profits they have no real right, and the employed must never be contented until they have absorbed the whole of them. So long as such a theory prevails, no satisfactory progress in the condition of labour is possible, 
partly because the employed, whatever advantages they may gain, will be no nearer to content than they were before, partly because the employers are constantly forced into a position of unwilling antagonism to men whom they would wish to befriend.

The object of this present work, so far as the The object of question of wealth and its distribution is concerned, work is to has been to show how absolutely false to fact are the show the theories to which this impracticable discontent is due, ${ }^{\text {theoretic basis }}$ and how intellectually ludicrous is the position of the socialistic disschool of thinkers who imagine that such theories socialistic represent accurate science.) These thinkers, in their ${ }^{\text {aspirations; }}$ dealings with property and capital, in spite of the esoteric admissions of a certain number of them to the contrary, touch the truth in their more popular utterances, only by the process of inverting it, or of putting the cart before the horse. They represent the employing classes as possessing exceptional strength merely because they are accidentally the possessors of capital. The actual truth is that these classes are possessors of capital because they themselves or their fathers have possessed exceptional strength. The arrows of Ulysses were more formidable than those of the suitors because Ulysses shot with a stronger bow than they; but he shot with a stronger bow for the very simple reason that he was strong enough to bend it and they were not. The employing classes contribute to the processes of production not less than the employed; in certain senses they contribute incalculably more, 
Book IV and in every sense they contribute as truly; and Chapter 4 they contribute not primarily because they possess capital, but because as a class they possess exceptional faculties, of which the capital possessed by them is at once the creation and the instrument. In other words, the inequalities which socialists regard as accidental are the natural result of the inequalities of human nature, and constitute also the sole social conditions under which men's unequal faculties can co-operate towards a common end.

and to show that the many are not a selfexistent power,

Socialists contend that the source of all power is in the multitude. It is impossible to imagine a greater or more abject error. The multitude, or the mass of average men - the men undistinguished by any exceptional faculties - are the source of certain powers, or rather they possess certain powers. That is true; but what may these powers be? Their most striking characteristic is their limitation. In the domain of industry the many, if left to themselves, could produce only a very small amount, which would have, moreover, no appreciable tendency to increase. In the domain of government they could initiate the simplest movements only, and carry out only the simplest measures. The powers which they actually possess under existing circumstances are as much greater than these as the man is greater than the child; but these added powers acquired by the average men, or by the many, do not depend upon average men alone. They are developed only with the development of another set of powers altogether - the powers belonging to the exceptional men or to 
the few; and if these latter powers were impaired, the former would be impaired also. In the domain of Book IV Chapter 4 production and the domain of government alike, not all, but nearly all, the powers of a democracy presuppose the powers of a de facto aristocracy, and although they modify them, they depend upon them. Here are the two factors or forces which we can but depend for all the powers never get rid of unless we get rid of civilisation the co-operaaltogether - the force represented by the mass of ordinary men, and the force represented by those who in various ways are more than ordinary. Let us destroy society a hundred times over, and attempt to reconstruct it in what way we will, these two forces will inevitably reassert themselves, and reveal their existence in the form which society takes, as surely as a man's figure will give its shape to whatever kind of cloak we hang on it. These two forces at the present time attract our attention principally by their activity in the domain of industry, where they show themselves under the forms of employer and employed. In order that any satisfactory solution of our industrial difficulties may be arrived at it is necessary that employers and employed alike should each recognise the importance of the part played by the other, the nature and the extent of the other's strength, and the permanent need each has of the other's strenuous co-operation. It is hardly to be expected that between these two, serious disputes and difficulties will ever completely cease. In the interest of social progress it is not necessary that they should. What is necessary is that what- 
Book IV ever disputes between these two parties may arise, and however unreasonable or excessive on any given occasion the claims of the few may seem to the many, or the claims of the many to the few, neither party shall regard the other as its opponent, excepting with reference to the particular points at issue; that the few shall not deal with the many as though the many, in asserting themselves, were rebels, nor the many attack the few, as though the powers of the few were usurpations. What is necessary is that each should recognise its own position and its own functions, and the position and the functions of the other, as being, in a general sense, all equally unalterable, and although admitting of indefinitely improved adjustment, not admitting of any fundamental change.

And what is true of the social forces that are involved in the production of wealth, is true of those that are involved in political government. In political government, just as in the production of wealth, the power of the few has a root in the nature of things as indestructible as has that of the many; and though the few can produce progress only when the many can co-operate with them, it is not from the many that their power is primarily derived. In the domain of speculative knowledge this is self-evident. The ordinary brains are pensioners of the few brains that are superior to them; and yet the superior brains are powerless to produce social results, except in so far as the ordinary brains respond to what their superiors 
teach them. So it is in economic production, so it is in political government. The power of democracy is not only an actual power; it is a power from which no society can ever wholly escape; but never - not even when nominally it reaches its extreme development - does it, or can it, or does it ever tend to be, a power which is self-existent. It always implies and rests upon the corresponding power of the few, as one half of an arch implies and rests upon the other. The whole object of the democratic formulas popular to-day is to deny or to obscure this fundamental truth; and no greater obstacle to general progress exists than the prevalence of the spirit which the acceptance of these formulas engenders. If there is anything sacred in the rights of the poorest wage-earners, there is something equally sacred in those of the greatest millionaires; and if whose rights the latter are capable of abusing their power, so also and whose are the former; but nothing will tend to prevent ${ }^{\text {power is as }}$ their abuse of it so much as the recognition that such own. an abuse on either side is possible. If there is any wisdom and power in the cumulative opinions of ordinary men, there is another kind of wisdom and another kind of power in the ideas, the insight, the imagination, and strength of will which belong to exceptional men; and these last, though they may give effect to what the many wish, do so only because they represent what the many do not possess. What is required to bring our political philosophy and not only our political philosophy but our political temper - into correspondence with facts is not to 
Book $1 \mathrm{~V}$
Chapter 4 deny the power that has been claimed during this century for the many, but to recognise that this power does not stand alone, and that those other powers represented by the wealthy few are not only essential to the wealth of the few themselves, but also to the prosperity, and most emphatically to the progress, of all. The recogni-
tion of the fact that the relations and positions of classes can never be fundamentally altered with the fact that the positions of all have no tendency to become equal, assumes, on the contrary, a more and more practicable aspect in proportion to the accuracy with which this fact is recognised; and that such is the case shall, in conclusion, be briefly shown by reference to the theory of progress which at present deceives the socialists. This theory, which was formulated by Karl Marx, bases itself on the fact, which is indubitable, that the industrial systems of the civilised races of the world have undergone great changes in the past, and may therefore be expected to undergo changes as great in the future. The three most marked stages in the sequence of change referred to are slavery, feudalism, and capitalism; and the practical conclusion drawn from them by the socialists is that as feudalism arose out of slavery, and capitalism arose out of feudalism,

(especially when we consider the facts of history to which Karl Marx drew attention) so will socialism arise out of capitalism. This argument is merely another example of those self-confusions by which the socialists are distinguished as reasoners. It is an argument which depends for its whole apparent point on the defective manner in which these various systems - socialism included - 
have been analysed. For, though slavery, feudalism, and capitalism differ from one another in many most important points, they happen not to differ at all in respect of that one particular point in respect of which socialism will have to differ from all three of them. That is to say, in whatever way these three systems differ from one another, they all agree with one another in being systems under which the few, the strongest, the most intellectual, the most energetic, not only controlled the actions of the average many, but received for their exceptional action a correspondingly exceptional recompense. The few who occupied this commanding position differed, at different times, in the nature of the powers which gave them the command. Sometimes it was the great fighters who were paramount, sometimes the great legislators, sometimes the great industrialists. But into whatever mould human society has been cast, with whatever circumstances it has been surrounded, and whatever kind of talent or strength has been most essential to it at given periods, the few who have possessed this kind of talent and strength to the highest degree have, as a whole, and with them their families, invariably occupied a position of exceptional wealth and power. We may deplore this fact or no, but the fact still remains, and consequently the argument of the socialists from the facts of social evolution, when reduced to its true terms, merely amounts to this - that because many social changes have taken place already, but one particular change in spite of these has never taken 
Book $1 \mathrm{~V}$

Chapter 4

shows us not only how chimerical are the hopes of the socialists, but what solid grounds there are for the hopes of more rational reformers.

place, yet this particular change which has refused to take place in the past is perfectly certain to take place in the future.

The historical evolution of society, however, and the social changes that have taken place, do indeed convey to us a very important moral ; but this moral which the changes convey to us is curiously different from that which the socialists draw from them. They draw from them the moral that because social arrangements have been greatly changed, therefore they can be fundamentally changed. The true moral is that, although they may be changed greatly, they can never be changed fundamentally; and from this there follows another as its yet more important corollary - that although social arrangements can never be changed fundamentally, they can, nevertheless, be progressively and indefinitely improved, but that real reforms can be accomplished only by those who abandon altogether every dream of fundamental revolution. Many reforms which socialists eagerly recommend, and many wishes which socialists entertain, may meet with the approval and sympathy of the most determined conservatives; but the error of the socialists is sufficiently indicated by the fact, already remarked upon in the course of this work, that the changes which they advocate, and whose advent they delight to prophesy, leave the possible and approach the absolutely impossible, in precise proportion as these visionaries set value upon them.

Nowhere is the impossibility of such changes more clearly indicated than in the phrases now most 
frequently used to indicate their specific nature such phrases as "the emancipation" and "the Book IV Chapter 4 economic freedom" of the labourer. These phrases, if they have any meaning at all, can mean one thing only - the emancipation of the average man, endowed with average capacities, from the control, from the guidance, or, in other words, from the help, of any man or men whose capacities are above the average - whose speculative abilities are exceptionally keen, whose inventive abilities are exceptionally great, whose judgments are, exceptionally sound, and whose powers of will, enterprise, and initiative are exceptionally strong. That is to say, these phrases, if they have any meaning at all, mean the deliberate loss and rejection, by the less efficient majority of mankind, of any advantage that might come to it from the powers of the more efficient minority. "Economic freedom," in fact, would mean economic poverty; and the "emancipation" of the average man would merely be the emancipation which a blind man achieves when he breaks away from his guide. The human race progresses because and when the strongest human powers and the highest human faculties lead it; such powers and faculties are embodied in and monopolised by a minority of exceptional men; these men enable the majority to progress, only on condition that the majority submit themselves to their control; and if all the ruling classes of to-day could be disposed of in a single massacre, and nobody left but those who at present call themselves the workers, these work- 
$\underset{\text { Chapter } 4}{\text { Bu }}$ ers would be as helpless as a flock of shepherdChapter 4 less sheep, until out of themselves a new minority had been evolved, to whose order the majority would have to submit themselves, precisely as they submit themselves to the orders of the ruling classes now, and whose rule, like the rule of all new masters, would be harder, and more arbitrary, and less humane than the rule of the old. 


\section{INDEX}

Accident, social inequality not an, $47 \mathrm{ff}$. Brazil, socialistic colony in, 232, note.

Activity, five domains of, 154 .

Browning, Robert, quoted, 124.

Agent, great man, of progress, 121.

Agents, the few not mere passive, 190.

Aggregate, Spencer's definition of an,

52.

Agitators, social, 342 .

Agriculture, Mill's argument concerning, $198 \mathrm{ff}$.

Aim of science to-day, 5 .

Analysis: Kidd's, of social aggregate, 23.

of case against great man, $63 \mathrm{ff}$.

of greatness, $120 \mathrm{ff}$.

of the democratic theory, 178-iso. of practical reasoning, 208-211.

Ancestors, great man and, 73 .

Application : of science to society, 5 . of knowledge, inventor and, ${ }_{3} 8$.

Aristocrats agree with democrats and socialists as to orderly government, 43 .

Aristotle: and intention, 100. on the average man, 259 .

Autocracy: of the inventor, 60-6r. of great man of business, 61 . of hotel-keeper, 62 .

competitive element in an, 178 .

Average men: action in co-operation, $215 \mathrm{ff}$.

emancipation of, 379 .

Bellamy, Edward, 65, 76, 77, 80, 82.

Bessemer, Sir Henry, $\delta_{7}$.

Bimetallism, used for illustration, 185 .

Birth-rate and socialistic State, 232.
Bryan, W. J., I 86.

Buckle, H. T., 10.

Capacity, degrees of, 113.

Capital: fixed and wage, 158 . as a wealth-producer, 3 II. income-yielding, $3^{1} 7$. forces behind, $377 \mathrm{ff}$.

Capitalism and progress, 167 .

Capitalists: the first, 159. Marx's conception of, 160 .

Carlyle, Thomas, 26, 50, 115, 215.

Catholicism, average believer and, 226-227.

Children : and socialistic State, 232. of the wealthy man, 317-318.

Chimeras, hopes of socialists are, 378.

Christianity: how spread, 146.

cause of general acceptance, $225 \mathrm{ff}$.

Church of Rome a religious democracy, 228-229.

Civilisation: meaning of, 238 . depends on the great man, 276 .

Classes: Kidd's division, 20-22. Spencer's division, II 3 . permanent nature of, 348 .

Cobden, Richard, I 86.

Collectivism and individualism, I4.

Columbus an example of force of mo tive, 274 .

Competition: socialists on, 168-1 70 . involved in socialism, $17 \mathbf{1}$.

Comte, Auguste, ro. 
Contract, true social, 274-275.

Control, how great man obtains, 157 .

Co-operation: 163. present inequalities necessary to, 372.

of the few, 373 .

Corvée, 162-163.

Craftsmanship, progress and, 254-255.

"Cut-throat struggle," competition termed a, 168.

Darwin, Charles R., 4, 96.

Deity, social change, and Spencer, 25.

Demand: dependent on the many, 237-238.

a democratic phenomenon, 239241.

for results and for means, 242-243. political and economic, 243-244.

Democracy : oligarchy compared with, 178 .

as master of its rulers, $18 \mathrm{I}$.

complete, an illusion, 183 .

disguised oligarchy, 187 .

and average faculties, $220 \mathrm{ff}$.

religious, a type, 229 .

and the family, $232 \mathrm{ff}$.

Desire : and production, 287 .

equality of, 357 .

law of expanding, 365 .

Dexterity, not progressive, 135 .

Discontent : socialistic theories cause, 368 .

fallacy of present socialistic, $37 \mathbf{I}$.

Discovery, great man and, 66-67.

Division of labour: cause of, $3 \mathbf{1}$.

Spencer on, 32.

Domination, struggle for, 152.

"Economic freedom": economic helplessness, 174 .

economic poverty, 379 .

Education : dangers of equalised, 334336.

and imperfect talents, 337 .

Election, of a governor, $177^{-1} 80$.

Element, military and industrial, 37 .
Emancipation of average man, 379.

Equality : of power non-existent, 189. of opportunity impossible, 328.

Equalisation of education, 345-346.

Errors : fundamental, of modern sociological study, $1-16$.

of Kidd, $2 \mathbf{I}-\mathbf{2} 3$.

of Spencer, 25 .

of the socialists, $215 \mathrm{ff}$.

Evolution : theory of development termed, 5 .

application of, to social science, 6 .

of marriage, 35 .

and intentional progress, 95 .

the result of intention, 104-105.

of society, moral of, 378 .

Fabian Essay's, quoted, 165-166.

Factors: Spencer's external and internal, 33-34.

two social, 373 .

Faculties : and results, $213 \mathrm{ff}$. actualised by motive, 273 .

Failure, useful and useless, 341.

Family, the, 35, $230 \mathrm{ff}$.

Fission, Spencer's process of, 36,41 .

Fittest survivor and progress, 90.

Formulas, object of popular democratic, 375 .

Freedom, economic, 174 .

Free trade: used for illustration, 147 , 185.

Froude, James A., 50.

Genius, definition of, criticised, 152.

George Eliot, quoted, $27 \mathrm{r}$.

George, Henry, 18, 310-31 I.

Government : war and evolution of, 37 . necessary to production and commerce, 156.

Governor, the elected, 177-180.

Great Man : autocracy of, in business, 61 .

case against the, 64-65.

debt of, to the past, 71 .

social inheritance of, $77 \mathrm{ff}$.

a true cause of progress, 83 . 
Great Man: and rapidity of progress, $94-95$.

uses unintended materials, 96 . evolution and, 106-107.

defined, I I5-I I 6 .

and knowledge, 135 .

as teacher, $136-137$.

influence on others, I $\& \mathbf{I}$.

and wealth-production, ${ }_{5}$ I $\mathrm{ff}$.

produces the increment, 204-207.

Great-man theory: Spencer un, 25,50.

Carlyle on, 26.

reasonably stated, II 5 .

fundamental proposition implied in, I $2 S$.

involves a competitive struggle, 144.

Greatness : many degrees of, I I 7.

analysis "If, I 20-I 29.

not equally beneficial, I 42 .

skill not a kind of, 253.

summed up, 272.

Handbook of Socialism, 285 .

Happiness: progress and, $35 \mathbf{I}-353$.

speculative and practical, $36 \mathrm{I}$.

Harrison, Frederic, 299-300.

Heroes, great men not necessarily, i 6 .

Home, democracy and the, 233-234.

Home Rule, 222, note.

Honour, substitute for wealth, 355 .

Illusion, complete democracy an, 183 .

Imagination, effect of, on desire, 362 .

Income, 149.

Increment, great men and the, 206-207.

Individualism and collectivism, $\mathbf{1} \mathbf{4}$.

Industrial civilisation, origin of, $3 \mathbf{I}$.

Inequality : origin of social, 47 .

in capacity, $48-49$.

various linds of, I I $8-1$ I9.

social, is permanent, $322-323$.

Influence : of social science, 7 . means of great man's, I 53 .

Inheritance : great man's social, 77 . fact of, irrelevant, 79-So. semi-socialists oppose, 309.
Intellect, compared to will, 125.

Intention: and the Walter press, $10_{3}$. evolution result of, 105.

Interference of socialists with progress, 369.

Inventions, socialists and, $S_{\mathbf{I}}$.

Inventor: autocracy of the, 60-6I. often helpless by himself, I 25 .

applied knowledge and the, 139.

Julius Cæesar as a "proximate initiator," $5^{6 .}$

Jury, trial by, 259-260.

Kidd, Benjamin : Io, I I, 2I-24, 29 I. his Social Evolution, 12, 14, I7-18, 90-9I.

on great-man theory, 64-65.

Knowledge: basis of progress, 133 . speculative, I 34 . great man and, I $35 \mathrm{ff}$. inventor and applied, I 39.

Labour, and trade unionism, 236 .

Labour-leaders, injure real social reform, $370 \mathrm{ff}$.

Land, and labour, 198-199.

Lassalle, Ferdinand, $3 \mathbf{1} 5$.

Lavelaye, Émile de, quoted, I9.

Law of expanding desire, 365 .

Laws, demand for, 242 ff.

Localisation of industry: cause, 3 . led to road-making, 33 .

Luxury, relativity of, $35 \mathrm{~S}$.

Macaulay, anticipates Spencer, 69.

Machines, as artificial slaves, $313-3 \mathbf{1} 4$.

Naine, Sir Henry, 259-260.

Man : sociologists and, I 7 .

Kidd on, I 8 ff.

de Lavelaye on, 20.

natural character and progress, 33 .

Marriage, evolution of, $3+-35$.

Marshall, Professor: II, 54.

his Princifles of Social Science, 12.

Marx, Karl, 53, I60, 209, 262, 263, 325 note, 343,376 . 
Mill, J. S., I0, 61, 132-133, 197 ff., Power of the few indestructible, 377. $296,326$.

Millionaires, rights of, sacred, 375 .

Mind, the supreme, 96-97.

Minority, the clever, I 15 .

Mischief of false theories, 368-369.

Monogamy, 35, 23I.

Morley, John, 192.

Morris, William, 255.

Motive: necessary for progression, 152.

actualises faculties, 273 .

scope of loftier, $293 \mathrm{ff}$.

Motive power of evolutionary process, 96.

Murger, Henri, 34 I.

Napoleon, Spencer and, 84-85.

Nature and social progress, 29.

Needs, human wants begin as, 238 .

Newman, Cardinal, 36r.

Oligarchy : compared with democracy, 178 .

democracy a disguised, 187.

Opinion: popular, requires a nucleus, I 87 .

origin of democratic, 222-223.

Opportunity, relativity of, 349 .

Ordinary man, meaning of term, $25 \mathrm{I}$.

Organisation of labour, 236 .

Past, great man's debt to the, $7 \mathbf{I} \mathrm{ff}$.

Permanence: of wage-system, I 73.

of present division of men in classes, $34^{8}$.

Poets not great men, 252.

Political economy, new position of, 7 .

Politics: great man's power in, I $76-$ 177.

supply and demand in, 242.

Popes and Councils, 227.

Poverty, socialism said to be protest of, 342 .

Power: equality of, non-existent, I 89. extent of, of the many, 190-19I.

limitation of, in the multitude, 372 .

Powers, inequality in natural, $\mathrm{I}$ I $\delta$.

Principles, false, concerning education, 347.

Producers, the few are the chief, I74I 75 .

Production: domain of economic, 156.

object of, 238.

producer's right to his, 289 .

Progress : of social science, 9 . great man a true cause of, 83 . fittest survivor and, 90.

a double movement, 93 .

must be due to the clever, II5.

in general, I $30 \mathrm{ff}$.

inventor an agent of social, 139 .

in knowledge, 219.

and craftsmanship, 254-256.

not the whole of life, $260-26 r$.

Protestantism, 226.

"Proximate initiator": Spencer and the, 27,63 .

Julius Casar as a, 56 .

Reasoning: Henry George and de

Lavelaye employ false, I9. analysis of practical, 208-2II.

Recompounding of family groups, $3^{6-}$ 37.

Relations of classes permanent, 376 .

Religion and average man, 225.

Representative, guide versus the, 179 .

Results : measure of greatness, 12 I.

faculties and, 213 .

Reward, great men demand a, 278 .

Rights : socialists' doctrine of, impossible, $3^{6} 7$.

of the few and the many, 375 .

Rivalry: of existence, 89.

of great men, 143 .

of employers, 148-149.

Road-making, origin of, 33 .

Rome, Church of, and democracy, 228229.

Rossi, Giovanni, 232, note.

Rousseau, J. J., 274. 
Science is undergoing a change, 2 .

Sentimentalists oppose productive machines, 254.

Shareholding under "co-operative" system, I 64 .

Skill not a sign of greatness, 253-254.

Slavery: and wage-system, 157 .

re-introduction of, impossible, 172.

Slave-system, socialism essentially a, 165.

Smith, Adam, 32.

Socialism: a slave-system, I65. competition involved in, I 7 I.

Socialists : so-called scientific, 53 . and inventions, $S_{\mathbf{I}}$.

and capital, $\mathbf{1} 60$.

on the wage-system, $165 \mathrm{ff}$.

errors concerning democracy, $2 \mathrm{I} 5 \mathrm{ff}$. and average man, $262 \mathrm{ff}$. on motive, $285-286,304$. on investment, 3 I 9 .

Sociologists and social science, $9 \mathrm{ff}$.

Sociology : success of speculative, I214.

failure of practical, 15-16.

Species, Darwinian theory of, 96 .

Spencer, Herbert : I I, 55 ff., 2 I 5,247 , 276,280 .

exponent of a fallacious method, 24. his sociological works, 25.

on great men, $26 \mathrm{ff}$.

as a "proximate initiator," 27 .

on division of labour, 32 .

and social aggregate, $40 \mathrm{ff}$.

ignores the individual, 45 .

on great-man theory, 50 .

on the military leader, 57 .

as an industrial dictator, $58 \mathrm{ff}$.

on social inheritance, 77 .

and Napoleon, $\mathrm{S}_{5}$.

his Social Statics, 86.

on Sir H. Bessemer, $8_{7}$.

on degrees of capacity, I 13.

and the clever minority, II4-115.

Soldier, work of, exceptional, 300-30r.

Starting-point of practical sociolugist, 48.
State: and advance of knowledge, 138 .

to supersede private employers, 165 . care of children, 232.

and art and science, 275.

and education, 334 .

Strada, Famiano, IO4 and note.

Strikes, 369 .

Struggle for existence, the Darwinian, 92.

Struggle, progressive, limits of, 147 .

"Successfuls and unsuccessfuls," 89 .

Superiority, extent of great man's, 6869.

Supply dependent on the few, 235 .

Survival of the fittest : monogamy example of, 35 .

modern sociology adopts doctrine of, 89 .

Talents: some are abortive, 34I-342. development of, 346 .

Tastes, development of needs, 238 .

Theocratic theory, 25.

Trade unionism, $235 \mathrm{ff}$.

Truisms: speculative, 73 . and absurdities, 75 .

Unanimity of multitudes, $18_{4}-18_{5}$.

Voltaire, comparison of Frederick the Great to, 121 .

Wage-payers and wage-earners, 169.

Wage-system: slavery and, 157. permanent nature of, $172-173$.

Walter press, the, result of unintended progress, $\mathrm{O}_{2}-\mathrm{IO}_{3}$.

Wants, needs, and tastes, $23 \mathrm{~S}$.

Wealth: means employed in producing, $155^{-1} 5^{6}$.

production of, and greed, 288.

desired as a means, 306-307.

Wealth of Niations, 32.

Webb, Sidney, 65, $73 \mathrm{ff}$., 263, 28o-281.

Will, intellect and, 125 .

World, every class its own, 259. 
- 


\section{Grandard Books on Economics.}

PUBLISIIED BY

\section{THE MACIMILLAN COMPANY.}

\section{Author's Ealition, in Popular Form, with Latest Revisions.}

\section{Social Evolution.}

By BEnJAmin KIDD. Popular Edition, with the Author's Latest Revisions and

New Copyright Preface. Price in paper 25 cents, cloth \$r.50.

"The volume... owes much of its success to its noble tone, its clear and delightful style, and to the very great pleasure the reader experiences as he is conducted through the strong, dignified, and courteous discussion. From a scientific point of view it is the most important contribution recently made to biological sociology." - Independent.

\section{An Introduction to Social Philosophy.}

By John S. Mackenzie, M.A., B.A., Assistant Lecturer on Philosophy in Owens College, Manchester, formerly Examiner in Philosophy in the University of Glasgow. 8vo. \$r.75, net.

“. . . The ideal depends upon three elements--individual culture, the subjugation of nature, and social organization; and true progress must include progress in all three. The details of this progress are worked out in a suggestive and interesting manner, and the whole discussion is marked with scholarship as well as gcod sense." - Independent.

\section{The Principles of Sociology. (Third edition.)}

An Analysis of the Phenomena of Association and of Social Organization. By Franklin Henry Gidings, M.A.. Professor of Sociology in Columbia University. Cloth. 8vo. Price $\$ 3.00$, net.

"The book is especially valuable because of the clearness and fulness with which it dis. cusses the psychical elements in social evolution." - EDWArd M. Colie in The Bookman.

\section{The Theory of Socialization.}

A Syllabus of the Principles of Sociology. By F. H. Giddings, M.A. With references to "The Prunciples of Sociology," by the same author. 8vo. Paper. Price 60 cents, net.

\section{Outlines of Economic Theory.}

By Herbert Joseph Davenport. 8vo. \$2.00, net.

The book is in two parts, of which the first sets forth the theory of economic science. A second part is entitled Economics in Art. Its discussions are of great practical value, and are timely, touching on the competitive system, coöperation and profit-sharing, state and municipal ownership, taxation, the eight-hour day, the apprentice system, sweating shops, the labor of women and children, the unemployed, the currency, etc., etc.

\section{Elementary Economics.}

By HERBERT J. DAVENPORT, author of "Outlines of Economic Theory." \$.8o, net.

This is not an adaptation for school purposes of Mr. Davenport's larger work, but in the main a new book both in matter and arrangement. In nethod and doctrine it follows $t$. "Outlines" in some degree. The same attempt is made to lead the student to do his uw. thinking, and in a serse the method is inductive.

\section{An Introduction to Public Finance.}

By Prof. Carl C. Plehn (Univ. of Cal.). izmo. \$r.6o, net.

An elementary text-book offering a simple outline of those things which are necessary to prepare the student for indepenđent research; a brief discussion of the leading principles that are generally accepted; a statement of the unsettied principles, with the grounds of controversy; and sufficient references to enable the student to form some opinion for himseli.

\section{THE MACMILLAN COMPANY, 66 FIFTH AVENUE, NEW YORK.}




\title{
Valuable Collateral Reading
}

IN

\section{ECONOMICS, HISTORY, ETC.}

\author{
BY JAMES BRYCE, M.P., D.C.L. \\ The American Commonwealth for Students' Use. \\ Crown 8vo, cloth. \$1.75, net.
}

Revised by Mr. BRYCE, with the assistance of Prof. JESSE MACY, of Iowa College.

This is not a mere condensation of the larger work, but a restatement, briefer and in a form more carefully adapted to use as a text-book, of the valuable material in Mr. Bryce's "American Commonwealth," a knowledge of which is conceded to be indispensable to any one who would acquire a just estimate of American institutions.

"It is a genuine pleasure to commend to our readers the abridged edition of "The American Commonwealth' just issued by The Macmillan Company. Mr. Bryce's book, which has heretofore been issued only in two volumes, has no peer as a commentary upon American political institutions."-Public Opinion.

\section{The American Commonwealth.}

2 vols. Large 12mo. Third edition. Revised throughout. $\$ 4.00$, net.

"His work rises at once to an eminent place among studies of great nations and their institutions. It is, so far as America goes, a work unique in scope, spirit, and knowledge. There is nothing like it anywhere extant - nothing that approaches it. . . Without exaggeration, it may be called the most consiłerable and gratifying tribute that has yet been bestowed upon us by an Englishman, and perhaps by even England herself. .. . Every thoughtful American will read it, and will long hold in grateful remembrance its author's name." - New York Times.

\section{A Political Primer for New York State and City.}

The City under the Greater New York Charter. By ADELE M. FiElDE, author of

"A Corner of Cathay." With maps. Cloth, 75 cts. Paper, 50 cts.

Miss Fielde has had frequent occasion during the past two or three years to instruct classes of women studying political questions. Now a larger class seeks her instruction, in the only way open, by the issue of this clear, concise, yet comprehensive book.

\section{The Study of City Government.}

An Outline of the Problems of Municipal Functions, Control, and Organization. By Delos F. Wir.cox, A.M., Pli.D. izmo. Cloth. \$1.50, net.

The author holds that the City Problem is the key to the immediate future of social progress in this country, and he offers for the first time a systematic outline of the whole municipal field, indicating the chief problems of function, of control, and of organization.

\section{The Finances of New York City.}

By E. Dana Durand. Cloth, 12mo. \$2.00.

A well-written, clear, straightforward, and interesting history of an important subject.

\section{THE MACMILLAN COMPANY,}

66 FIFTH AVENUE, NEW YORK. 

$\checkmark$ 
$$
\text { . }
$$ 
This book is DUE on the last date stamped below

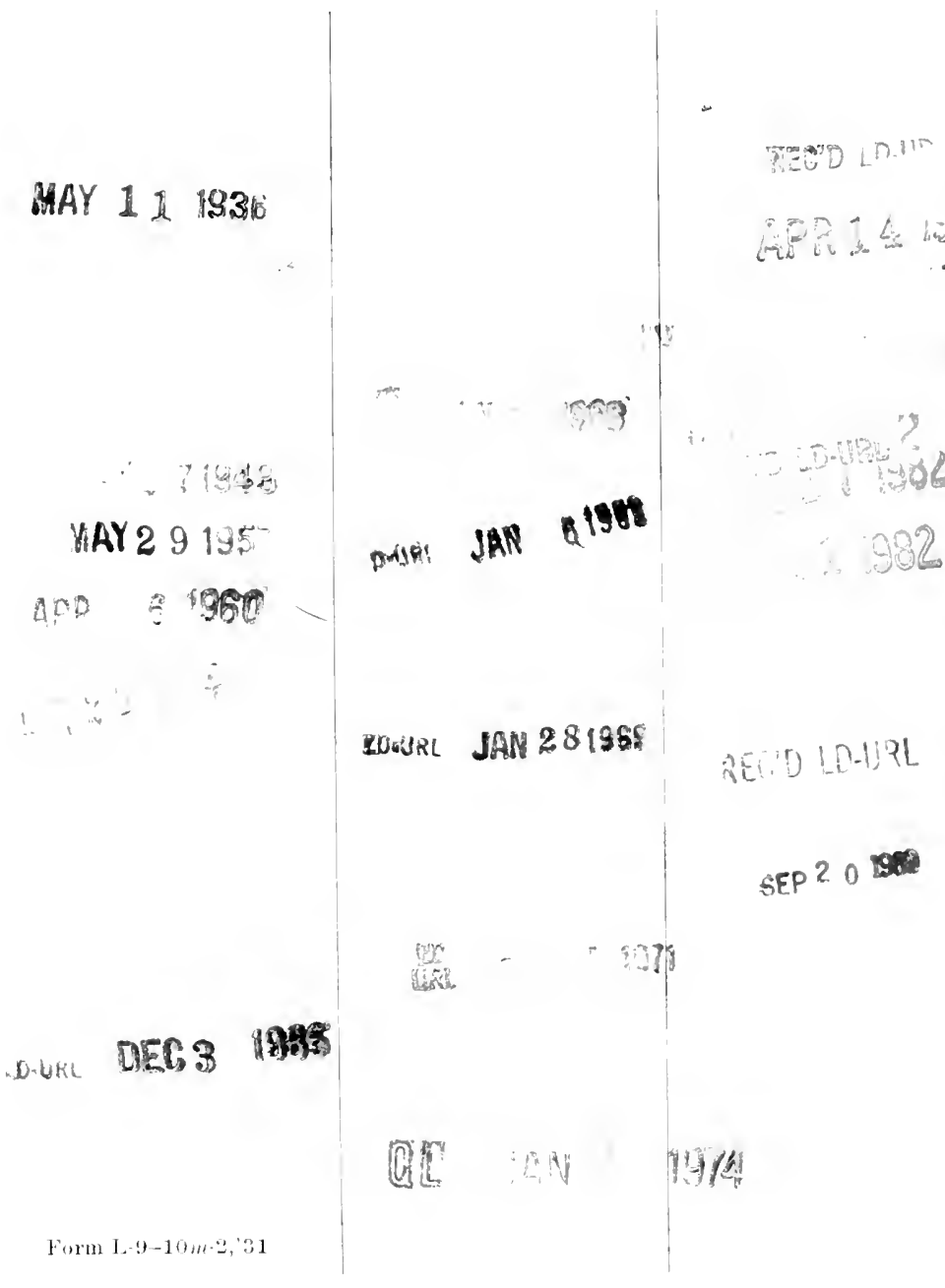


(d)

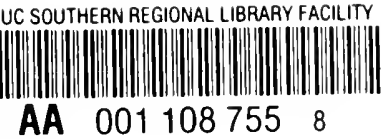


